\title{
FIRE PERFORMANCE OF CONCEALED WOOD-STEEL-WOOD CONNECTIONS WITH PERPENDICULAR TO GRAIN REINFORCEMENT
}

\author{
by \\ Oluwamuyiwa A. Okunrounmu
}

A thesis submitted to

the Faculty of Graduate and Postdoctoral Affairs

in partial fulfillment of the requirements for the degree of

Master of Applied Science

In

Civil Engineering

Department of Civil and Environmental Engineering

Carleton University

Ottawa, Ontario, Canada

CC Copyright 2020

Oluwamuyiwa A. Okunrounmu 


\section{Abstract}

The use of wood as a construction material for high-rise and non-residential buildings has significantly increased over the past decade around the world. This trend leads to a need to conduct research on timber connections to meet the fire-resistance ratings required by building codes. Timber connections are typically the weakest link in heavy timber structures subjected to a fire. Recent research has shown that the predominant failure modes of concealed connections, which is the connection type most used in the industry, at both ambient and elevated temperatures are perpendicular-to-grain tensile splitting and parallel-to-grain row shear out. The majority of research on the use of reinforcement to strengthen concealed connections against such failure modes has been conducted at ambient temperatures. There are only a very few studies that deal with the behaviour of concealed connections with reinforcement in fire.

This study aimed to investigate the fire behaviour of these connections by considering the effects of parameters such as the number of bolts, bolt pattern and load ratios. The connections used for this study were fire-protected glulam beam-to-column reinforced concealed connections loaded perpendicular-to-grain resulting in bending moment on the connection. Eight (8) full-scale fire tests were conducted involving four different connection configurations. All metal connecting components, i.e., bolt heads and nuts, and steel plate edges were fire protected using wood plugs and strips, respectively. The connections were designed in accordance with the Canadian engineering design in wood standard, CSA O86-14, and the fire tests were conducted in compliance with the CAN/ULC-S101 standard procedure. The specimens were reinforced perpendicular-to-grain with six (6) or eight (8) fully-threaded selftapping screws (STS) depending on their bolt number, and exposed to elevated temperatures that follow the CAN/ULC-S101 standard fire time-temperature curve while being constantly 
loaded perpendicular-to-grain with a transverse load. The load ratios applied during fire testing were $60 \%, 100 \%$ and $130 \%$ of the ultimate design load capacity of the weakest unreinforced connection configuration. A 1 oad ratio of $100 \%$ was applied on four specimens consisting of four-and six-bolt connection configurations. Thereafter, two specimens with four-bolt connection configurations were subjected to a load ratio of $60 \%$ while the remaining two specimens with six-bolt connection configurations were subjected to a load ratio of $130 \%$.

The test results showed that the failure times of all the tested beam-to-column concealed connections were more than 50 minutes, which is higher than the 45 minutes rating prescribed in the National Building Code of Canada for combustible construction. Specimens with the two rows of bolts symmetrically positioned near the top and bottom sides of the beam cross-section (bolt pattern P1) performed better than specimens with the bottom row raised to the mid-height of the beam section (bolt pattern P2). The results showed that increasing the number of bolts from four (4) to six (6), improved the failure time by a factor of 1.25 and 1.07 in bolt patterns $\mathrm{P} 1$ and $\mathrm{P} 2$, respectively. Increasing the load ratio from $60 \%$ to $100 \%$ and from $100 \%$ to $130 \%$ decreased the failure time of the connections. The wood strips and plugs used to protect the metal parts of the connections prevented the wood around the T-stub flange from charring. The brittle failure modes frequently encountered in unreinforced concealed connections were prevented by the application of self-tapping screws and the specimens experienced a gradual failure in deflection. 


\section{Acknowledgements}

My gratitude goes to the Almighty God for His divine favour, help, grace and wisdom I enjoyed during my Master's program. To Him alone be all the glory, honour, and adoration.

I would like to express my sincere gratitude to my supervisor, Professor George Hadjisophocleous for his patient guidance, encouragement, and continued support during the course of this research project. Thank you for the mentorship and opportunity to contribute to the field of fire safety engineering.

My profound gratitude goes to my co-supervisor, Professor Osama (Sam) Salem for his advice, constructive suggestions, and unparalleled assistance throughout the research. Thank you, Sir, for believing in me and allowing me to use the Lakehead University's Fire Testing and Research Laboratory (LUFTRL) for the research work. To Mr. Cory Hubbard of LUFTRL, thanks for all the help and guidance provided during the experiment.

Special thanks go to my brother, Oluwadamilola, for his care and support in successfully completing my study. I also acknowledge the following friends and colleagues for their keen interest in seeing me succeed in this endeavour: Lanrewaju Adetunji, Opeyemi Ajayi, Bimbo Solanke, and Aba Owusu. May God bless you abundantly.

Finally, I am extremely grateful to my family in Nigeria for their love, prayers, encouragement, and sacrifices throughout my Master's program. 


\section{Table of Contents}

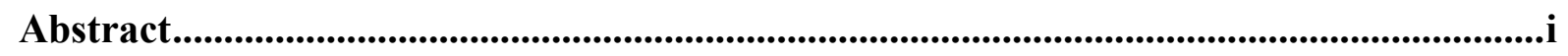

Acknowledgements .................................................................................................................... iii

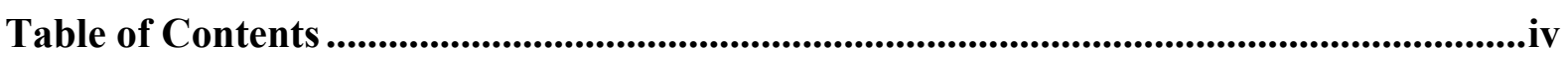

List of Tables ....................................................................................................................................

List of Figures.........................................................................................................................................

1 INTRODUCTION ...................................................................................................................1

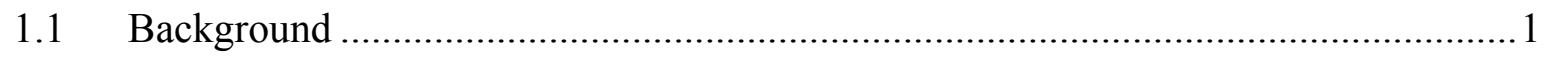

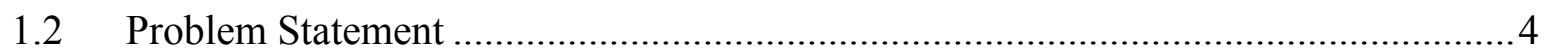

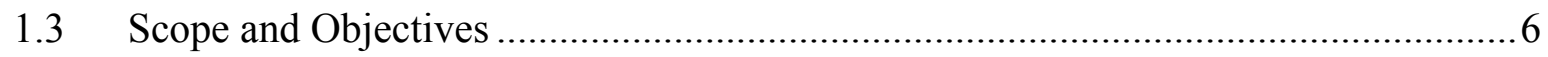

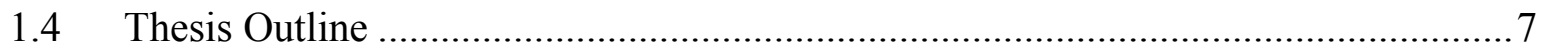

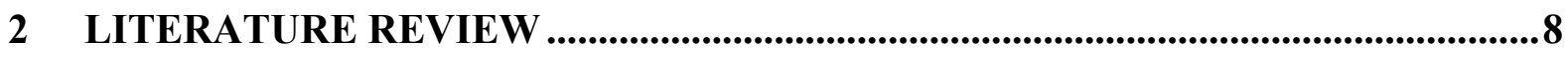

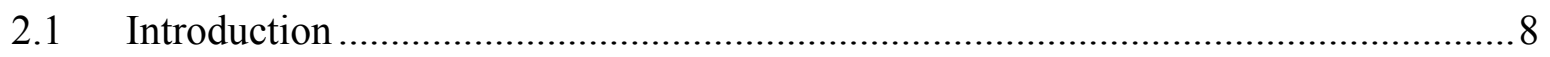

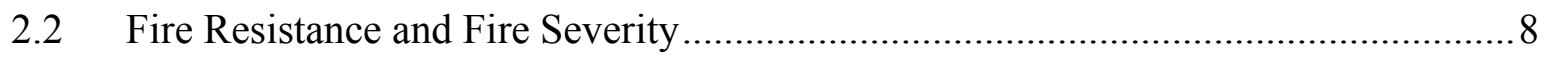

2.2.1 Assessment of Fire Resistance ................................................................

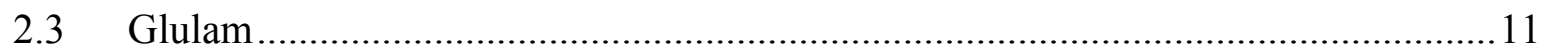

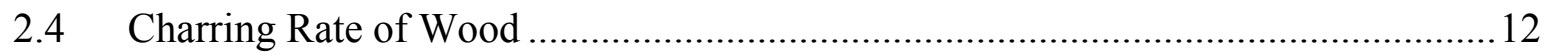

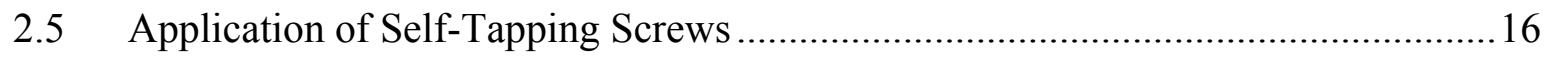

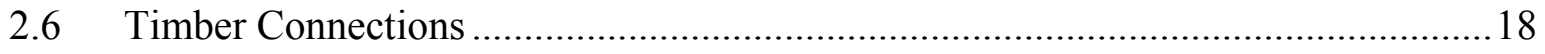

2.6.1 Behaviour of Connections at Ambient Temperature …..................................... 19

2.6.1.1 Design of Connections Loaded Perpendicular to the Wood Grain ................21 
2.6.1.2 Perpendicular-to-grain Splitting Resistance.............................................21

2.6.1.3 Yielding Resistance .................................................................................2 22

2.7 Review of Pertinent Literature on Timber Connections .........................................25

2.7.1 Summary of Reviewed Literature on Concealed Connections .............................55

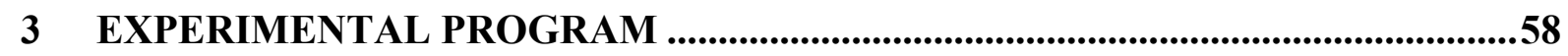

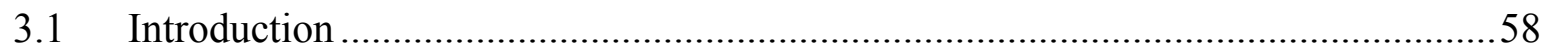

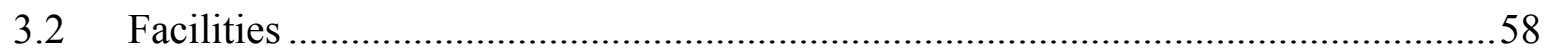

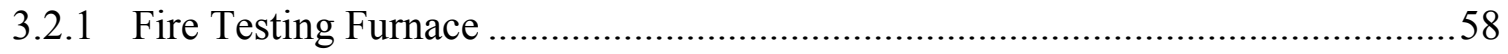

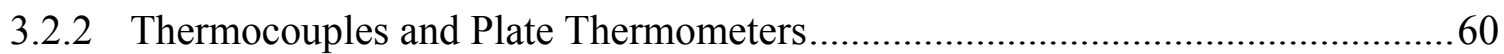

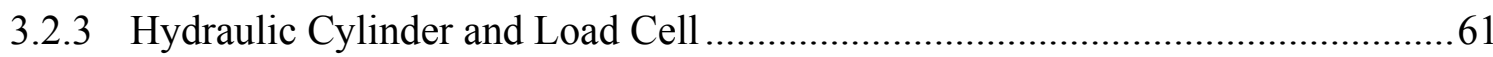

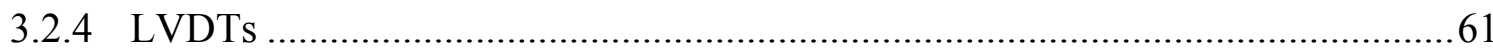

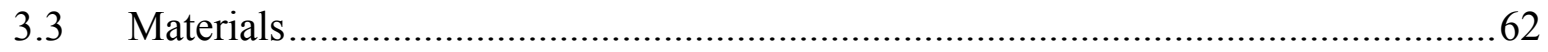

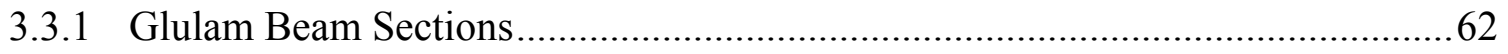

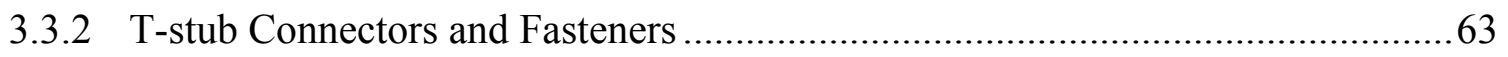

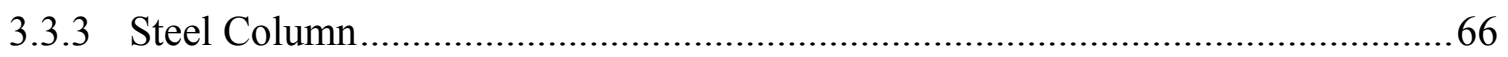

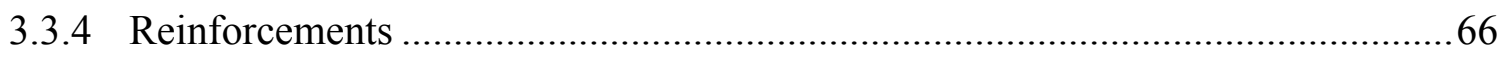

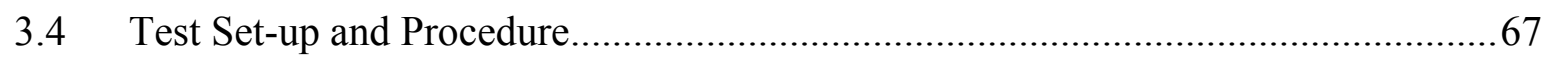

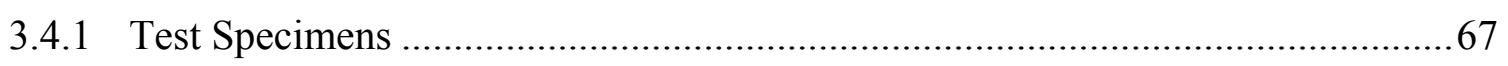

3.4.1.1 Connection Configuration Types and Test Matrix....................................67

3.4.1.2 Test Details and Fabrication................................................................ 73

3.4.1.3 Placement of Bolts in a Connection Loaded Perpendicular-to-grain ..............75

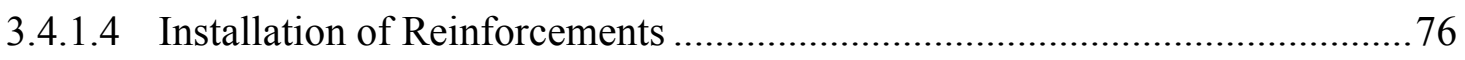


3.4.1.5 Specimen Temperatures .78

3.4.2 Tests Set-up and Procedure. .79

3.5 Load Ratio .82

4 RESULTS AND DISCUSSION. .84

4.1 Introduction .84

4.2 Loading. .84

4.3 Time-Temperature Curves .86

4.4 Charring Rates .92

4.5 Time to Failure in Fire .94

4.6 Connection Rotations 97

4.6.1 Effect of Bolt Pattern on the Connection Rotations with the Same Load Ratio...97

4.6.1.1 Effect of Bolt Pattern on the Connection Rotations at $60 \%$ Load Ratio .97

4.6.1.2 Effect of Bolt Pattern on the Connection Rotations at 100\% Load Ratio... .99

4.6.1.3 Effect of Bolt Pattern on the Connection Rotations at 130\% Load Ratio....102

4.6.2 Effect of the Number of Bolts on the Connection Rotations 104

4.6.3 Effect of Load Ratio on the Connection Rotations 107

4.6.3.1 Effect of Load Ratio on the Four-Bolt Pattern P1 Connection Rotations .... 107

4.6.3.2 Effect of Load Ratio on the Four-Bolt Pattern P2 Connection Rotations .... 108

4.6.3.3 Effect of Load Ratio on the Six-Bolt Pattern P1 Connection Rotations

4.6.3.4 Effect of Load Ratio on the Six-Bolt Pattern P2 Connection Rotations ...... 110

4.6.4 Influence of Self-Tapping Screws on the Connection Rotations

4.6.4.1 Influence of Self-Tapping Screws on the Four-Bolt Connection Rotations 111 
4.6.4.2 Influence of Self-Tapping Screws on the Six-Bolt Connection Rotations... 113

4.7 Failure Modes.

4.8 Summary of Results 120

4.8.1 Effect of Load Ratio.

4.8.2 Effect of Bolt Pattern

4.8.3 Effect of Number of Bolts

4.8.4 Influence of Self-Tapping Screws........

5 SUMMARY, CONCLUSIONS AND RECOMMENDATIONS

5.1 Summary 126

5.2 Conclusions 126

5.3 Recommendations for Future Work 128

REFERENCES 130

APPENDIX A.

A.1.1 Wood and Steel.

A.1.1.1 Wood at Ambient Temperature

A.1.1.2 Steel at Ambient Temperature

A.1.1.3 Wood at Elevated Temperatures

A.1.1.4 Thermal Properties of Wood

A.1.1.4.1 Thermal Conductivity 144

A.1.1.4.2 Specific Heat 146

A.1.1.4.3 Density 148 


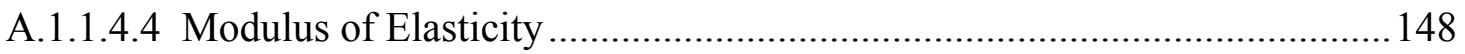

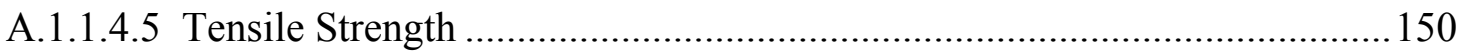

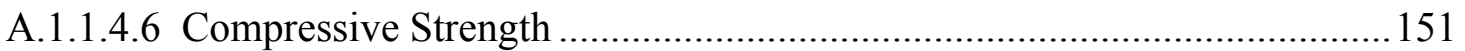

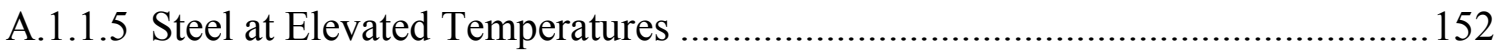

A.1.1.5.1 Thermal Properties of Steel................................................................... 153

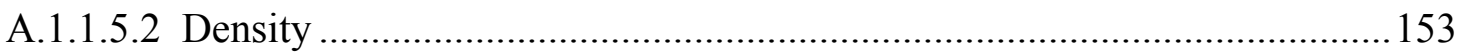

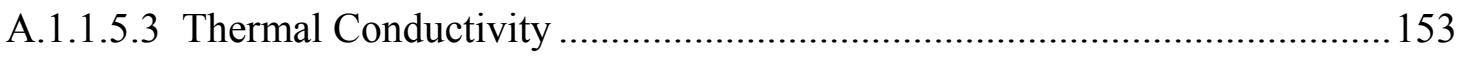

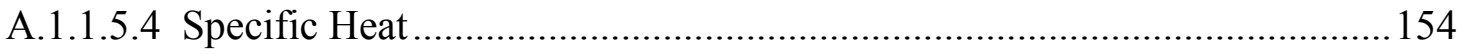

APPENDIX B .............................................................................................................................. 156

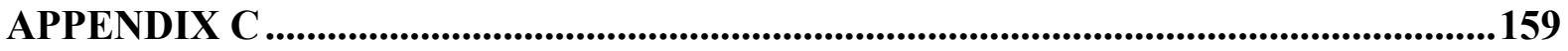

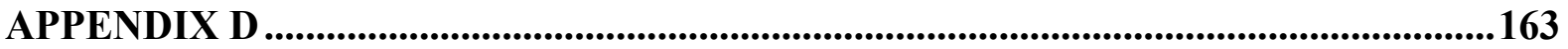




\section{List of Tables}

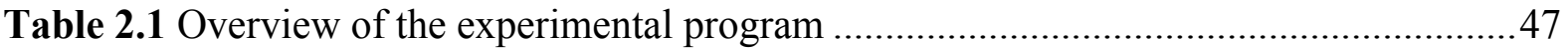

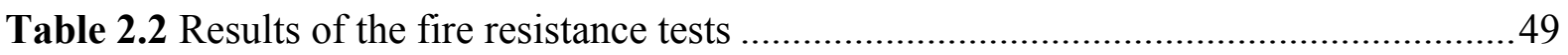

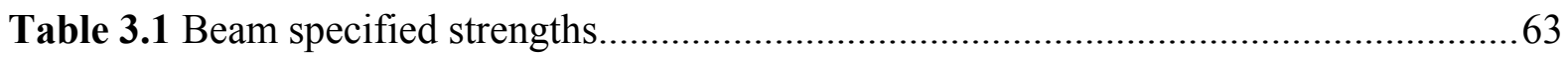

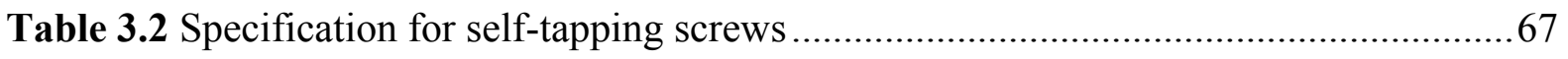

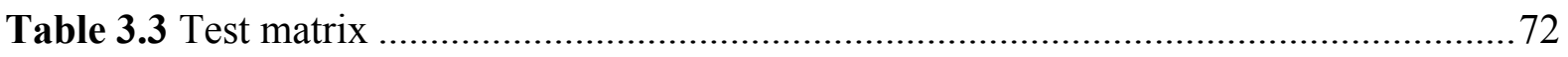

Table 3.4 Spacing requirement for bolt pattern $\mathrm{P} 1$ and $\mathrm{P} 2$........................................... 75

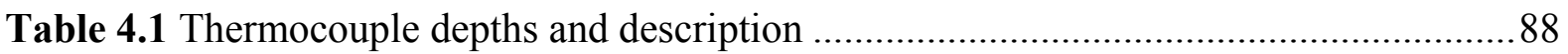

Table 4.2 Charring rates $(\mathrm{mm} / \mathrm{min})$ estimated for all eight connections tested in fire............94

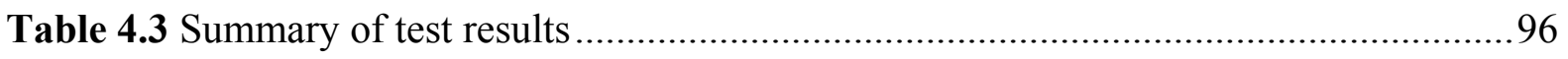

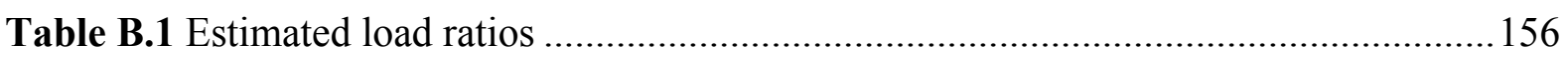

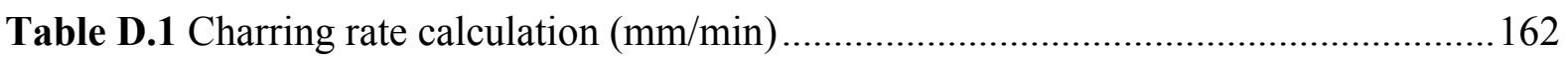




\section{List of Figures}

Figure 2.1 Standard fire time-temperature curves .................................................... 10

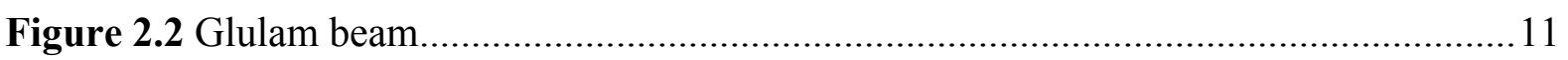

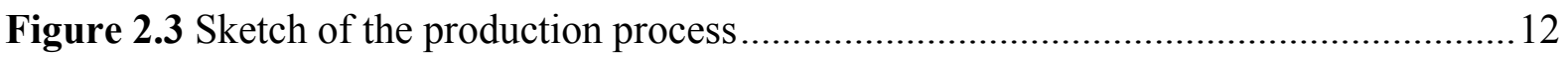

Figure 2.4 Variation of charring depth with exposure time ............................................ 14

Figure 2.5 Influence of density and moisture content on charring rate ..............................15

Figure 2.6 Potential failure modes in wood connections (CAN/CSA O86-14) .....................20

Figure 2.7 Ductile failure modes for double shear timber connections ...............................23

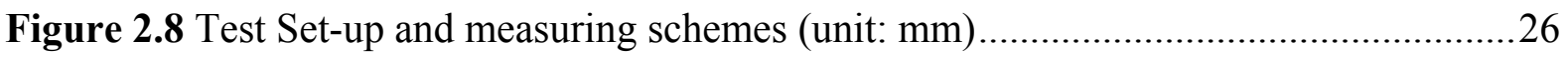

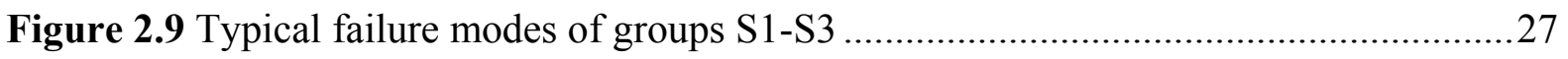

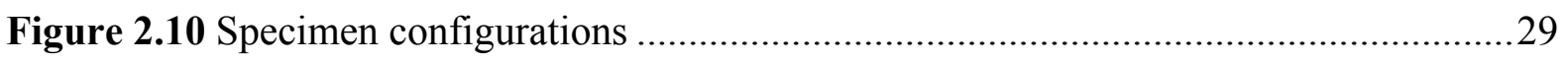

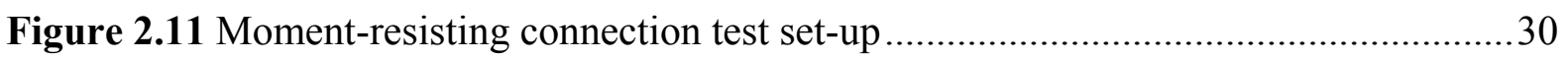

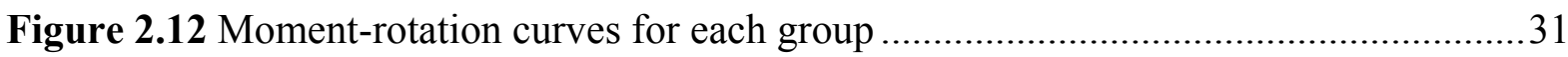

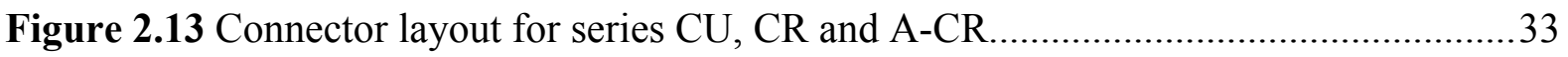

Figure 2.14 Connector layout for series B-CR …......................................................... 33

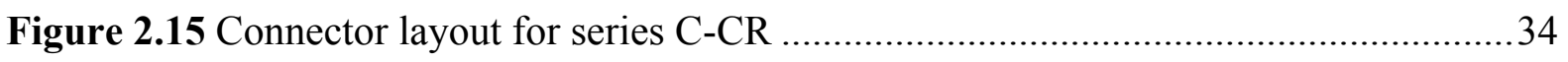

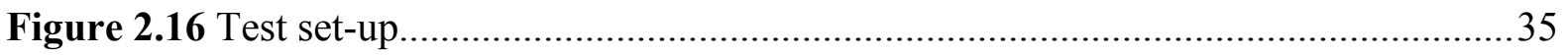

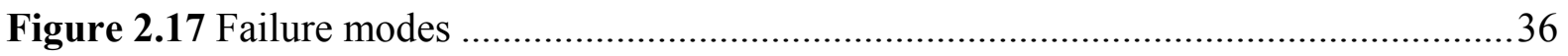

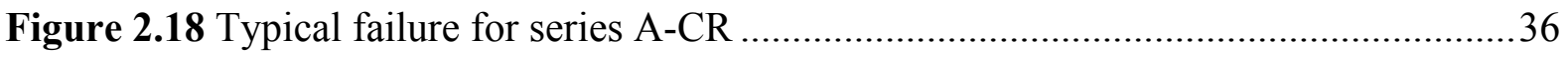

Figure 2.19 Typical failure for (a) series B-CR and (b) series C-CR ................................37

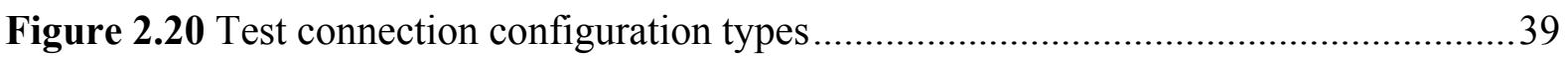

Figure 2.21 Ambient temperature test set-up ............................................................ 40

Figure 2.22 Failure modes of connections in ambient temperature tests ............................. 41

Figure 2.23 Failure modes of connections in fire tests ..................................................... 41 
Figure 2.24 The effect of protection on the failure time of all the connection types .42

Figure 2.25 Bolted Wood-Steel-Wood connection configuration .43

Figure 2.26 Bolted Steel-Wood-Steel connection configuration 43

Figure 2.27 Furnace appearance (left) and front cross-section view (right) 44

Figure 2.28 Typical failure modes of WSW connections .45

Figure 2.29 Typical failure modes of SWS connections .45

Figure 2.30 Reinforcement with self-drilling screws .48

Figure 2.31 End of a fire test in the small furnace 48

Figure 2.32 Failure modes of connections in the fire tests .50

Figure 2.33 Failure modes of connections .50

Figure 2.34 Influence of the gap between the beam and the column for connections .51

Figure 2.35 Typical test assembly installed inside the furnace. .53

Figure 2.36 Self-tapping screw layout in a glulam beam section .54

Figure 2.37 Brittle failure modes encountered in the unreinforced WSW connections .55

Figure 3.1 Lakehead University Fire Testing and Research Laboratory (LUFTRL) .59

Figure 3.2 Large fire testing furnace accommodated at LUFTRL .60

Figure 3.3 Human-Machine Interface (HMI) touch screen of the furnace's control panel ....61

Figure 3.4 Dimensions and details of the four-bolt Pattern P1 T-stub connector .64

Figure 3.5 Dimensions and details of the six-bolt Pattern P2 T-stub connector. .64

Figure 3.6 Isometric view of the four connection configuration types..... .65

Figure 3.7 Steel column .66

Figure 3.8 Dimension and details of self-tapping screw $(8.0 \mathrm{~mm} \times 300 \mathrm{~mm})$ .67

Figure 3.9 Bolt layout details of the four connection configurations .69

Figure 3.10 Self-tapping screws layout details of the four connection configuration .72

Figure 3.11 Fabrication steps of a typical test specimen .74 
Figure 3.12 Placement of bolts in six-bolt pattern P1 (6BP1) connection............................ 75

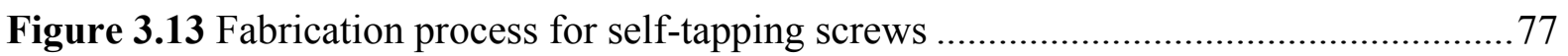

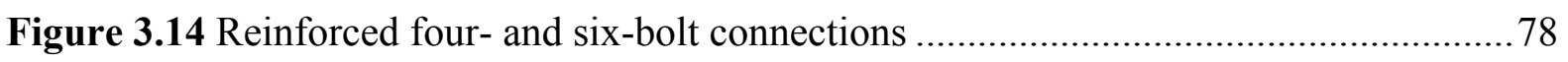

Figure 3.15 Typical thermocouples layout of the four-bolt pattern P1 connection ................79

Figure 3.16 Experimental test set-up, and installed specimen inside the fire-testing furnace 81

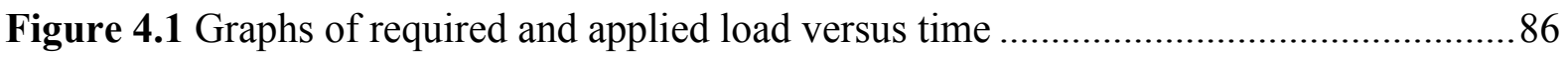

Figure 4.2 Time-temperature curves for the eight (8) connections...................................92

Figure 4.3 Time-rotation curves for four-bolt patterns P1 and P2 subjected to a $60 \%$ load ratio

Figure 4.4 Time-rotation curves for four-bolt patterns P1 and P2 connections subjected to a $100 \%$ load ratio

Figure 4.5 Time-rotation curves for six-bolt patterns P1 and P2 connections subjected to a $100 \%$ load ratio

Figure 4.6 Time-rotation curves for six-bolt patterns P1 and P2 connections subjected to a $130 \%$ load ratio 104

Figure 4.7 Time-rotation curves for four and six-bolt patterns P1 connection subjected to a $100 \%$ load ratio 105

Figure 4.8 Time-rotation curves for four- and six-bolt patterns P2 connections subjected to a $100 \%$ load ratio .106

Figure 4.9 Time-rotation curves for four-bolt pattern P1 connection subjected to $60 \%$ and $100 \%$ load ratios 107

Figure 4.10 Time-rotation curves for the four-bolt patterns P2 connection subjected to $60 \%$ and $100 \%$ load ratios. 108

Figure 4.11 Time-rotation curves for the six-bolt patterns P1 connection subjected to $100 \%$ and $130 \%$ load ratios. 110 
Figure 4.12 Time-rotation curves for the six-bolt patterns P2 connection subjected to $100 \%$ and $130 \%$ load ratios.

Figure 4.13 Time-rotation curves for unreinforced four-bolt connections 4BP1 and 4BP2.112

Figure 4.14 Time-rotation curves for reinforced four-bolt connections 4BP1 and 4BP2 2...113

Figure 4.15 Time-rotation curves for unreinforced six-bolt connections 6BP1 and 6BP2...114

Figure 4.16 Time-rotation curves for the reinforced six-bolt connections 6BP1 and 6BP2.114

Figure 4.17 Rotation of the connections with time caused by the degradation of wood members

Figure 4.18 Typical failure mode for self-tapping screws

Figure 4.19 The effect of load ratio on the failure time for all connection configurations...122

Figure 4.20 The effect of bolt patterns on the failure time for all connection configurations

Figure 4.21 The effect of number of bolts on bolt pattern for connections subjected to $100 \%$ load ratio 124

Figure 4.22 The influence of self-tapping screws on the connections' time to failure in fire condition 125

Figure A.1 The three principal axes in Wood 140

Figure A.2 Stress-Strain relationships for clear wood. 141

Figure A.3 Loading of wood members in parallel and perpendicular to grain directions....142

Figure A.4 Charring Distribution on a wooden beam 144

Figure A.5 Thermal conductivity of wood at elevated temperatures 154

Figure A.6 Specific heat of wood at elevated temperatures. 147

Figure A.7 Density of wood at elevated temperatures. 148

Figure A.8 Elastic modulus of wood at elevated temperatures. 149

Figure A.9 Elastic modulus of wood at elevated temperatures 150 
Figure A.10 Elastic modulus of wood at elevated temperatures....................................... 151

Figure A.11 Compressive strength of wood at elevated temperatures. .............................152

Figure A.12 Thermal conductivity of steel as a function of the temperature. .................... 154

Figure A.13 Time-temperature curves for the eight (8) connections................................155

Figure C.1 Time-temperature curves for the eight (8) connections...................................161 


\section{INTRODUCTION}

\subsection{Background}

Wood is one of the long-established construction materials used for thousands of years, ever since the existence of mankind. Wood being the only renewable construction material in the construction industry can last for decades if properly protected against moisture and insect attack. Insects such as termites or dust beetles could damage wood by making holes in it. Wood as a versatile material is widely used to construct shelters, houses, furniture, boats, and interior decoration. In the building construction industry around the world, the usage of wood has significantly increased owing to its sustainability and renewability. North America has a long and traditional history in the usage of wood and wood products as construction materials; therefore, ancient wood buildings (Heritage buildings) are part of the Canadian rich culture and history.

According to a survey conducted by Surprenant, the production of wood-based products creates about $41 \%$ of the economic impact from the forest industry and is used predominately for residential construction in North America [1]. There are many advantages of wood as a building material including a high strength-to-mass ratio than other traditional building materials, easy adjustment on site, simple prefabrication and less construction time [2]. Other benefits include less energy consumption than other building materials, good fire performance due to formation of char, code compliance, easy production, and easy construction assembly [3].

Timber construction can be categorized as either heavy timber or light wood frame [4]. The primary difference between the light wood frame and heavy timber is the section size of the structural members. The heavy timber construction comprised of structural members of big sizes used as columns, beams, and decks. Timber construction with nominal dimensions exceeding $50 \mathrm{~mm}$ for decks and $150 \mathrm{~mm}$ for beams and columns are in this category [4]. These 
principal structural members are typically made from engineered-wood products such as crosslaminated timber (CLT), nailed-laminated timber (NLT), glued-laminated timber (GLT), laminated strand lumber (LSL), laminated veneer lumber (LVL) and other largedimensioned structural composite lumber (SCL) which are all known as mass timber. On the other hand, the light wood frame construction comprises smaller timber sizes such as studs in walls, joists in floors, and panels of wood in construction.

Heavy timber members are known to have a good fire performance when exposed to fire due to their large size, which results in a relatively reduced charring rate (the rate of advance of char into the wood) over a prolonged exposure to fire due to the increasing formation of char layer that insulates the uncharred wood behind. Although, this is not considered in most design codes [4]. The charred layer formed on the exposed surface of heavy timber members protects the solid wood underneath from exposure to flame and impede oxygen penetration. A research study by [5] had shown that the charring rates of wood frame members were observed to be higher than heavy timber members such as glulam beams, due to the influence of the shape of the cross section. According to White [6], the charring rate for heavy timber members subjected to standard fire exposure is about $0.6-0.7 \mathrm{~mm} / \mathrm{min}$.

Light frame constructions are extensively used as wall assemblies and floor assemblies in residential buildings of one to four storeys. Due to their small size, wood members do not perform well in a fire, therefore, they are covered with gypsum boards [7]. In the case of a fire, the gypsum board slows down the transfer of heat from the fire to the wood studs or joists due to the presence of moisture which requires a large amount of heat to undergo dehydration. The application of light wood frame construction includes wood-frame shear walls which are placed between steel columns in a structure to form the lateral load resisting elements [8]. 
Heavy timber members are used in non-residential buildings such as tall buildings or buildings with large spans depending on the construction requirement. The National Building Code of Canada (NBCC) [9] categorized wood and wood-based products as combustible construction. They are utilized in both residential and non-residential buildings, with a recent increase in its usage in the later. The NBCC permits a structure to be of combustible construction if the fireresistance rating required is not more than $45-\mathrm{min}$, the use of heavy timber construction is permitted as per Sentence 3.1.4.6.(1) of the code. The code provides the minimum crosssectional dimensions of wood elements in heavy timber construction for a 45-min prescriptive requirement. The minimum dimensions of wood elements in heavy timber construction specified in Table 3.1.4.7 of the code [9].

The National Building code of Canada (NBCC) restricts the number of storeys allowed to be constructed with combustible building materials depending on the type of occupancy, building area, number of facing streets, required fire resistance rating and the availability of sprinkler systems. The current version of the National Building Code permits a building height of combustible construction up to six (6) storeys (NBCC, 2015) [9], while there is a significant increase in the number of storeys to twelve (12) in the upcoming version of the NBCC, 2020 [10]. This poses a demand for the research and design of connections to meet up with the new fire resistance ratings required by the code.

Timber constructions can be used in conjunction with other building materials such as steel or concrete to create a hybrid building system. A hybrid building system utilizes the different properties of the materials involved in the load distribution among its members. For instance, wood may be used as beams, floors, or decks in combination with concrete or steel columns in some hybrid building system. Such a system enhances the application of wood as a sustainable construction material used for structural members in tall buildings. 
Since wood, steel, and concrete react differently in fire condition depending on their thermal properties, hybrid system connections are crucial in the overall stability of the building framework and, hence, the integrity of the structure. While light framing systems use fasteners such as nails, screws and light-gauge steel plates, heavy timber systems use dowels, bolts, and thicker steel plates. Therefore, the behaviour of a hybrid building system in fire condition especially at the connections is of great importance to researchers and engineers designing such buildings.

\subsection{Problem Statement}

Fire occurrence in buildings is unpredictable and its effects on structural elements are destructive, especially in timber structures. Under fire exposure, timber connections are often the weakest component of any timber structure and the overall strength as well as the fire performance of a timber structure are usually determined by the strength and behaviour of its connections [11]. This makes connections the most crucial component of any structure, in particular timber buildings.

Bolted timber connections with slotted-in steel plates are commonly used in heavy timber construction due to their ability to transfer shear forces since wood is widely known to be weak in longitudinal shear and tension perpendicular to the grain. The most common types of connections used in heavy timber construction are exposed (steel-wood-steel), seated and concealed connections (wood-steel-wood). The concealed connections are preferably used owing to their simplicity in assembling and aesthetic appearance.

The capacity, as well as the fire resistance rating of concealed connections are significantly impaired due to the reduction in member cross-section by the notches produced and slotted cuts. Furthermore, the presence of metal fasteners along with the middle steel plate transmitting heat to the core of the wood increases the charring rate and thus, decreases the fire resistance 
of the connection [11]. As a result, concealed connections perform poorer under fire exposure than exposed and seated connections [12].

Recent research had shown that the two predominant failure modes of concealed (wood-steelwood) bolted timber connections at both ambient and elevated temperatures are perpendicularto-grain tensile splitting and parallel-to-grain row shear (Brittle failures) [13]. These failure modes play a major role in reducing the moment-resisting capacity that can be attained in concealed bolted timber connections. At elevated temperatures, it was observed that the splitting of the wood occurred along the glued-line plane of the glulam and this resulted in premature failure of the connection.

A study conducted at ambient temperature by Zhang et al. [14] shows that self-tapping screws can be used to enhance the rotational capacity, control crack propagation and significantly prevent splitting failure in dowel-type moment-resisting connections. In another study by Gehloff et al. [15], experimental tests were conducted at ambient temperature to evaluate the performance of moment-resisting bolted timber connections with self-tapping screws acting as perpendicular-to-grain reinforcement. In that study, it was observed that employing selftapping screws as reinforcements greatly increased the ductility and overall performance of the connection. However, at elevated temperatures, self-tapping screws used as perpendicular to grain reinforcement in connections may increase the charring rate of the wood and thereafter reduce the fire resistance of the connection [16].

The behaviour of connections at ambient temperature under different loading levels has been extensively studied by several researchers $[17,18]$. However, limited data exists on the behaviour of concealed timber connections at elevated temperatures.

Several studies had been conducted on the application of various forms of reinforcements to strengthen timber connections at ambient temperature $[15,19,20]$; however, very few tests 
have been done at elevated temperatures [16, 21]. Meanwhile, virtually none has been done on fully concealed connections loaded perpendicular to grain to cause bending moment on the connection. Therefore, this study experimentally investigates through full-scale testing the fire performance of fully protected concealed wood-steel-wood connections strengthened with selftapping screws acting as perpendicular-to-wood grain reinforcement.

\subsection{Scope and Objectives}

The research presented in this thesis aims to investigate the fire performance of momentresisting fully concealed bolted connections (loaded perpendicular-to-wood grain) with selftapping screws (STS) acting as perpendicular to grain reinforcement. This work extends the research conducted by Owusu [22] that investigated the performance of protected and unprotected concealed connections at both ambient and elevated temperatures. Variables that affect the fire performance of the connections, such as the applied load ratio, influence of STS, number of bolts, and the bolt pattern were examined.

The main objectives of the research presented in this thesis are listed below:

- To experimentally study the fire performance of moment-resisting fully protected concealed connections strengthened with self-tapping screws (STS) acting as perpendicular-to-wood grain reinforcement.

- To investigate the influence of the load ratios $(60 \%, 100 \%$ and $130 \%)$ on the performance of fully concealed connections when exposed to CAN/ULC S101 standard fire.

- To determine the effects of the number of bolts and bolt patterns on the fire performance of the connections when subjected to standard fire. 
- To determine and compare the relative time to failure of the various connection configurations in standard fire condition.

\subsection{Thesis Outline}

This thesis document includes five chapters. Chapter 1 gives background information on the research project, problem statement, scope, and objectives, as well as brief review of existing literature on concealed connections at both ambient and elevated temperatures. Chapter 2 presents a brief introduction to fire resistance and assessment of fire resistance, material properties of wood and steel at ambient and elevated temperatures, and a literature review on the performance of concealed (WSW) connections with and without reinforcement at both ambient and elevated temperatures. This chapter also discusses the charring rates of wood and the ambient design of timber connections loaded perpendicular-to-grain. In Chapter 3, the methodology followed in the experimental program, the equipment used, materials, and a detailed description of the specimens are presented. Chapter 3 also includes the testing procedures and the test setup. Chapter 4 presents all obtained experimental results accompanied with detail discussions. This includes the loading of the specimens, the wood charring rates of the specimens, the time to failure and failure modes of the connections when exposed to standard fire, the time-temperature curves of all fire-tested specimens, and a summary of the results. Furthermore, Chapter 4 presents the rotational behaviour of the connections under the effects of bolt patterns, load ratio, number of bolts and the influence of self-tapping screws. Chapter 5 encapsulates the most significant findings of the research project presented in this thesis and presents conclusions based on the experimental observations and results derived from the experimental research. Finally, recommendations for future work needed to expand the spectrum of this research are provided. 


\section{LITERATURE REVIEW}

\subsection{Introduction}

This chapter presents a literature review that includes an introduction to fire resistance and assessment of fire resistance of structures, material properties of wood and steel at ambient and elevated temperatures, and research on the performance of concealed timber connections at both ambient and elevated temperatures. Also, previous studies on wood-steel-wood connections reinforced with self-tapping screws at both ambient and elevated temperatures are discussed.

\subsection{Fire Resistance and Fire Severity}

Fire resistance is a measure of the ability of structural elements to resist collapse, fire spread or other failures during standard fire exposure of a specified severity for a certain duration of time [23]. The primary goals of providing fire resistance for building elements are to prevent the internal spread of fire to adjacent compartments, minimize the probability of fire spread to other buildings, and to prevent the structural collapse of structural elements [7]. This aims to provide life safety, property protection and environmental protection.

The time assigned to a building element after satisfying specific criteria when exposed to a fullscale standard fire resistance test is referred to as the Fire Resistance Rating (FRR). This quantified fire resistance is usually assigned in a rounded whole number of hours or parts of hours (or minutes).

The potential of a fire to cause damages to structural elements is referred to as fire severity. Buchanan [7] defined fire severity as a measure of the destructive impact of a fire or a measure of the forces or temperatures which could cause collapse or other failures as a result of the fire. This can cause a partial or total collapse of a structure. In designing a structure for fire safety, 
building codes require that the fire resistance of building elements be greater than the destructive capacities of the fire [9]. This means that the equation below must be satisfied:

$$
\text { fire resistance } \geq \text { fire severity }
$$

The comparison of fire severity with fire resistance can be verified in the time domain, temperature domain and strength domain.

\subsubsection{Assessment of Fire Resistance}

The fire resistance of building elements is commonly determined by conducting full-scale fire resistance tests. Other approaches permitted by the code are the use of listing and calculation methods to predict the fire-resistance rating.

Fire resistance is one of the most important components of passive fire protection of structures and it is designed to prevent the spread of fire and structural collapse in fire conditions. Building elements such as columns, beams, walls, composite floors, and ceilings are designed to have a minimum fire-resistance rating as required by the building code. In the NBCC, the fire resistance of building elements depends on the intended occupancy, size and type of structure [9]. Most countries in Europe and North America use International Standard ISO 834 [24] and ASTM E119 [25], respectively, as standards for fire resistance. Most national standards such as the Canadian Standard CAN/ULC S101-14 [26] is based on the ASTM E119 [25] test and also the British Standards. BS 476, Parts 20-23 is based on the ISO 834 test. In fire-resistance tests, the time-temperature curve used is referred to as the standard fire. In Figure 2.1, it can be seen that the time-temperature curve for CAN/ULC S101-14 is similar to the ASTM E119 and the ISO 834 standard. 


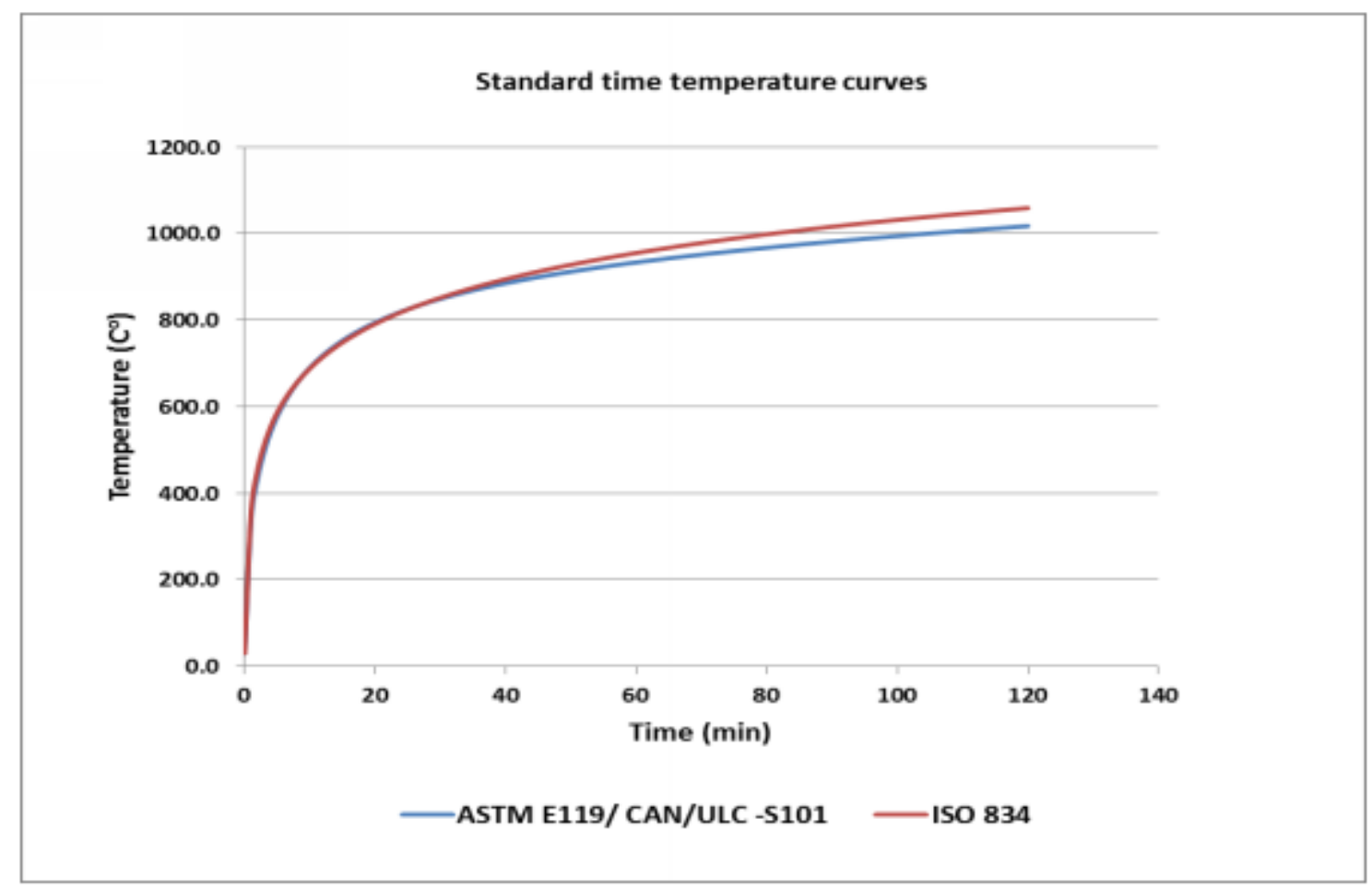

Figure 2.1 Standard fire time-temperature curves [27]

The design standards set the specifications for the load, geometry, support conditions and fire severity required to determine the fire-resistance rating based on the type of element in question. CAN/ULC-S101 [26] considers three failure criteria to determine the fire-resistance: stability, integrity and insulation. This is further explained as follows:

Stability criterion: To satisfy this criterion, load-bearing structural elements like beams, columns, floors, load-bearing walls, must perform their intended purpose of carrying the subjected loads for the period of the test without structural collapse during the test period.

Integrity criterion: This criterion is met when non-structural building elements such as doors, partitions and glazing do not develop cracks or fissures during a standard test in order not to allow the passage of smoke or hot gases through the assembly.

Insulation criterion: This criterion is met if the average temperature increase on the unexposed surface of the test specimen does not rise by $140^{\circ} \mathrm{C}$ above its initial temperature or $180^{\circ} \mathrm{C}$ rise 
at a single location. This is similar to the integrity criterion and is intended to examine the ability of a barrier to contain a fire and also prevent spread to other compartments.

\subsection{Glulam}

In heavy timber construction, glulam is one of the commonly used engineered wood products due to its unique characteristics and high quality. Structural glued-laminated timber or glulam is one of the long-lived engineered wood products which is manufactured from lumber laminations glued together and end jointed with adhesives under controlled conditions. The laminas are made of short-length pieces and they are end-jointed using a structural finger joint. The laminates are arranged in horizontal layers with the grain in the longitudinal direction and the length of each lamination is the full length of the structural element (e.g. beam member). The net thickness of individual lamination can range from 25 to $45 \mathrm{~mm}$ in straight members, while curve members have thinner laminations of thickness which ranges from 10 to $25 \mathrm{~mm}$, depending on the radius of the curve [7]. Owing to its flexibility, glulam members can be produced to any desired shape, length, or size. The length of a glulam member is limited due to transportation problems. Glued laminated timbers have a wide variety of uses such as large beams, columns, arches and other curved shapes.
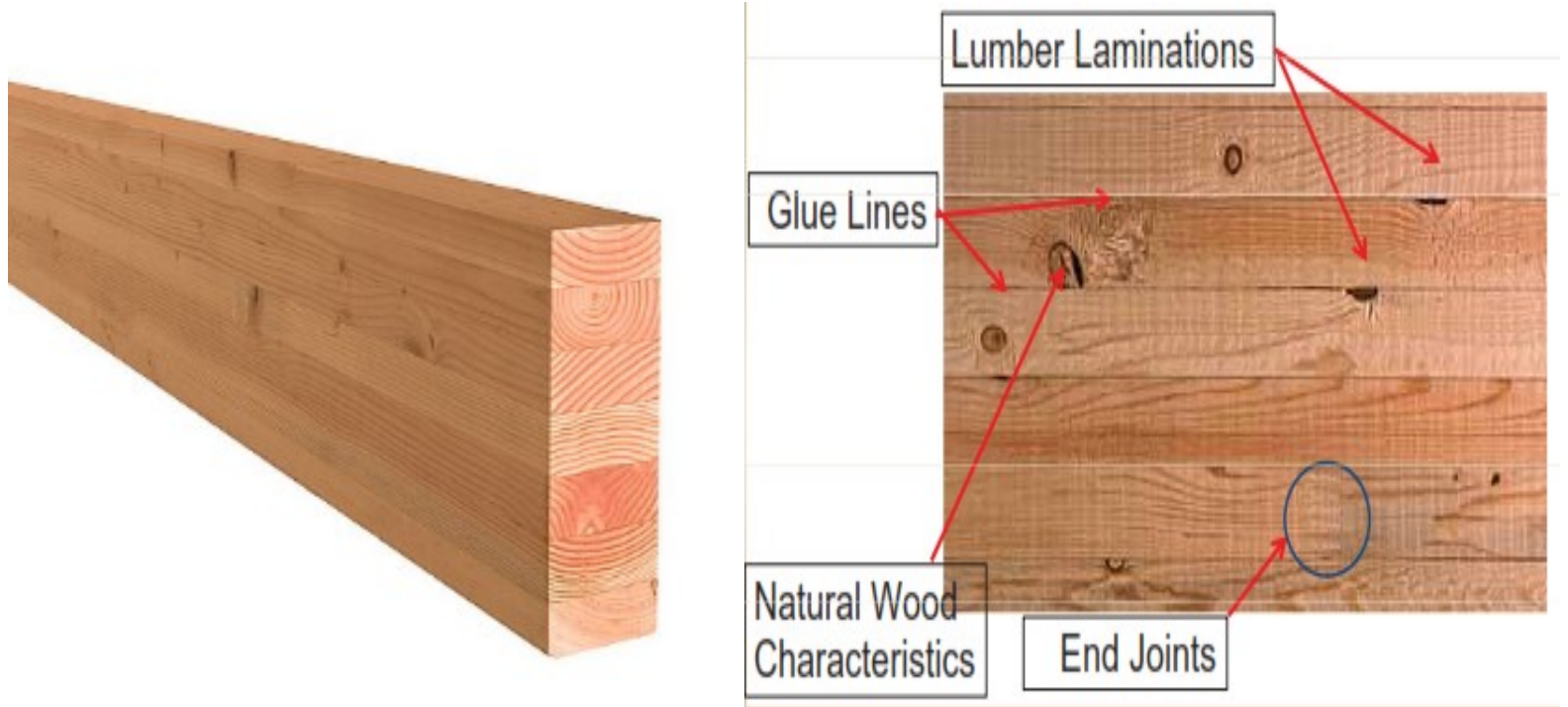

Figure 2.2 Glulam beam [28] 
The manufacturing process of glulam is done in the same way irrespective of the manufacturer or country [29]. A schematic sketch of the manufacturing process is shown in Figure 2.3.

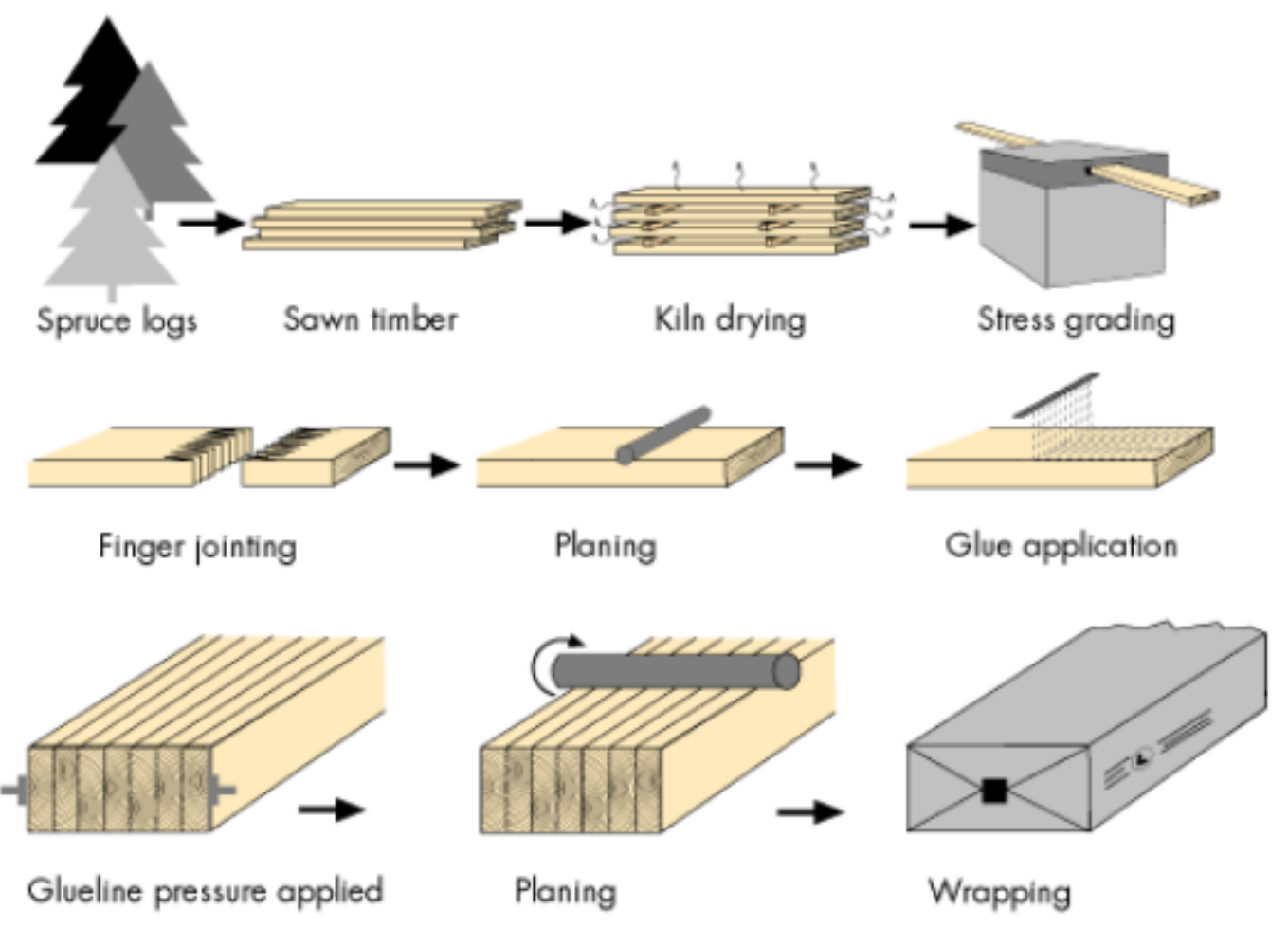

Figure 2.3 Sketch of the production process [29]

The properties of wood and steel at both ambient and elevated temperatures are summarized in appendix A.

\subsection{Charring Rate of Wood}

When wood is exposed to elevated temperatures, it undergoes thermal decomposition and rapidly turns to char. The charring rate of wood generally refers to a measure of the speed of conversion of wood into char when exposed to fire [30]. It is also referred to as the dimensional rate, which is the ratio of the charred depth to exposure time [mm/min] [31].

Charring rate of wood depends on density and moisture content of wood, external heat flux and oxygen concentration of the surrounding air [32]. However, in a standard fire test, experimental 
studies have shown that the charring rate of wood is a function of wood species, density and moisture content of the wood $[31,33]$.

The charring rate is very important in structural fire safety design. The charred layer of a wooden structural member practically has no strength and stiffness and thus, cannot resist any structural load. The structural load is therefore resisted by the residual core of the timber crosssection which did not char during fire exposure. Hence, the capacity as well as the stability of a structural wood member when exposed to fire is determined by the capacity of the residual section. Therefore, it is essential to accurately calculate the charring rate of wood to determine the residual cross-section of the member during a fire.

Many researchers have extensively investigated the charring rates of various wood species [31, 34, 35]. Konig and Walleij [5] experimentally studied the charring of timber members of spruce exposed to the ISO 834 standard temperature-time curve. In this study, a fairly linear relationship between ISO 834 [24] fire exposure time and charring depth for four identical test specimens, A1-A4 was reported. Figure 2.4 illustrates the charring depth as a function of the fire exposed time of the four compared specimens. The relationship between time and the charring rates was determined from the position of the $300^{\circ} \mathrm{C}$ isotherms. In addition, it was found that the mean charring rate value varies linearly between $0.6-0.7 \mathrm{~mm} / \mathrm{min}[5]$. 


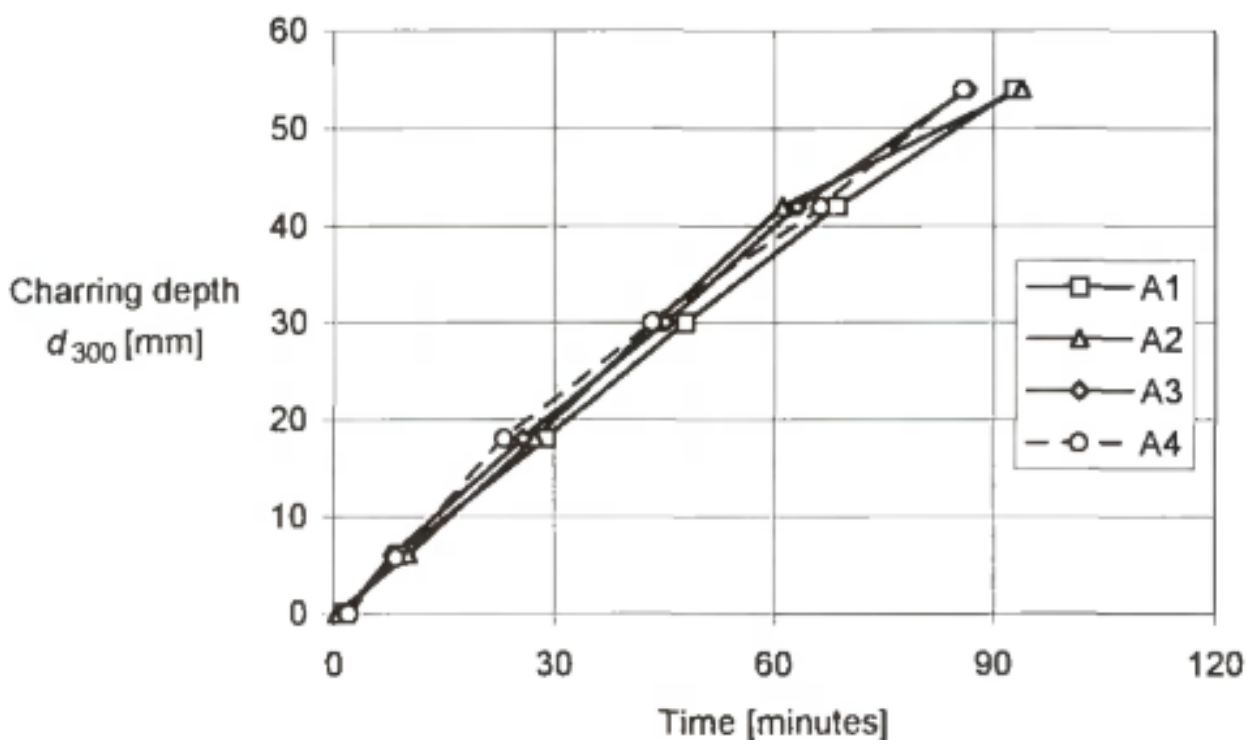

Figure 2.4 Variation of charring depth with exposure time [5]

In another study, White [31] tested eight samples of different wood species consisting of four hardwood and four softwood specimens to investigate the charring rates and several material properties. The author used regression analysis to develop empirical models for estimating charring rates of these wood species and their differences following the American Society for Testing and Materials (ASTM) Standard test method E 119 [36]. The tests were conducted in a vertical gas-fired furnace where the wood slabs were exposed to follow the ASTM E119-83 fire [36]. The char front used in determining the charring rate was based on the $288^{\circ} \mathrm{C}$ isotherms. The data considered for the charring rates were recorded at depths $13 \mathrm{~mm}, 25 \mathrm{~mm}$, and $38 \mathrm{~mm}$ from the exposed fire surface of the slab. From the empirical model, the author suggested the estimation of the charring rate as follows:

$$
\mathrm{t}=\mathrm{mx}_{\mathrm{c}}^{1.23}
$$

or the linear form of Equation 2.1

$$
\operatorname{In} t=1.23 \operatorname{In} x_{c}+\operatorname{In} m
$$

Where; $\mathrm{t}$ is the exposure time $(\mathrm{min}), \mathrm{x}_{\mathrm{c}}$ is the char depth $(\mathrm{mm})$ and $\mathrm{m}$ is the reciprocal charring rate which is a dependent factor of moisture content, density and contraction factor [34]. 
Several studies have been conducted on the effect of density on charring rates and from available data, it is widely established that charring rates of wood decreases with increasing density [7, 37-39], Figure 2.5 illustrates the charring rate as a function of density and moisture content.

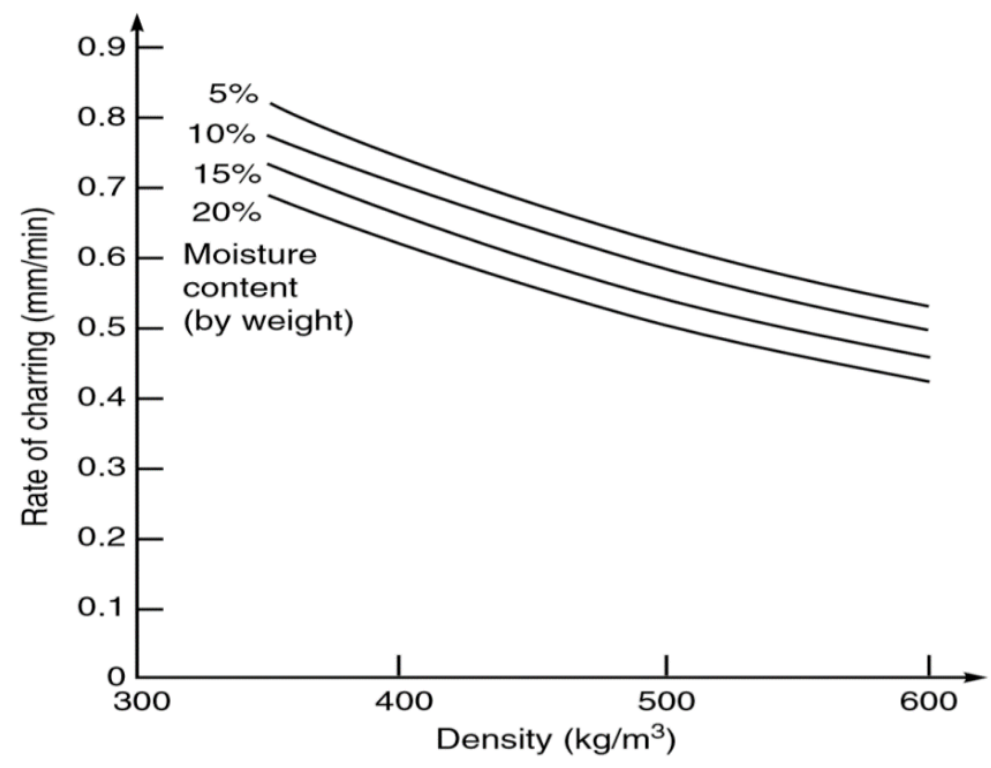

Figure 2.5 Influence of density and moisture content on charring rate [7]

Eurocode 5 suggests a value of $0.65 \mathrm{~mm} / \mathrm{min}$ for the charring rate of softwoods and if the effect of corner rounding is included, a slightly higher value is used in Eurocode 5 [40]. While in North America, the recommended charring rate for solid wood and glulam timber is 0.635 $\mathrm{mm} / \mathrm{min}$ based on White's model [7, 41]. Yang et. al. [42] performed experiments on gluelaminated timbers made from five softwood species to investigate the charring rates and charring depths under standard fire exposure. It was found that the average charring rate and char layer depth at the bottom sides of the specimens were higher than those of the lateral sides in the same specimen. Also, it was observed that the charring rate of the specimens decreases with an increase in density.

In timber connections, the charring rates reported for concealed WSW connections were slightly higher than the charring rate for WWW connections, exposed and seated connections. 
This is due to the metal components conducting heat to the inner core of the wood which increases the charring rate [27, 43, 44]. In a paper review by Peng et. al. [45], charring rates of $0.65 \mathrm{~mm} / \mathrm{min}, 0.67 \mathrm{~mm} / \mathrm{min}$, and $0.7 \mathrm{~mm} / \mathrm{min}$ were reported for WWW connections, but for WSW connections, charring rates of $0.81 \mathrm{~mm} / \mathrm{min}$ and $0.82 \mathrm{~mm} / \mathrm{min}$ were reported. In another study, Ali and Hadjisophocleous [27] reported a charring rate range of 0.63 to $0.76 \mathrm{~mm} / \mathrm{min}$ for concealed wood-steel-wood connections.

\subsection{Application of Self-Tapping Screws}

Due to the weakness of timber in tension perpendicular to grain and in longitudinal shear, researchers had employed various reinforcement techniques to improve the capacity of connections and strengthen them against ductile and brittle failure modes. These techniques include reinforcement by glued-in steel rods [46], self-tapping screws [19], glued-in glass fibrereinforced polymer (GFRP) [47] and glued-on wood-based panels [48]. Among these techniques, self-tapping screws are widely used by designers to strengthen connections and particularly to repair existing timber structures. This technique of reinforcing connections is a new trend preferably used because of its simple installation and economic benefit over other traditional reinforcement methods [49].

Extensive studies by [50-53] had shown that self-tapping screws can be effectively used to prevent or fully control the brittle and ductile failure modes frequently encountered in concealed connections. Bejtka and Blaß [54] strengthened dowel-type connections with fully threaded self-tapping screws to enhance their load-carrying capacity. A total of ten (10) tests were conducted on steel-to-timber connections, which comprises of five reinforced and five unreinforced specimens. It was reported that placing the screws in contact with the dowel fasteners prevented splitting, increased the stiffness and the load-carrying capacity of the connections by up to $120 \%$ when compared to the unreinforced connections [54]. Also, the 
authors developed calculation model based on Johansen's yield theory to estimate the load carrying capacity for reinforced steel-to-timber connections. In another study, Bejtka and Blaß [55] conducted a total of 19 tests at ambient temperature to investigate the load-carrying capacity of beam support when reinforced with self-tapping screws. The test results showed that the load-carrying capacity of the reinforced beam supports increased by a maximum of $300 \%$ than those of the unreinforced beam supports. In that study, a calculation model was developed to estimate the load-carrying (compressive) capacity of the reinforced beam support. Bejtka and Blaß [52] studied the effectiveness of fully threaded self-tapping screws as compressive and tensile reinforcements perpendicular to grain to enhance timber's strength, since the strength values (tensile and compressive) of timber perpendicular to grain is lesser than the respective strength values in parallel to grain [52].

Zhang et al. [14] conducted experimental test on two timber portal frames, each consisting of three glulam beams. The authors used partially threaded self-tapping screws to improve the mechanical performance of dowel-type Wood-Steel-Wood (WSW) connections in timber portal frames. The test results showed that the screws effectively controlled crack propagation and increased the moment-resisting capacity as well as ultimate rotation by $31 \%$ and $51 \%$, respectively. In another study, Petrycki and Salem [56] investigated the behaviour of beam-tocolumn bolted concealed connections reinforced with self-tapping screws, while subjected to monotonic loading in a column removal scenario. It was reported that the screws increased the moment-carrying capacity of the reinforced connections by a factor ranging between 1.3 and 2.4. In another study, Lam et al. [57] studied the influence of self-tapping screw in the performance of bolted glulam connections with slotted-in steel plates, subjected to monotonic and reverse cyclic loadings. The study demonstrated that a ductile and high-capacity momentresisting bolted concealed connections can be achieved by employing self-tapping screws. In that study, failed unreinforced connections were also retrofitted with self-tapping screws. It 
was reported that the capacity of the reinforced connections increased by a factor of 2 and 1.7 under monotonic and reverse cyclic loading, respectively; while, an increase by a factor of 1.87 and 1.53 was observed in the capacity of the retrofitted connections when subjected to monotonic and reverse cyclic loading, respectively. Studies by [48, 58, 59] have been conducted to investigate the application of self-tapping screws to reduce splitting and increase the moment-resisting capacity, ductility, load-carry capacity, as well as the stiffness of connections.

Despite the benefits of employing self-tapping screws in timber connections, no design or requirements are provided for in the Canadian timber design standard CSA O86 to estimate the capacity of reinforced connections nor guidelines and procedures for employing STS. Therefore, more studies need to be conducted to further understand the performance of connections with self-tapping screw reinforcement at ambient temperatures. Very few tests have been conducted at elevated temperatures to investigate the fire performance of reinforced connections. Therefore, more tests are also necessary at elevated temperatures to understand the influence of self-tapping screws on the fire performance of beam-to-column concealed connections in order to comply with the fire-resistance rating prescribed in the code for combustible buildings.

\subsection{Timber Connections}

The overall performance of a timber structure depends largely on the design and behaviour of its connections. Timber connections are the most important and crucial components of any wood structure since they are the weakest component in the structure. In recent years, the performance of timber connections at both normal and elevated temperatures has attracted the attention of researchers. This section discusses the design of connections and the behaviour of timber connections at ambient temperature as well as elevated temperatures. 


\subsubsection{Behaviour of Connections at Ambient Temperature}

The proper design of connections is vital to the stability of timber structures as the connection is used to transfer loads between members such as from beams to a column and from column to the foundation. Therefore, the connection is the critical factor in the safety design of a structure because the behaviour of the connection usually dictates the strength and performance of the structure. In timber construction, steel fasteners such as nails, dowels, bolts, and lag screws are widely used as fasteners in mechanical connections because of their efficiency in transferring loads [16]. According to the Canadian Engineering Design in wood standard CAN/CSA O86-14 [60], timber connections are mainly classified into two groups based on the direction of loading, which are parallel-to-grain loaded connections and perpendicular-to-grain loaded connections. In parallel-to-grain loaded connections, also known as shear connections, the load is applied parallel to the wood grains and perpendicular to the length of the fastener while in perpendicular-to-grain loaded connections, the load is applied perpendicular to the wood grain and parallel to the length of the fastener. Connections can further be classified by types of main and side members, such as wood-wood-wood, wood-steel-wood, and steel-woodsteel connections.

CSA O86-14 [60] classifies the two major failure modes encountered in bolted timber connections as yielding (ductile) and brittle failure modes (sudden failure). Ductile failure mode can occur in wood connections loaded perpendicular to grain when there is an excessive crushing of the wood fibres underneath the fastener due to huge embedment stresses exerted and yielding of the fastener in bending or shear. A splitting failure (brittle failure) occurs because of perpendicular-to-grain tensile stress concentration at the end of the wood member. In design, it is preferable to design for yielding failure mode than brittle failure, because yielding allows for load distribution among the bolts of a connection. The possible failure modes experienced in bolted timber connections are illustrated in Figure 2.6. 
The overall resistance of the connection significantly depends on the resistance of the bolt to bending (i.e. plastic deformation), and the embedment strength of the timber underneath the bolt to resist crushing of the wood fibres. To estimate the resistance of a single bolt fastener at a local level, Johansen's yield theory (also known as European Yield Model, EYM) included in the European code is widely used while at a global level, criteria on fasteners spacing, edge and end distances are used to avoid brittle failures [16]. CSA O86-14 [60] prescribes the required minimum fasteners spacing, edge distance and end distance, in order to avoid premature brittle failure of a connection.

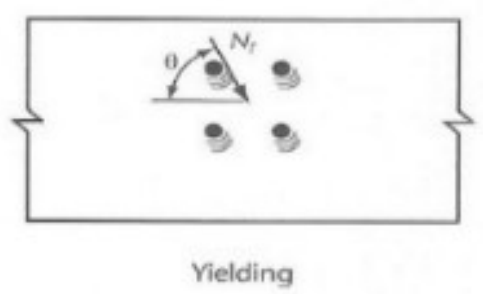

(a) All loading directions
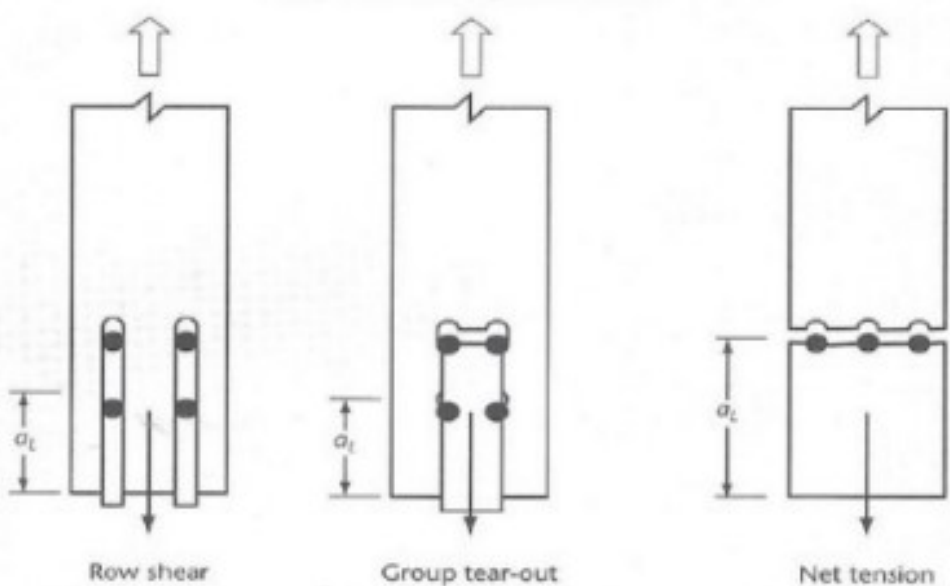

Row shear

Group tear-out

Net tension

(b) Parallel-to-grain

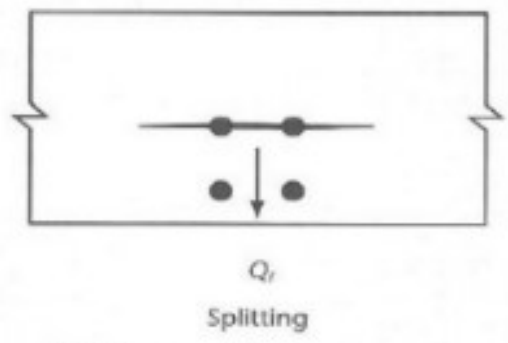

(c) Perpendicular-to-grain

Figure 2.6 Potential failure modes in wood connections (CAN/CSA O86-14) [60] 


\subsubsection{Design of Connections Loaded Perpendicular to the Wood Grain}

In this section, the design rules for connections loaded perpendicular to grain are presented. CSA O86-14 [60] states the design equations for calculating the perpendicular-to-grain splitting resistance, embedment strengths, and yielding resistance for a bolted timber connection. The symbols used in the design rules for connections are from the original publication from the design standard, CSA O86-14 [60].

\subsubsection{Perpendicular-to-grain Splitting Resistance}

CSA O86-14 [60] requires connections loaded perpendicular-to-grain to be designed to satisfy equation 2.7 .

$$
Q_{f} \leq Q_{r}
$$

Where $Q_{f}$ is the factored load perpendicular to the grain, and $Q_{r}$ is the factored splitting resistance.

The factored splitting resistance is calculated as follows:

$$
Q_{r}=Q S_{r T}
$$

The sum of the splitting resistance of the wood member resisting the load is equal to the total factored splitting resistance of the connection and it is calculated as follows:

$$
Q S_{r T}=\sum Q S_{r i}
$$

The factored perpendicular-to-grain splitting resistance of a wood member i, N, is calculated as follows:

$$
Q S_{r i}=\emptyset_{W} Q S_{i}\left(K_{D} K_{S F} K_{T}\right)
$$

Where $\emptyset_{W}$ is the resistance factor for brittle failures $=0.7$ 


$$
Q S_{i}=14 t \sqrt{\frac{d_{e}}{1-\frac{d_{e}}{d}}}
$$

Where:

$t$ : is the side member's thickness, mm

de: is the effective depth of the member, mm

$$
\mathrm{d}_{\mathrm{e}}=d-\mathrm{e}_{\mathrm{p}}
$$

$d$ : is the total depth of the wood member, mm

$e_{p}:$ is unloaded edge distance, $\mathrm{mm}$

$\emptyset_{\mathrm{w}}$ : is the resistance factor for brittle failures which equal to 0.7

$K_{\mathrm{D}}$ : is the duration of the load factor

$K_{\mathrm{S}}$ : is the service condition factor

$K_{\mathrm{T}}:$ is the fire-retardant treatment factor

\subsubsection{Yielding Resistance}

Yielding failure can occur in a connection when a load is applied at any angle to the wood grain. CSA O86-14 provides the possible ductile failure modes for double-shear connections at normal temperature. Figure 2.7 shows the ductile failure modes for a double shear timber connection (two shear planes). 
(I)

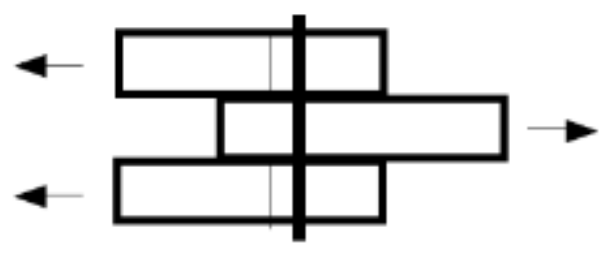

(III)

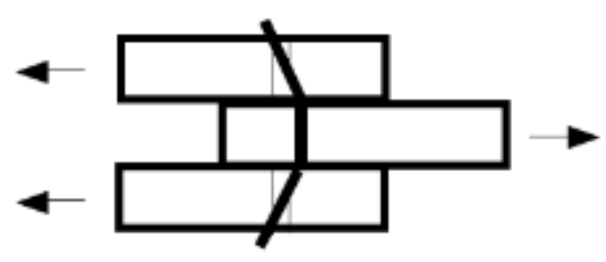

(II)

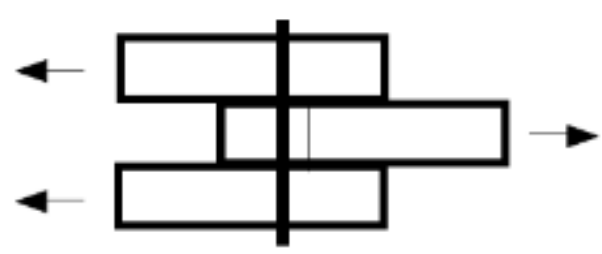

(IV)

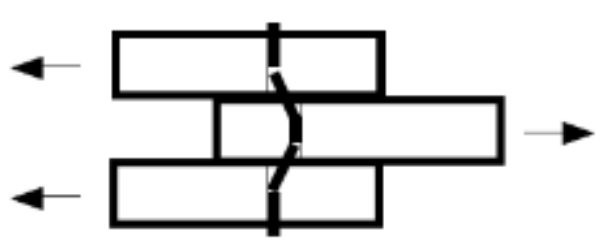

Figure 2.7 Ductile failure modes for double shear timber connections [63]

The design for yielding resistance shall fulfil equation 2.12 .

$$
N_{f} \leq N_{r}
$$

Where $N_{f}$ is the factored load on the joint, and $N_{r}$ is the factored lateral yielding resistance.

The factored lateral yielding resistance is:

$$
N_{r}=\emptyset_{y} n_{u} n_{s} n_{f}
$$

Where:

$\emptyset_{\mathrm{y}}=$ resistance factor for yielding failures

$$
=0.8
$$

$n_{u}=$ unit lateral yielding resistance, $\mathrm{N}$ (Clause 12.4.4.3.2)

$n_{s}=$ number of shear planes in the connection

$n_{f}=$ number of fasteners in the connection. 


\section{Unit lateral yielding resistance $\boldsymbol{n}_{u}$}

The unit lateral yielding resistance $n_{u}$ (per shear plane) is taken as the smallest value calculated in accordance with the following expressions with items failure modes (I), (II), (III), and (IV) as shown in Figure 2.7:

For failure mode I: $\quad n_{u}=f_{1} d_{f} t_{1}$

For failure mode II: $n_{u}=\frac{1}{2} f_{2} d_{f} t_{2}$

For failure mode III: $n_{u}=f_{1} d_{f}^{2}\left[\sqrt{\frac{1}{6} \frac{f_{2}}{\left(f_{1}+f_{2}\right)} \frac{f_{y}}{f_{1}}}+\frac{1}{5} \frac{t_{1}}{d_{f}}\right]$

For failure mode IV: $n_{u}=f_{1} \cdot d_{f}^{2} \sqrt{\frac{2}{3} \frac{f_{2}}{\left(f_{1}+f_{2}\right)} \frac{f_{y}}{f_{1}}}$

Where:

$f_{1}$ : is the embedment strength of side member, Mpa

$f_{2}$ : is the embedment strength of main plate, Mpa

$f_{y}:$ is the bolt's yield strength, MPa

$t_{1}$ : is the side member's thickness, mm

$t_{2}:$ is the main member's thickness, mm

$d_{f}:$ is the fastener's diameter, $\mathrm{mm}$

For wood member embedment strength:

$f_{1}=22 G\left(1-0.1 d_{f}\right)$ for fastener bearing perpendicular to grain

For steel member embedment strength:

$f_{2}=3 f_{u}\left(\frac{\emptyset_{\text {steel }}}{\emptyset_{y}}\right)$

$G$ : is mean relative density

$f_{u}$ : is the ultimate strength of steel grade, MPa 
$\emptyset_{\text {steel }}=0.67$, is the resistance factor for metal member

$\emptyset_{\mathrm{y}}=0.8$, is the resistance factor for yielding failures

\subsection{Review of Pertinent Literature on Timber Connections}

Wang et al. [61] investigated the bending moment resistance of beam-to-column connections with slotted-in plates, the authors conducted a series of experimental and numerical studies on the mechanical behaviour of bolted glulam beam-column connections under various combinations of shear force and bending moment. A finite element-based model was also developed to determine the elastic-plastic damage behaviour of wood. Before the development of a three dimensional (3-D) finite element-based model for the prediction of plastic deformation and damage evolution of wood, the authors carried out a series of experimental tests which consisted of monotonic pure bending tests, pure shear tests, and combined shear and bending tests. The specimens were divided into three groups consisting of five replicates each; specimens in group S1 were subjected to pure bending while specimens in groups S2 and S3 were subjected to combined shear and bending with different shear-to-bending ratios.

In total, 15 full-scale tests were conducted on bolted glulam beam-to-column connections. All the specimens used were prepared from Canadian spruce-pine-fir (S-P-F) with grade No. 1. A steel plate of $9.5 \mathrm{~mm}$ thickness was employed to connect the beam to the column support. The metal fasteners used in fastening the connections together were 20 -mm diameter steel bolt with grade 8.8 low-carbon. The group S1 specimens were fabricated to form a spliced beam with the splice joint placed at midspan while groups S2 and S3 specimens were similar to tests conducted by Lam et al. [57]. To avoid premature bearing failure in all tests, a 5-mm wide gap was maintained between the glulam beams or beam and column. The group S1 specimens were simply supported, and the specimens were loaded 900-mm away from the supports (Figure 2.8a). The tests were conducted in load control with a loading rate of $3 \mathrm{kN} / \mathrm{min}$ while for groups 
S2 and S3, a hydraulic actuator was used to apply the load near the free end of the beam in displacement control with a loading rate of $10 \mathrm{~mm} / \mathrm{min}$ (Figure $2.8 \mathrm{~b}$ ). The experimental data collected included the applied load and vertical displacements. As shown in Figure 2.8, Linear Variable Differential Transducers (LVDTs) were strategically positioned around the beams to measure the displacements (vertical and angular) and the built-in load cell of the hydraulic jack or actuator measured the applied load. Figures $2.8 \mathrm{a}$ and $2.8 \mathrm{~b}$ present the test set-ups for the pure bending test and combined shear and bending, respectively.

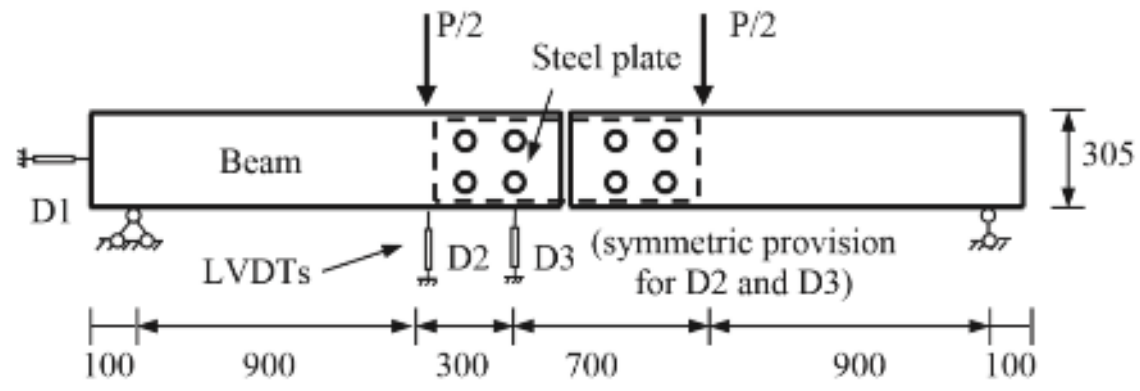

(a) Pure bending test (S1)

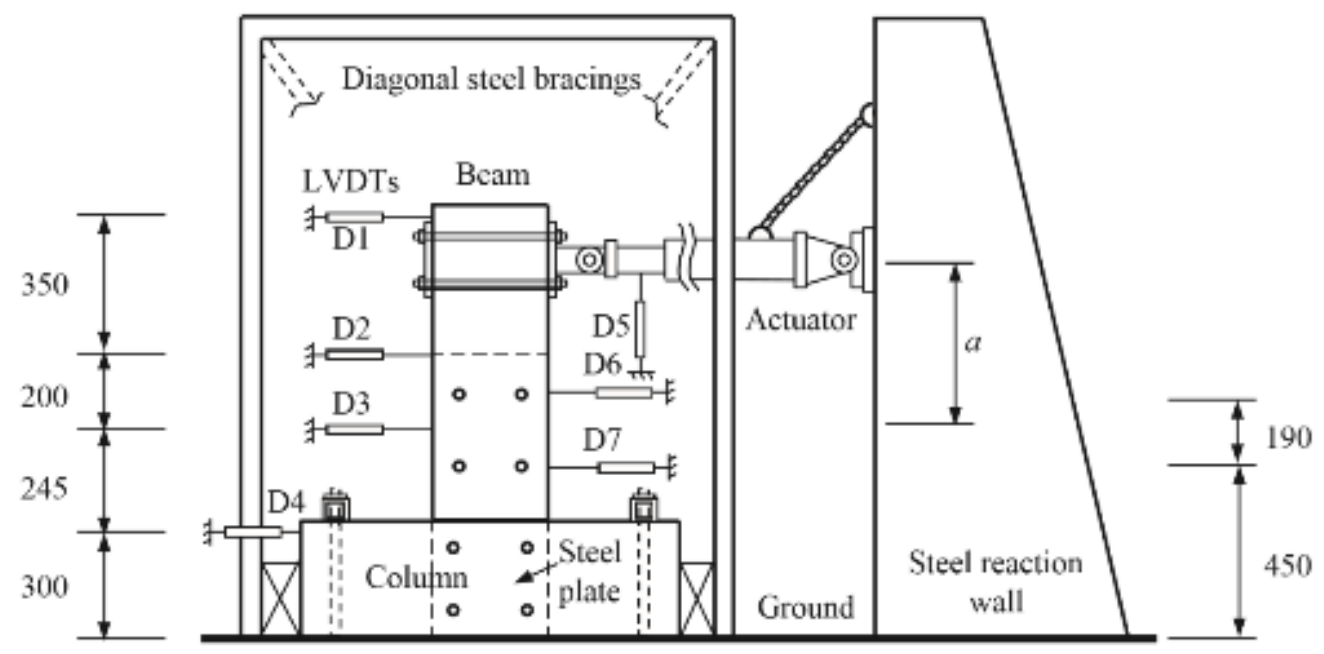

(b) Combined shear and bending test (S2 and S3)

Figure 2.8 Test Set-up and measuring schemes (unit: $\mathrm{mm}$ ) [61] 
Based on the observation from the experimental tests, Wang et al. [61] reported a shear plug failure mode for the combined shear and bending tests (groups S2 and S3), while in the pure bending test (group S1), a perpendicular-to-grain splitting failure was observed and this was caused by perpendicular-to-grain tensile stress. In the pure bending tests, the splitting was observed from the tensile side of the specimen due to action of bending moment, while in pure shear tests, the cracking initiated from the loading side. Despite the 5-mm gap, it was seen that contact between the glulam beam and beam or beam and column occurred, and the authors reported that such contact was beneficial to the prevention or delay of tensile splitting (Figures 2.9a-c). Figure 2.9 depicts that the typical failure modes encountered during the pure bending tests, and combined shear and bending tests.

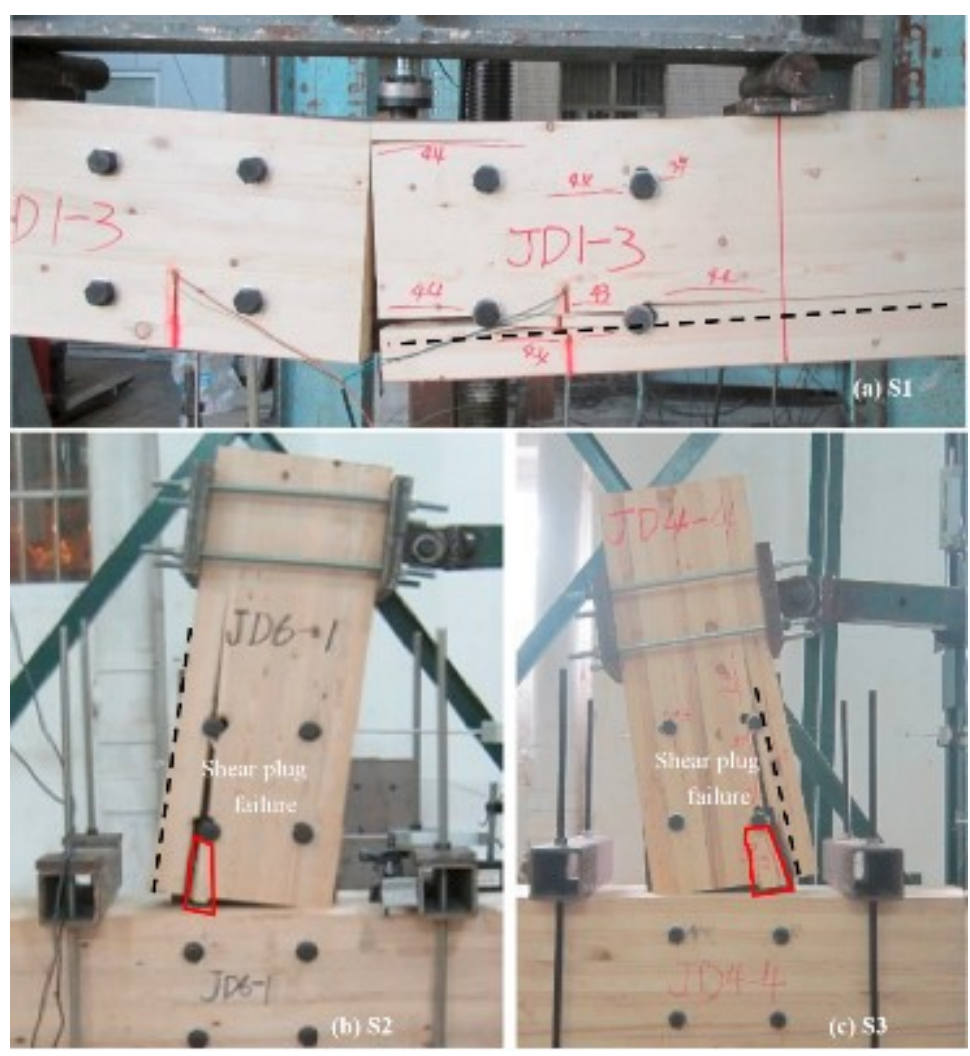

Figure 2.9 Typical failure modes of groups S1-S3 [61]

The authors concluded that the two dominant failure modes encountered in the shear and bending tests were perpendicular-to-grain splitting and parallel-to-grain shear. It was also 
found that the moment resistance of the connections decreased with an increase of the shearto-bending ratio by up to $31.6 \%$ of the pure moment resistance, whereas the shear resistance decreased with the decrease of the shear-to-bending ratio by up to $46.1 \%$ of the pure shear resistance. Furthermore, it was stated that the FEM model developed based on an elastic-plastic damage model of wood agreed well with the test results.

In another study conducted by Zhang et al. [51], the authors conducted physical tests at ambient temperature to enhance the mechanical properties of damaged and undamaged dowel-type timber connections. The primary objective of this study was to investigate the effectiveness of self-tapping screws with various thread configurations to enhance the moment resistance of connections with and without artificial cracks. To achieve this, 24 tests were conducted on wood-steel-wood (WSW) connections reinforced with partially threaded screws while being loaded perpendicular-to-grain. All the glulam beams were prepared from European Whitewood with GL24c classification and were $1500 \mathrm{~mm}$ long with a rectangular cross-sectional dimension of $140 \mathrm{~mm}$ wide x $300 \mathrm{~mm}$ deep. The test specimens were divided into 4 groups and each group consisted of six tests. Figure 2.10 illustrates the specimen configurations.

A 5-mm steel plate slotted into the $140 \mathrm{~mm}$ x $300 \mathrm{~mm}$ beam and sandwiched between the timber side members of $67 \mathrm{~mm}$ thickness each, was used to structurally connect the specimens to a column support. For each specimen, the diameter of the dowel used was $12 \mathrm{~mm}$ and a total of 9 dowels were employed as fasteners in each connection. An artificial crack of $1.5 \mathrm{~mm}$ wide and $315 \mathrm{~mm}$ long, located at the middle row of the dowels was made on 12 specimens with the aid of a bandsaw. To improve the moment resistance of the connections with and without cracks, 12 specimens were reinforced perpendicular to grain with six (6) partially threaded selftapping screws installed on each specimen around the connection area. The self-tapping screws were $300 \mathrm{~mm}$ long, with $100 \mathrm{~mm}$ threaded part along the shank. 

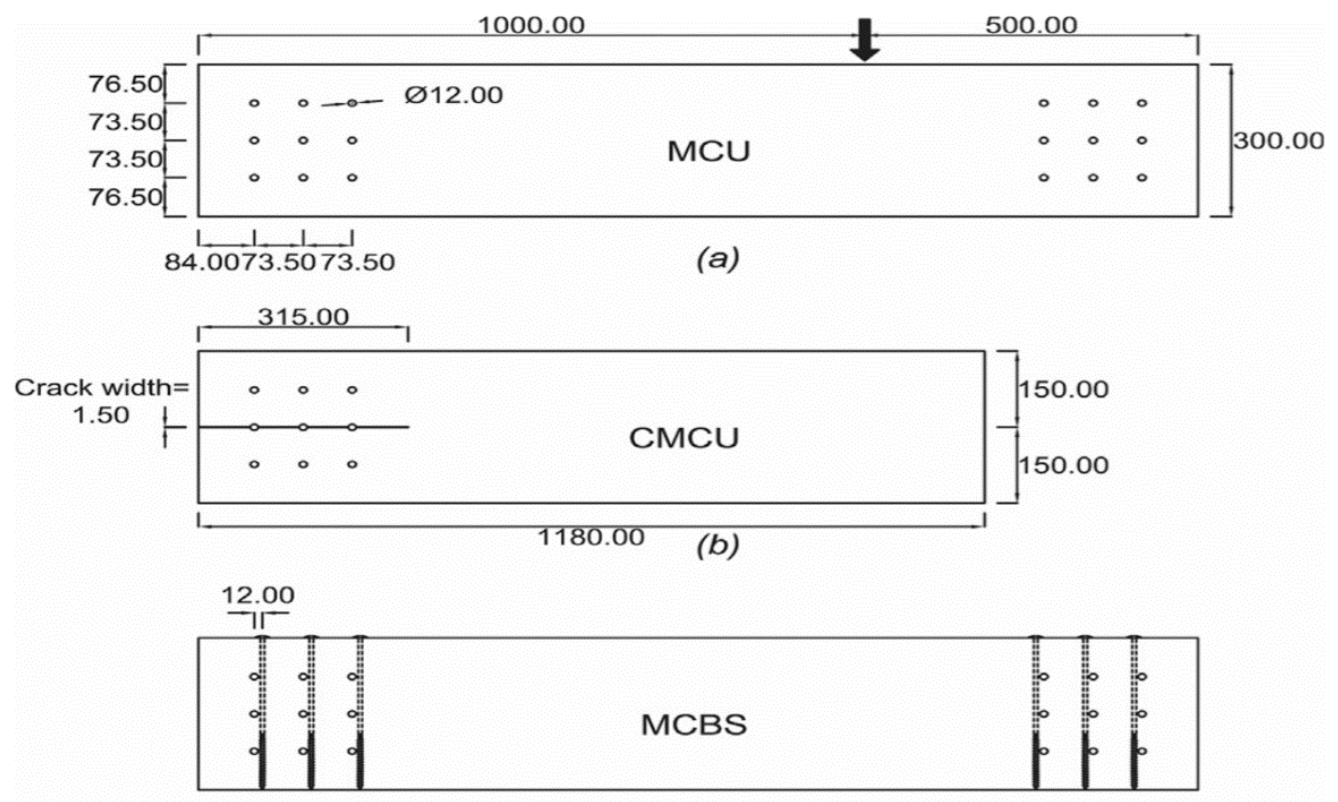

(c)

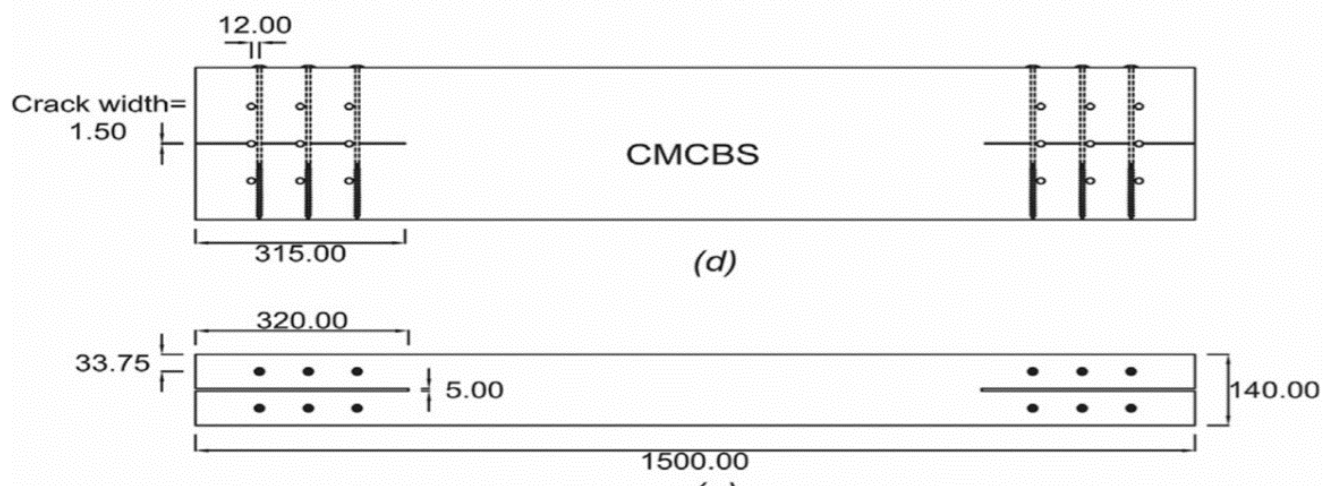

(e)

Figure 2.10 Specimen configurations: (a) Moment Connection Unreinforced (MCU), (b) Cracked Moment Connection Unreinforced (CMCU), (c) Moment Connection Reinforced with Screw (MCBS), (d) Cracked Moment Connection Reinforced with Screw (CMCBS) and

(e) top view of the glulam beam indicating the positions of the screw reinforcement [51]

As shown in Figure 2.11, a hydraulic jack installed $1.0 \mathrm{~m}$ away from the beam support was used to load the specimen by pulling the beam downwards. The tests were performed by applying a controlled loading and the connection specimens were loaded until failure. Six (6) linear variable displacement transducers (LVDTs) were used to measure the displacements of the assemblies and a Digital Image Correlation (DIC) was used to observe the surface strain distribution as well as to track crack propagation in the specimen. 

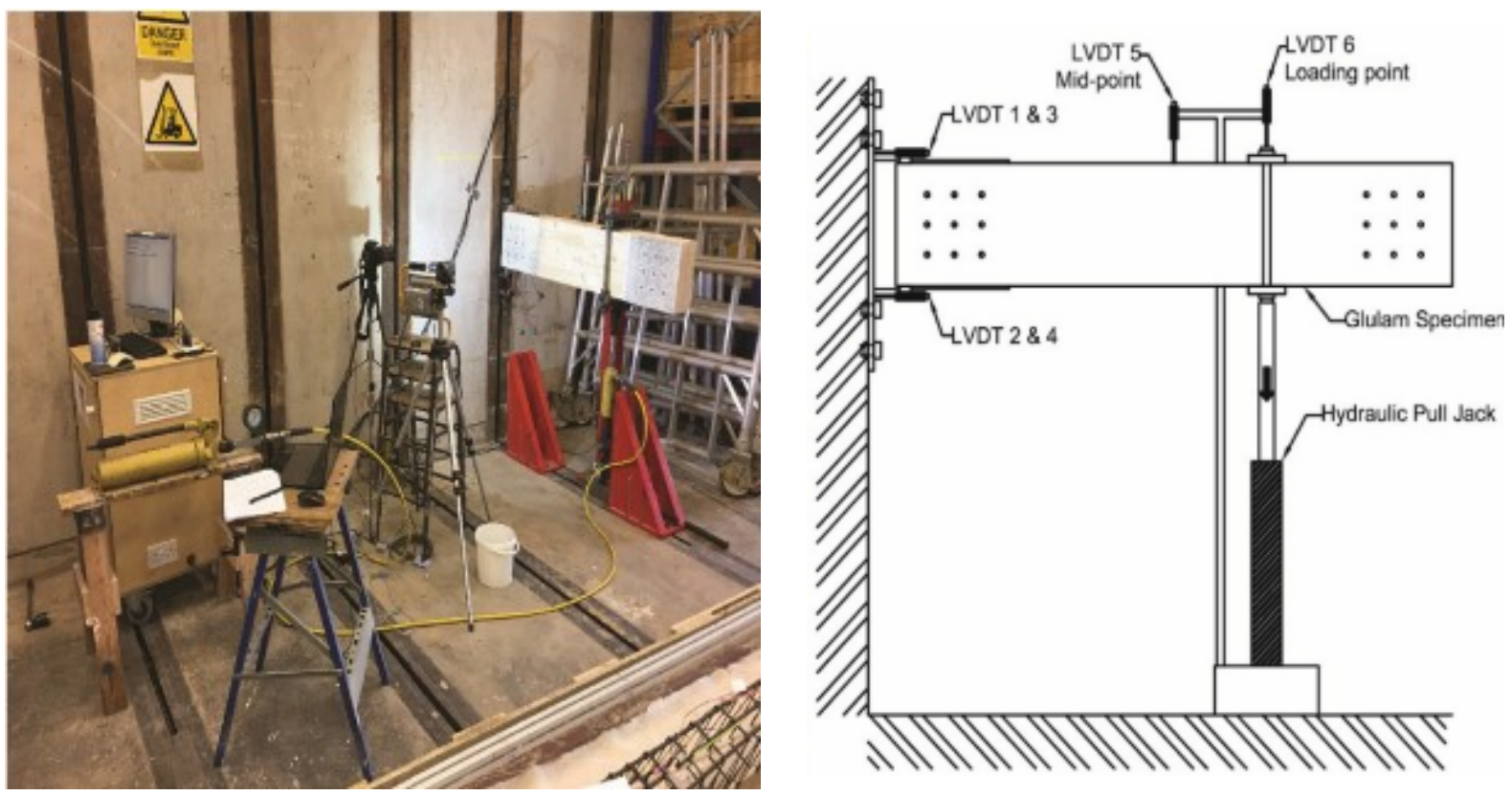

Figure 2.11 Moment-resisting connection test set-up (left) and locations of the LVDTs

$$
\text { (right) [51] }
$$

The results revealed that the average rotation of the unreinforced group CMCU with artificial cracks showed the least value with a capacity of $61 \%$ of the original unreinforced group MCU. This implies that the rotational capacity of a connection can be greatly reduced by cracks in the timber. However, the reinforced group CMCBS with artificial cracks had the second-best maximum rotation, its capacity was $10 \%$ higher than the unreinforced, undamaged (MCU) connections. As expected, the reinforced group MCBS had the highest rotational capacity, with a capacity of $45.6 \%$ greater than the connections in the unreinforced group MCU without a crack. This infers that self-tapping screws can be used effectively to restore the rotational capacity of damaged connections. Figure 2.12 shows the graphs representing the momentrotation curves for the four groups of connections. 

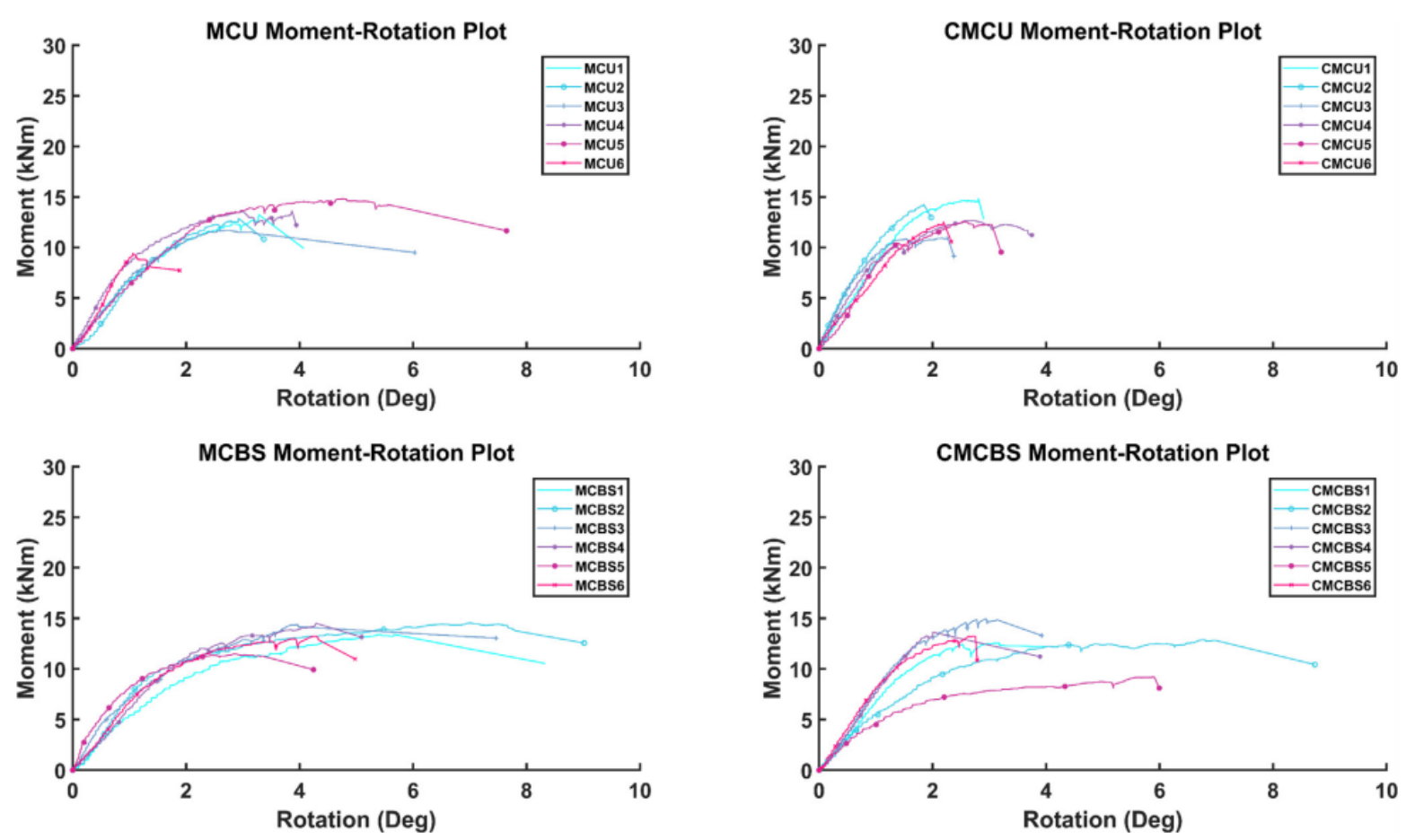

Figure 2.12 Moment-rotation curves for each group [51]

Overall, it was found that employing partially threaded self-tapping screws on the connections significantly enhanced the rotational capacity while a slight improvement was observed in the moment-resisting capacity of the connection. The authors also observed that employing the self-tapping screws greatly controlled the splitting failure as well as crack propagation in the connections. It was concluded that self-tapping screws can be used to restore the ductility of a connection after the development of cracks.

Lam et al. [53] conducted tests at ambient temperature on moment-resisting bolted timber connections reinforced perpendicular to grain with self-tapping screws under reverse-cyclic loading. The authors explored the effectiveness of self-tapping screws in improving the moment-resisting capacity and ductility of beam-to-column connections with slotted in steel plates. The main aim of this experimental study was to investigate the influence of bolt 
diameter, reduced edge distances, the influence of self-tapping screws, and the location of selftapping screws on the performance of the connections.

To investigate these variables, 25 full-scale tests were performed on beam-to-column connections with a $9.5-\mathrm{mm}$ steel plate sandwiched between the beam and two column members. The glulam beam and columns were prepared from Canadian 24f-E Douglas Fir and had a rectangular cross-sectional dimensions of $130 \mathrm{~mm}$ wide x $304 \mathrm{~mm}$ depth. The beam members were $830 \mathrm{~mm}$ long while the column members were $1000 \mathrm{~mm}$ long. The specimens were grouped into five-test series CU, CR, A-CR, B-CR and C-CR based on the size of bolts, reduced edge distance and self-tapping screws layouts. Figures 2.13, 2.14, and 2.15 show the geometry of the connection configurations for series A-CR, B-CR, and C-CR, respectively.

Two steel bolts of diameters $19.0 \mathrm{~mm}$ and $25.4 \mathrm{~mm}$ made from mild carbon steel SAE J429 Grade No. 5 were examined. The $19.0 \mathrm{~mm}$ diameter bolts were employed for tests series CU and $\mathrm{CR}$ while $25.4 \mathrm{~mm}$ diameter bolts were used for the remaining test series. Before the reinforced specimens were tested, 8-mm diameter fully threaded self-tapping screws (STS) with a length of $300 \mathrm{~mm}$ were installed perpendicular to grain around the connection areas. The self-tapping screws were installed to the full depth of the specimens from the top to the bottom of the beams. 

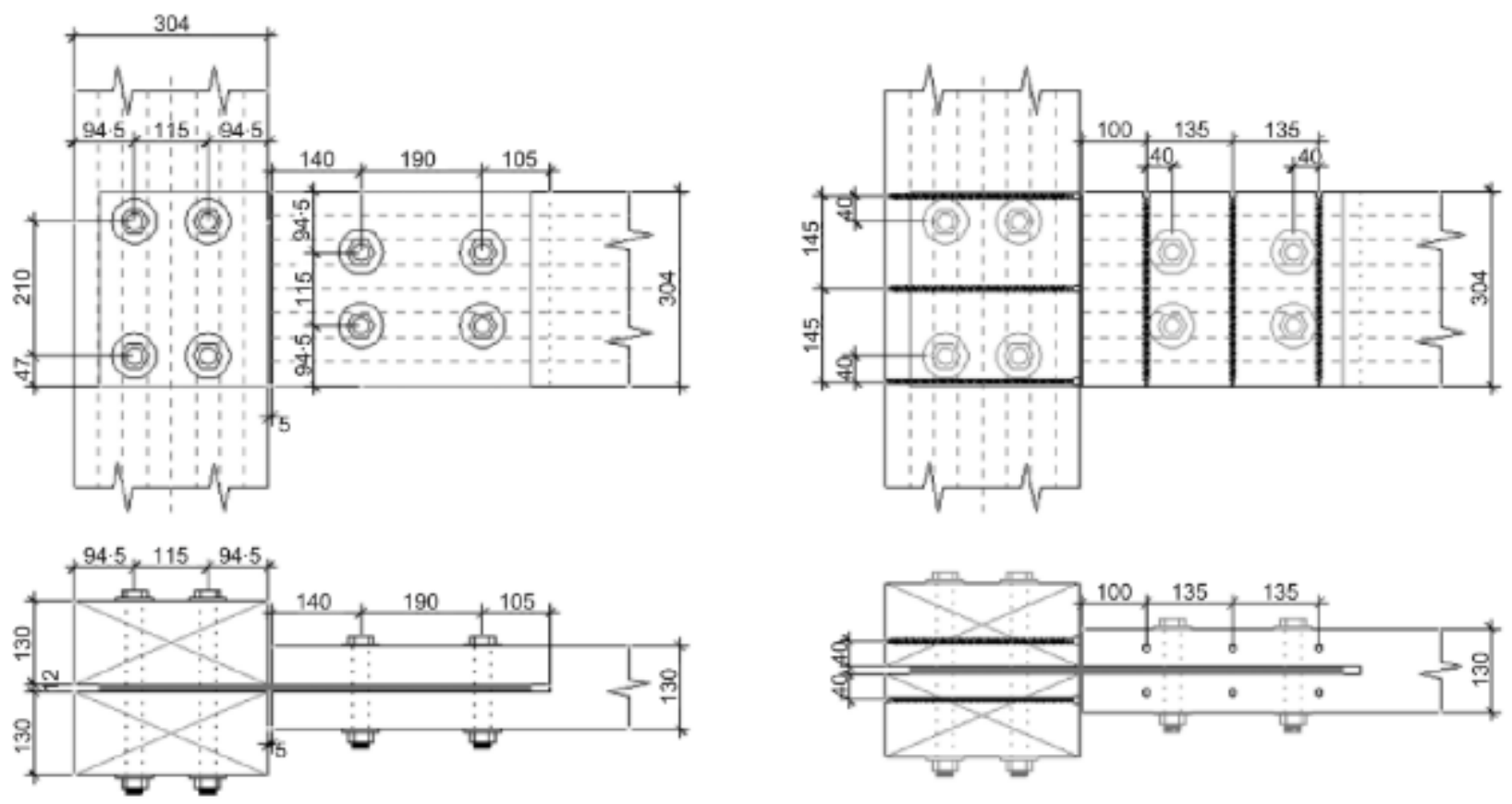

Figure 2.13 Connector layout for series CU, CR and A-CR (all dimensions in $\mathrm{mm}$ ) [53]
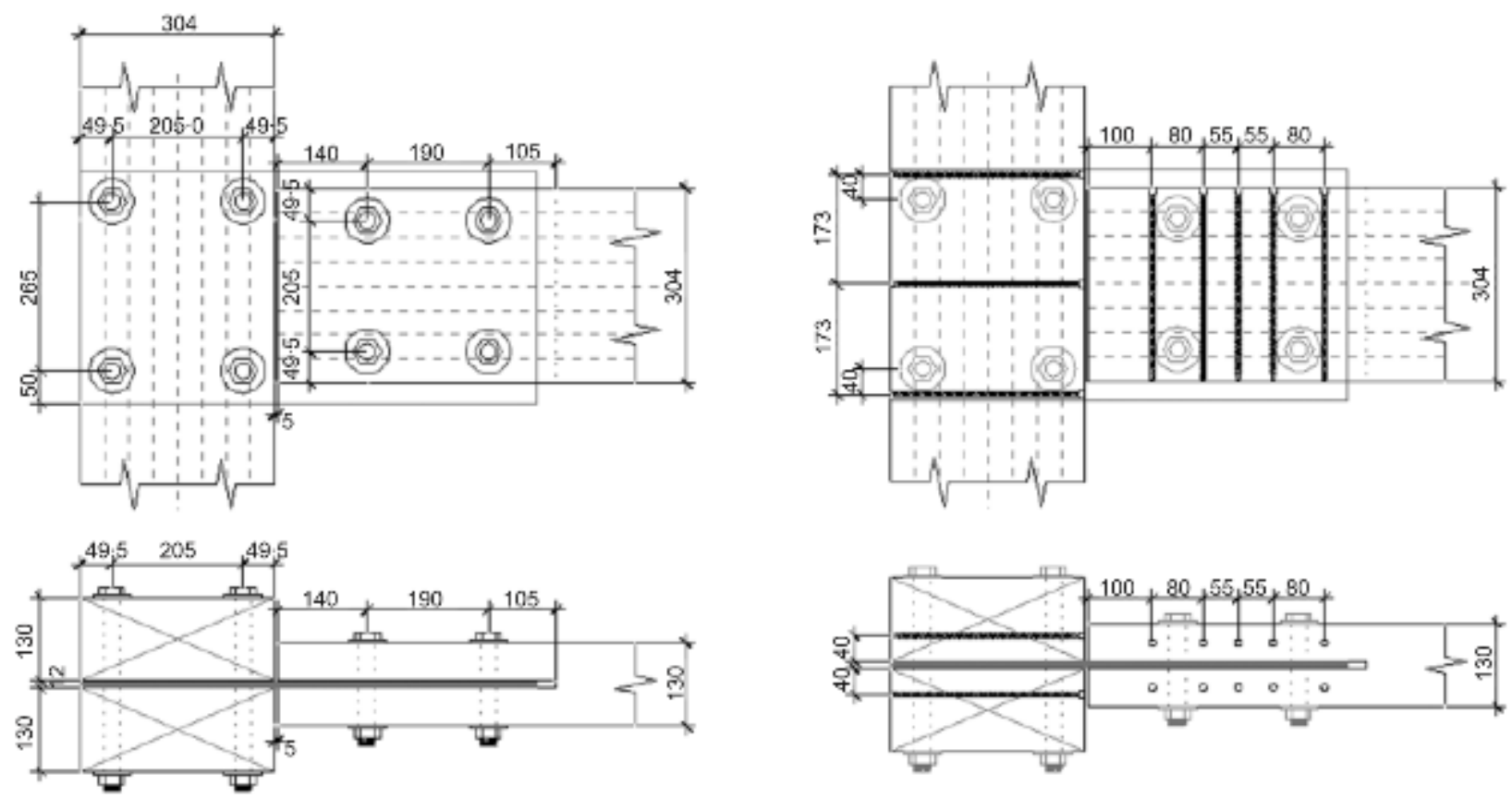

Figure 2.14 Connector layout for series B-CR (all dimensions in $\mathrm{mm}$ ) [53] 

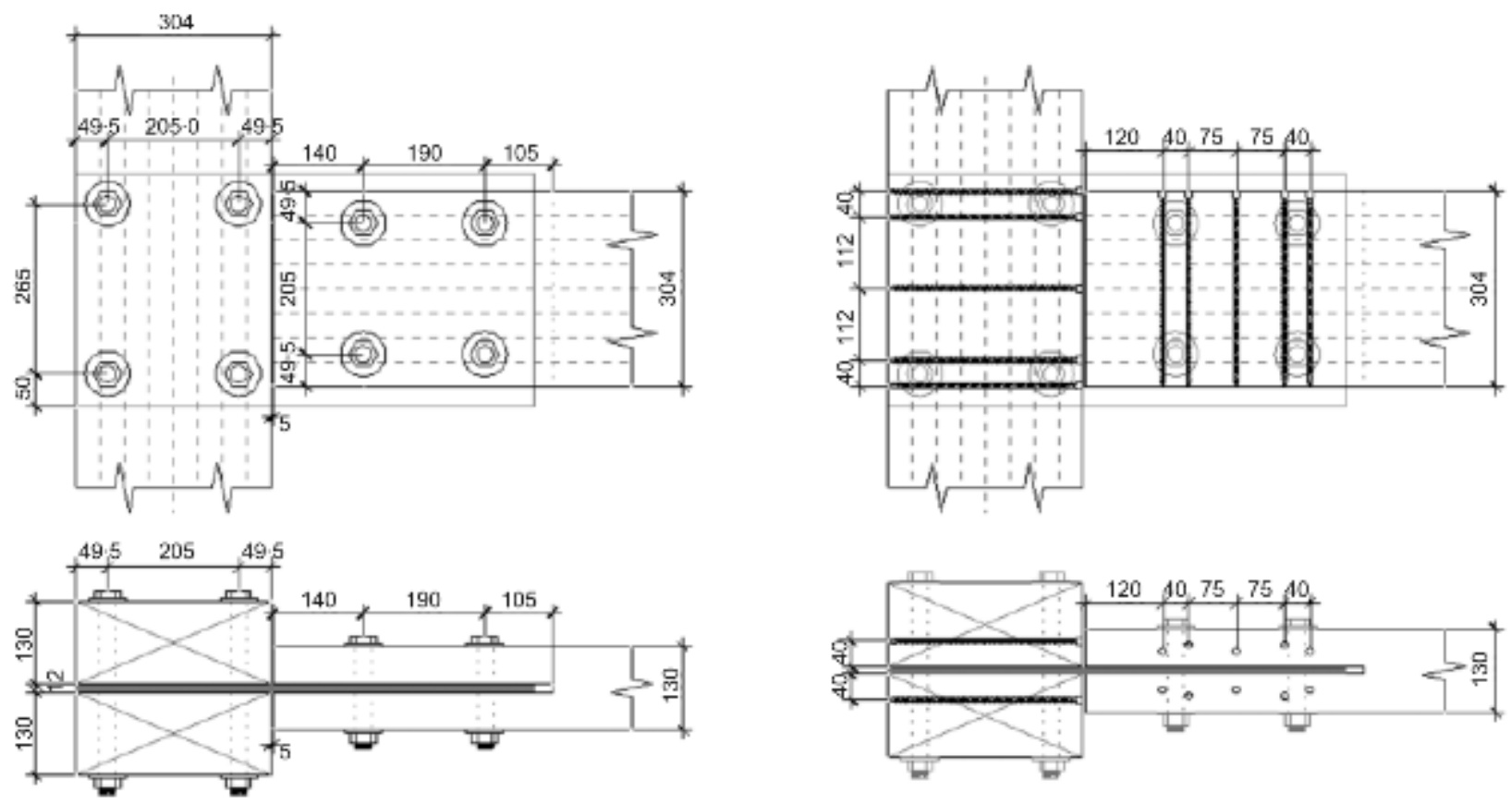

Figure 2.15 Connector layout for series C-CR (all dimensions in $\mathrm{mm}$ ) [53]

In all the test series, a single-ended MTS actuator was used to apply a displacement controlled reverse cyclic protocol loading in order to simulate extreme loading conditions such as earthquakes. As shown in Figure 2.16, linear position transducers were strategically positioned around the assemblies to measure the vertical and horizontal displacements of the specimen and steel plate, respectively. The recorded data was used to determine the rotation of the steel plate relative to the column member. The typical test set-up of the five-test series is shown in Figure 2.16. 


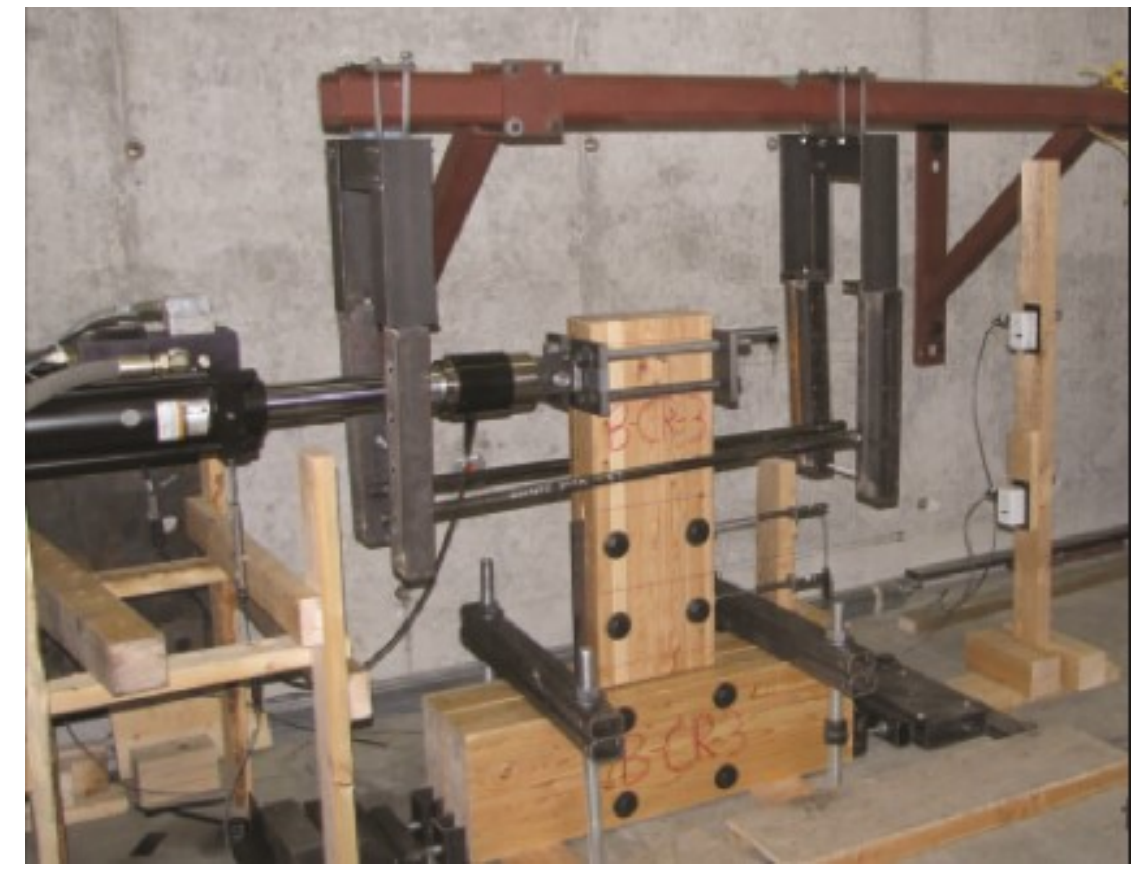

Figure 2.16 Test set-up [53]

In the unreinforced connections $(\mathrm{CU})$, the authors reported a brittle failure mode and low moment-resistance due to early crack development caused by high perpendicular-to-grain and longitudinal shear stresses. A shear failure along the whole length of the beam member was also reported (Figure 2.17b). For the reinforced specimens (CR), a significant increase in moment-resisting capacity and ductility was observed as compared to the unreinforced connections (CU). It was also found that reinforcing the specimens with self-tapping screws increased the moment-resisting capacity of the connections by a factor of 1.7 under reverse cyclic loading. Furthermore, the embedment of the wood fibres and yielding of the bolts was observed in both the column and the beam members. 


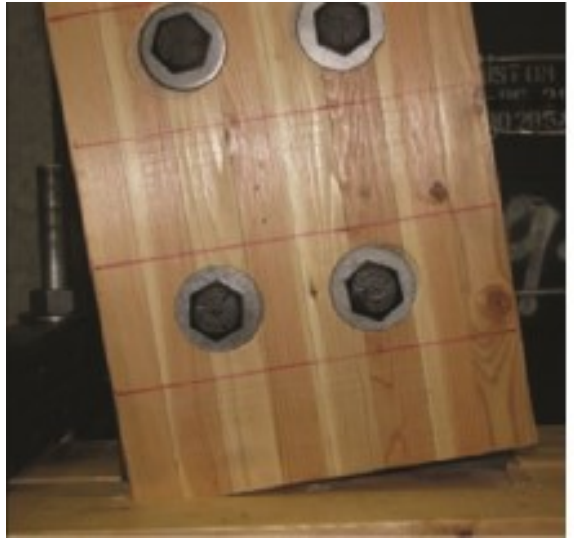

(a)

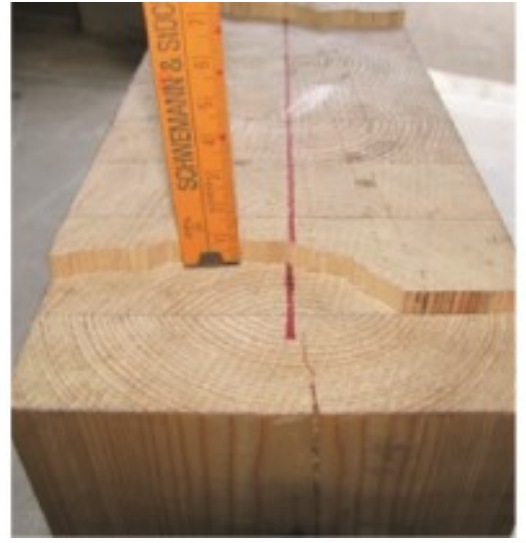

(b)

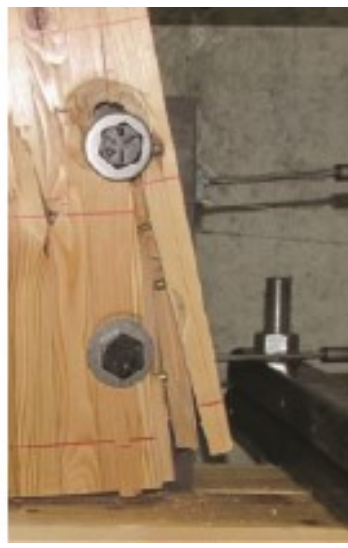

(c)

Figure 2.17 Failure modes: (a) Beam member bearing on the column, (b) associated failure (series A-CR), (c) Open crack at transducer (series B-CR) [53]

For the A-CR test series with additional two self-tapping screws, it was observed that increasing the bolt diameter from $19.0 \mathrm{~mm}$ to $25.4 \mathrm{~mm}$ increased the moment resistance and elastic stiffness of the connections by a factor of 1.2 as compared to unreinforced connections (CU) and test series CR. The increase in the elastic stiffness of the connections resulted in a reduction of the corresponding rotation by 50\%. As shown in Figure 2.18, plug shear failure which was succeeded by slight cracks and wood embedment failure were reported by the authors [53]. Wider opening of cracks was observed at higher rotations due to bending and compression failures. Additionally, slight yielding was observed in the column member bolts.

Figure 2.18 shows typical failure modes for series A-CR.
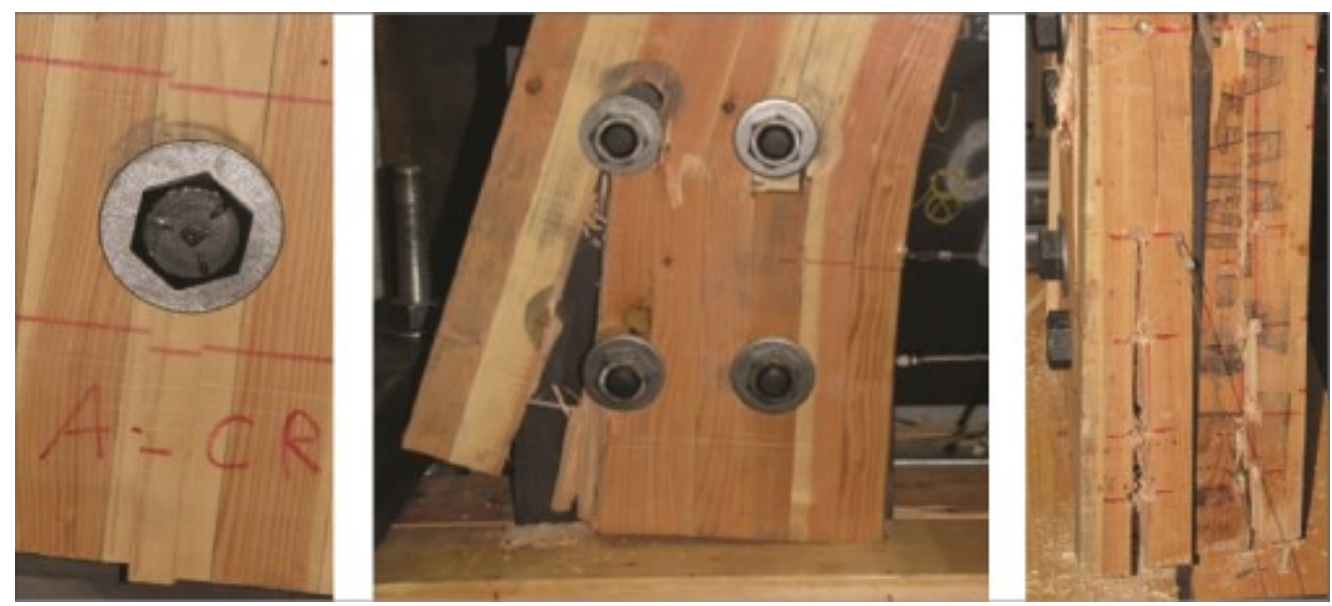

Figure 2.18 Typical failure for series A-CR [53] 
By reducing the edge distances in connections with test series B-CR and C-CR, it was reported that the moment-carrying capacity of the connections could be increased if the brittle failure of the connection can be controlled by employing self-tapping screws. It was observed that the moment-resisting capacity of these connections increased by a factor of 1.35 as compared to the A-CR series, and a reduction in the rotation of the connections by about the same factor was discovered. These effects resulted in an increase in elastic stiffness by a factor of 2.0 as compared to the A-CR series. Brittle failure modes (splitting failure) were reported at high loads. Figure 2.19 depicts typical failure modes of connections with series B-CR and C-CR after testing.

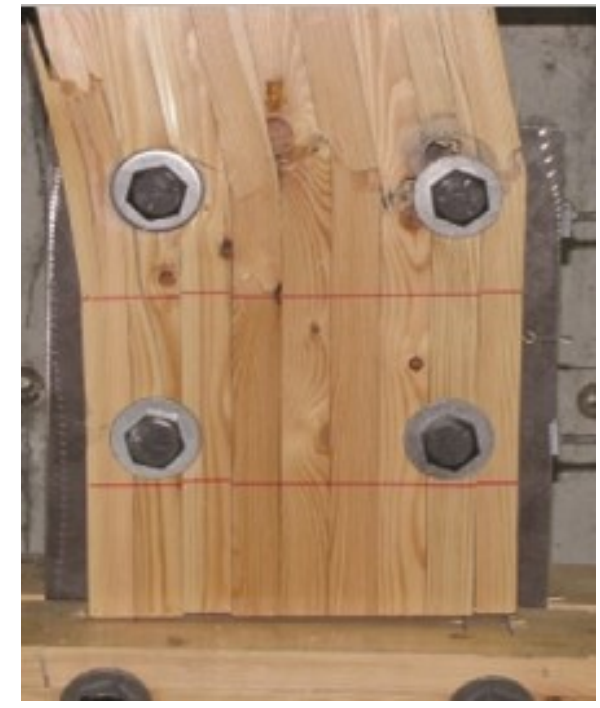

(a)

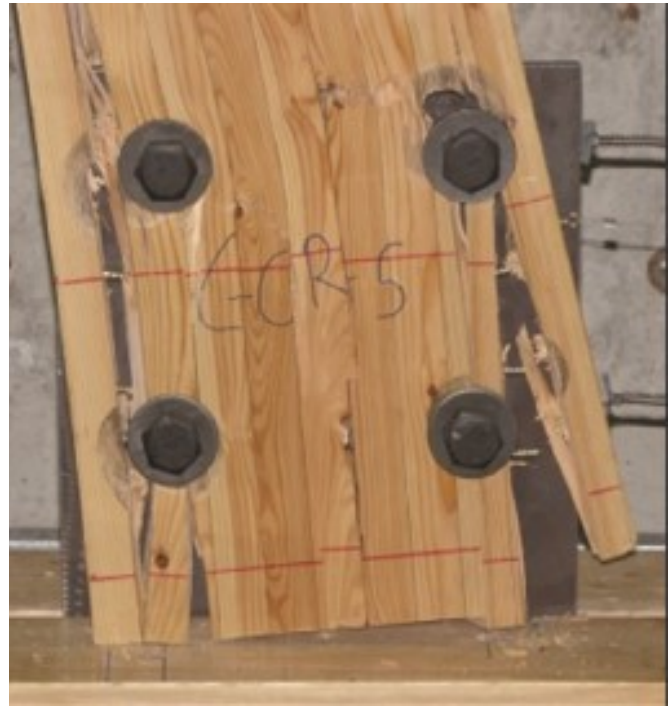

(b)

Figure 2.19 Typical failure for (a) series B-CR and (b) series C-CR [53]

The authors concluded that the application of self-tapping screws enhanced the ductility and overall connection performance even when small edge distances of the bolts were used. It was found that the ultimate moment resistance of the reinforced connection with reduced edge distances increased by a factor of 2.9 as compared with the unreinforced connection. By reinforcing the connections with self-tapping screws, the moment-resisting capacity of the 
connections was increased by a factor of 1.7 under reverse cyclic loading. Therefore, a ductile and high-capacity moment-resisting bolted timber connection can be achieved by using selftapping screws as perpendicular-to-grain reinforcement.

Owusu et al. [22] examined the structural performance of concealed wood-steel-wood (WSW) bolted connections by conducting full-scale experiments at both ambient and elevated temperatures. The study considered protected and unprotected concealed wood-steel-wood (WSW) beam connections. The main purpose of this study was to investigate the fireperformance of moment-resisting timber connections. In this study, fifteen (15) full-scale tests were conducted on concealed glulam beam-to-column connections loaded perpendicular to the wood grain in bending moment on the connection. The glulam beams were prepared from Canadian black spruce-pine with grade 24f-EX and had rectangular cross-sectional dimensions of $184 \mathrm{~mm}$ wide x $362 \mathrm{~mm}$ deep x 1600mm long. Five (5) samples were tested at ambient temperature to investigate the failure modes, failure load and the maximum moment-resisting capacity of the connections. Ten (10) specimens were tested at elevated temperatures to determine the average charring rate, failure modes and failure time.

Four (4) connection configurations were used, and in each configuration, the beams were fastened to the steel plate using four and six bolts in two rows. Figure 2.20 shows the types of unprotected and protected connection configurations examined. Figure 2.20(a) shows the unprotected connection configuration, labelled $(\mathrm{N})$, in which neither the steel plate nor the bolts' heads or nuts were fire protected. Figure 2.20(b) shows the other connection configuration, labelled $(\mathrm{P})$, that was made using the same bolt pattern, however, the bolts' heads and nuts and the steel plate's top and bottom edges were fire protected using glued-in wood plugs and strips, respectively. The wood plugs used to cover the bolt heads and nuts had thicknesses of $30 \mathrm{~mm}$ and $20 \mathrm{~mm}$, respectively. 


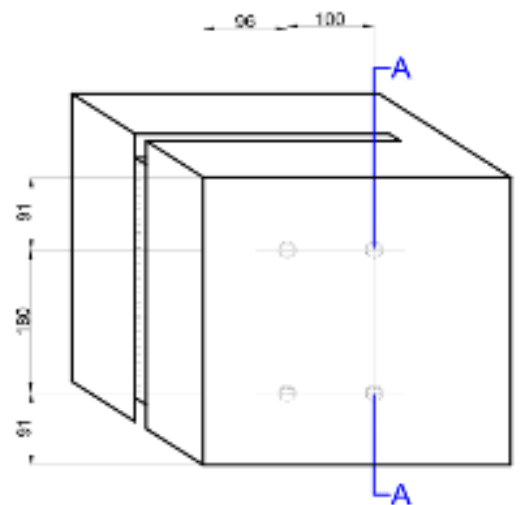

a) connection configuration $(\mathrm{N})$

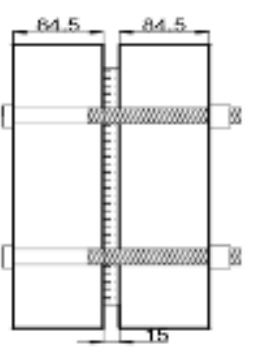

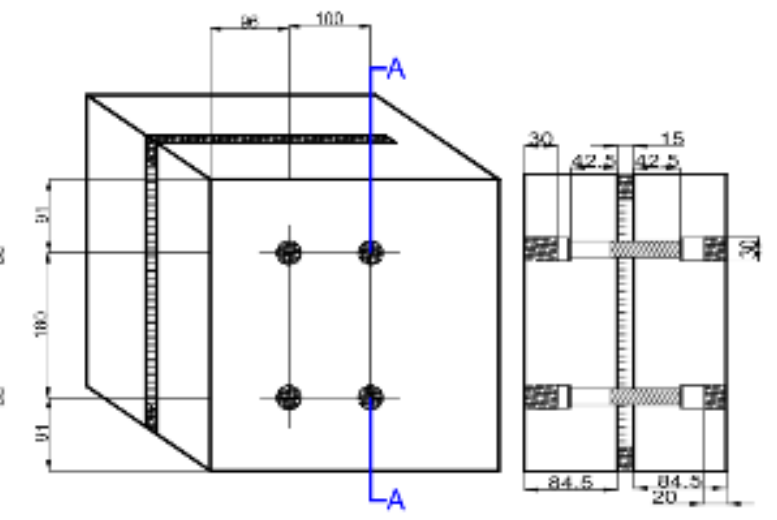

b) connection configuration (P)

Figure 2.20 Test connection configuration types: a) connection configuration $(\mathrm{N})$ without fire protection; b) connection configuration $(\mathrm{P})$ with fire protection [22]

In the ambient tests, a T-stub section made of 12.7-mm (1/2”) thick plate and four 19.1-mm (3/4") diameter bolts were used to structurally connect the beam specimens to a steel column support as shown in Figure 2.21. The experimental data collected includes displacements and the applied load. As shown in Figure 2.21, two Linear Variable Displacements Transducers (LVDTs) were used to measure the displacements of the connection and a concentrated load was applied $1400 \mathrm{~mm}$ away from the beam support using a Universal testing machine (UTM). The tests were performed by applying controlled loading and the connection specimens were loaded until failure. 


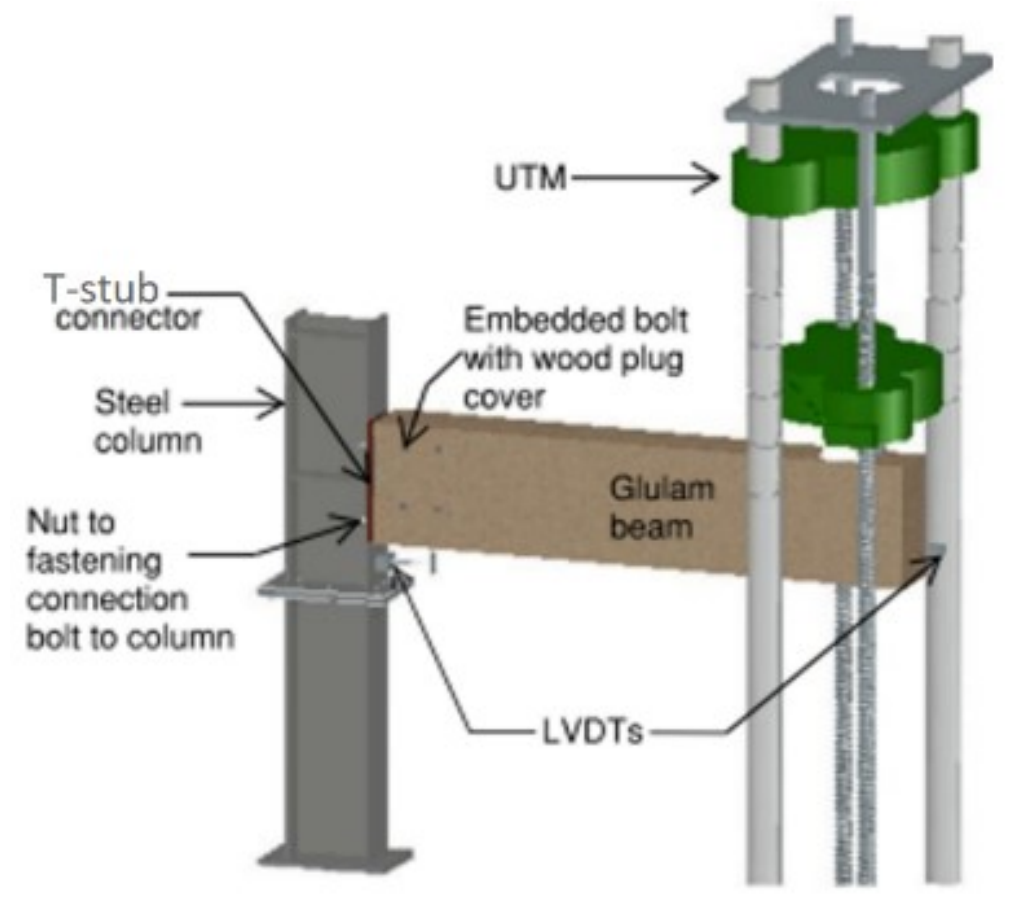

Figure 2.21 Ambient temperature test set-up

In the tests at elevated temperatures, the test assemblies were exposed to the CAN/ULC-S101 standard fire and a constant load of $100 \%$ of the ultimate design load capacity of the weakest connection was applied. The results revealed that the two predominant failure modes of concealed (wood-steel-wood) bolted timber connections at both ambient and elevated temperatures are perpendicular-to-grain tensile splitting and internal parallel-to-grain row shear (Brittle failures) (Figures 2.22 and 2.23). It was observed that the splitting of the wood occurred along the glued-line plane of the glulam and this resulted in an earlier failure of the connections. These failure modes play a major role in reducing the moment-resisting capacity as well as the maximum load capacity that can be attained in concealed bolted timber connections. 

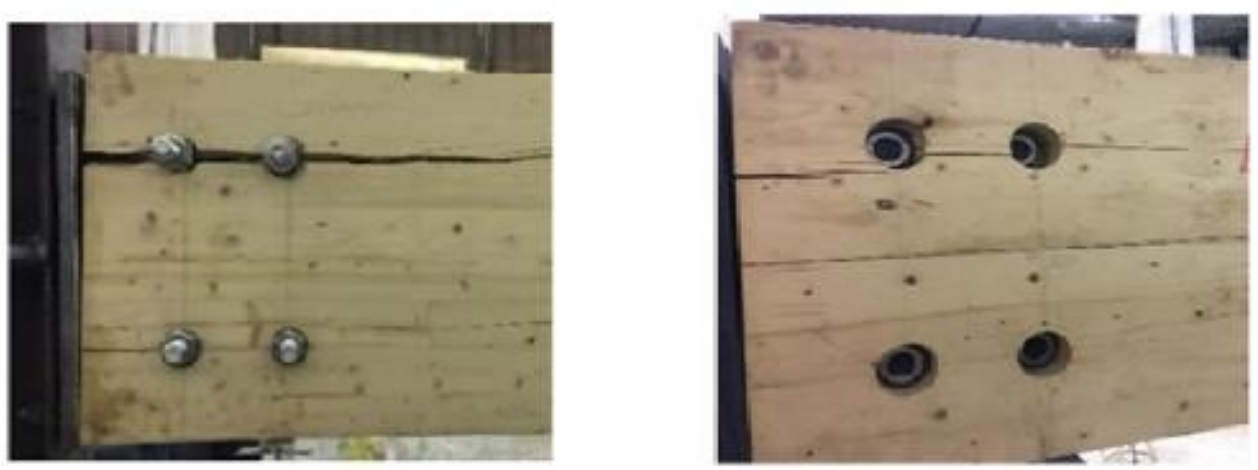

Figure 2.22 Failure modes of connections in ambient temperature tests; N(left) and P(right)
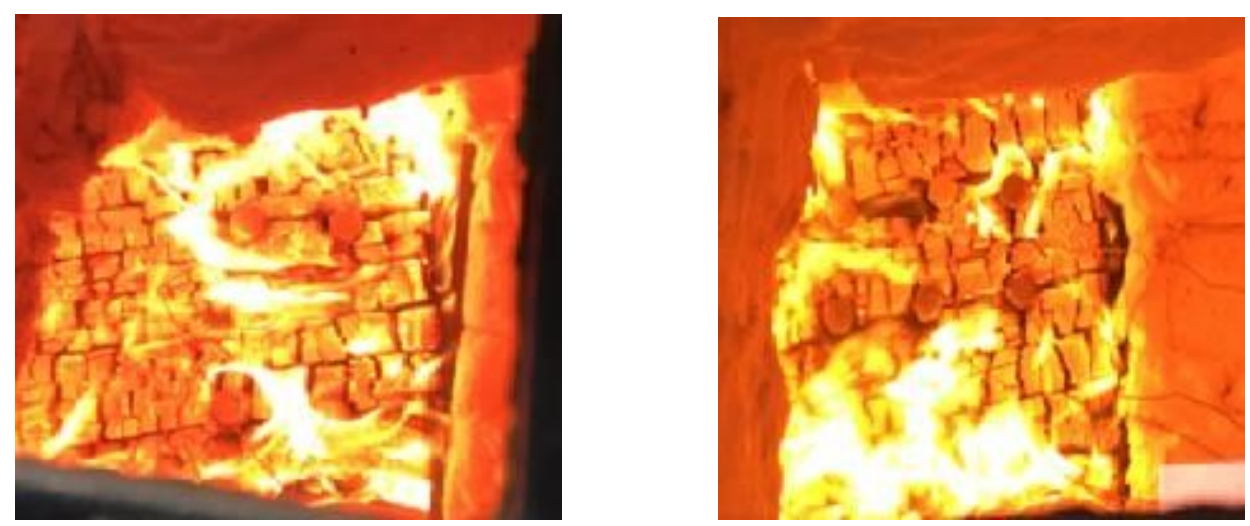

Figure 2.23 Failure modes of connections in fire tests; Unprotected (left) and protected

$$
\text { (right) [22] }
$$

At ambient temperature, the unprotected connection exerted a higher moment-resisting capacity than the protected connection due to the reduction of the effective thickness caused by the notch produced, whereas, at elevated temperatures, the protected connections performed better in fire than the unprotected connections (see Figure 2.24). Also, it was observed at ambient temperatures that the connections which had the bottom bolt row raised to the midheight of the beam section (bolt pattern P2) showed higher moment-resisting capacity than the connections with the two rows of bolts symmetrically positioned near the top and bottom sides of the beam cross-section (bolt pattern P1), but at elevated temperature, no conclusion could 
be drawn on which bolt pattern performed better. However, it was reported that the wood plug protection increased the failure time by 20 minutes.

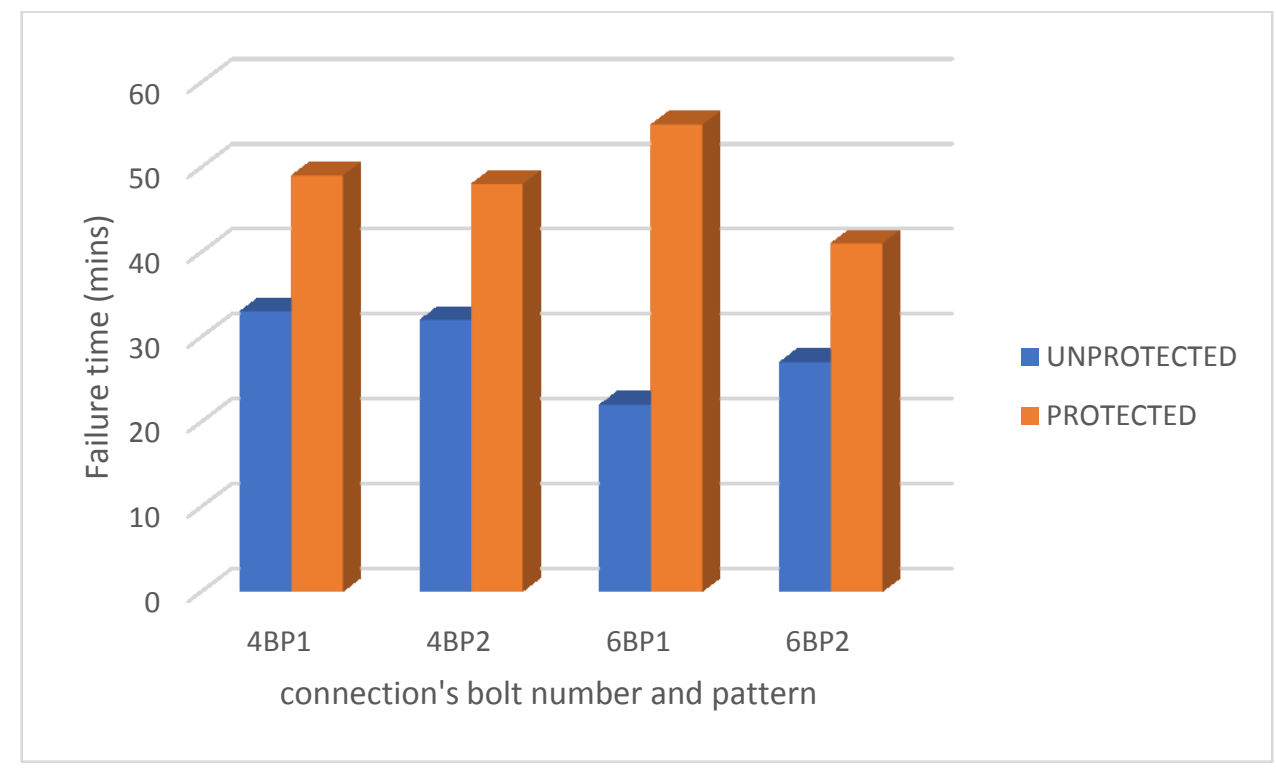

Figure 2.24 The effect of protection on the failure time of all the connection types [22]

To understand the behaviour of timber connections under fire exposure, Peng et al. [62] investigated the performance of two connection types: bolted wood-steel-wood (WSW) and steel-wood-steel (SWS) connections, under standard fire exposure. The main objective of the tests was to study the influence of wood side member thickness, fastener diameter, number of fasteners, edge distance, load level and protection of the fasteners. In the effort to study these variables and connection types, 16 specimens of bolted wood-steel-wood (WSW) and 6 specimens of steel-wood-steel (SWS) connections were tested at elevated temperatures that followed the CAN/ULC-S101 standard time-temperature curve. The WSW and SWS connections were divided into 5 groups and 3 groups, respectively.

For specimens with WSW connections, the wood members were prepared from Canadian spruce-pine-fir (SPF) sawn lumber or spruce-pine (SP) grade 20f-EX with a side thickness of $38 \mathrm{~mm}, 60 \mathrm{~mm}$, or $80 \mathrm{~mm}$, while for the SWS connections, the wood members were Douglas fir glulam timber of 24f-EX grade, with $80 \mathrm{~mm}$ or $130 \mathrm{~mm}$ thick and $190 \mathrm{~mm}$ wide. For both 
WSW and SWS connections, a $9.5 \mathrm{~mm}\left(3 / 8^{\prime \prime}\right)$ thick steel plate was used and bolt with a diameter of $12.7 \mathrm{~mm}(1 / 2$ ") or $19.1 \mathrm{~mm}(3 / 4$ ") was employed. Figures 2.25 and 2.26 show a typical bolted WSW and SWS connection, respectively.

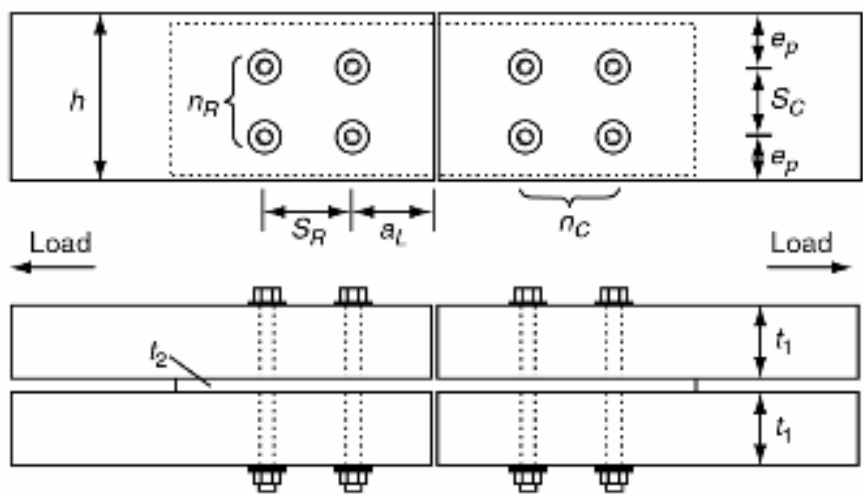

Figure 2.25 Bolted Wood-Steel-Wood connection configuration [62]
Legend:

$\theta_{\rho}=$ unloaded edge distance

$a_{L}=$ loaded end distance

$S_{C}=$ row spacing

$S_{R}=$ spacing in a row

$t_{1}=$ wood side member

thickness

$t_{p}=$ steel thickness

$h=$ wood member width

$n_{R}=$ number of row

$n_{C}=$ number of fasteners

in a row

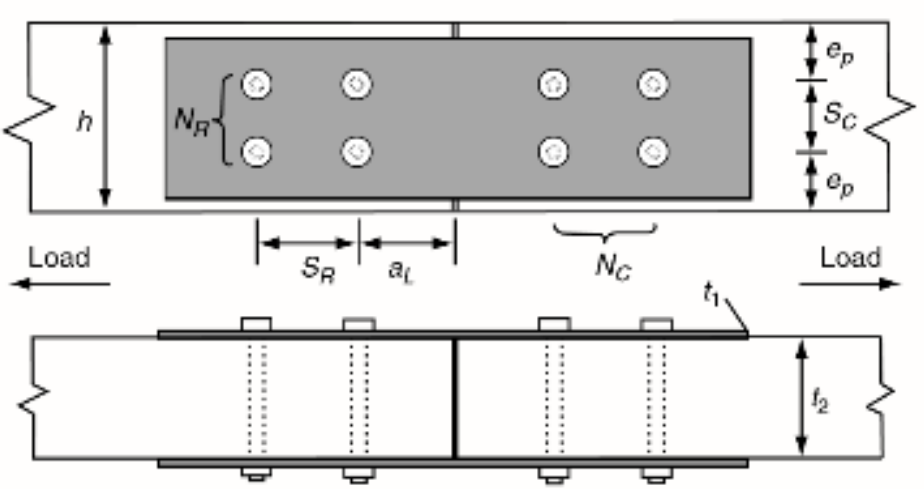

Legend:

$e_{p}=$ unloaded edge distance

$a_{L}=$ loaded end distance

$S_{C}=$ row spacing

$S_{R}=$ spacing in a row

$t_{1}=$ steel thickness

$t_{2}=$ wood member thickness

$h=$ wood member width

$N_{B}=$ number of rows

$N_{C}=$ number of fasteners

in a row

Figure 2.26 Bolted Steel-Wood-Steel connection configuration [62]

The fire-resistance tests were conducted in a medium-scale furnace located at the fire research facility of Carleton University. The test specimens were subjected to load ratios of $10 \%, 20 \%$, and $30 \%$ of the ultimate load capacity obtained from tensile tests at ambient temperatures, and a constant tensile load parallel-to-grain was applied on all the specimens during the fire tests. Figures 2.27 (left) and (right) shows a picture of the furnace and a front cross-section of the furnace with the connection mounted, respectively. Two test specimens, WSW \#4.3 and WSW 
\#5.4 were protected with a single-layer of $15.9 \mathrm{~mm}$ (5/8") Type X gypsum board and a doublelayer of $12.7 \mathrm{~mm}(1 / 2$ ") Douglas fir plywood, respectively. Experimental data collected includes displacements and temperatures using 4 LVDTs and type k thermocouples, as well as the failure time of the connections.
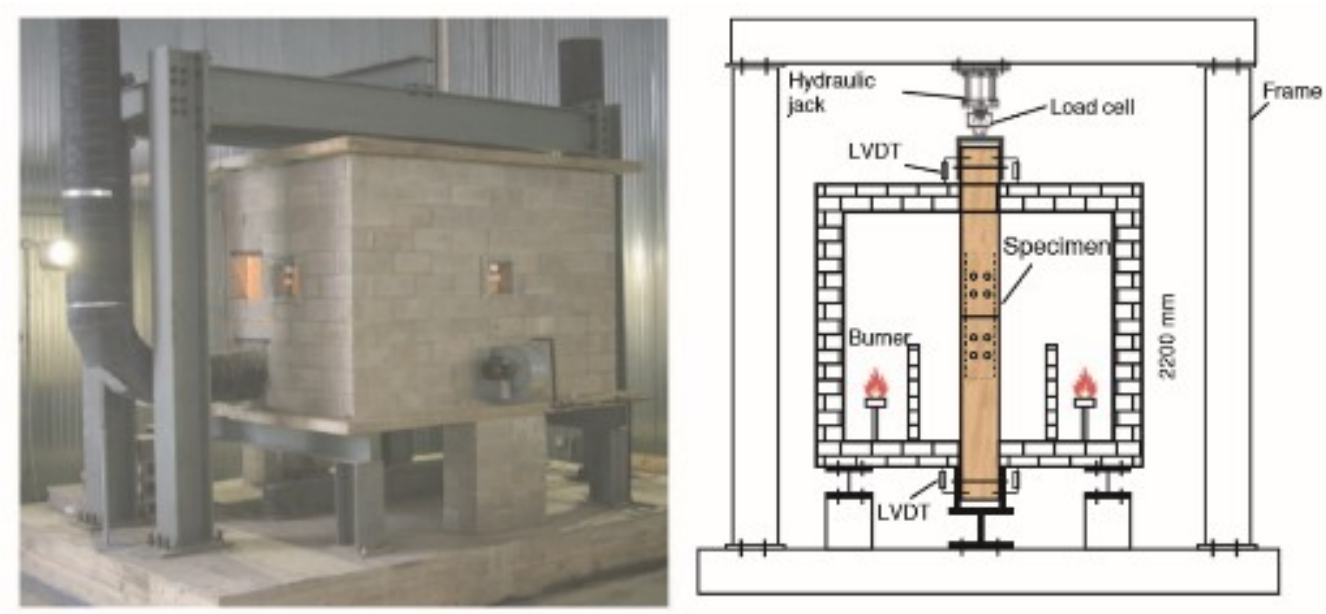

Figure 2.27 Furnace appearance (left) and front cross-section view (right) [62]

The results of the WSW connections showed that the failure occurred in the wood members and no considerable deformations was observed in the steel plate and bolts, while in the SWS connections, the bolts underwent a bending deformation due to the large exposed area of the steel plates causing the bolts to be heated more quickly which led to a partial loss of the bolt's stiffness and strength.

It was observed that the failure modes experienced in the wood members for both the WSW and SWS connections were row shear out, edge material tear-out, hole elongation and splitting of the side wood members, especially for the thinner wood members. The frequent failure mode encountered in all the connections was hole elongation and this was responsible for the shear (either row or group tear-out shear) and splitting failure mode experienced in the wood members. Figures 2.28 and 2.29 shows the typical failure modes observed in the WSW and SWS connections, respectively. 

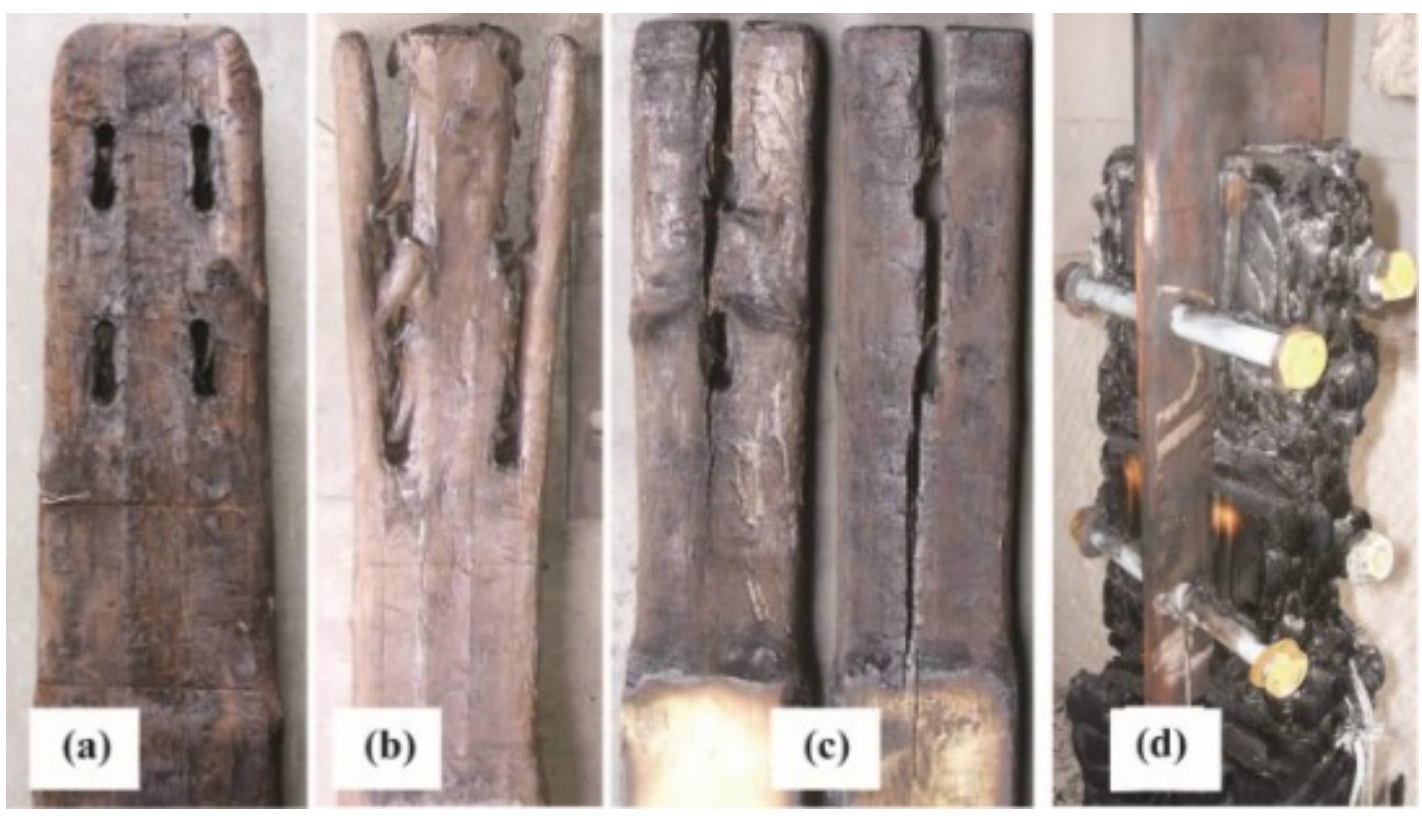

Figure 2.28 Typical failure modes of WSW connections: (a) hole elongation, (b) row shear out, (c) hole elongation and splitting, (d) edge group tear-out [62]
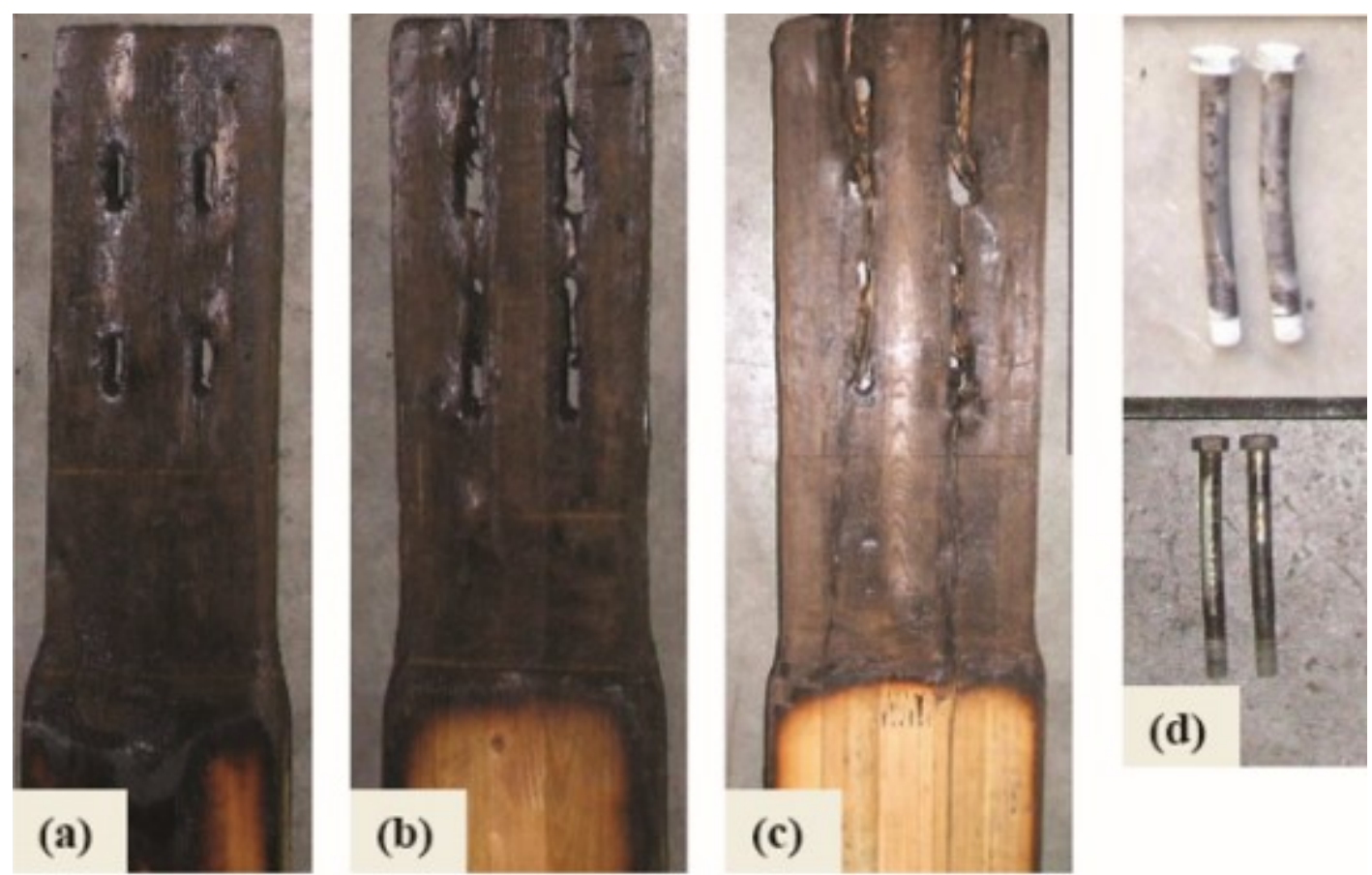

Figure 2.29 Typical failure modes of SWS connections: (a) hole elongation, (b) row shearing through the wood, (c) hole elongation and splitting, (d) yielding of the bolts [62] 
For the WSW connections, the authors reported an average charring rate of $0.78 \mathrm{~mm} / \mathrm{min}$ for the cross-section A near the steel plate face and $0.71 \mathrm{~mm} / \mathrm{min}$ within the wood member away from the steel plate. It was found that the steel plate (and bolts) conducted heat which enhanced the charring rate in the inner core of the wood member. However, for SWS connections, the charring rate underneath the steel plates was less than that of the other surface because the steel plates shielded the wood members from direct fire exposure on these surfaces.

Furthermore, it was found that reducing the load ratio improved the time to failure of all the connections tested (confirming the results by Ali [27] and Akotuah et al. [43]). The results also showed that increasing the bolt diameter and edge distances improved the time to failure of the connections.

Based on the experimental results and observation, the following conclusions were drawn:

- The failure time for both the WSW and SWS connections with no protection of the bolt fasteners were less than 45 minutes and 25 minutes, respectively.

- For the unprotected bolted timber connections, improved failure time can be achieved by increasing the wood member thickness, diameter of fasteners and number of fasteners.

- It was found that a single-layer of $15.9 \mathrm{~mm}$ Type X gypsum board improved the failure time by at least 30 minutes, while a double-layer of $12.7 \mathrm{~mm}$ plywood improved the failure time by about 15 minutes.

In another paper, Peng et al. [45] recommended a charring rate of $0.8 \mathrm{~mm} / \mathrm{min}$ for WSW connection and suggested that the bolt head and nut of the connections be protected from fire since their exposure to fire can significantly impair the fire-resistance rating of the connections. 
To access the influence of reinforcement on the fire resistance of timber connections, Pedro et al. [63] performed fire-resistance tests on steel-to-timber dowelled connections reinforced with self-drilling screws. The primary aim of this experimental study was to understand the behaviour of different connection typologies reinforced with self-drilling screws at ambient temperature and under elevated temperatures that followed the ISO 834 [24] standard timetemperature curve. To achieve this objective, a total of 25 tests which comprised of 15 ambient temperature tests and 10 fire resistance tests, were conducted on spruce glued laminated timber with strength class GL 24h. The main variables considered in the connections were diameter, number and location of self-drilling screws, and diameter of dowels. In this study, five (5) different connection typologies were examined in a WSW connection type. Table 2.1 illustrates an overview of the experimental program.

Table 2.1 Overview of the experimental program [63]

\begin{tabular}{|c|c|c|c|c|c|}
\hline $\begin{array}{l}\text { Connection } \\
\text { typology }\end{array}$ & $\begin{array}{l}\text { Number } \\
\text { of tests }\end{array}$ & $\begin{array}{l}\text { Type of } \\
\text { test }\end{array}$ & Load ratio & Geometry & \\
\hline \multirow{2}{*}{ D01.1.R } & 3 & $20^{\circ} \mathrm{C}$ & Until failure & \multirow{2}{*}{$\begin{array}{l}\text { Geometry: } \\
\text { Reinforcement: }\end{array}$} & \multirow{2}{*}{$\begin{array}{l}\text { same as D01.1 } \\
2 \text { self-drilling screws } \\
(d=7 \mathrm{~mm})\end{array}$} \\
\hline & 2 & Fire & $30 \% \cdot R_{\mathrm{m}, \mathrm{D} 01.1,20^{\circ} \mathrm{C}}$ & & \\
\hline \multirow{2}{*}{ D03.1.R } & 3 & $20^{\circ} \mathrm{C}$ & Until failure & \multirow{2}{*}{$\begin{array}{l}\text { Geometry: } \\
\text { Reinforcement: } \\
(d=7 \mathrm{~mm})\end{array}$} & \multirow{2}{*}{$\begin{array}{l}\text { same as D03.1 } \\
8 \text { self-drilling screws }\end{array}$} \\
\hline & 2 & Fire & $30 \% \cdot R_{\mathrm{m}, \mathrm{D} 03.1,20^{\circ} \mathrm{C}}$ & & \\
\hline \multirow{2}{*}{ D04.1.R } & 3 & $20^{\circ} \mathrm{C}$ & Until failure & \multirow{2}{*}{$\begin{array}{l}\text { Geometry: } \\
\text { Reinforcement: }\end{array}$} & \multirow{2}{*}{$\begin{array}{l}\text { same as D04.1 } \\
4 \text { self-drilling screws } \\
(d=9 \mathrm{~mm})\end{array}$} \\
\hline & 2 & Fire & $30 \% \cdot R_{\mathrm{m}, \mathrm{D} 04.1,20^{\circ} \mathrm{C}}$ & & \\
\hline \multirow{2}{*}{ D05.1 } & 3 & $20^{\circ} \mathrm{C}$ & Until failure & $\begin{array}{l}\text { Cross section: } \\
\text { rasteners: }\end{array}$ & $\begin{array}{l}160 \times 160 \mathrm{~mm}^{2} \\
2 \text { rows with } \angle \text { dowels } \\
(d=12 \mathrm{~mm})\end{array}$ \\
\hline & 2 & Fire & $30 \% \cdot R_{\mathrm{m}, \mathrm{D} 05.1,20^{\circ} \mathrm{C}}$ & Steel plates: & $\begin{array}{l}(d=12 \mathrm{~mm}) \\
1 \text { (thickness } 5 \mathrm{~mm})\end{array}$ \\
\hline \multirow{2}{*}{ D05.1.R } & 3 & $20^{\circ} \mathrm{C}$ & Until failure & \multirow{2}{*}{$\begin{array}{l}\text { Geometry: } \\
\text { Reinforcement: }\end{array}$} & \multirow{2}{*}{$\begin{array}{l}\text { same as D05.1 } \\
4 \text { self-drilling screws } \\
-(d=7 \mathrm{~mm})\end{array}$} \\
\hline & 2 & Fire & $30 \% \cdot R_{\mathrm{m}, \mathrm{D} 05.1,20^{\circ} \mathrm{C}}$ & & \\
\hline
\end{tabular}

A 5-mm thick steel plate was used to connect the wood members which were fastened together with dowels and the connections were reinforced with fully threaded self-drilling screws. Figure 2.30 shows the unreinforced connection and the reinforced connection. 

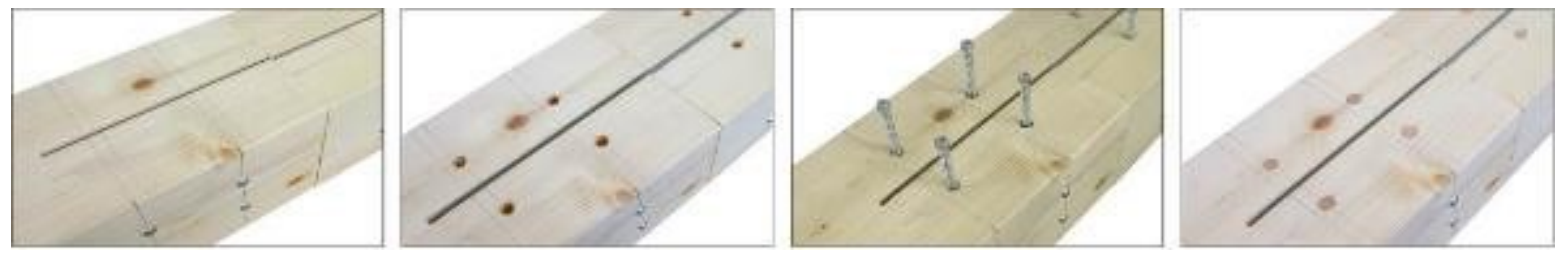

Figure 2.30 Reinforcement with self-drilling screws: unreinforced connection, boring the clearance holes, driving the screws, and inserting the wooden plugs (connection D05.1) [63]

At ambient temperature, the tests were carried out in accordance with EN 26891 where the standard prescribes that the load on the specimens be increased up to $40 \%$ of the estimated load-carrying capacity $F_{\text {est }}$ of the connection, then reduced to $10 \% F_{\text {est }}$, and thereafter increased until failure. Experimental data collected includes displacements and applied load. While at elevated temperatures, the fire-resistance tests were conducted in a small furnace where the test specimens were connected to a steel frame on top of the furnace and enclosed in an insulated outer covering. The specimens were loaded to $30 \%$ of the average load-carrying capacity of the corresponding unreinforced connection before being exposed to the effects of the ISO 834 standard fire on all sides. The load was kept constant throughout the test. Figure 2.31 shows the specimen after the test.
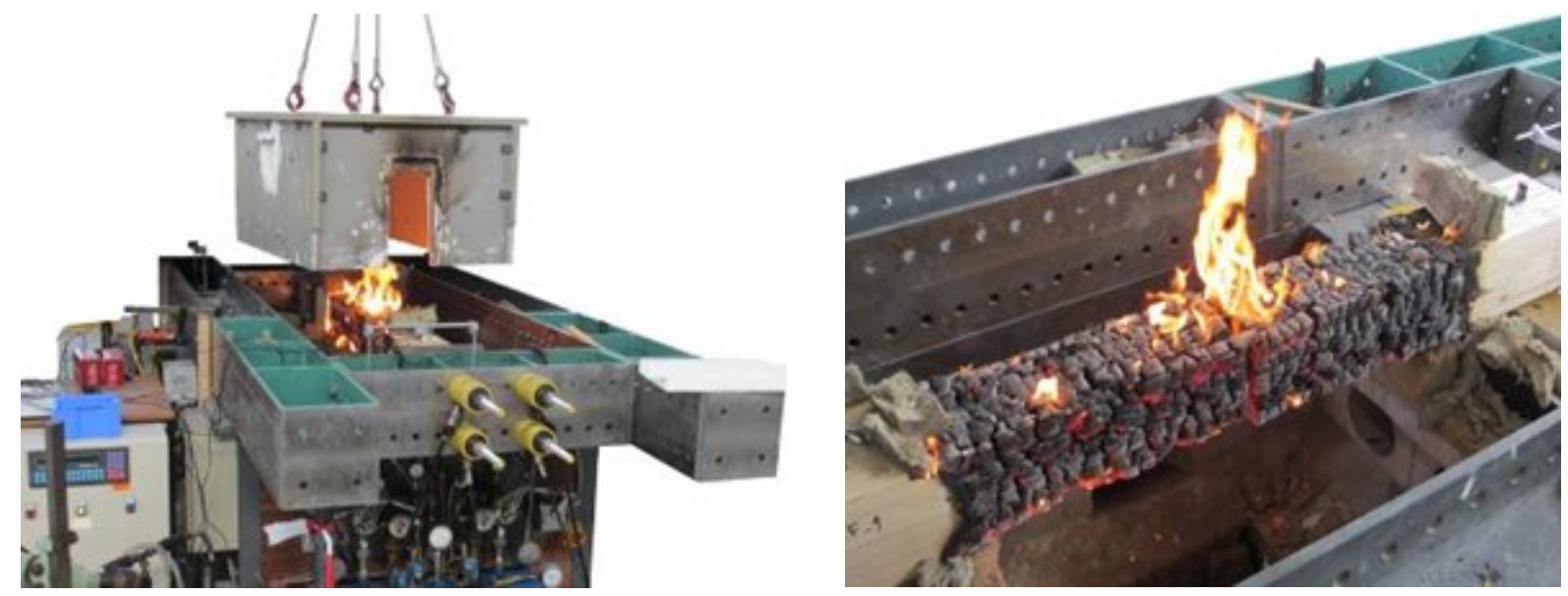

Figure 2.31 End of a fire test in the small furnace [63]

After the tests, the authors observed minor influence of the reinforcement on the load-carrying capacity of the tested connections with multiple shear planes, however, the screws had a major 
influence on ductility. In the D01.1.R connection, a brittle net-section tension and block-shear failures were observed due to the high number of holes and slots produced. In D04.1.R. connections, plastic hinges were induced in the dowels and the reinforcing screws were not fully utilized. Overall, from connections D03.1, it was noted that the reinforcements did not improve the load-carrying capacity of these connections at ambient temperature, but significantly increased their ductility. On the contrary, connections D05.1 with one steel plate had the embedment of the bent dowels in the wood significantly reduced by the screws and thus, improved the load-carry capacity and ductility of the connections.

At elevated temperatures, it was reported that the fire resistance of connections D03.1.R and D05.1.R was increased by employing reinforcement while no increase was observed in connections D01.1.R and D04.1.R. A summary of the fire test results is shown in Table 2.2.

Table 2.2 Results of the fire resistance tests [63]

\begin{tabular}{|c|c|c|c|}
\hline \multirow{3}{*}{$\begin{array}{l}\text { Connection } \\
\text { typology }\end{array}$} & \multicolumn{2}{|c|}{$\begin{array}{c}\text { Fire resistance } \\
\qquad \begin{array}{c}t_{\mathrm{fi}, \text { mean }} \\
\text { [min.] }\end{array}\end{array}$} & \multirow{3}{*}{$\begin{array}{c}\text { Load } \\
E_{\mathrm{fi}}\left(0.3 \cdot R_{\text {mean,unreinforced, } 20^{\circ} \mathrm{C}}\right) \\
{[\mathrm{kN}]} \\
145\end{array}$} \\
\hline & 33.0 & $(32.0 ; 34.0)$ & \\
\hline & 32.0 & $(32.0 ; 32.0)$ & \\
\hline D03.1 & 32.5 & $(32.0 ; 33.0)$ & \multirow{2}{*}{69} \\
\hline D03.1.R & 41.5 & $(42.0 ; 41.0)$ & \\
\hline D04.1 & 34.8 & $(34.5 ; 35.0)$ & \multirow{2}{*}{124} \\
\hline D04.1.R & 34.0 & $(34.0 ; 34.0)$ & \\
\hline D05.1 & 34.0 & $(34.0 ; 34.0)$ & \multirow{2}{*}{30} \\
\hline D05.1.R & 39.5 & $(40,0 ; 39,0)$ & \\
\hline
\end{tabular}

At both ambient temperature and fire-resistance tests, it was observed that the failure modes of two connections (D01.1.R and D04.1.R) were not influenced by the reinforcement. In the D03.1 connection, splitting failures were delayed as the screws induced plastic hinges on the fasteners. Figures 2.32 (left), and (right) shows the block shear failures in the internal timber members and bending (plastic hinge) failure imposed in the dowels, respectively. 

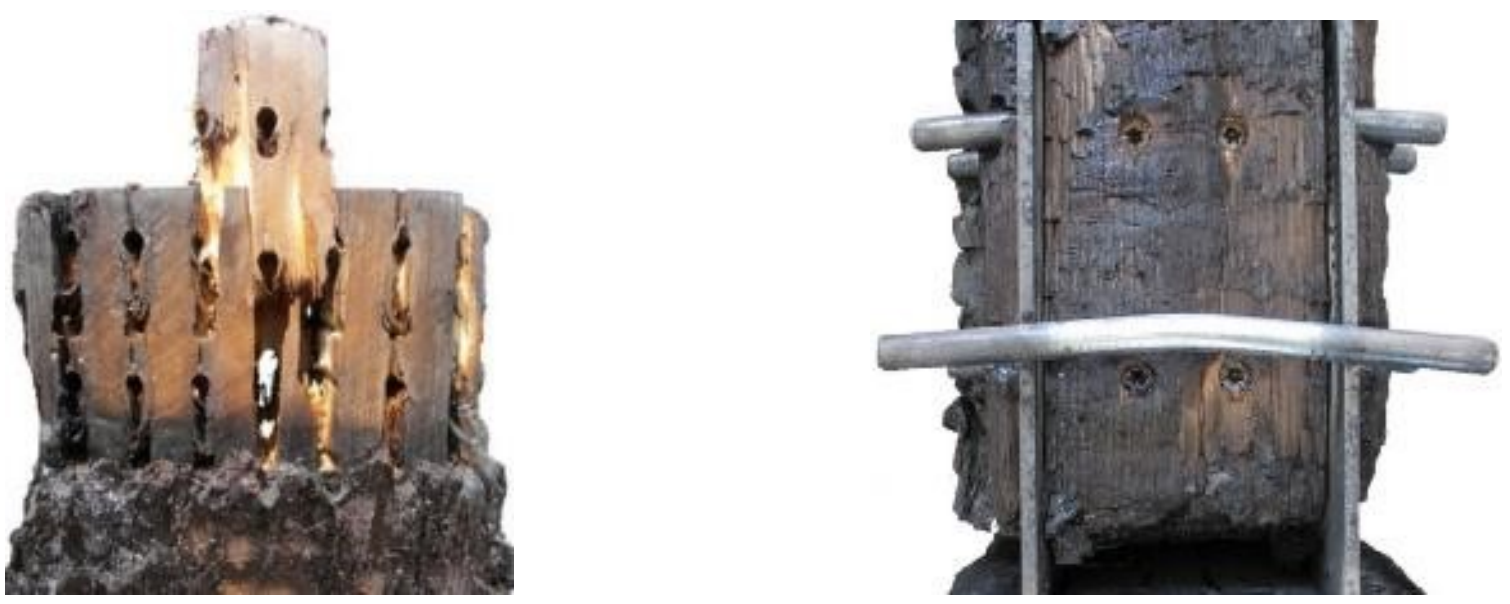

Figure 2.32 Failure modes of connections D01.1.R-1 (left) and D04.1.R-1 (right) in the fire tests [63]

It was also found that in the connection with a single steel plate (two shear planes), the selfdrilling screws enhanced both the load-carrying capacity and ductility at normal temperature and also the fire resistance, by effectively locally increasing the embedment properties. Though, due to the long length of the screws and their early exposure to fire, a slight improvement in fire resistance was observed (Figure 2.33, right). This could be improved if the screws were more protected. Figure 2.46 shows the failure modes in connections D03.1.R1 (left) and D05.1.R-1 (right).
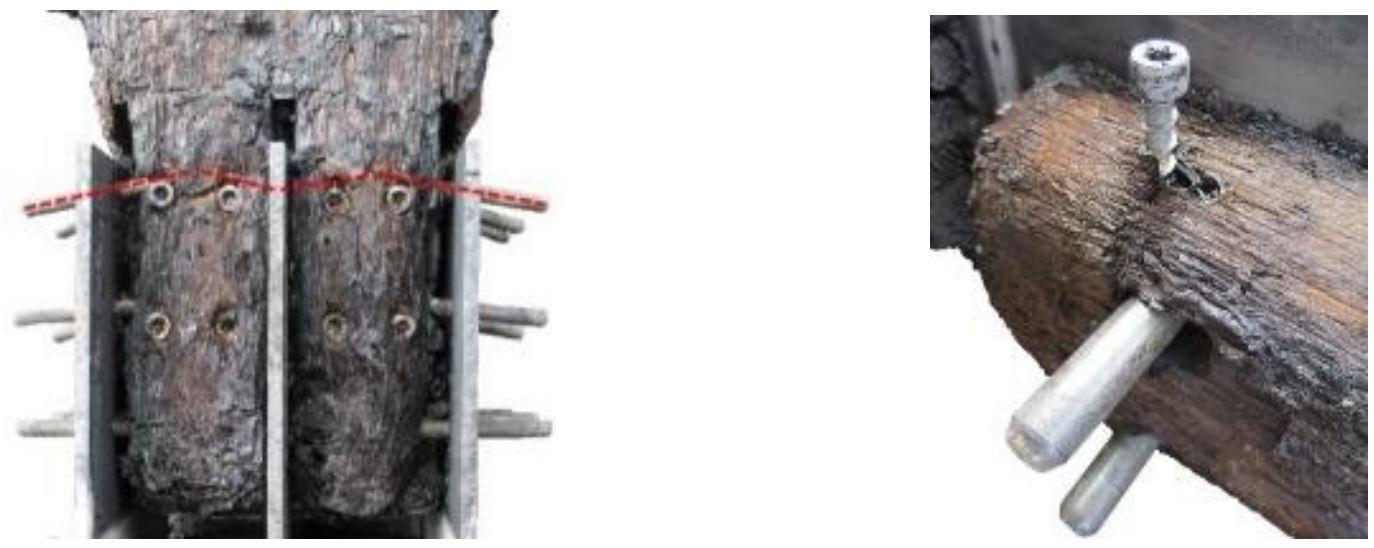

Figure 2.33 Failure modes of connections D03.1.R-1 (left) and D05.1.R-1 (right) in the fire tests [63] 
In another study conducted on fire resistance tests on timber beam-to-column shear connections, Palma et al. [64] investigated the influence of the gap distance between the beam and the column on the fire resistance of the connections. The authors reported that the gap impairs the fire resistance of the connections and hence, the wider the gap the lesser the fire resistance of the connections. Figure 2.34 shows the influence of the gap on connections A1 to A3 after the tests. Although it was reported that the presence of self-drilling screws had a negative influence on the fire resistance of all the connections, the steel-to-timber dowelled connections reached more than 30 and even 60 minutes of fire resistance.
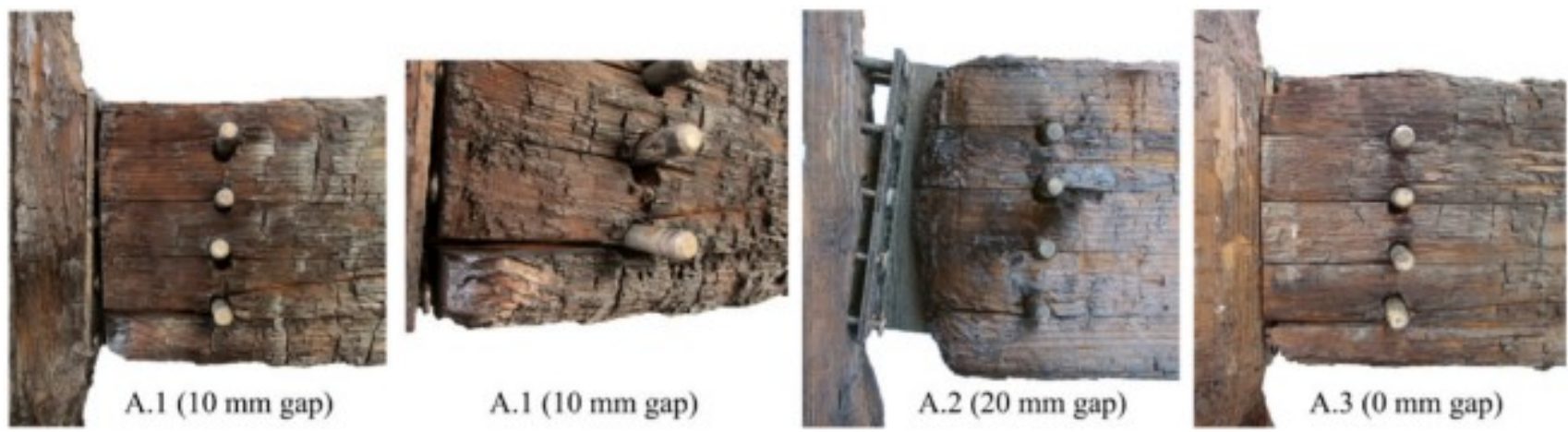

Figure 2.34 Influence of the gap between the beam and the column for connections A.1, A.2 and A.3 after the tests [64]

To better understand the influence of self-tapping screws on the structural fire performance of concealed timber connections, Petrycki and Salem [65] conducted fire tests on beam-to-column connections which were exposed to the effects of elevated temperatures that followed CAN/ULC-S101 standard time-temperature curve. Experimental variables such as effects of the number of bolt rows, loaded bolt end, and influence of reinforcements were considered to investigate the fire performance of the semi-rigid wood-steel-wood (concealed) connections. 
To investigate these variables, 16 full-size beam-to-column connections in 8 large-scale subframe test assemblies were tested on wood-steel-wood bolted connections with and without perpendicular-to-grain reinforcements, while being subjected to monotonic loading. In this study, four different connection configurations were examined and four of the sub-frame assemblies were reinforced with self-tapping screws. The glulam beam sections were prepared from Canadian black spruce-pine, with a stress grade of 24 F-ES/NPG and had rectangular cross-sectional dimensions of $137 \mathrm{~mm}$ wide x $318 \mathrm{~mm}$ deep. Two T-stub connectors with 12.7$\mathrm{mm}(1 / 2$-inch) thickness were employed to connect the beams symmetrically to a centre column and the assemblies were inversely carried at the beam ends on two insulated steel supports. The eight test assemblies were divided into two groups based on their bolt end distance: four- or five-times the bolt diameter, and in each group, two-bolt patterns consisting of four bolts in two rows and six bolts in three rows were employed.

A transverse load was applied with the aid of a hydraulic cylinder mounted above the furnace and had a load cell attached to it in order to record the loads. The loads were measured and kept constant during the test with the aid of a hydraulic cylinder connected to a hydraulic pump. As shown in Figure 2.35, two Linear Variable Differential Transducers (LVDTs) installed above the furnace and connected to ceramic rods were used to measure the vertical displacements of the connections. Experimental data collected includes displacements, applied loads, and temperatures. 


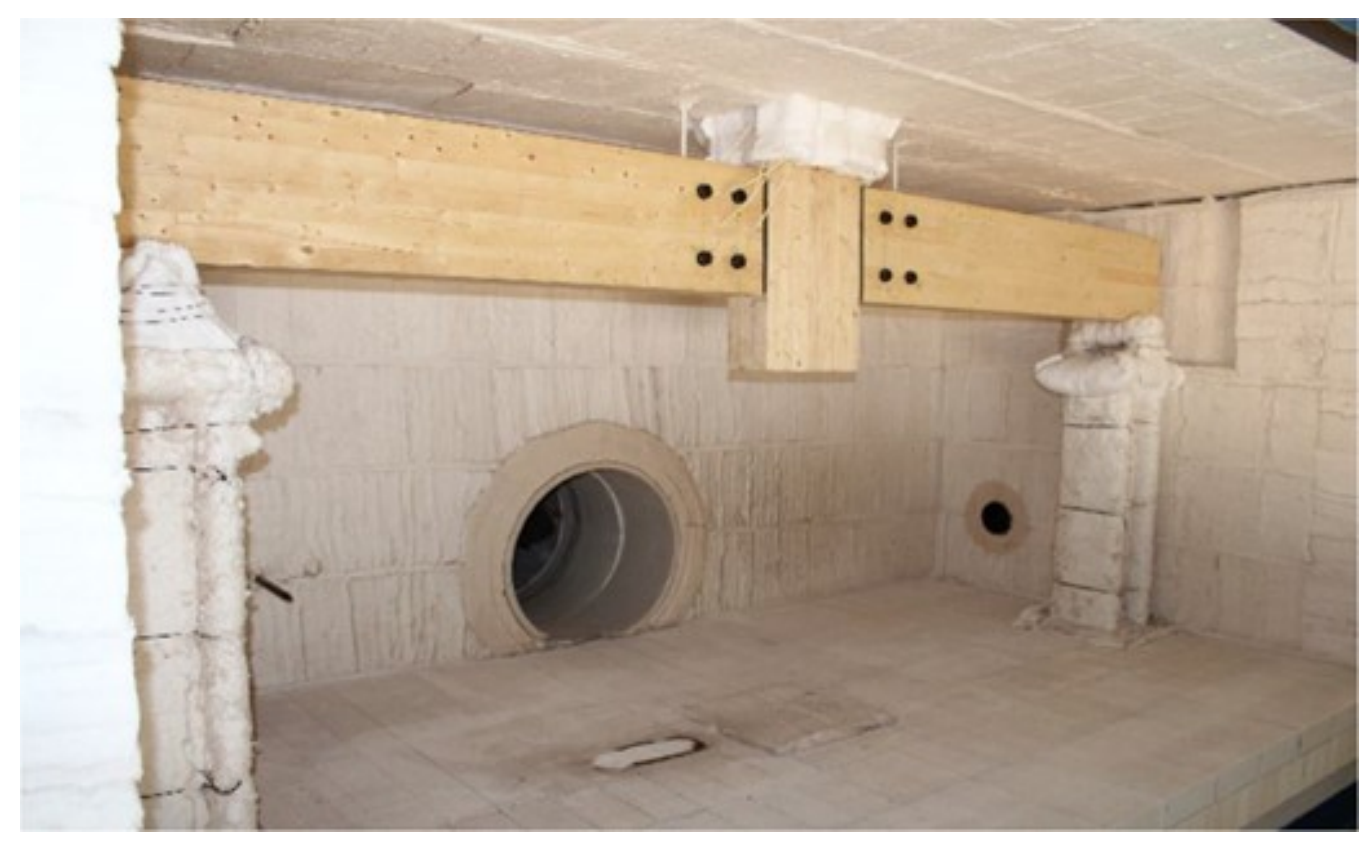

Figure 2.35 Typical test assembly with two symmetric beam-to-column connections installed inside the furnace [65]

Before the four reinforced specimens were installed inside the furnace, six self-tapping screws of 300-mm long and a diameter of $8-\mathrm{mm}$ were installed from top to bottom of each beam. Figure 2.36 shows the self-tapping screw layout as installed around the connection. During the tests, the specimens were loaded to $100 \%$ of the ultimate design load of the weakest connection configuration and were exposed on all sides to the effects of CAN/ULC S101 [24] standard fire. Also, the temperatures of the specimens were measured by 12 high-temperature resistance K-type thermocouples that were inserted in pre-drilled holes around the connections. 


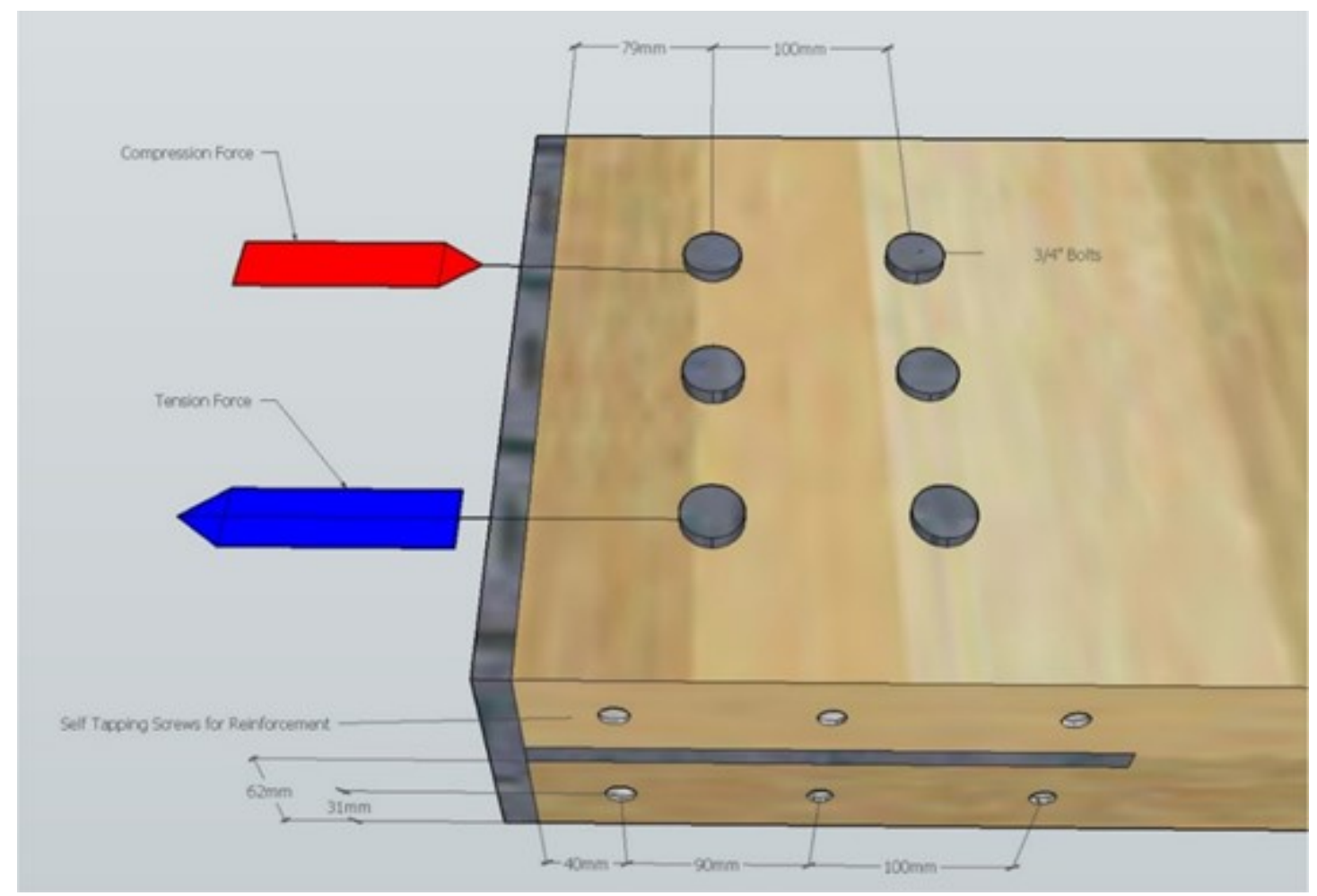

Figure 2.36 Self-tapping screw layout in a glulam beam section [65]

The test results showed that increasing the number of bolt rows from two to three improved the time to failure of the connections than increasing the bolt's end distances. The authors found that there was an incremental increase in the time to failure for the two-bolt row unreinforced connections than the three rows of bolts when the bolt end distance was increased. On the other hand, the reverse was observed in the reinforced connections. The failure time reported for all the connections tested was below 20 minutes.

It was also observed that the primary failure mode of the unreinforced connections was row shear out that developed into perpendicular to grain tensile splitting. However, such failure modes were found to be fully restrained when the connections were reinforced with selftapping screws and thus, increased the failure time of the reinforced connections, as well as promoted ductile failures such as elongation of the holes and yielding of the steel components. Figure 2.37 shows the brittle failure modes experienced in the unreinforced connections. 


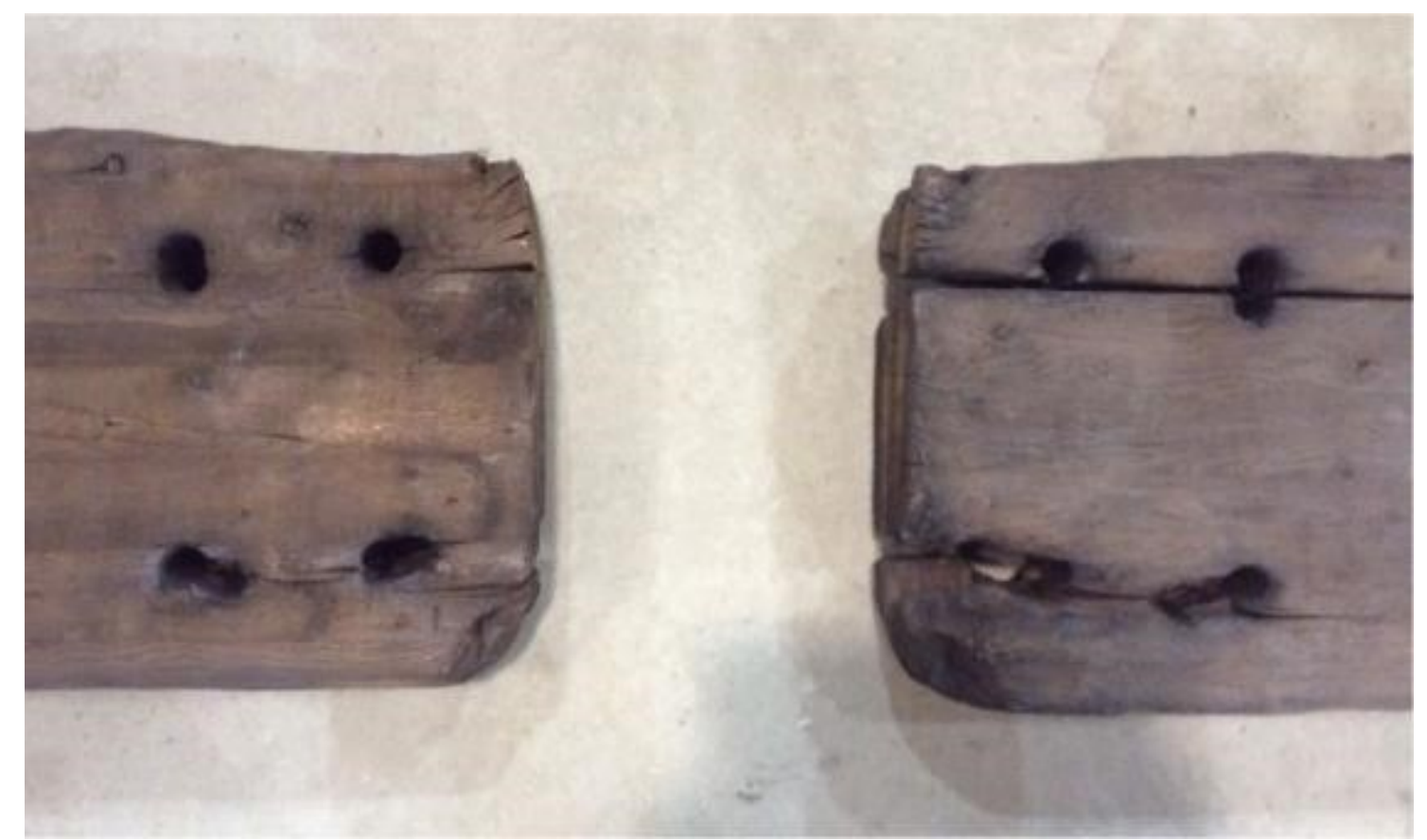

Figure 2.37 Brittle failure modes encountered in the unreinforced WSW connections [65]

\subsubsection{Summary of Reviewed Literature on Concealed Wood-Steel-Wood Connections}

Many studies had been conducted to investigate the behaviour of concealed connections at both ambient and elevated temperatures. Wang et al. [61], Karagiannis et al. [50], Owusu et al. [66], and Lam et al. [53, 57] conducted physical tests on moment-resisting wood-steel-wood connections at ambient temperatures and reported that the two predominant failure modes frequently encountered in such concealed connections loaded in bending are perpendicular-tograin tensile splitting and parallel-to-grain shear failures.

In an effort to control or prevent such failure modes at ambient temperature, Lam et al. [53, 57], Karagiannis et al. [50], Zhang et al. [51], Petrycki and Salem [56] employed self-tapping screws on moment-resisting connections to enhance the mechanical properties and also improve their moment-resisting capacity. The authors reported that the splitting failure was fully restrained by the application of self-tapping screws, leading to a more ductile, safer failure. In addition, Zhang et al. [51] and Lam et al. [57] reported that reinforcing the connections improved the rotational capacity and moment-resisting capacity by a factor of 1.46 
and 2, respectively. Overall, the authors concluded that the ductility and moment-resisting capacity can be enhanced by using self-tapping screws. However, little data exist on the influence of self-tapping screws on concealed connections at elevated temperatures.

At elevated temperatures, Petrycki and Salem [65], and Owusu [22] investigated the effect of number of bolts on concealed beam-to-column connections. For connections with and without protection, Owusu [22] reported that increasing the number of fasteners from four (4) to six (6) did not noticeably affect the time to failure, however, in another study conducted by Petrycki and Salem [71] on the fire performance of unprotected wood-steel-wood connections with and without reinforcement, the authors reported that increasing the number of bolts from four (4) to six (6) for both unreinforced and reinforced connections slightly improved the time to failure and led to a stiffer connection.

For the effect of protection, Owusu et al. [22] and Peng et al. [62] reported that protecting the connection's metal component against fire improved the failure time of the connections by 20 minutes and 30 minutes, respectively. Also, fire test results reported by Owusu [22] showed that the effect of bolt pattern was inconclusive as bolt pattern P1 performed better in four-bolt connections while bolt pattern P2 had improved failure time in six-bolt connections. Although, Owusu [22] reported that bolt pattern P2 had higher moment-resisting capacity than bolt pattern P1 at ambient temperatures. In other studies, Peng et al. [62], Akotuah et al. [43], and Ali [27] reported that reducing the load ratio increased the time to failure of the connections in fire.

Peng et al. [62], Owusu et al. [66], Petrycki and Salem [65], and Palma et al. [63] reported that at elevated temperatures, the failure mode experienced in wood-steel-wood connections loaded in bending and tension are perpendicular-to-grain tensile splitting, hole elongation (ductile failure), block shear out and parallel-to-grain row shear out, while the dominant failure mode was splitting (brittle failure). To strengthen this connection against such failure modes, Petrycki 
and Salem [65], and Palma et al. [63] conducted fire tests on wood-steel-wood connections with perpendicular-to-grain reinforcements using self-tapping screws. The authors reported that the application of self-tapping screws prevented the splitting failure and increased the loadcarrying capacity as well as the ductility of the connections. As a result, the failure time of the connections increased, although, Palma et al. [63] reported a reduction (or slight improvement in some cases) in the failure time of the connections due to the long length of the screws which resulted in a premature exposure to fire. It was reported that the screws conducted heat into the cross-section and increase charring, which in some cases compromises the fire resistance. In contrast, Petrycki and Salem [65] reported an increase in the failure time of the connections when STS was employed. The failure times reported in both papers were below the minimum fire-resistance rating of 45 minutes specified in the current National Building code of Canada (NBCC) [9] for combustible construction. In another study, Palma et al. [64] reported that the gap between the beam and the column of a beam-to-column concealed connection impairs the fire resistance of the connections. Hence, the larger the gap the lesser the failure time of the connections.

Therefore, to further improve the fire performance of concealed beam-to-column connections, the research presented in the thesis considered eight (8) full-scale protected wood-steel-wood connections involving four connection configuration types. The connections were tested to investigate the effect of number of fasteners, bolt patterns and influence of self-tapping screws at different load ratios. The metal components of the connections were fire protected using wood plugs and strips in order to delay heat transfer to the bolt heads, nuts, and steel plate edges, which as a result prevented the wood from charring from the inner core. In addition, the connections were reinforced perpendicular-to-grain with self-tapping screws to prevent against brittle failure modes. In this study, the beams flashes with the T-stub connectors and were connected to the column such that there were zero gaps. 


\section{EXPERIMENTAL PROGRAM}

\subsection{Introduction}

In order to investigate the performance of fully protected concealed beam-to-column reinforced connections under CAN/ULC-S101 Standard fire exposure, fire tests were conducted on eight (8) glulam beams in a large-scale horizontal furnace accommodated at Lakehead University's Fire Testing and Research Laboratory (LUFTRL), Thunder Bay, Ontario, Canada. In this study, an experimental program was developed to improve the performance of fully protected concealed connections of four different connection configurations by employing perpendicular-to-wood grain reinforcements using self-tapping screws. The test specimens were subjected to a transverse load at the beam free end resulting in bending moment on the connection. A description of the test facilities, test specimens and test procedure is provided in this chapter.

\subsection{Facilities}

This section focuses on the description of the test facilities, furnace and instrumentation employed.

\subsubsection{Fire Testing Furnace}

The fire testing furnace used for this research project is accommodated in the Lakehead University Fire Testing and Research Laboratory (LUFTRL), Figure 3.1. The furnace has interior dimensions of $3.4 \times 1.8 \times 1.6 \mathrm{~m}(\mathrm{~L} \mathrm{x} \mathrm{B} \mathrm{x} \mathrm{H})$ and is equipped with two natural gas burners that can raise the interior temperature of the furnace to $1300^{\circ} \mathrm{C}$. The burners are installed, one on each opposite sidewalls of the furnace along with blowers to supply air for combustion. The gas input into the furnace is regulated by a built-in gas electronic actuator and computer logic circuit to control and monitor the furnace temperatures in order to follow the 
standard time-temperature profile or any other fire curve. The exterior view of the furnace with the loading steel frame structure is shown in Figure 3.2. The furnace is built from strengthened heavy-steel plated walls that are insulated with layers of thick mineral Fibrefrax blanket. The door and the roof of the furnace can be removed using the 1-ton jib crane installed in the facility. As shown in Figure 3.2, the furnace is equipped with two observation ports on the door of the furnace. The windows' glass are cooled by fresh air supplied through a pipe. At the bottom-centre of the back wall of the furnace, a big circular exhaust pipe is installed to release the combustion gases during and after fire tests. Additional vents on the furnace's floor and roof are present to ease the access of instrumentation and set up of large experimental assemblies.

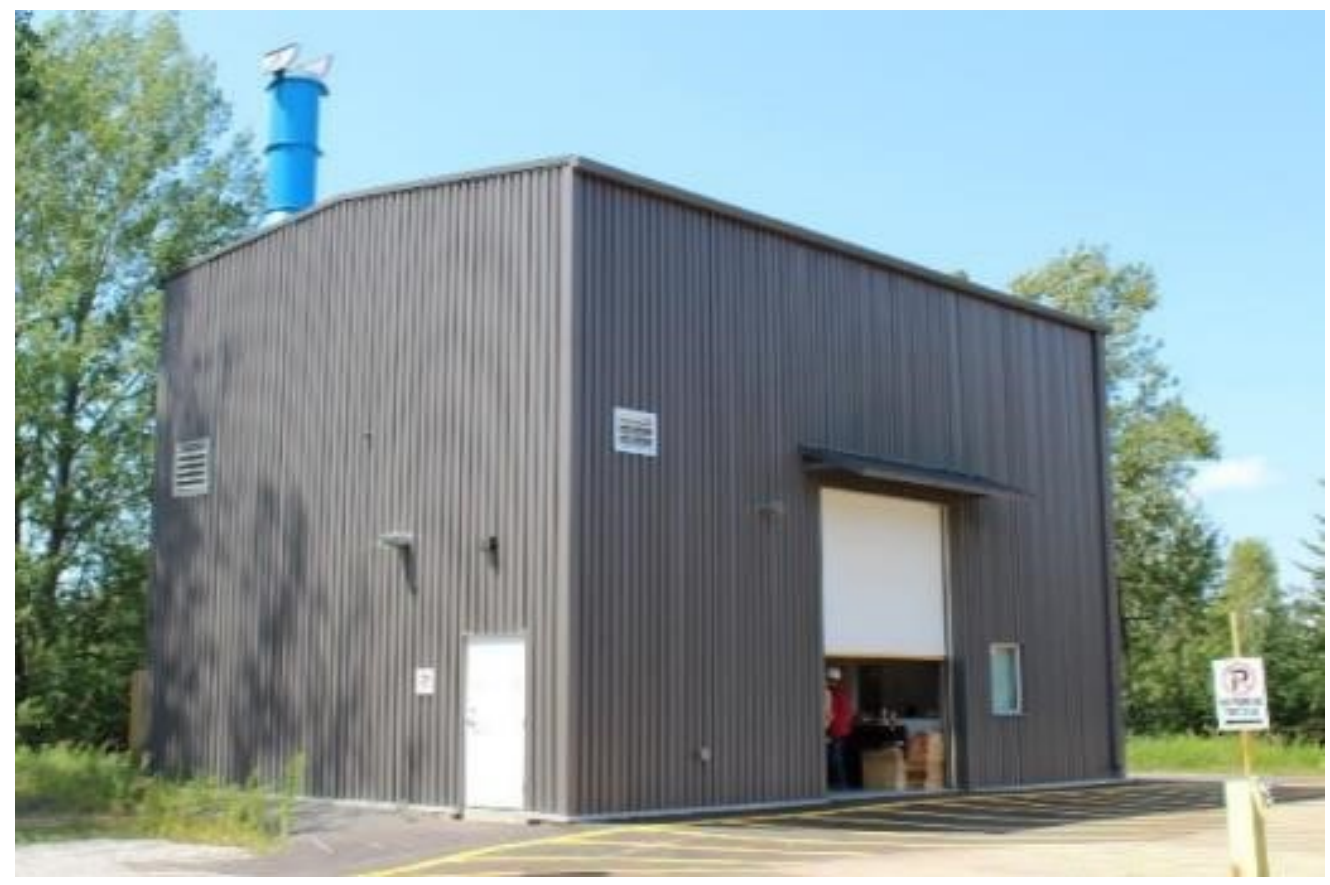

Figure 3.1 Lakehead University Fire Testing and Research Laboratory (LUFTRL) [Courtesy of Dr. Sam Salem, 2019] 


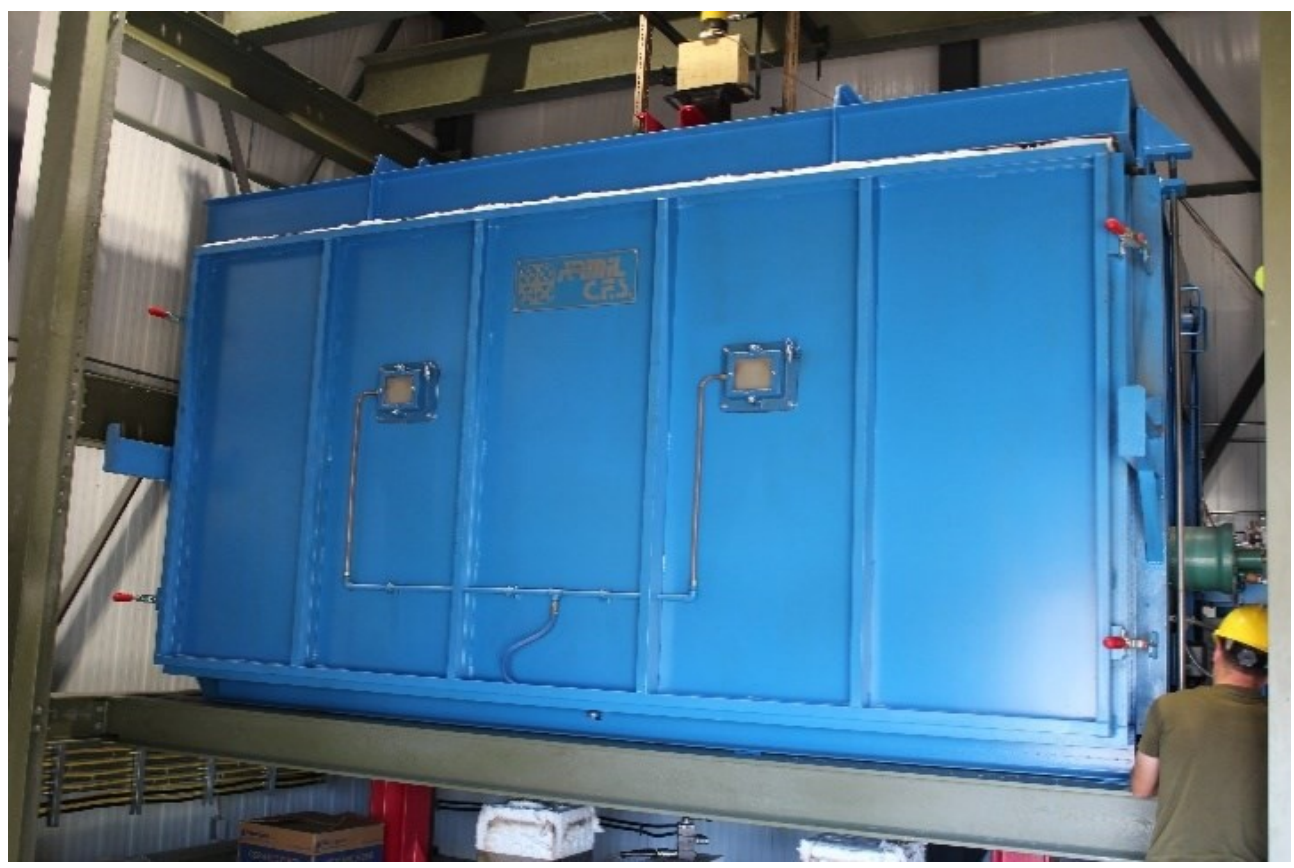

Figure 3.2 Large fire testing furnace accommodated at LUFTRL [Courtesy of Dr. Sam Salem, 2019]

\subsubsection{Thermocouples and Plate Thermometers}

The furnace is equipped with several shielded thermocouples (TC) and plate thermometers. As recommended by the CAN/ULC-S101 [26] standard, the thermocouples are Type K thermocouple wires insulated within a metal shielded protection tube. The shielded thermocouples (TC) are used to measure the temperatures within the furnace. The furnace temperatures are regulated to follow the CAN/ULC-S101 [26] standard time-temperature profile using a computer system built into the furnace control panel as shown in Figure 3.3. The Type $\mathrm{K}$ thermocouples have an accuracy of $\pm 2.2^{\circ} \mathrm{C}$ or $\pm 0.75 \%$, whichever is greater. 


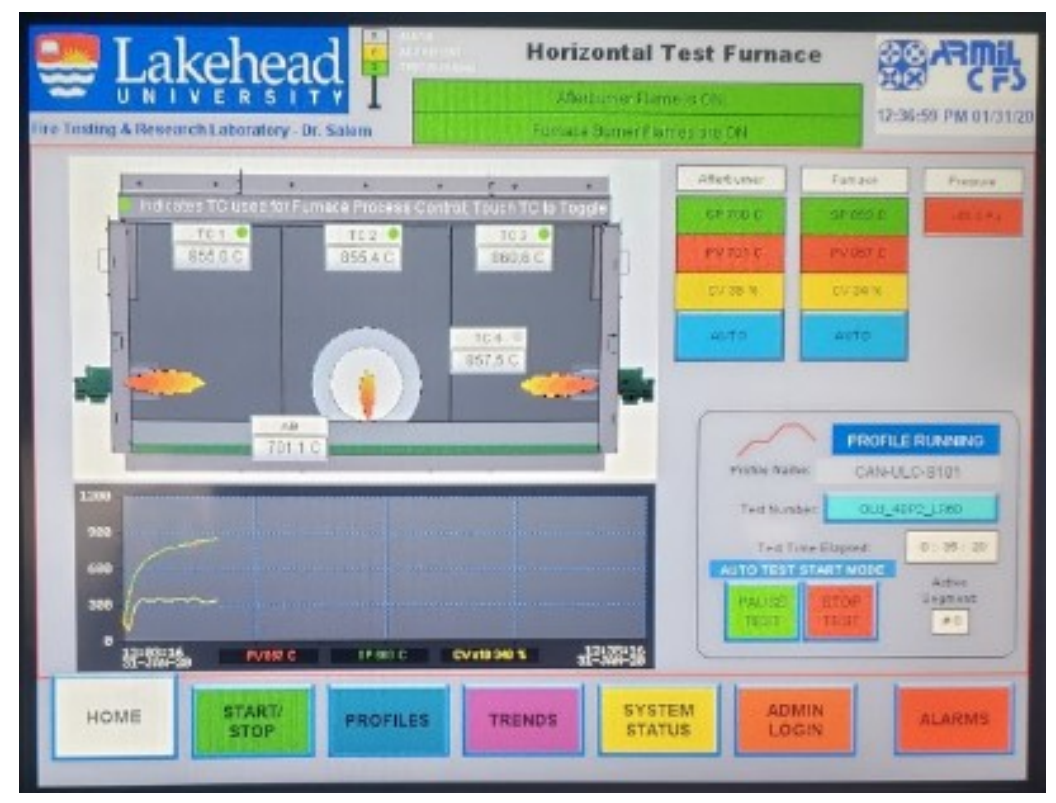

Figure 3.3 Human-Machine Interface (HMI) touch screen of the furnace's control panel [Courtesy of Dr. Sam Salem, 2020]

\subsubsection{Hydraulic Cylinder and Load Cell}

As shown in Figure 3.2, a high capacity hydraulic cylinder supported by a strong steel frame structure that is raising up the furnace above the floor is used to apply a monotonic concentrated load on the test specimen. A high capacity load cell is placed between the hydraulic cylinder piston and the loading post to precisely measure the applied loads. The load cell was calibrated before running the series of fire tests of this project. In order to maintain a constant load on the specimens as the glulam beam undergoes deflection, a manual hydraulic pump was connected to the hydraulic cylinder.

\subsubsection{LVDTs}

Linear variable differential transformers (LVDTs) are used to measure the displacements of the beam specimens during the tests. The LVDTs are installed outside the furnace at the top and long low-thermal elongation ceramic rods are used to measure the vertical displacement of the specimen inside the furnace. The measured displacements are used to calculate the rotation 
of the connections. The LVDTs used in this study have an outstanding linearity up to $\pm 0.075 \%$ and repeatability to $\pm 0.002 \mathrm{~mm}$.

\subsection{Materials}

\subsubsection{Glulam Beam Sections}

The glulam beam sections used in this study were obtained from Nordic Structures. The glulam beams were produced from black spruce-pine (SP), with a stress grade of $24 \mathrm{f}-\mathrm{EX}$ and an architectural appearance grade. The beams were $1600-\mathrm{mm}$ in length with a rectangular crosssectional dimension of $184 \mathrm{~mm}$ wide x $362 \mathrm{~mm}$ deep. The glulam beams were built up from laminas having approximate dimensions of $25 \mathrm{~mm}$ x $50 \mathrm{~mm}$ that were bonded together with a polyurethane adhesive. The laminas were made of short-length pieces, typically $900 \mathrm{~mm}$ long and they were end-jointed using a structural finger joint. The laminates were arranged in horizontal layers with the grain in the longitudinal direction and the length of each lamination is the full length of the beam member, $1600 \mathrm{~mm}$. The wood members were conditioned indoor at $20^{\circ} \mathrm{C}$ and $60 \%$ relative humidity $(\mathrm{RH})$. Some of the beams experienced shrinkage of about 2 $\mathrm{mm}$ in depth due to the reduction of moisture content. The measured average moisture content before the tests were recorded to be about $8 \%$. Table 3.1 summarizes the mechanical properties of the glulam sections as given in the Canadian Construction Materials Centre (CCMC) Evaluation report 13216-R [67]. 
Table 3.1 Beam specified strengths [67]

\begin{tabular}{|l|c|}
\hline \multicolumn{1}{|c|}{ Property } & $\begin{array}{c}\text { Strength } \\
\text { (MPa) }\end{array}$ \\
\hline Compression parallel-to-grain & 33.0 \\
\hline Compression perpendicular-to-grain & 7.5 \\
\hline Tension parallel-to-grain & 20.4 \\
\hline Longitudinal shear & 2.2 \\
\hline Flexural bending & 30.7 \\
\hline Modulus of elasticity & 13,100 \\
\hline
\end{tabular}

\subsubsection{T-stub Connectors and Fasteners}

The steel T-stub connectors were fabricated from a 12.7-mm (1/2") thick steel plate of grade $300 \mathrm{~W}$. The fabrication of the T-stub connectors was based on the wood connection configurations. In this study, four different T-stub connectors were used as shown in Figure 3.6. The first type has two rows of bolts that are symmetrically positioned near the top and bottom sides of the beam cross-section. While the second type has the bottom row shifted upwards to the mid-height of the beam section to further contribute to the moment-resisting capacity of the connection. Figures 3.4 and 3.5 show the detailed geometries of the steel T-stub connectors for the four-bolt pattern P1 (4BP1) and six-bolt pattern P2 (6BP2).

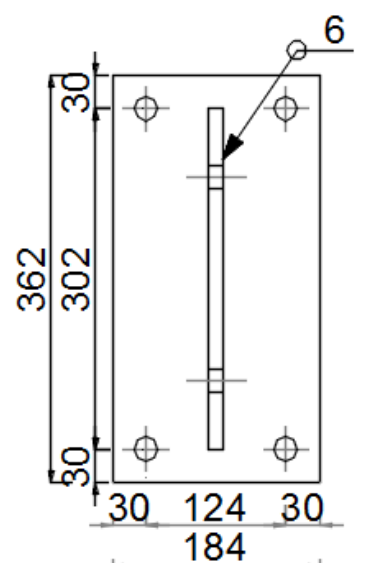

(a) Side View

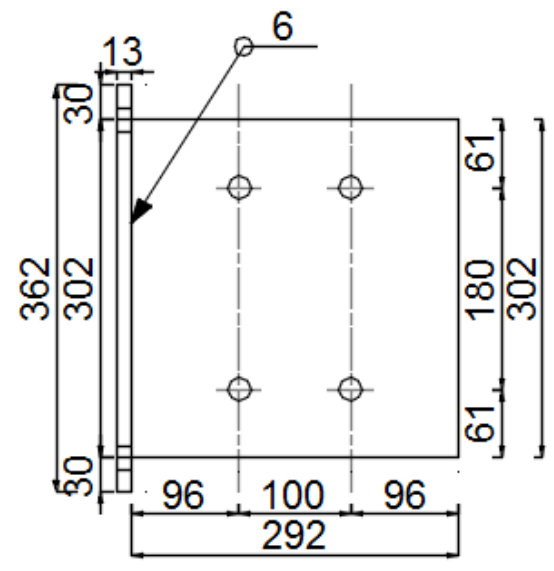

(b) Elevation 


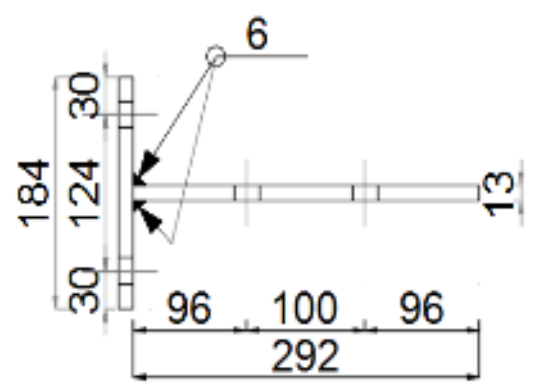

(c) Plan

Figure 3.4 Dimensions (all in $\mathrm{mm}$ ) and details of the four-bolt Pattern P1 T-stub connector

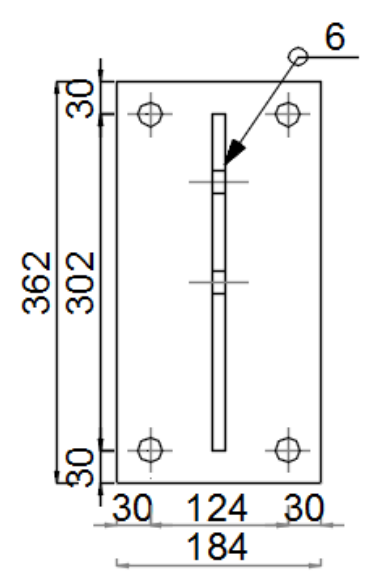

(a) Side View

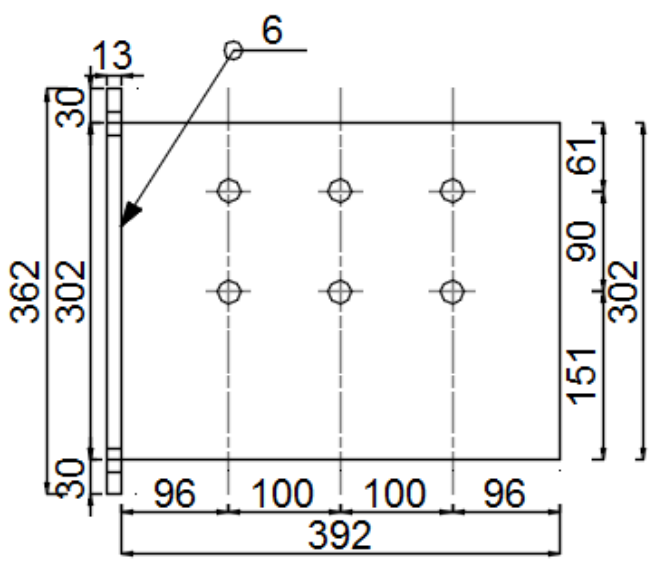

(b) Elevation

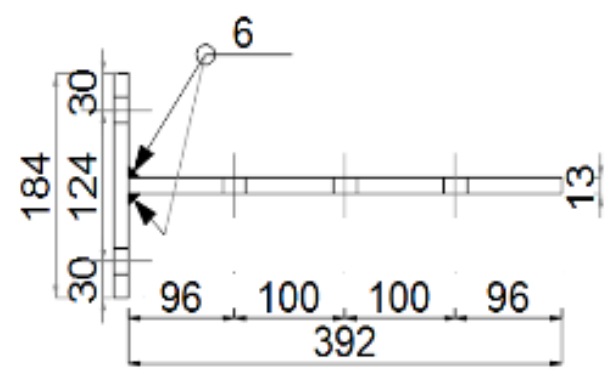

(c) Plan

Figure 3.5 Dimensions (all in mm) and details of the six-bolt Pattern P2 T-stub connector

For all the T-stub connectors, the connectors' flanges have a height of 302-mm in order to accommodate the protections of a $30-\mathrm{mm}$ rectangular glued-in wood plug at both the top and bottom side of the steel connector's flange. The fasteners employed in this research were made 
of 19.1-mm (3/4") diameter A325M high-strength structural steel bolts and thus, all the fastener holes on the T-stub connectors were all sized to be 1 to $2 \mathrm{~mm}(1 / 16 \mathrm{inch})$ larger than the fasteners' diameter as per CAN/CSA 086-14. Therefore, all the holes were 20.6-mm (13/16 inch) in diameter and a weld size of 6-mm was used to join the connector's flange to the face of the steel T-stub that flashes with the cross-section of the beam. Figure 3.6 shows the isometric view of the four connection configuration types.

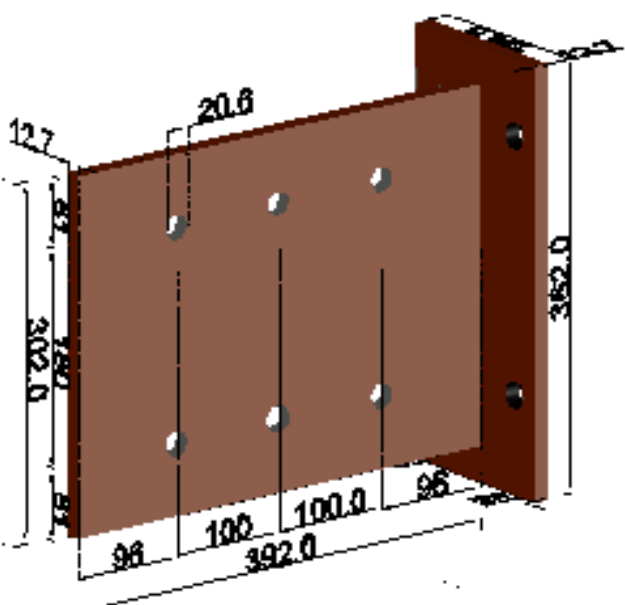

(a) T-Stub for six-bolt pattern P1, 6BP1

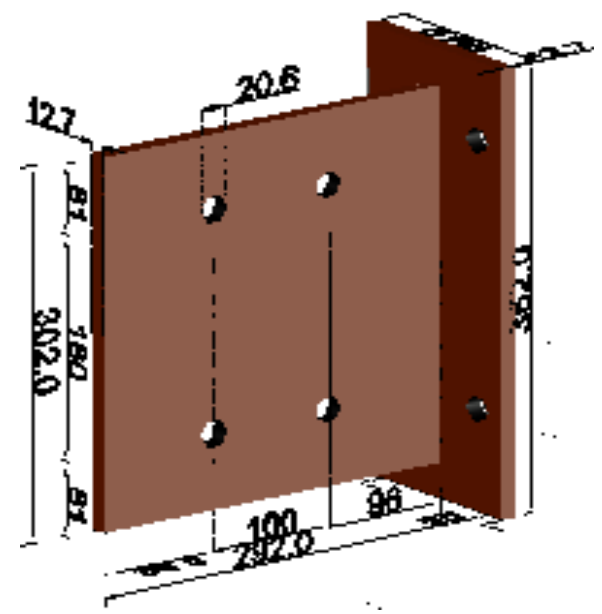

(c) T-Stub for four-bolt pattern P1, 4BP1

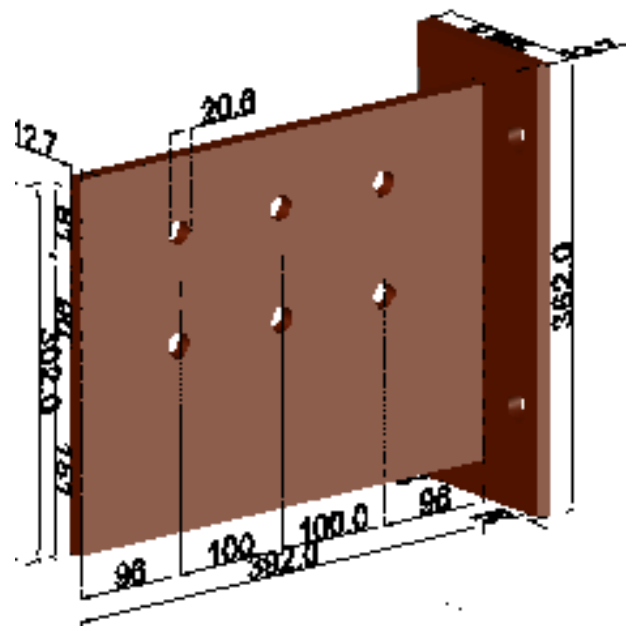

(b) T-Stub for six-bolt pattern P2, 6BP2

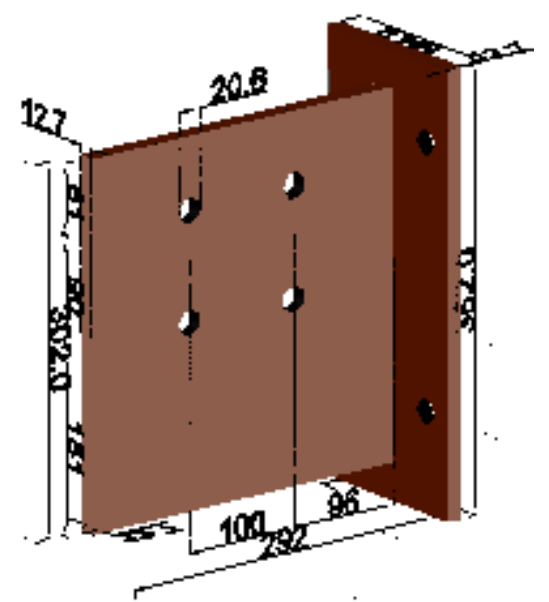

(d) T-Stub for four-bolt pattern P2, 4BP2

Figure 3.6 Isometric view of the four connection configuration types (all dimensions in $\mathrm{mm}$ ) 


\subsubsection{Steel Column}

All test assemblies were supported by a W200 steel column of grade $300 \mathrm{~W}$, having a flange and web thickness of 8-mm and 6-mm, respectively. The four threaded 19.1-mm diameter bolts rods welded to the face of the steel T-stub connector that flashes with the cross-section of the beam were used to secure the connections to the column. The bolt rods were fastened to the column using nuts as shown in Figure 3.7, which shows a picture of the steel column used to support the specimen at one beam end.

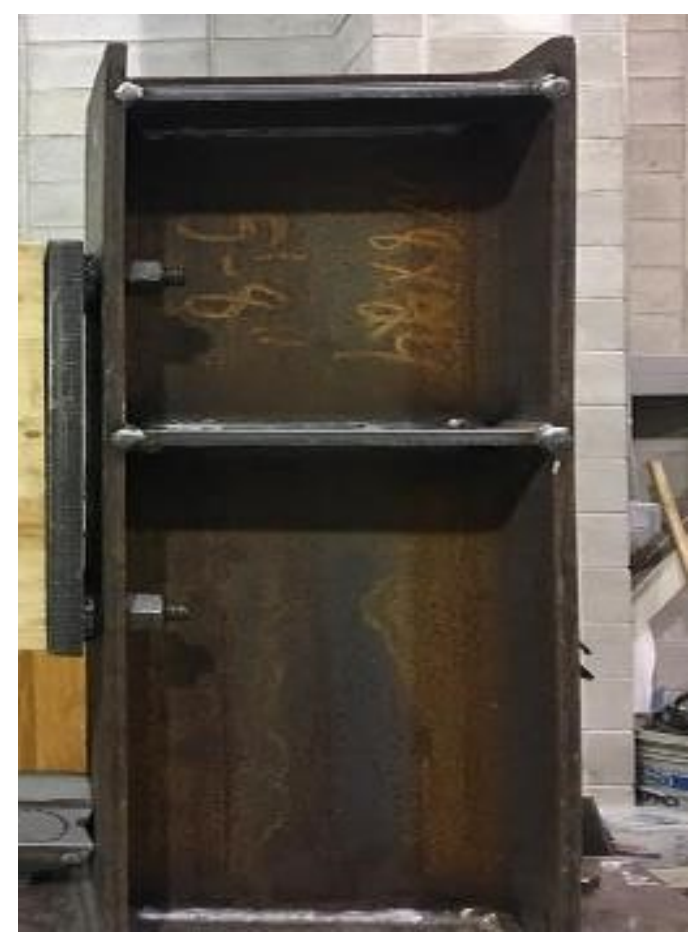

Figure 3.7 Steel column [22]

\subsubsection{Reinforcements}

The reinforcements used in the fire tests to strengthen the connections perpendicular-to-grain were SWG ASSY VG plus CSK self-tapping screws (STS). The self-tapping screws with the thread running along the full length were made from carbon steel and have a bending yield strength of 1,015 MPa and an unfactored shear strength of $641 \mathrm{MPa}$ [68]. The self-tapping screws were $300 \mathrm{~mm}$ in length and $8 \mathrm{~mm}$ in outer thread diameter. Table 3.2 provides the 
detailed dimensions of the SWG ASSY VG plus SCK self-tapping screws as reproduced from the Canadian Construction Materials Centre (CCMC) Evaluation report 13677-R [68]. Figure 3.8 shows the geometry of the self-tapping screws employed in this study.

Table 3.2 Specification for self-tapping screws [68]

\begin{tabular}{|c|c|c|c|c|c|c|c|c|c|}
\hline \multirow{2}{*}{$\mathrm{d}$} & $\mathrm{L}$ & $\mathrm{L}_{\text {thread }}$ & $\mathrm{L}_{\text {tip }}$ & $\mathrm{d}_{\text {head }}$ & $\mathrm{d}_{\min }$ & $\mathrm{d}_{\mathrm{a}}$ & $\mathrm{t}_{\mathrm{h}}$ & $\mathrm{d}_{\mathrm{p}}$ & \multirow{2}{*}{$\mathrm{Bit}$} \\
\cline { 2 - 10 } & \multicolumn{8}{|c|}{$\mathrm{mm}$} & \\
\hline 8 & 300 & 283 & 8 & 14.8 & 5 & 9 & 4.6 & 19 & $\begin{array}{c}\mathrm{AW} \\
40\end{array}$ \\
\hline
\end{tabular}
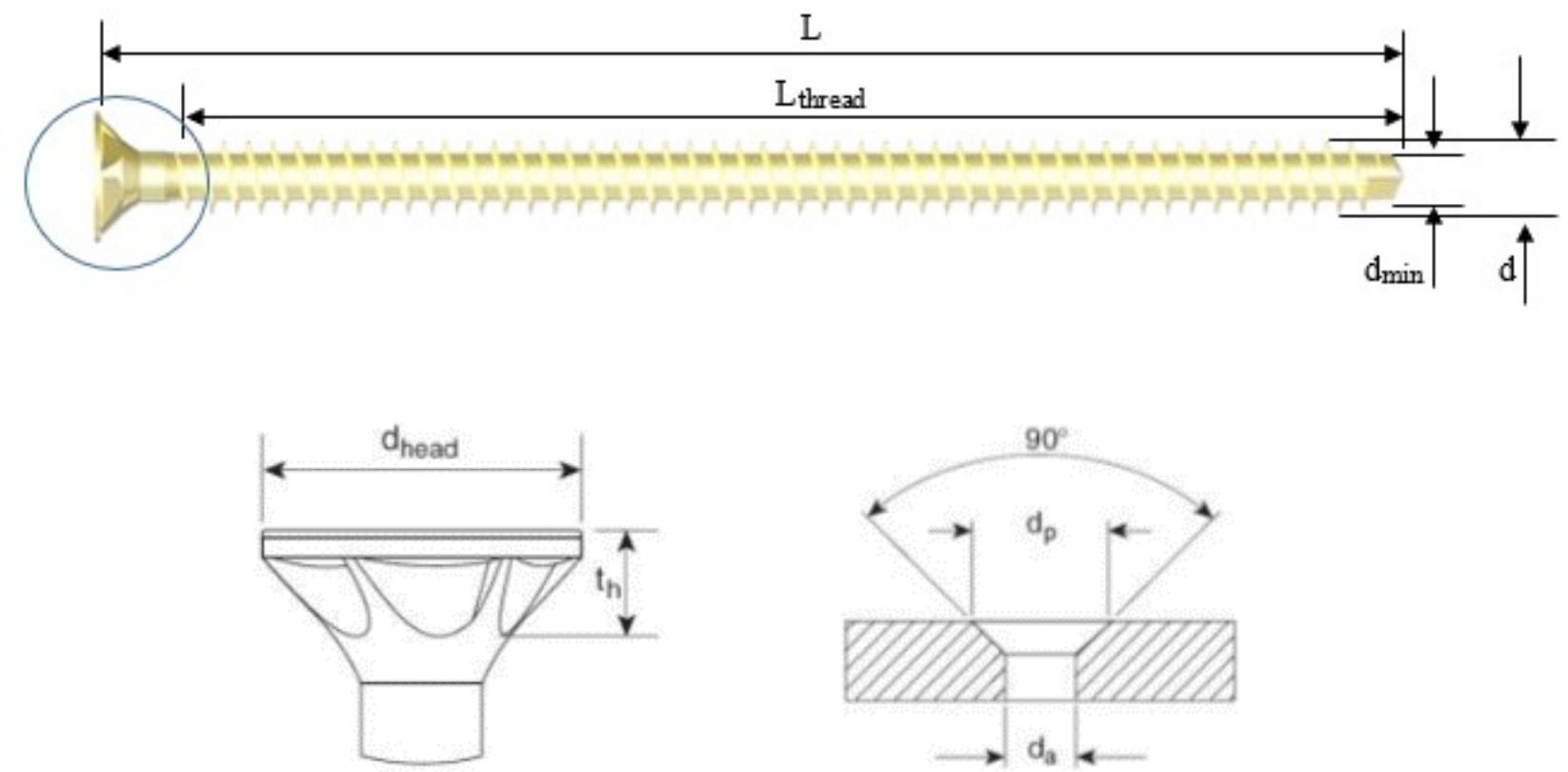

Figure 3.8 Dimension and details of self-tapping screw (8.0mm x $300 \mathrm{~mm})$ [68]

where $\mathrm{L}_{\text {tip }}=$ length of un-threaded portion on screw tip.

All dimensions are in $\mathrm{mm}$

\subsection{Test Set-up and Procedure}

\subsubsection{Test Specimens}

\subsubsection{Connection Configuration Types and Test Matrix}

In total, eight (8) full-scale fire tests were conducted on glulam beam end connections while being loaded perpendicular-to-grain in bending. The four connection configuration types 
employed were divided into two groups based on the number of fasteners: four (4) and six (6) bolts. For each group, two-bolt patterns were considered. For bolt pattern P1, two rows of bolts were symmetrically positioned near the top and bottom sides of the beam cross-section, the bolt pattern P2 has the bottom row shifted upward to the mid-height of the beam section to further contribute to the moment-resisting capacity of the connection. Hence, the unloaded edge distance for connections with bolt pattern P2 was increased to $181 \mathrm{~mm}$ as compared to that of bolt pattern P1 which was $91 \mathrm{~mm}$. Figures 3.9 and 3.10 illustrate the geometry of the connection configurations of the tested concealed wood-steel-wood connections for both bolt patterns, P1 and P2 along with the self-tapping screws layouts of the connections showing the installed reinforcements. In all the connection configurations, the metal components of the connections were protected with glued-in wood plugs of the same wood material as the beam. The concealed connections were designed to satisfy CSA O86-14 [60]. The matrix of the fire tests is presented in Table 3.2

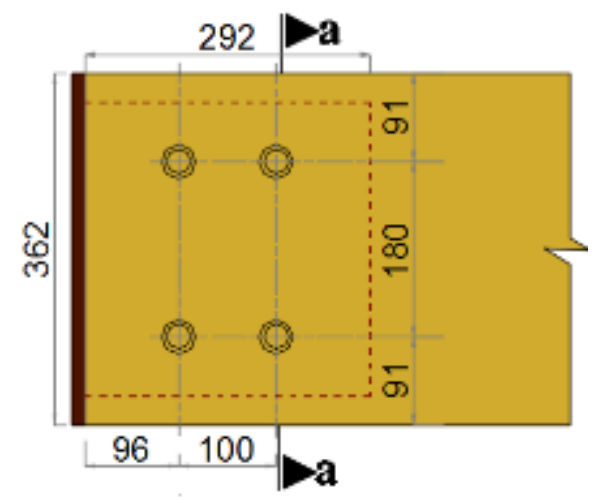

Front view

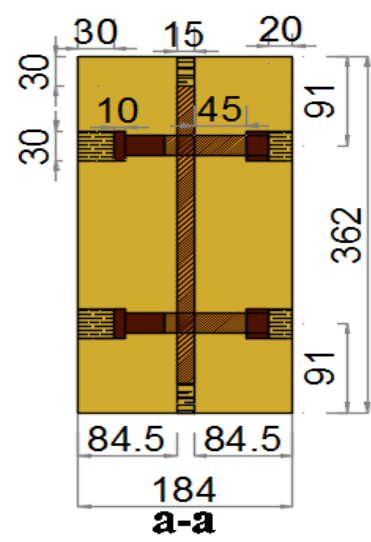

Cross-section

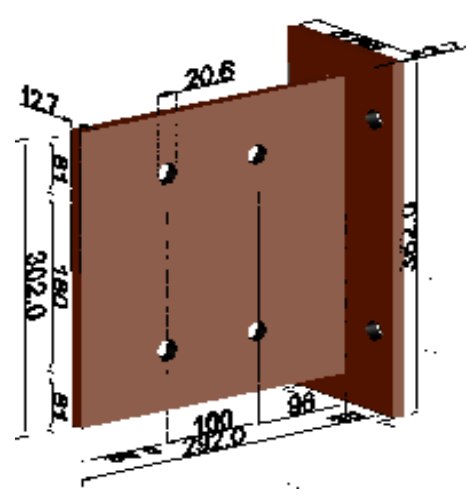

T-stub for 4BP1

(a) Dimension and details of four-bolt pattern P1 connection configuration 


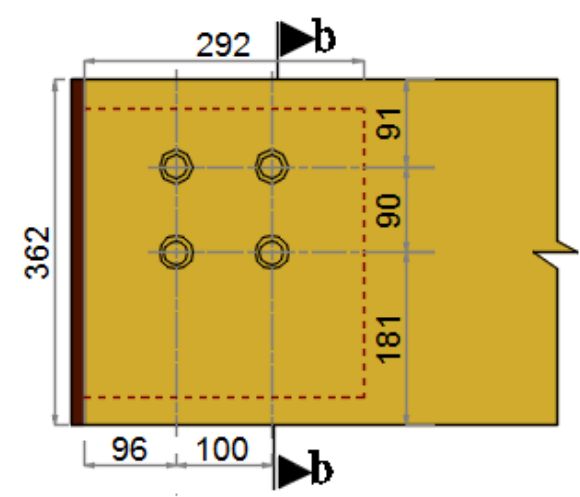

Front view

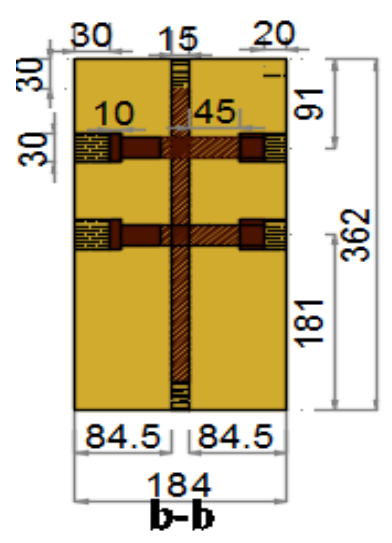

Cross-section

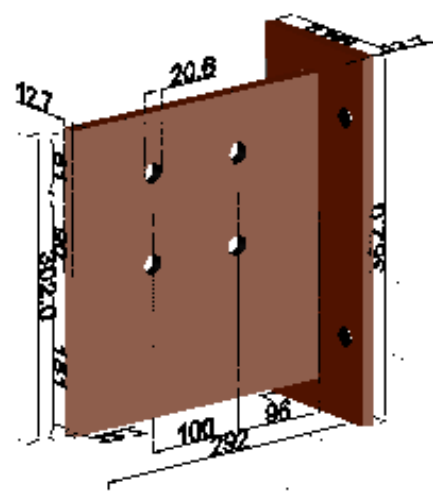

T-stub for 4BP2

(b) Dimension and details of four-bolt pattern P2 connection configuration

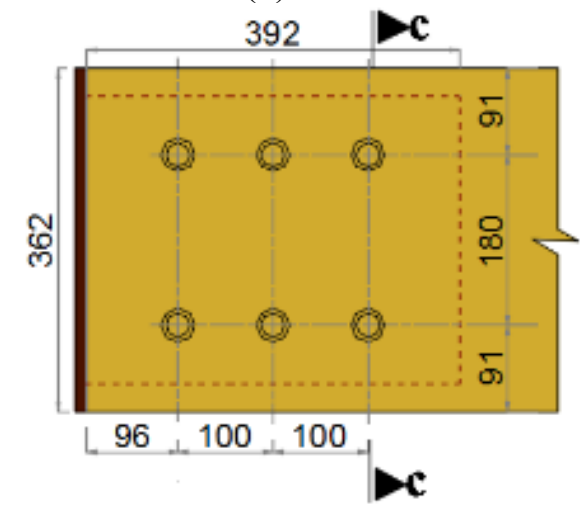

Front view

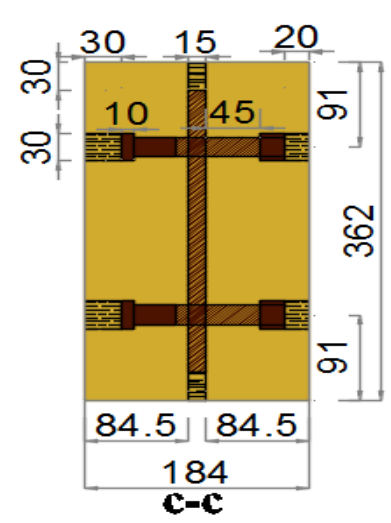

Cross-section

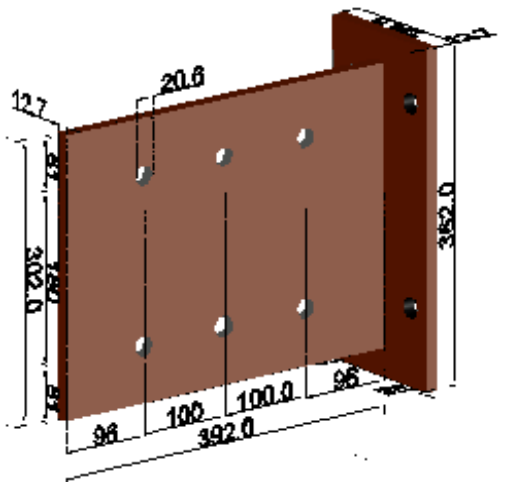

T-stub for $6 \mathrm{BP} 1$

(c) Dimension and details of six-bolt pattern P1 connection configuration

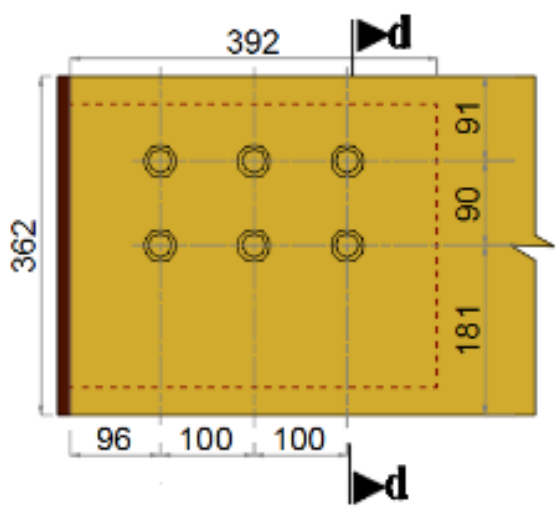

Front view

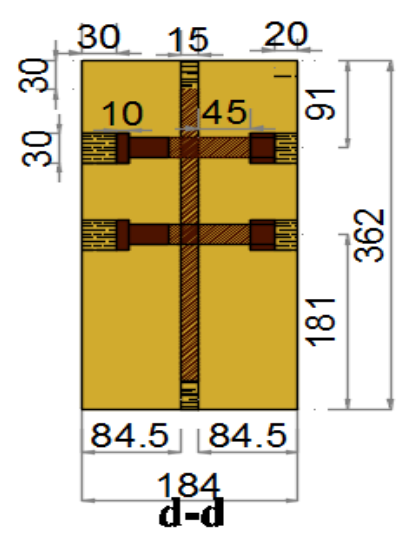

Cross-section

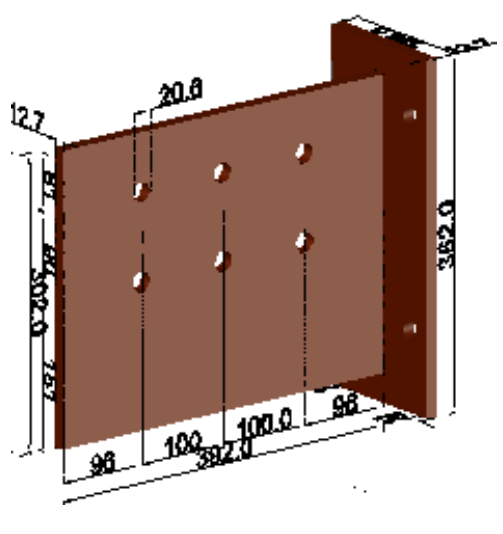

T-stub for $6 \mathrm{BP} 2$

(d) Dimension and details of six-bolt pattern P2 connection configuration

Figure 3.9 Bolt layout details of the four connection configurations 


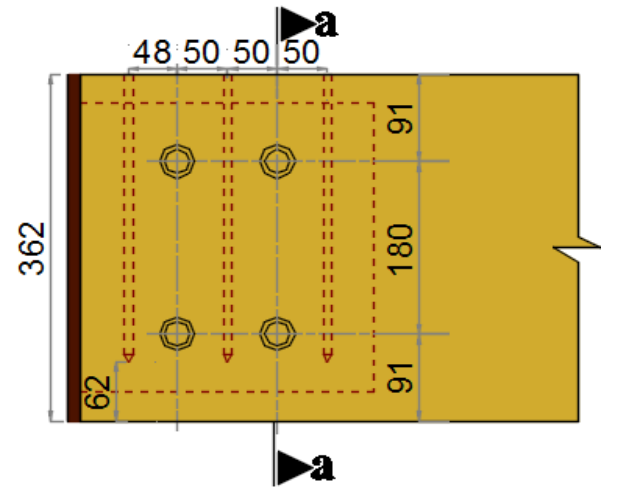

Front view

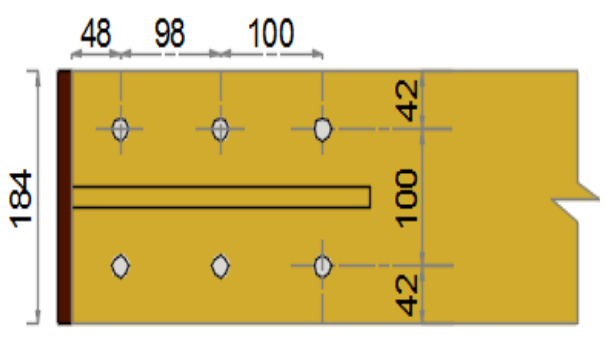

Plan view

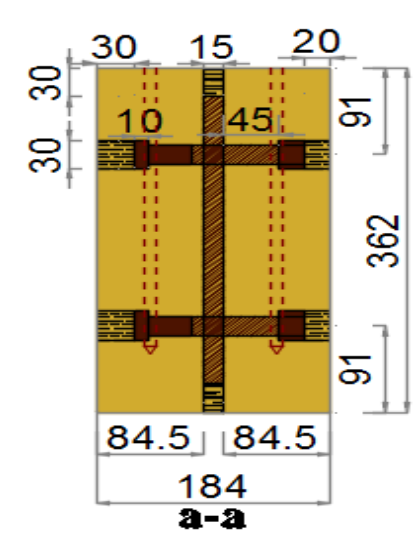

Cross-section

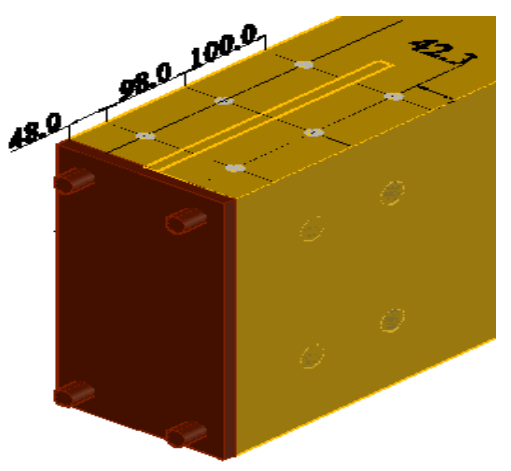

Isometric view

(a) Self-tapping screw layout details of the 4BP1 connection configuration

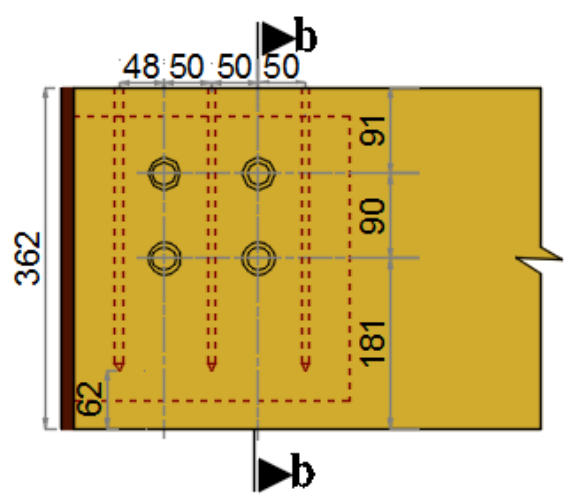

Front view

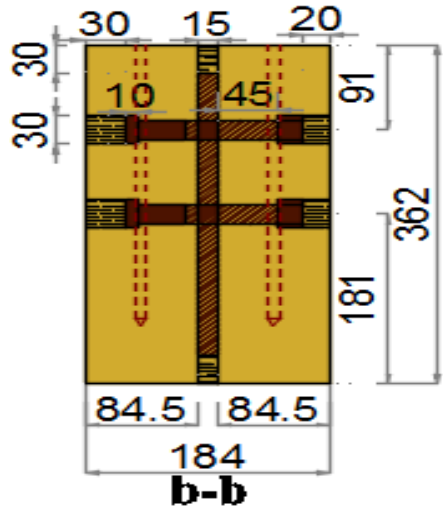

Cross-section 

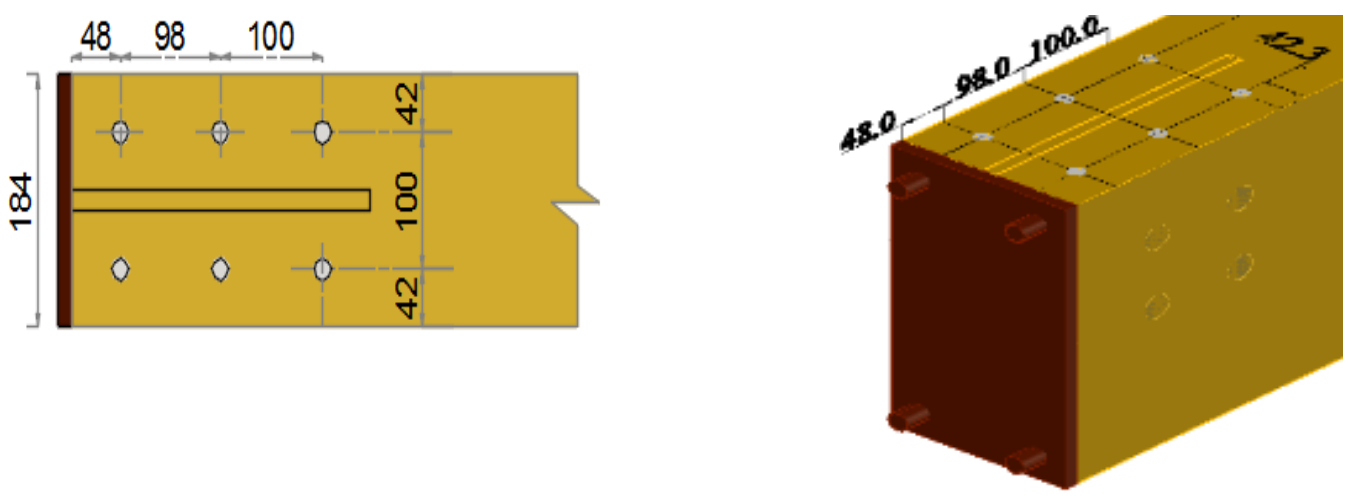

Plan view

Isometric view

(b) Self-tapping screw layout details of the 4BP2 connection configuration
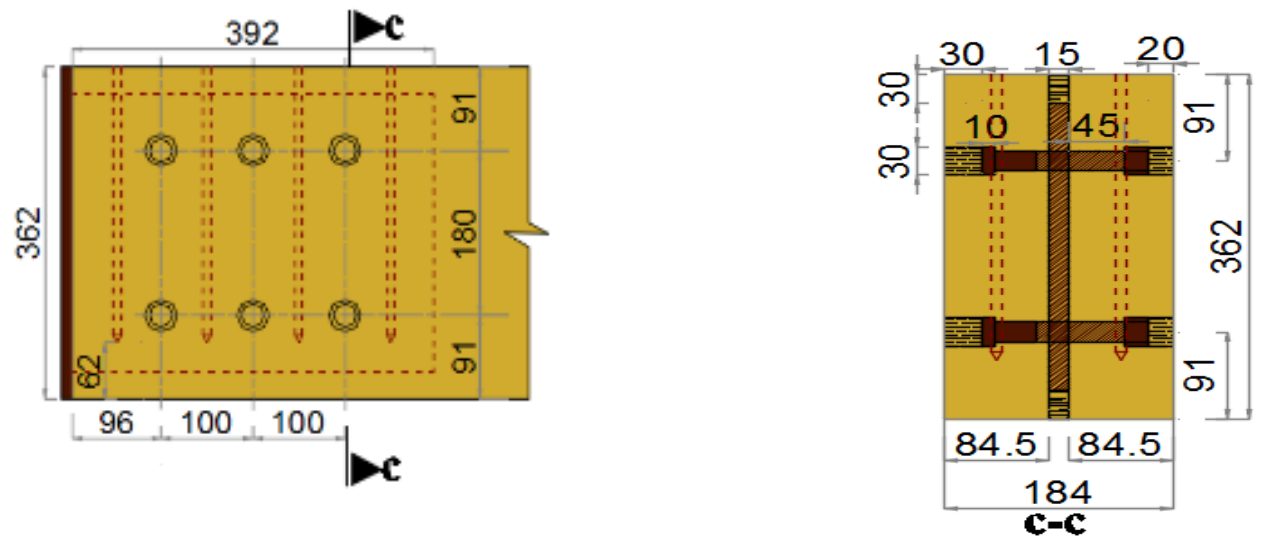

Front view

Cross-section
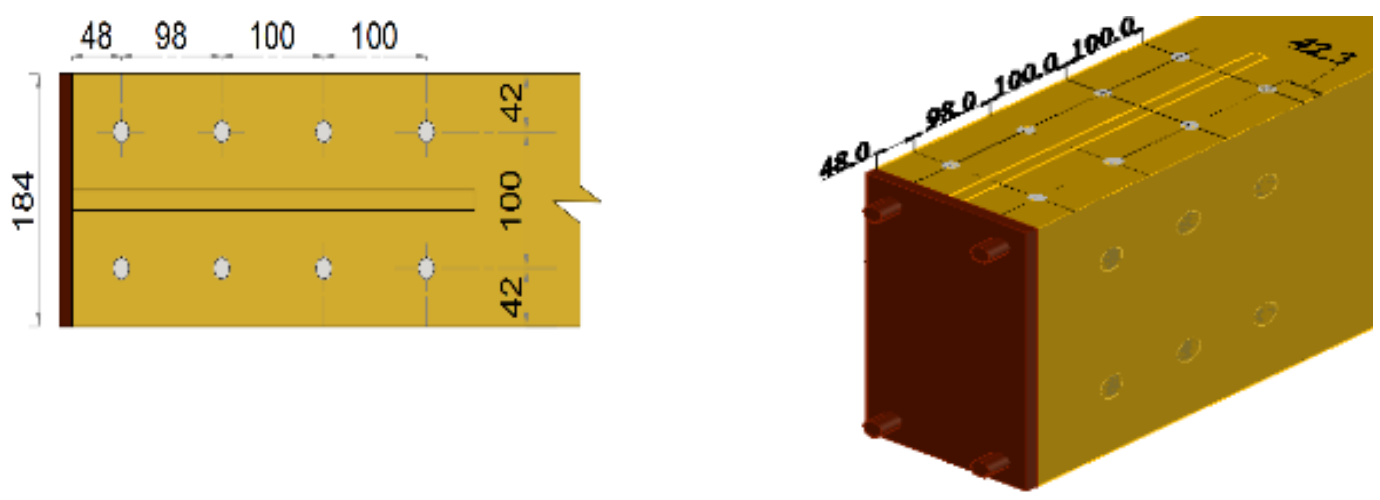

Plan view

Isometric view

(c) Self-tapping screw layout details of 6BP1 connection configuration 


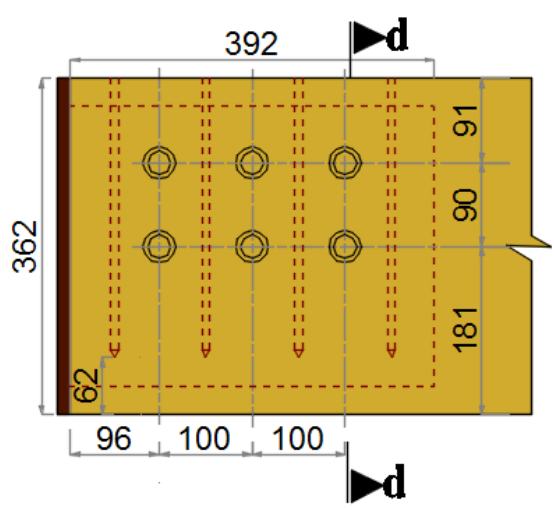

Front view

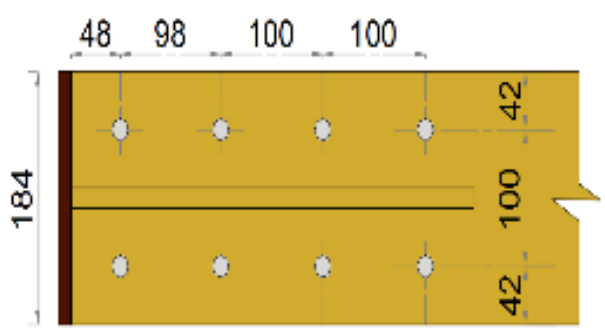

Plan view

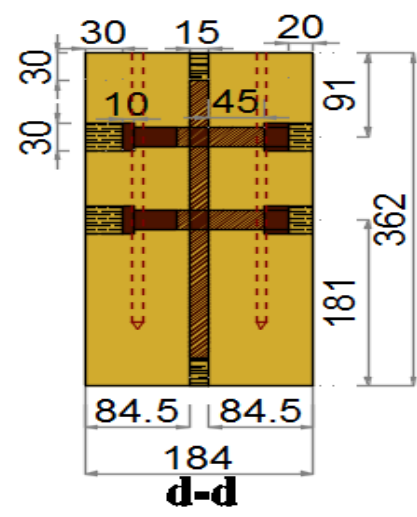

Cross-section

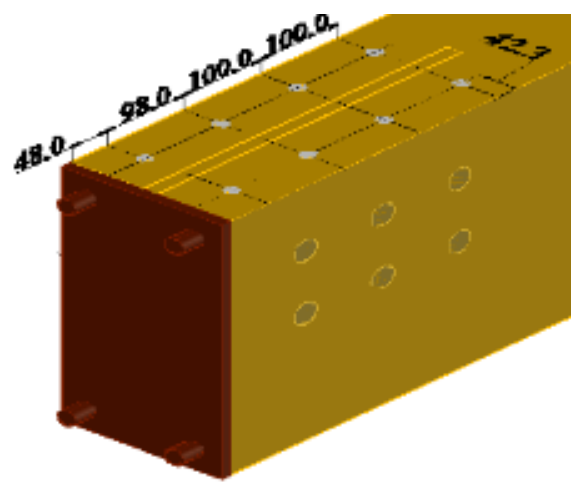

Isometric view

(d) Self-tapping screw layout details of 6BP2 connection configuration

Figure 3.10 Self-tapping screws layout details of the four connection configuration

Table 3.3 Test matrix

\begin{tabular}{|c|c|c|c|c|c|c|c|}
\hline $\begin{array}{c}\text { Connection } \\
\text { configurations }\end{array}$ & Bolt & $\begin{array}{c}\text { Applied } \\
\text { pattern } \\
(\%) \\
(\%)\end{array}$ & $\begin{array}{c}\text { Estimated } \\
\text { load ratio } \\
(\%)^{* *}\end{array}$ & $\begin{array}{c}\text { Number } \\
\text { of bolts }\end{array}$ & $\begin{array}{c}\text { Number } \\
\text { of Self- } \\
\text { tapping } \\
\text { screws }\end{array}$ & $\begin{array}{c}\text { Unloaded } \\
\text { edge } \\
\text { distance } \\
(\mathrm{mm})\end{array}$ & $\begin{array}{c}\text { Number } \\
\text { of tests }\end{array}$ \\
\hline 4BP1LR60 & 1 & 60 & 30 & 4 & 6 & 91 & 1 \\
\hline 4BP2LR60 & 2 & 60 & 15 & 4 & 6 & 181 & 1 \\
\hline 4BP1LR100 & 1 & 100 & 50 & 4 & 6 & 91 & 1 \\
\hline 4BP2LR100 & 2 & 100 & 25 & 4 & 6 & 181 & 1 \\
\hline 6BP1LR100 & 1 & 100 & 40 & 6 & 8 & 91 & 1 \\
\hline 6BP2LR100 & 2 & 100 & 20 & 6 & 8 & 181 & 1 \\
\hline 6BP1LR130 & 1 & 130 & 50 & 6 & 8 & 91 & 1 \\
\hline 6BP2LR130 & 2 & 130 & 30 & 6 & 8 & 181 & 1 \\
\hline
\end{tabular}


*Load ratio is calculated based on the moment-carrying capacity of the weakest unreinforced, unprotected connection as per [20].

**Estimated load ratio with respect to the maximum moment resistance of each reinforced connection (see Appendix B for explanation and calculation).

\subsubsection{Test Details and Fabrication}

For each test specimen, a T-stub steel section was used to connect the glulam beam section to the supporting steel column. A portable bandsaw was used to make a vertical slot in all the beams in order to accommodate the T-stub connector, as shown in Figure 3.10a. The slot for the $12.7 \mathrm{~mm}\left(1 / 2^{\prime \prime}\right) \mathrm{T}$-stub plate was cut to $15 \mathrm{~mm}$ wide to allow for a fabrication tolerance of 1 to $2 \mathrm{~mm}$ as required by CAN/CSA O86-14 [60] and also to reduce friction in the connection. Circular holes were drilled into the glulam beam faces with the use of a $30 \mathrm{~mm}$ diameter spade bit to embed the bolt heads and nuts, as well as to accommodate the wood plug protection (Figure 3.10b). The inner 19.1-mm bolt holes were milled using a $20 \mathrm{~mm}$ drill bit to allow for a minimum of 1-mm fabrication tolerance (Figure 3.10c). The T-stub plate was slotted into the $184 \mathrm{~mm}$ x $362 \mathrm{~mm}$ beam section, thereby sandwiched between two wood side sections, each of $84.5 \mathrm{~mm}$ thickness, and fastened together with $19.1 \mathrm{~mm} \mathrm{(3/4”)} \mathrm{diameter} \mathrm{A325M} \mathrm{high-}$ strength structural steel bolts. Subsequently, the metal components of the connections were protected with glued-in wood plugs. Thereafter, the glulam beam section was connected to the supporting steel column via the T-stub connector using a $19.1 \mathrm{~mm}(3 / 4$ ”) diameter structural steel bolts. The fabrication process of the specimens is shown in Figure 3.11. The spacing of the fasteners was designed in accordance with CAN/CSA 086-14 [60]. The summary of the design of the fastener spacing is presented in Table 3.4. 


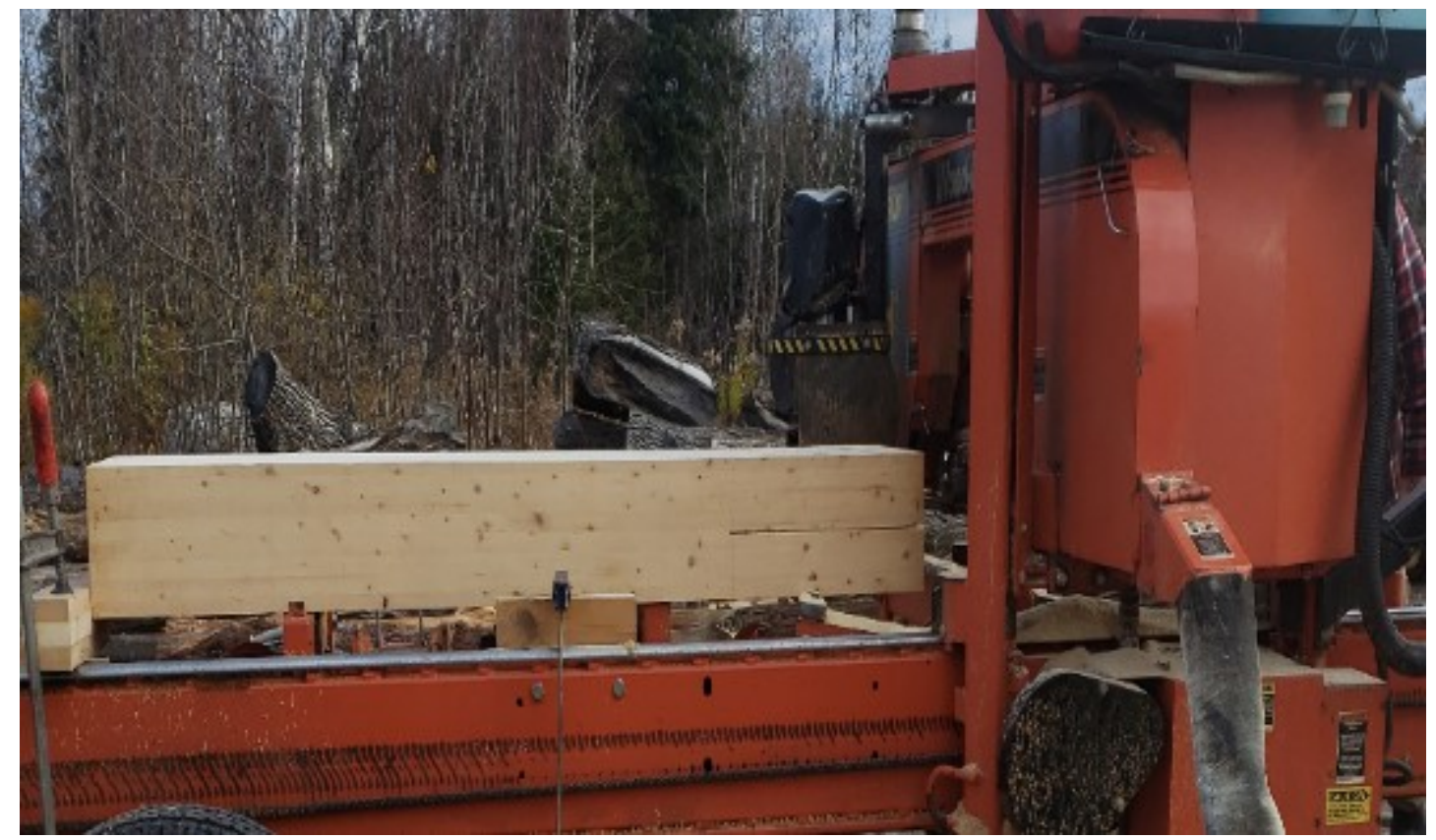

(a) Cutting of the vertical slots for the T-stub connector (Courtesy of Dr. Matthew Leitch, 2020)

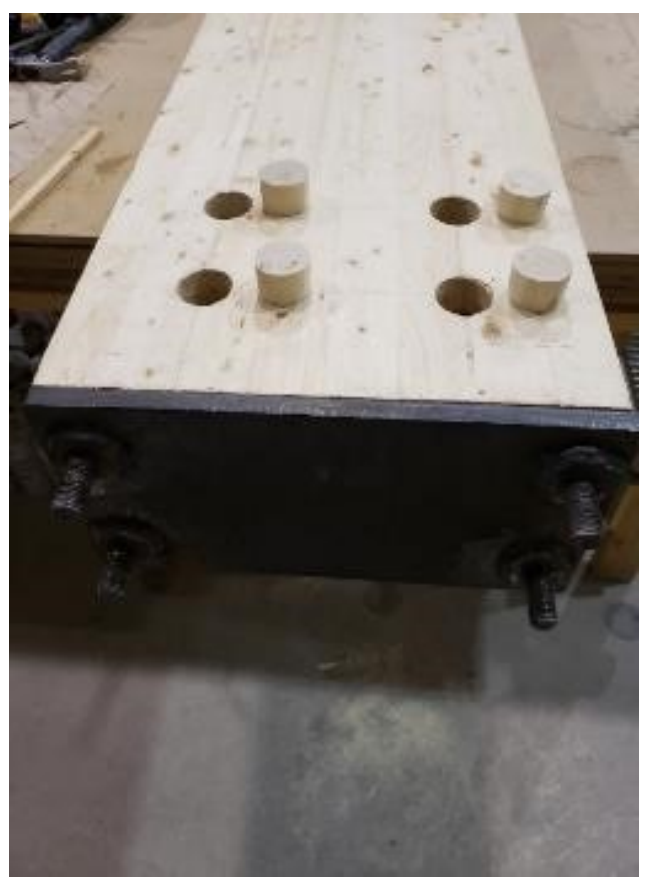

(b) 30-mm diameter hole for wood plug protection for 4BP1 configuration

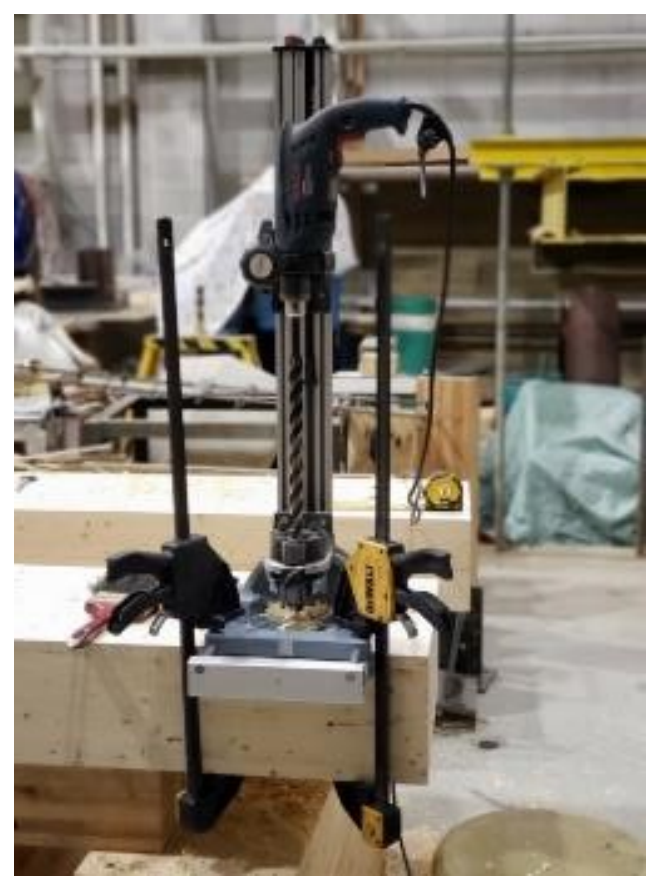

(c) Drilling of 20.6-mm internal bolt

hole

Figure 3.11 Fabrication steps of a typical test specimen 


\subsubsection{Placement of Bolts in a Connection Loaded Perpendicular-to-grain}

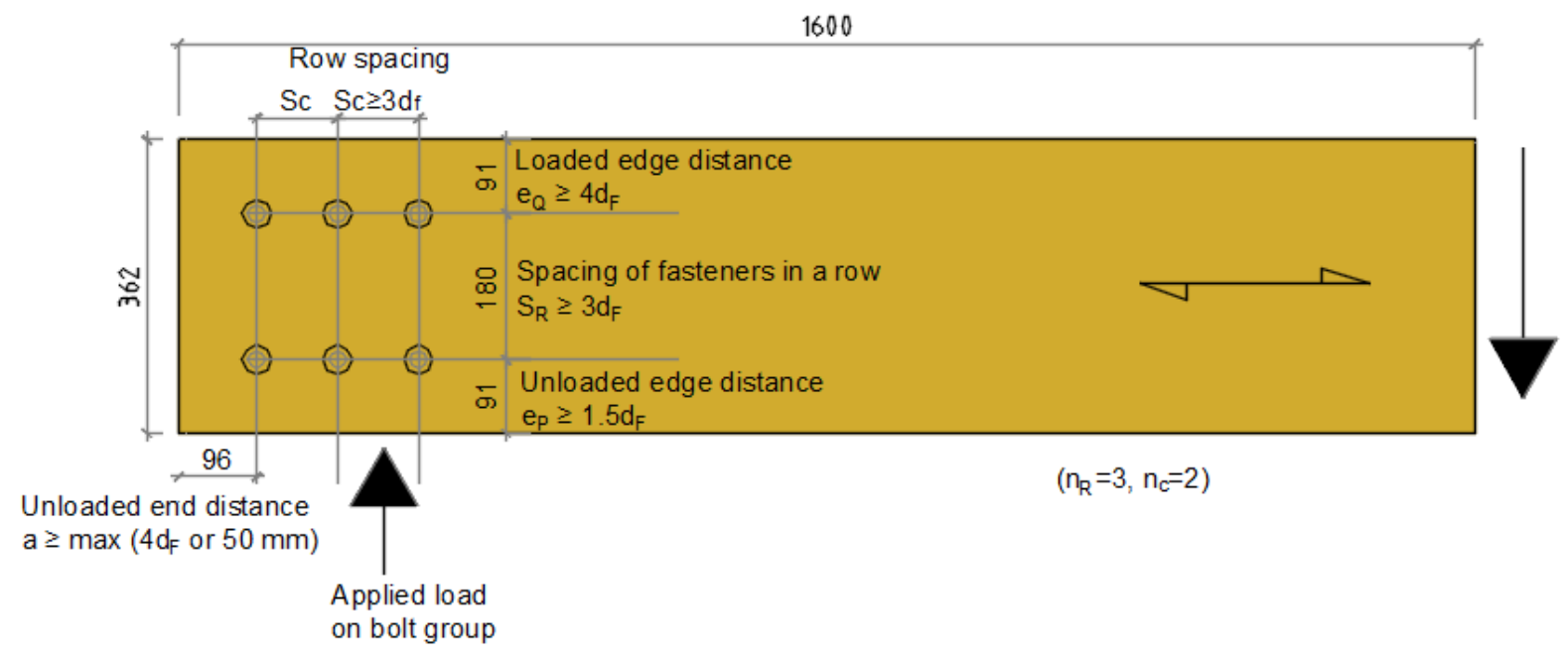

Figure 3.12 Placement of bolts in six-bolt pattern P1 (6BP1) connection

Where:

$\mathrm{S}_{\mathrm{R}}=$ spacing of fasteners in row

$\mathrm{S}_{\mathrm{C}}=$ row spacing

$\mathrm{a}=$ unloaded end distance

$\mathrm{eQ}=$ loaded edge distance

ep $=$ unloaded edge distance

$\mathrm{d}_{\mathrm{F}}=$ diameter of fastener, $\mathrm{mm}$

\section{Spacing verification}

Parameters:

$$
\begin{array}{ll}
\mathrm{d}_{\mathrm{F}}=19.1 \mathrm{~mm} & \mathrm{a}=96 \mathrm{~mm} \\
\mathrm{e}_{\mathrm{Q}}=91 \mathrm{~mm} & \mathrm{e}_{\mathrm{p}}=91 \mathrm{~mm} \\
\mathrm{~S}_{\mathrm{c}}=100 \mathrm{~mm} & \mathrm{~S}_{\mathrm{R}}=180 \mathrm{~mm}
\end{array}
$$

Table 3.4 Spacing requirement for bolt pattern $\mathrm{P} 1$ and $\mathrm{P} 2$

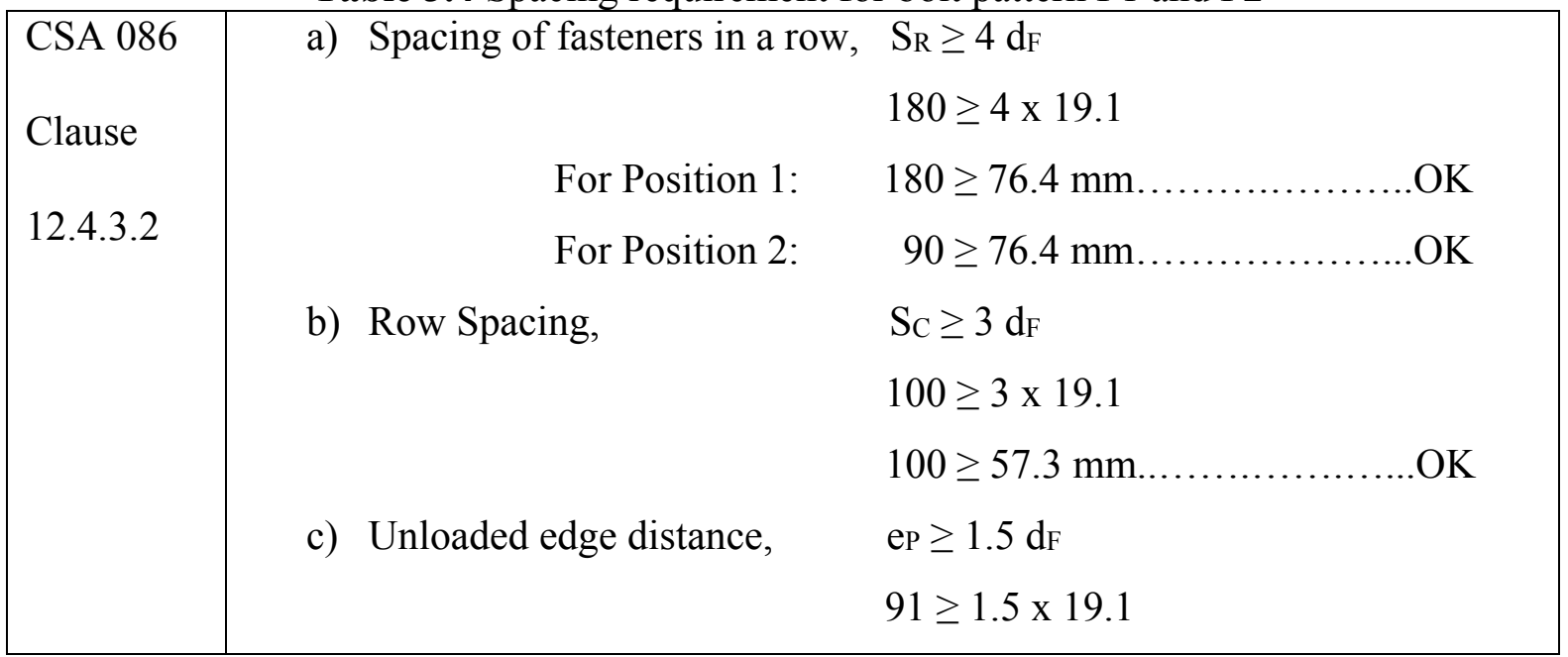




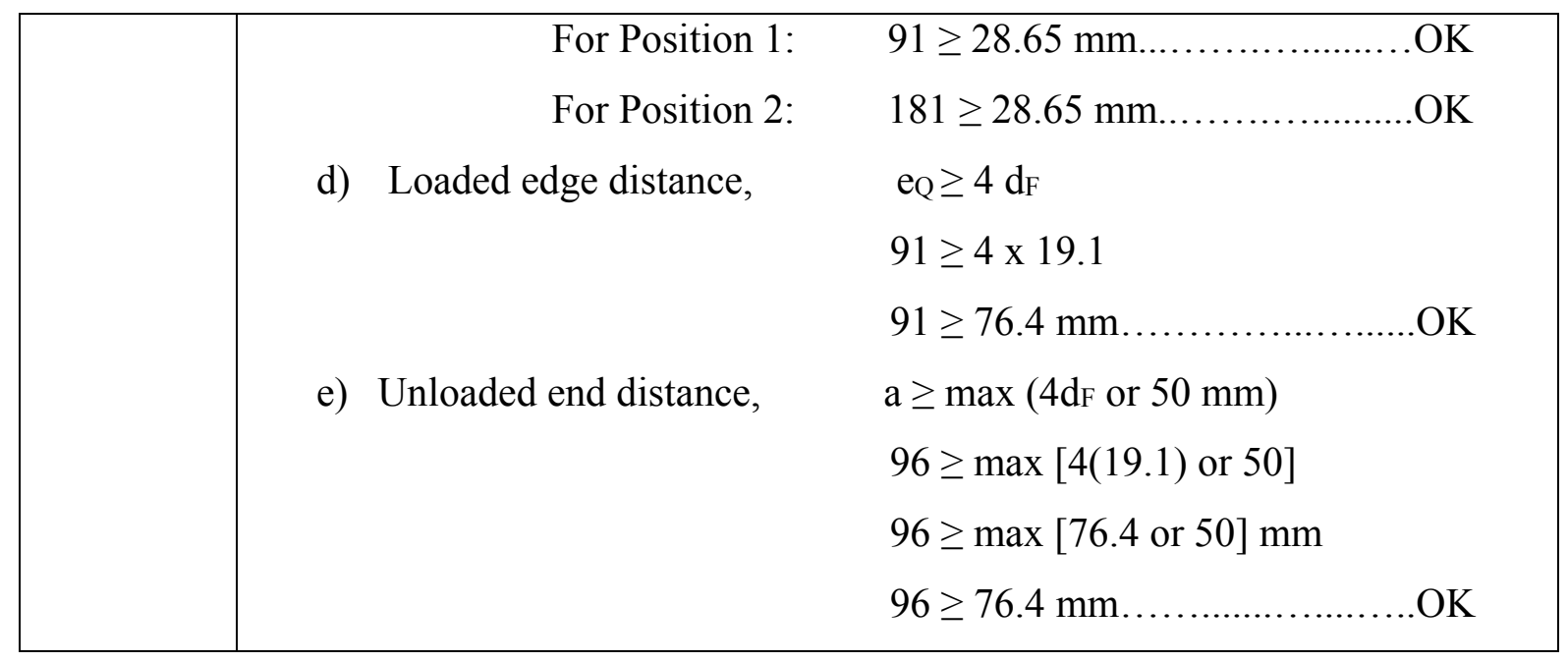

Therefore, all the minimum fasteners spacings for this bolt configurations satisfied the spacings requirements as per CAN/CSA O86-14 [60].

\subsubsection{Installation of Reinforcements}

Before each connection was assembled for testing, fully-threaded self-tapping screws (STS) were installed perpendicular-to-wood grain and parallel to the steel plate through most of the full depth of the beam section to strengthen the connection and prevent premature splitting failure. During the installation of the fully threaded long self-tapping screws, a hole for the self-tapping screws was pre-drilled to avoid either splitting of the timber or damage of the screw which could be caused by large frictional forces that were generated. The screw holes were pre-drilled with the aid of a $3 \mathrm{~mm}$ drill bit to about $280 \mathrm{~mm}$ depth to aid the precision of the screw positioning and to minimize the frictional forces, Figure 3.13(a) and (b). The number of reinforcements installed at the connection area of each specimen is based on the number of bolts. For connections with four (4) bolts, six (6) self-tapping screws were installed, while eight (8) screws were employed for connections with six (6) bolts. The reinforcement screws were installed from the top to the near bottom of each specimen at the location of the connection (Figure 3.13c). Each screw was concealed inside the centre of the wood side members and placed on a row of three or four on each side of the steel plate. At the face of the beam, each 
screw row was installed at the centre of the beam end and the first column of bolts; another between the centre of bolt columns 1 and 2, and the last screw was placed at a distance of 50 mm beyond bolt column 2 or 3 . In this study, the selection (i.e. size and length) and location of the screws were based on the approach used in research conducted by Petrycki and Salem $[21,65]$ to strengthen wood-steel-wood connections against brittle failure modes. The selftapping screws layout as installed around the connection area of the beam section for four-bolt and six-bolt connection configurations is shown in Figure 3.14.

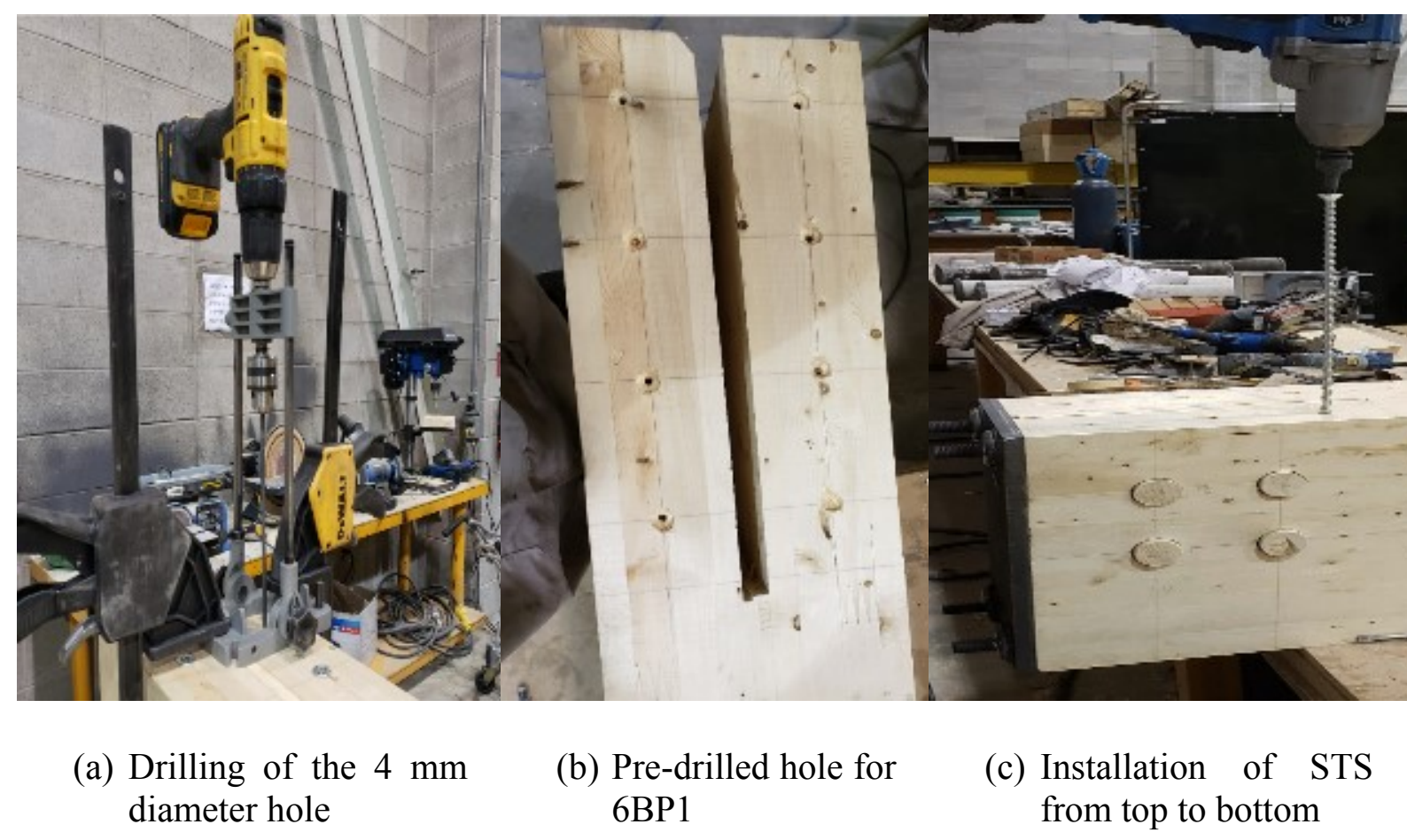

Figure 3.13 Fabrication process for self-tapping screws 


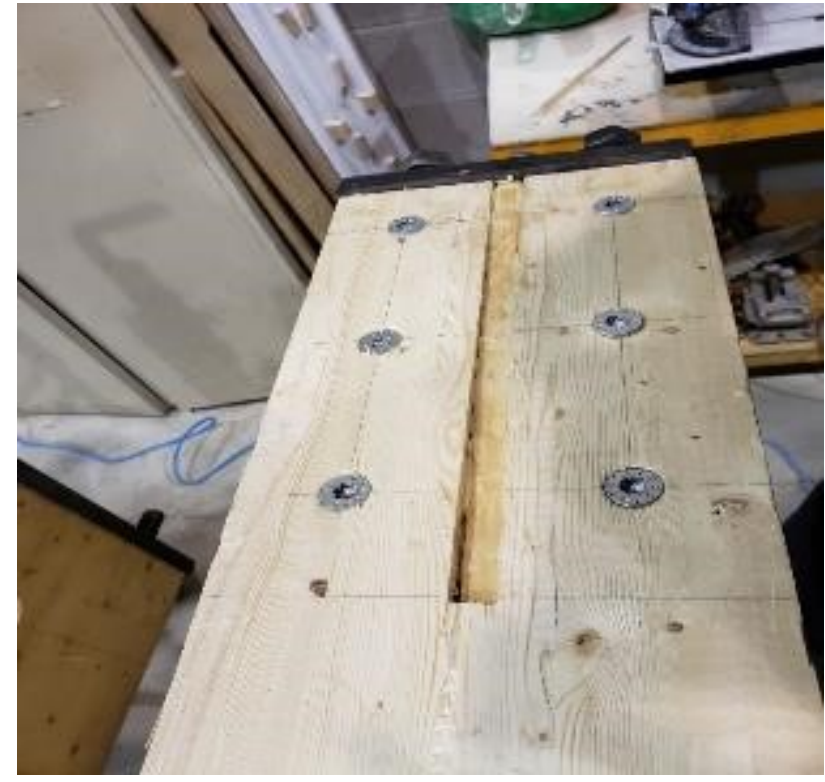

(a) Reinforced connection with four bolts

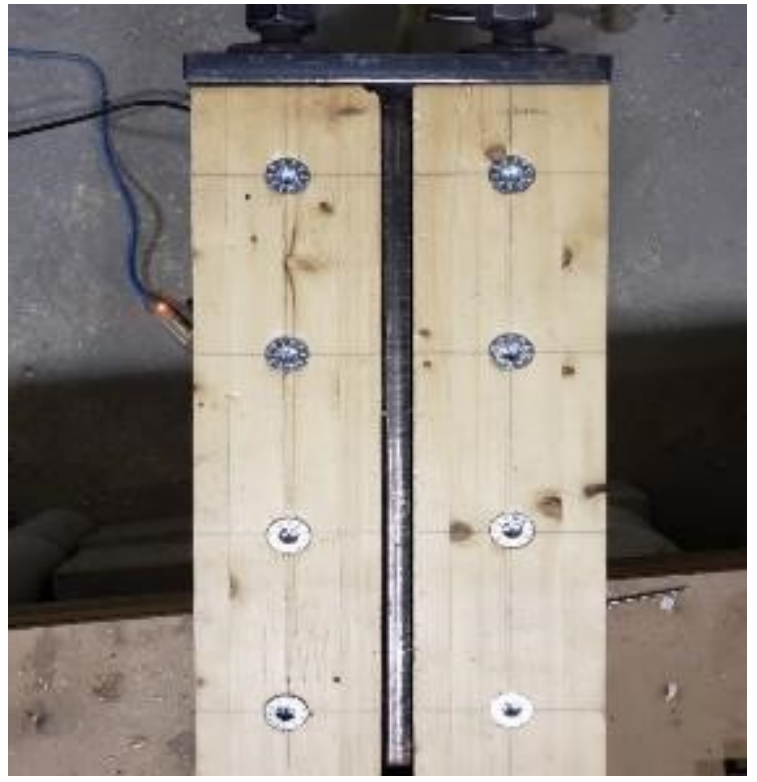

(b) Reinforced connection with six bolts

Figure 3.14 Reinforced four- and six-bolt connections

\subsubsection{Specimen Temperatures}

Temperature measurements were recorded surrounding the connection at both the front and back face of the beam section. For each specimen, twelve (12) metal-shielded K-type thermocouples (TC) were placed at different locations and depths inside the various components of the connection to measure the temperatures. The thermocouples were inserted in 1-mm diameter pre-drilled holes and were placed at depths of $20 \mathrm{~mm}, 30 \mathrm{~mm}, 40 \mathrm{~mm}, 60$ $\mathrm{mm}$, and $85.7 \mathrm{~mm}$ from the fire-exposed surface. Eight (8) thermocouples were placed at the front face of the beam, and four thermocouples from the beam back face, as shown in Figure 3.14. The location, as well as the depth at which each thermocouple was inserted inside the wood section, are also shown in the figure. At the beam front face; two thermocouples (TC 1 and TC 8 ) were installed at $30 \mathrm{~mm}$ depth to measure the temperatures at the bolt heads, another two thermocouples (TC 2 and TC 6) were employed at $85.7 \mathrm{~mm}$ depths to measure the steel plate temperature, TC 4 and TC 5 were used to obtain temperatures at $60 \mathrm{~mm}$ deep, 
thermocouples TC 3 and TC 10 were installed at $40 \mathrm{~mm}$ and $20 \mathrm{~mm}$ respectively to record the temperatures used for the calculation of the rate of advancement of char at the connection area. At the beam back face, TC 11 and TC 12 recorded the temperature near the bolt face with 20 mm wood cover; and thermocouples TC 7 and TC 9 were installed at $40 \mathrm{~mm}$ and $20 \mathrm{~mm}$, respectively to record the temperatures and to determine the progress of charring of the wood around the connection location. Figures 3.15 (a) and (b) illustrate the thermocouple layout for both the beam front face and beam back face, respectively.

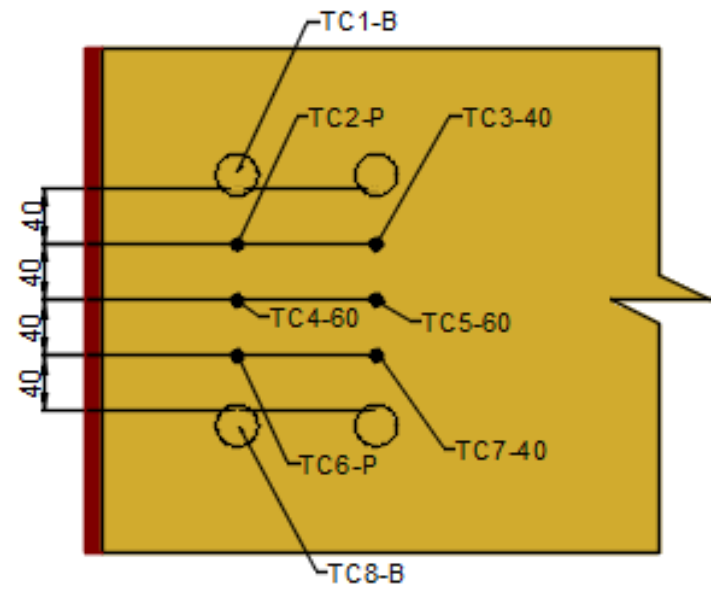

(a) Thermocouples layout at the beam front face

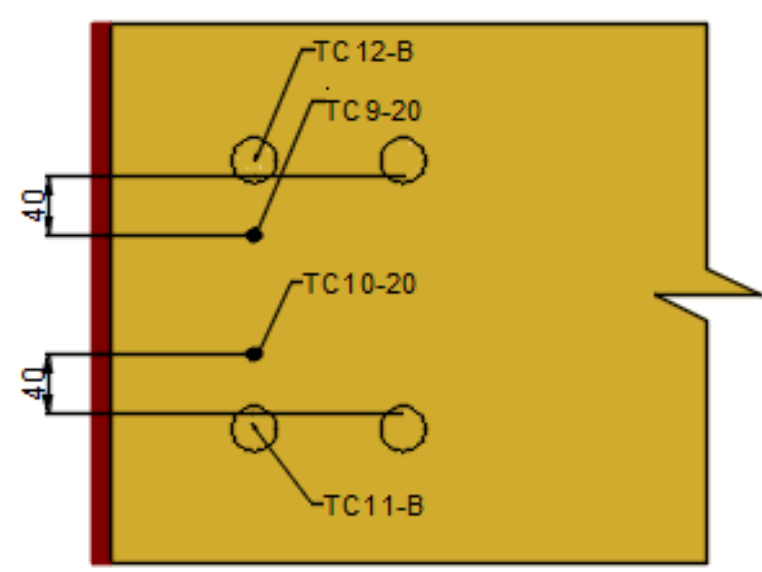

(b) Thermocouples layout at the beam back face

Figure 3.15 Typical thermocouples layout of the four-bolt pattern P1 connection

\subsubsection{Tests Set-up and Procedure}

For each test assembly, a T-stub steel connector was used to connect each glulam beam section to a supporting steel column at one beam end and a hydraulic cylinder supported by a steel frame which was mounted surrounding the furnace was used to apply a constant transverse load on the specimen at the free end of the beam at a distance of $1400 \mathrm{~mm}$ away from the beam support. Figure 3.16 shows the experimental set-up as well as the specimen inside the fireresistance test furnace. Each specimen was gradually pre-loaded in four increments of $25 \%$ to allow for stabilization of deflection after each increment. The tests were conducted in 
accordance with CAN/ULC S101-14 [26]. This standard prescribes the procedure for loading the specimen before, as well as during the test and the failure criteria. The test commenced 30 minutes after the full load was applied. During the test, the load level on the specimen was measured and maintained constant with the aid of a load cell and pump jack connected to the hydraulic cylinder. A LVDT installed outside the furnace was used to continuously measure the beam vertical displacement of the connection throughout the tests.

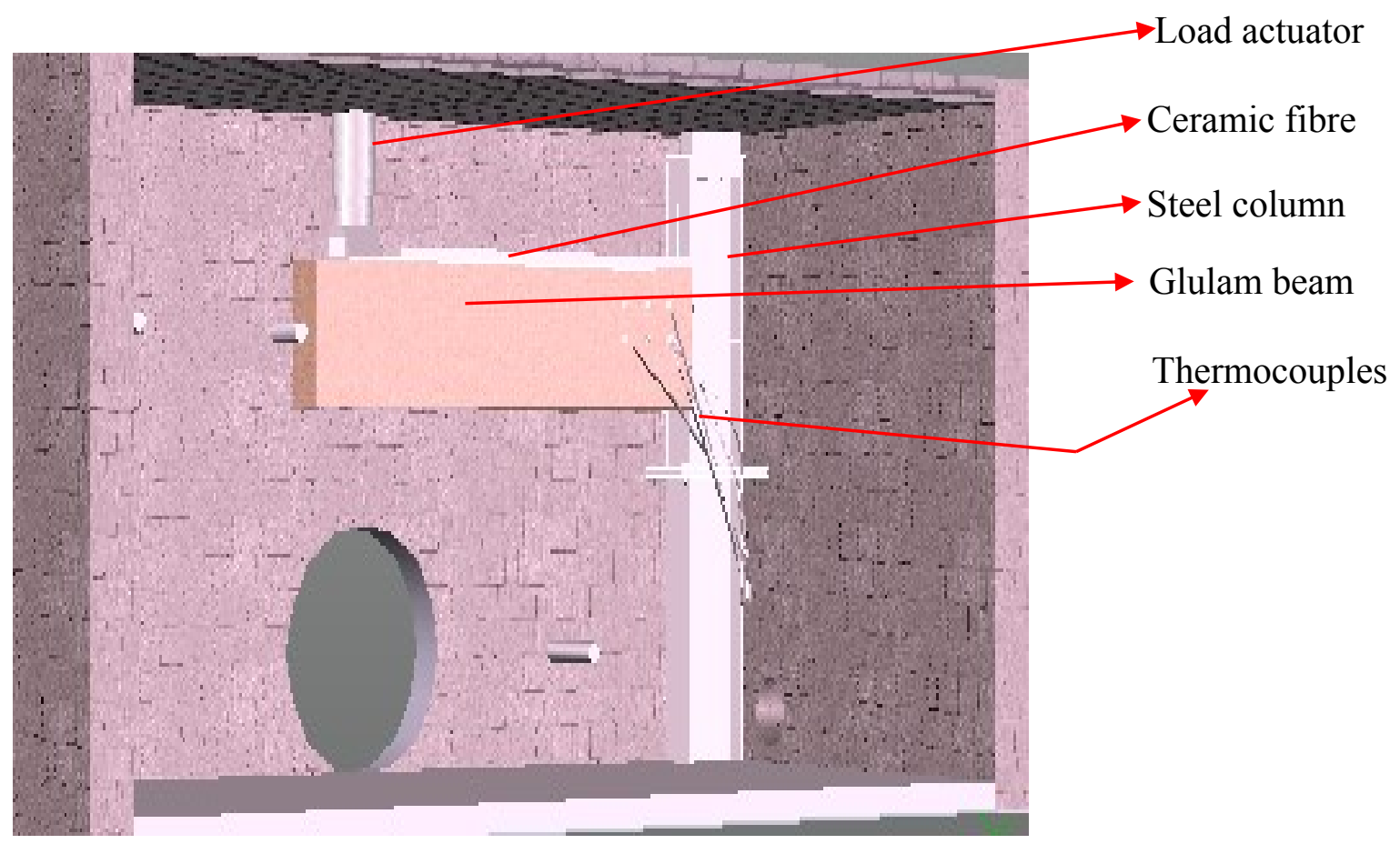

(a) Schematic view of the experimental set-up 


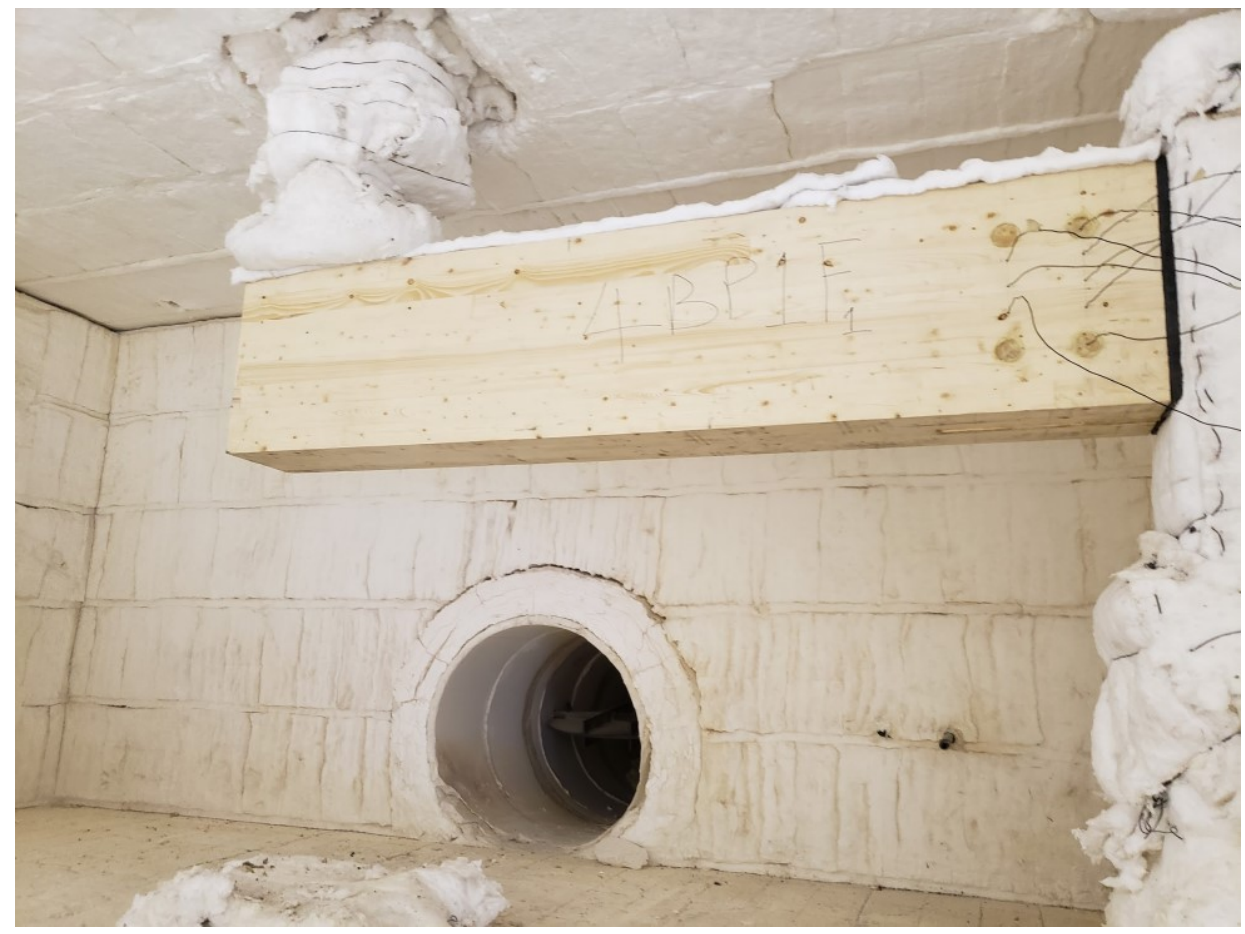

b) Experimental set-up

Figure 3.16 Experimental test set-up, and installed specimen inside the fire-testing furnace

In all the fire tests, the specimens were exposed to elevated temperatures that followed the CAN/ULC S101-14 [26] standard time-temperature curve on all sides except the top one simulating the existence of a slab on top of the beam. The top of the beam and the supporting steel column was protected from fire using a 1.0-inch thick ceramic-fibre blanket. Two of the test assemblies with different bolt patterns were loaded to $60 \%$ of the ultimate design load capacity of the weakest connection configuration, another four of the tests assemblies were loaded to $100 \%$, while the remaining two assemblies were loaded to $130 \%$ of the ultimate design load capacity of the weakest connection configuration. The failure criterion for the connections occurred when the beam-end deflection corresponds to the rotational limit of magnitude 0.1 radians. However, the tests continued beyond this point until the test assembly could not sustain the applied load and a significant load drop with no recovery was observed, at which point the test was terminated, and the cooling phase of the furnace commenced. The time to failure and the thermal measurements of each test specimen were recorded and the 
temperatures were used to determine the average charring rate of the wood at the connection location since there was a complete burnout of the beam during the cooling phase of the furnace.

\subsection{Load Ratio}

The load ratio is defined as the applied load in fire conditions divided by the ultimate loadcarrying capacity at ambient condition. Several researchers $[27,43,62]$ have reported that the amount of load applied on structural elements during a fire test has a significant influence on the fire resistance of the element (e.g. connections). Hence, an increase in the load level decreases the fire resistance of the connections. During a fire-resistance test, the load to be applied on the test specimen should be similar to the loads that would produce stresses in the test specimen in the event of a fire situation in the actual building [7]. In fire-resistance test, the Canadian timber design standard CSA O86 recommends a load level that is close to the factored resistance of the test specimen estimated in accordance with the timber design standard CAN/CSA O86-14 [60], to be applied on the specimen. Though, a lower load is also permitted by the standard provided such loads are described accurately and reported. Table 3.3 shows the decided load ratios. A 1 oad ratio of $100 \%$ of the ultimate design load of the weakest unreinforced connection, i.e., 4BP1 with no STS, was applied on four specimens consisting of four-and six-bolt connection configurations. Thereafter, two specimens with four bolts connection configurations (4BP1 and 4BP2) were subjected to a load ratio of $60 \%$ while the remaining two specimens with six-bolt connection configuration types (6BP1 and 6BP2) were subjected to a load ratio of $130 \%$. The load level was maintained constant during the test with the aid of a pump jack until the required failure criterion was met.

For consistency and comparison with results of fire tests of unreinforced connections conducted by Owusu et al. [22] in 2019, the reinforced specimens in this research were 
subjected to the same load (ultimate capacity) of the weakest unreinforced connection. Utilizing the same load in both cases gives a chance to assess the effect of the reinforcement in the fire tests. Therefore, based on the design calculation of unreinforced connection configuration with four bolts pattern $\mathrm{P} 1$, the specimens were loaded at $100 \%$ load ratio.

$$
\mathrm{QS}_{\mathrm{i}}=14 \mathrm{t} \sqrt{\frac{\mathrm{de}}{1-\frac{\mathrm{de}}{\mathrm{d}}}}=14 \times 85 \sqrt{\frac{271}{1-\frac{271}{362}}}=39.07 \mathrm{kN}
$$

$\mathrm{t}=85 \mathrm{~mm}$ (thickness of member)

de $=$ d-ep (effective depth)

where:

$\mathrm{d}=362$ (depth of member)

ep $=91$ (unloaded edge distance)

$$
\begin{gathered}
\mathrm{QS} r i=0.7 \times 39.07=27.35 \mathrm{kN} \\
\mathrm{QS} r T=\Sigma(\mathrm{QS} r i)=2 \times 27.35=54.7 \mathrm{kN}
\end{gathered}
$$

The moment arm which was $271 \mathrm{~mm}$ for all connections multiplied by the force acting along one axial direction was used to calculate the couple moment between the compression and tension zone [22].

$$
\mathrm{Mi}=\mathrm{QSrT} * \mathrm{~L}=54.7 * 271 * 10^{-6}=14.8 \mathrm{kNm}
$$




\section{RESULTS AND DISCUSSION}

\subsection{Introduction}

This chapter describes and discusses the test results of the eight beam-to-column concealed connections (with protection) subjected to constant transverse loading at elevated temperatures. The glulam beam end connections were loaded perpendicular-to-wood grain in bending, with load ratios of $60 \%, 100 \%$ and $130 \%$ exposed to the CAN/ULC-S101 [26] standard timetemperature curve. All the tested concealed connections satisfied CAN/CSA O86-14 [60] and the tests were conducted in accordance with CAN/ULC-S101 [26]. The effects of load ratios, self-tapping screws, number of bolts, and bolt patterns on the connection rotations and failure time are presented. Furthermore, the failure modes, charring rates, and time-temperature curves are presented and discussed.

\subsection{Loading}

The specimens were loaded to the full target load level for about 30 minutes before the burners were turned on to start the fire tests. The applied load was kept constant during the tests with the aid of a hydraulic cylinder connected to a manually controlled hydraulic pump. Figure 4.1 shows the measured load curves with respect to time for tests 4BP1LR60, 4BP2LR100 and 6BP1LR130 as examples. As previously stated in the experimental program section, the failure criterion for the connections was set to occur when the beam-end deflection corresponds with the rotational limit of magnitude 0.1 radians. However, the tests continued beyond this point until the test assembly could not sustain the applied load and a significant load drop with no recovery was observed. This is represented on the curves by a dramatic fall with no recovery. 


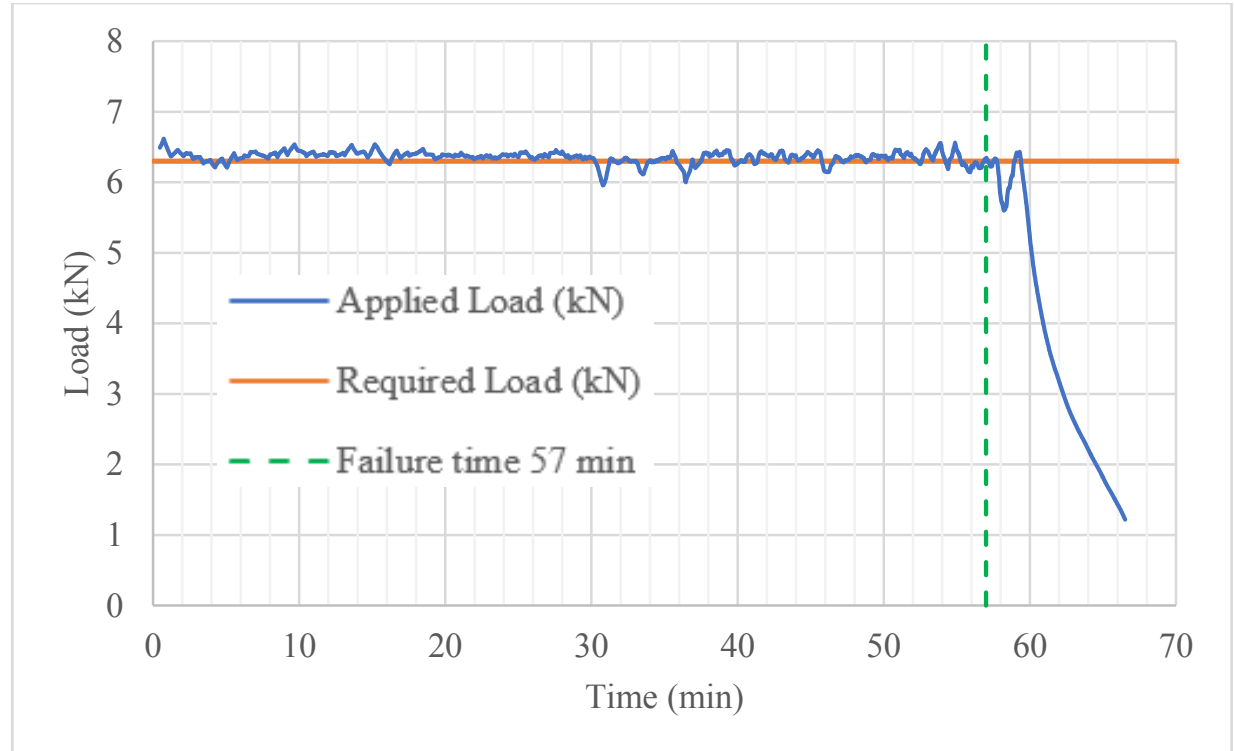

(a) Applied Load vs Time (60\% load ratio)

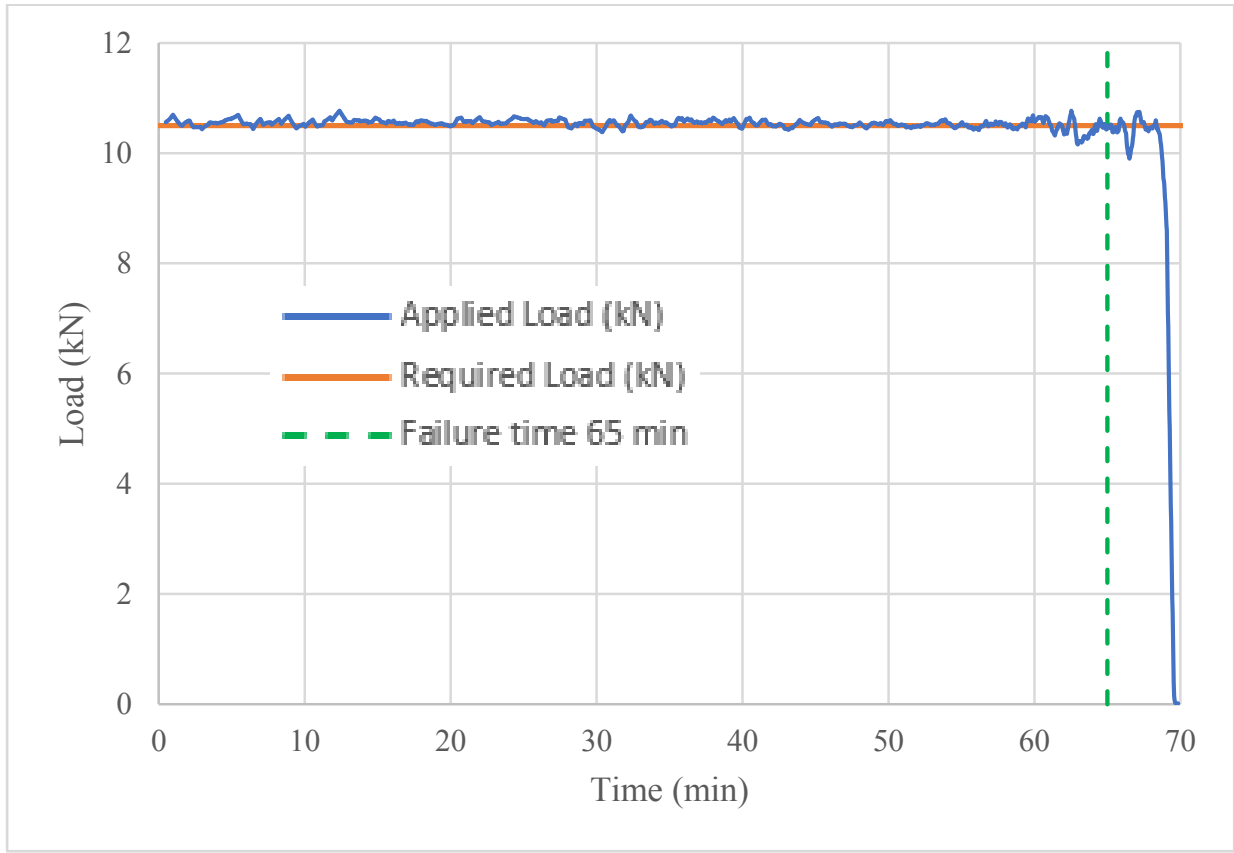

(b) Applied Load vs Time (100\% load ratio) 


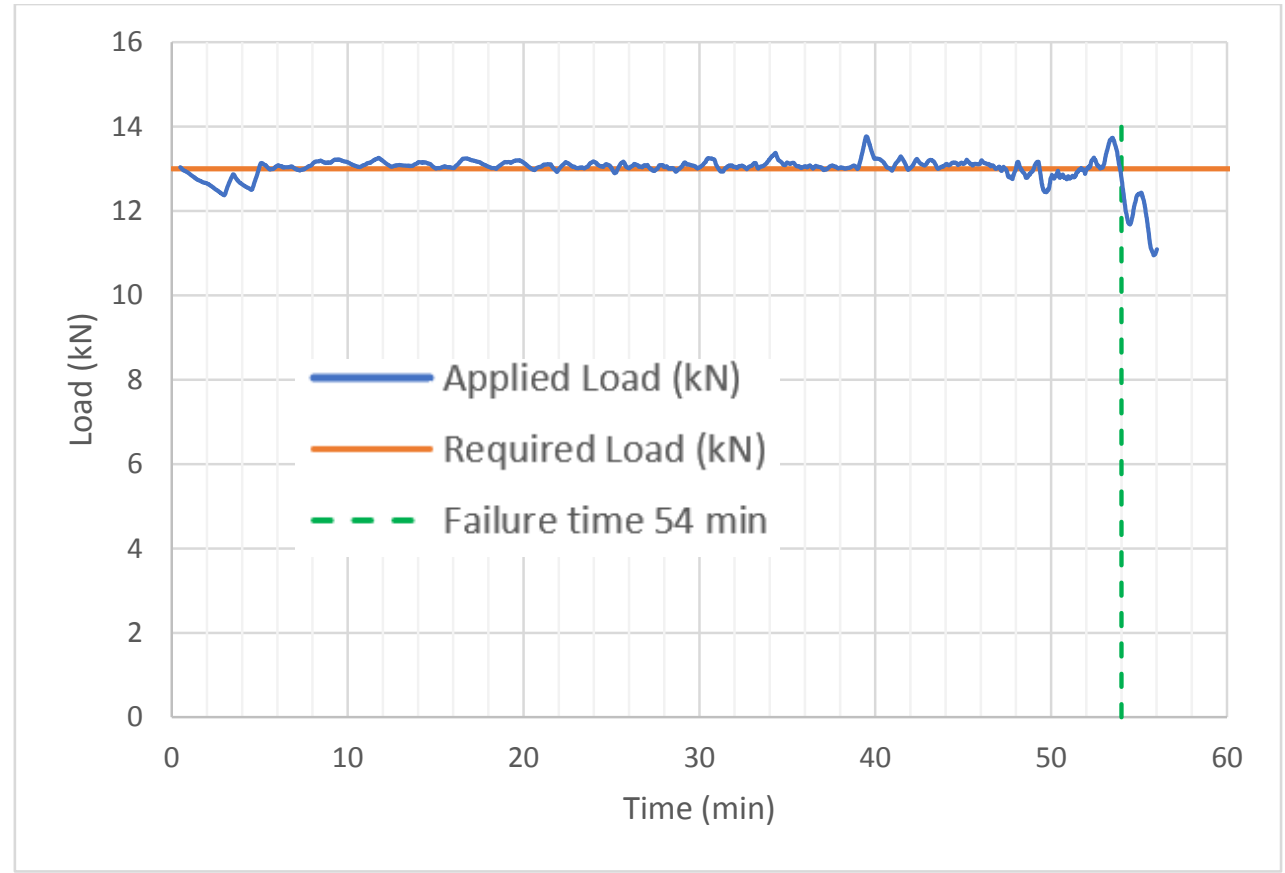

(c) Applied Load vs Time (130\% load ratio)

Figure 4.1 Graphs of required and applied load versus time

\subsection{Time-Temperature Curves}

Thermal measurements recorded from the twelve (12) metal-shielded K-type thermocouples installed at specific locations around the connection were used to plot the time-temperature curves as shown in Figure 4.2. Table 4.1 shows the depths at which the thermocouples were inserted into the wood section. As shown in Figure 4.2, at the early stage of all the tests, thermocouples TC 9 and TC 10 inserted at $20 \mathrm{~mm}$ depths from the fire exposed face of the beam records temperature of $100^{\circ} \mathrm{C}$ after about 5 minutes. As the temperature continues to increase from $100^{\circ} \mathrm{C}$, the moisture in the wooden cells starts to evaporate from the surface and as a result, at around $180^{\circ} \mathrm{C}$ to $200^{\circ} \mathrm{C}$ the wood starts to decompose and subsequently char at $300^{\circ} \mathrm{C}$ at about a range of $13-17$ minutes from the start of the test. In all tests, it is observed that the temperature of the steel plate (TC 2 and TC 6), as well as that of thermocouples TC 4 and TC 5 at a depth of $60 \mathrm{~mm}$, are below the $300^{\circ} \mathrm{C}$ char front. This indicates that the char layer 
depth of the beam section did not reach the $60 \mathrm{~mm}$ depth from the fire exposed surface and the steel plate did not contribute to the charring of the wood due to the $30-\mathrm{mm}$ glued-in wood plug protection. However, at about a range of 27-35 minutes, it was found that the bolt heads temperature has risen above $300^{\circ} \mathrm{C}$ which causes slight charring around the internal bolt holes. This leads to the elongation of the holes that further increases the connections' rotation. At about a range of 37-49 minutes, thermocouples TC 3 and TC 7 at a depth of $40-\mathrm{mm}$ from the beam face records temperature that corresponds with the wood's charring temperature and a few minutes after, the char layer progresses to the location of the reinforcements. At failure time, it can be seen that thermocouples TC 9 and TC 10 at a depth of $20 \mathrm{~mm}$ recorded temperatures close to the furnace temperature (about $940{ }^{\circ} \mathrm{C}$ ), and thermocouples TC 2 and TC 6 at the face of the steel plate measured temperatures below $250^{\circ} \mathrm{C}$. It should be noted that the decrease in the time-temperature curves after failure is due to the fact that the gas burners were turned off. This marks the beginning of the cooling phase of the furnace. At the end of the tests, it was observed that some of the thermocouples experienced a sudden decrease in temperature due to a shift in the wood plugs, which caused a better protection of the bolt heads and nuts. The shift in the wood plugs occurred as a result of the deflection of the beams. For instance, at about 25 minutes and 29 minutes, thermocouples TC 8 and TC 1 in Figure $4.2 \mathrm{a}$ experienced a decrease in temperature and later increased at 29-and 31 minutes, respectively. At 27 minutes and 25 minutes, TC 8 in Figure 4.2c and TC 1 in Figure 4.2d, respectively, experienced a decrease in temperature due a shift in the wood plug which better protected the bolt heads. Also, at 24 minutes and 17 minutes, thermocouples TC 12 and TC 8 in Figure $4.2 \mathrm{f}$ experienced similar decrease in temperatures, respectively. Figure 4.2 shows the time-temperature curves of the eight (8) test specimens. 
Table 4.1 Thermocouple depths and description

\begin{tabular}{|c|c|c|}
\hline Thermocouple number & Insertion depth & Description \\
\hline TC 1 & $30 \mathrm{~mm}$ & Bolt head \\
\hline TC 2 & $87.5 \mathrm{~mm}$ & Steel plate \\
\hline TC 3 & $40 \mathrm{~mm}$ & Specimen \\
\hline TC 4 & $60 \mathrm{~mm}$ & Specimen \\
\hline TC 5 & $60 \mathrm{~mm}$ & Steel plate \\
\hline TC 6 & $87.5 \mathrm{~mm}$ & Specimen \\
\hline TC 7 & $40 \mathrm{~mm}$ & Bolt head \\
\hline TC 8 & $30 \mathrm{~mm}$ & Specimen \\
\hline TC 9 & $20 \mathrm{~mm}$ & Specimen \\
\hline TC 10 & $20 \mathrm{~mm}$ & Bolt face \\
\hline TC 11 & $20 \mathrm{~mm}$ & Bolt face \\
\hline TC 12 & $20 \mathrm{~mm}$ & \\
\hline
\end{tabular}

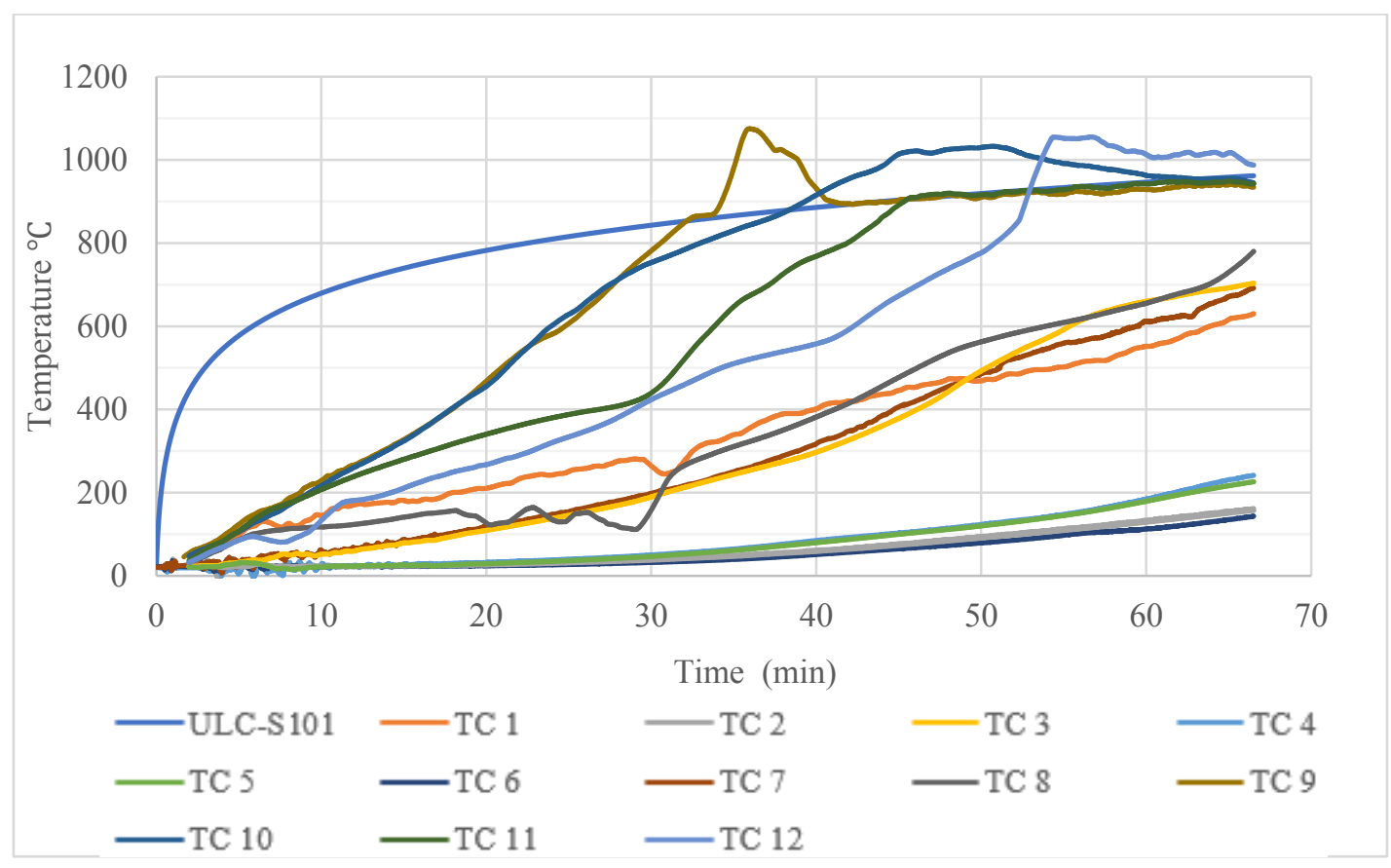

(a) Time-temperature curves for four-bolt pattern P1 connection subjected to $60 \%$ load ratio 


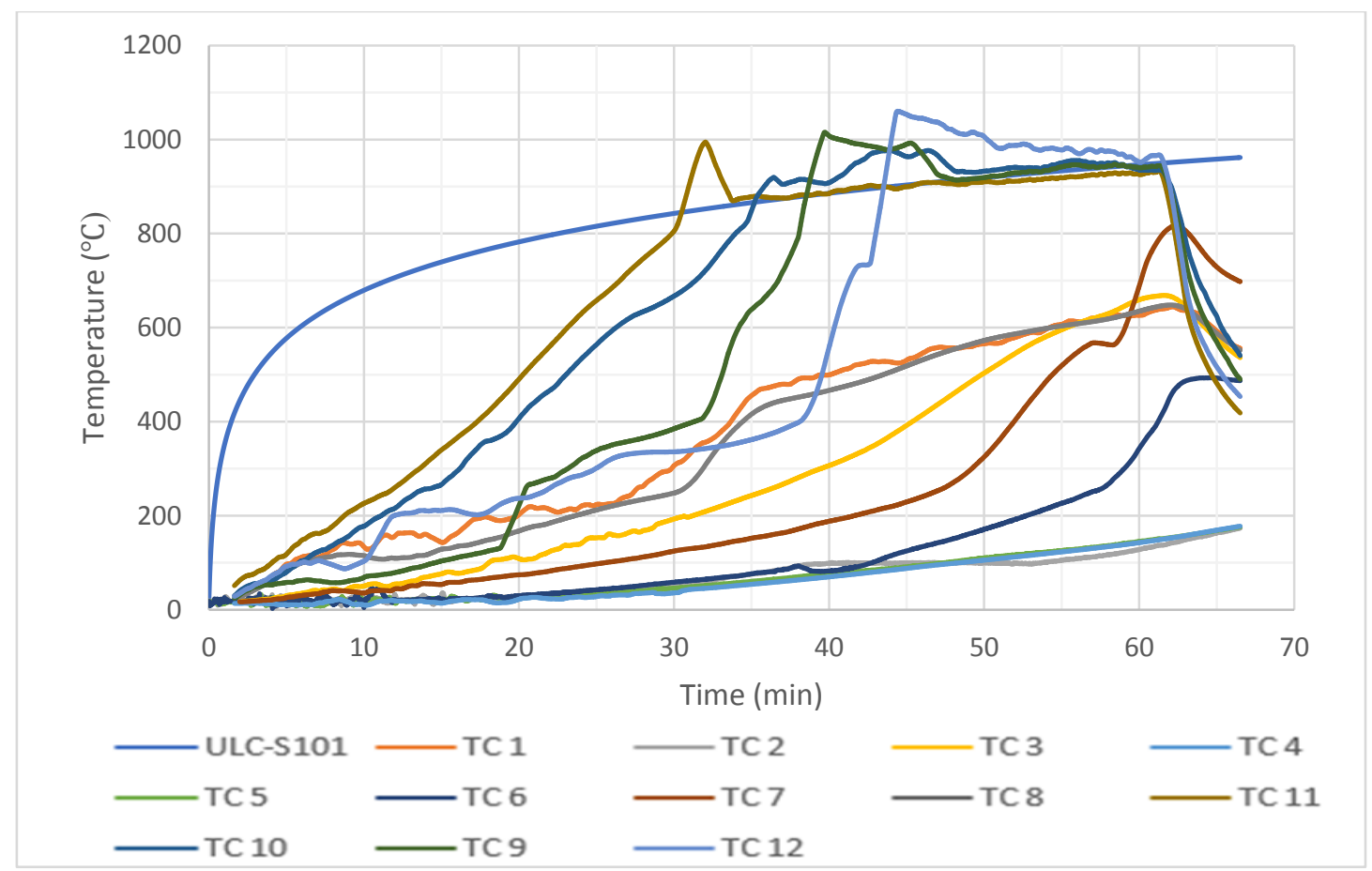

(b) Time-temperature curves for four-bolt pattern P2 connection subjected to $60 \%$ load ratio

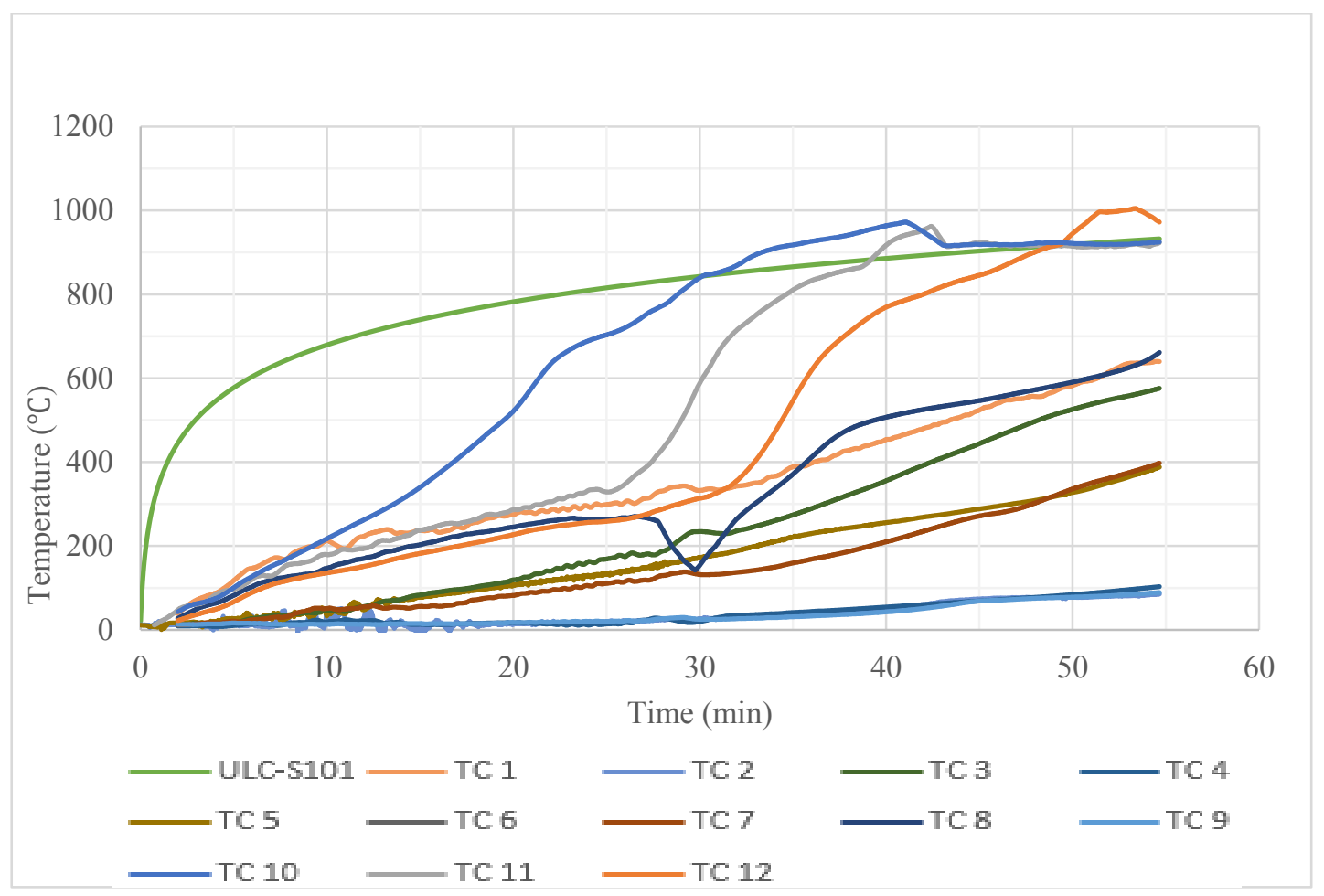

(c) Time-temperature curves for four-bolt pattern P1 connection subjected to $100 \%$ load ratio 


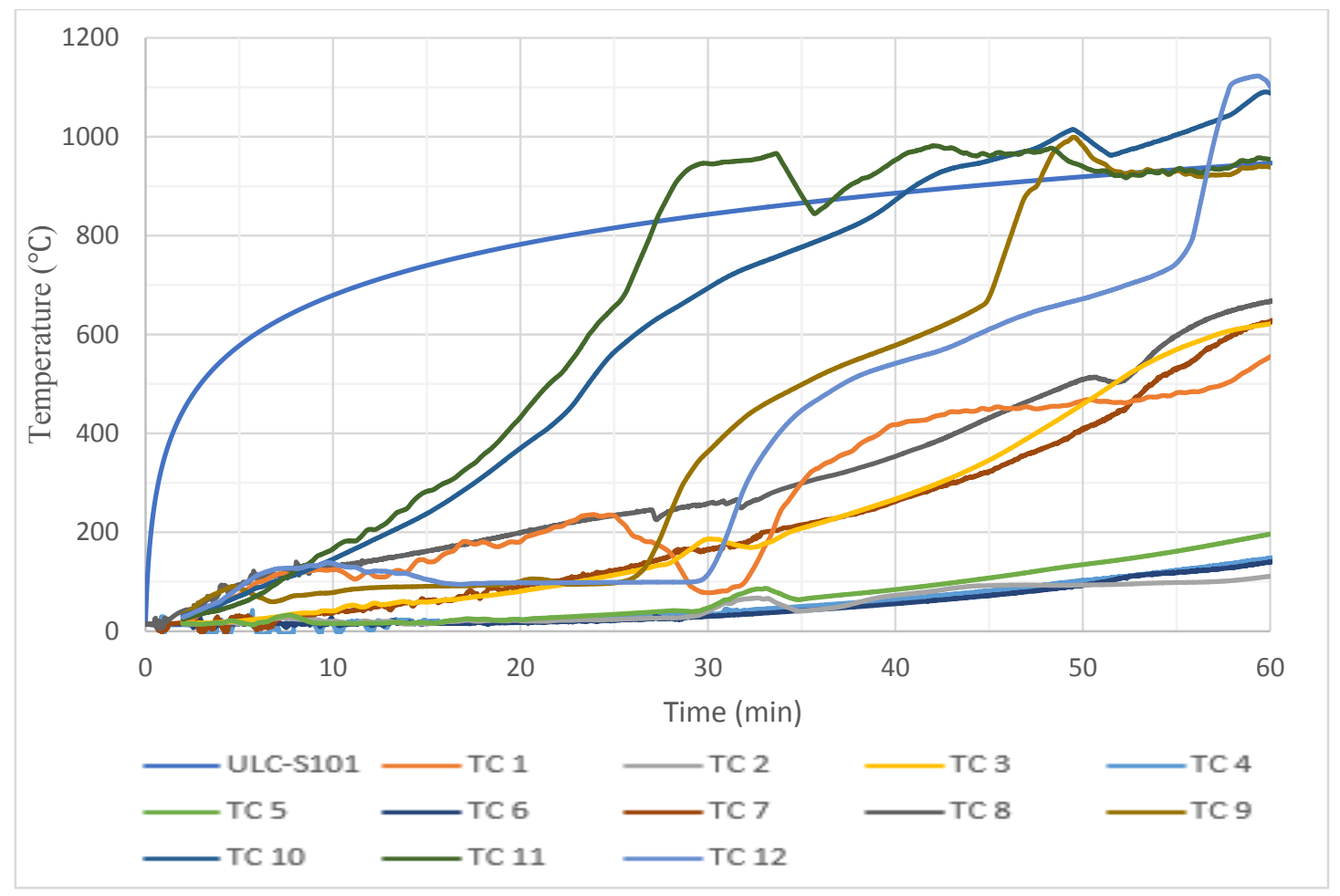

(d) Time-temperature curves for four-bolt pattern P2 connection subjected to $100 \%$ load ratio

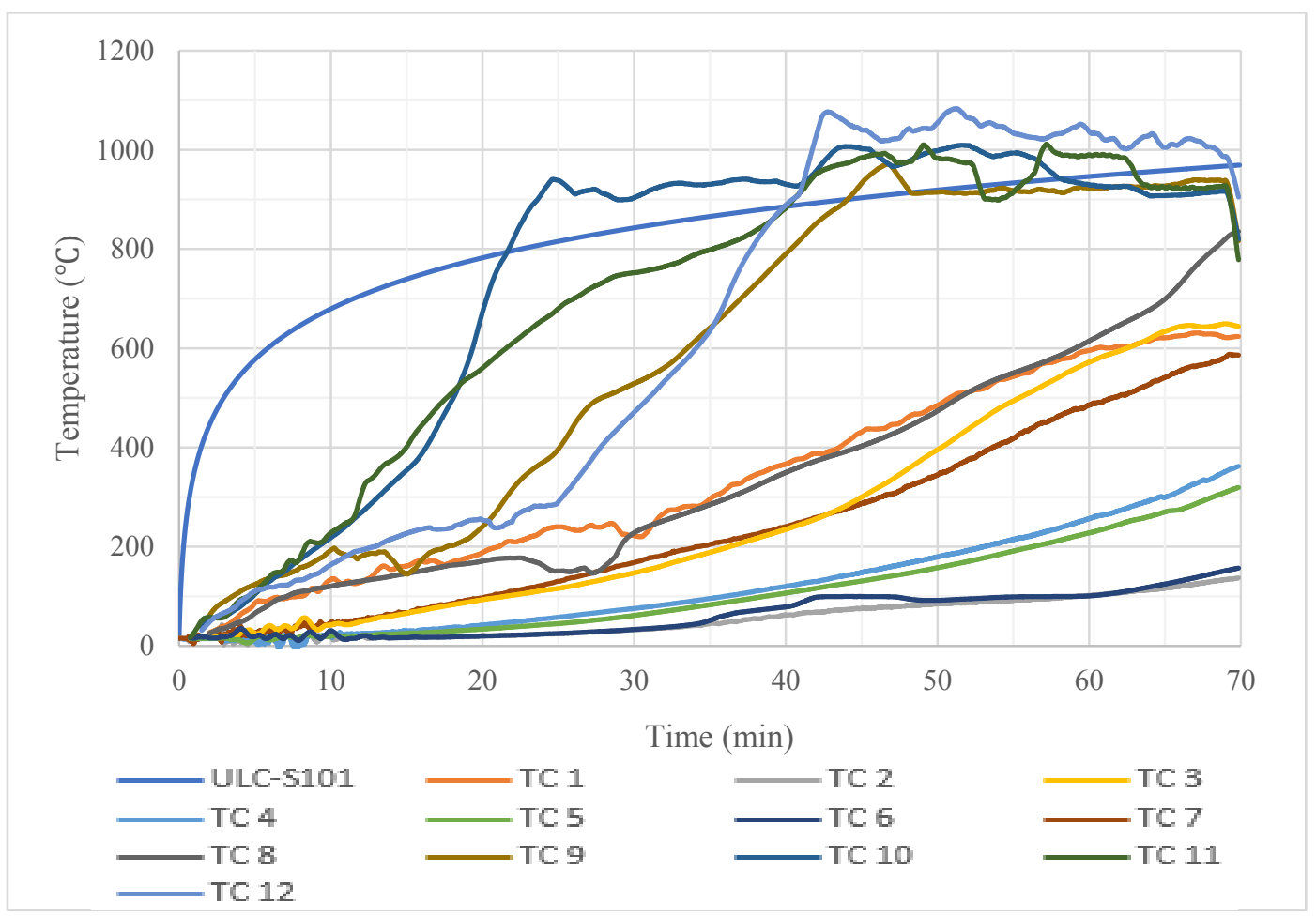

(e) Time-temperature curves for six-bolt pattern P1 connection subjected to $100 \%$ load ratio 


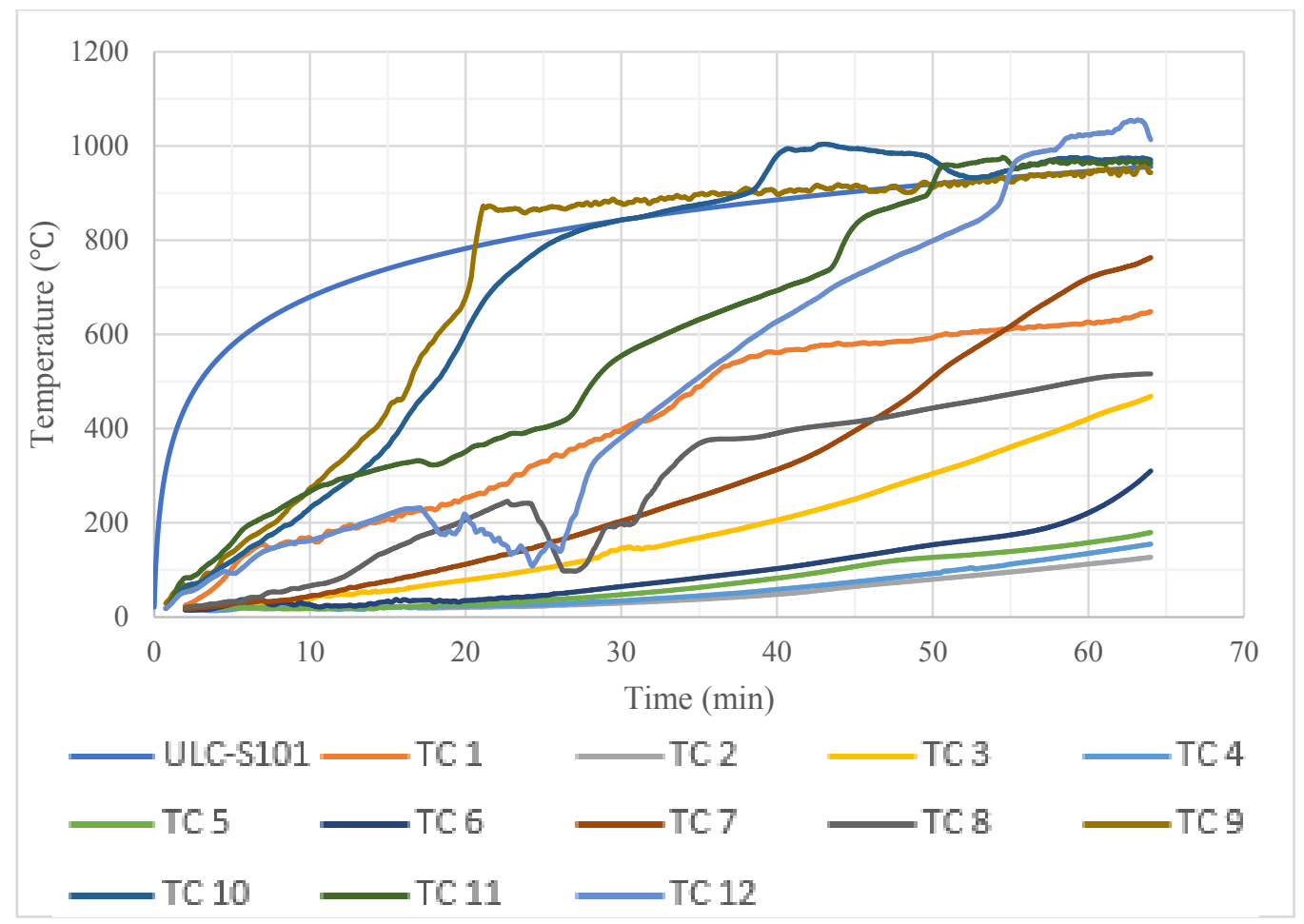

(f) Time-temperature curves for six-bolt pattern P2 connection subjected to $100 \%$ load ratio

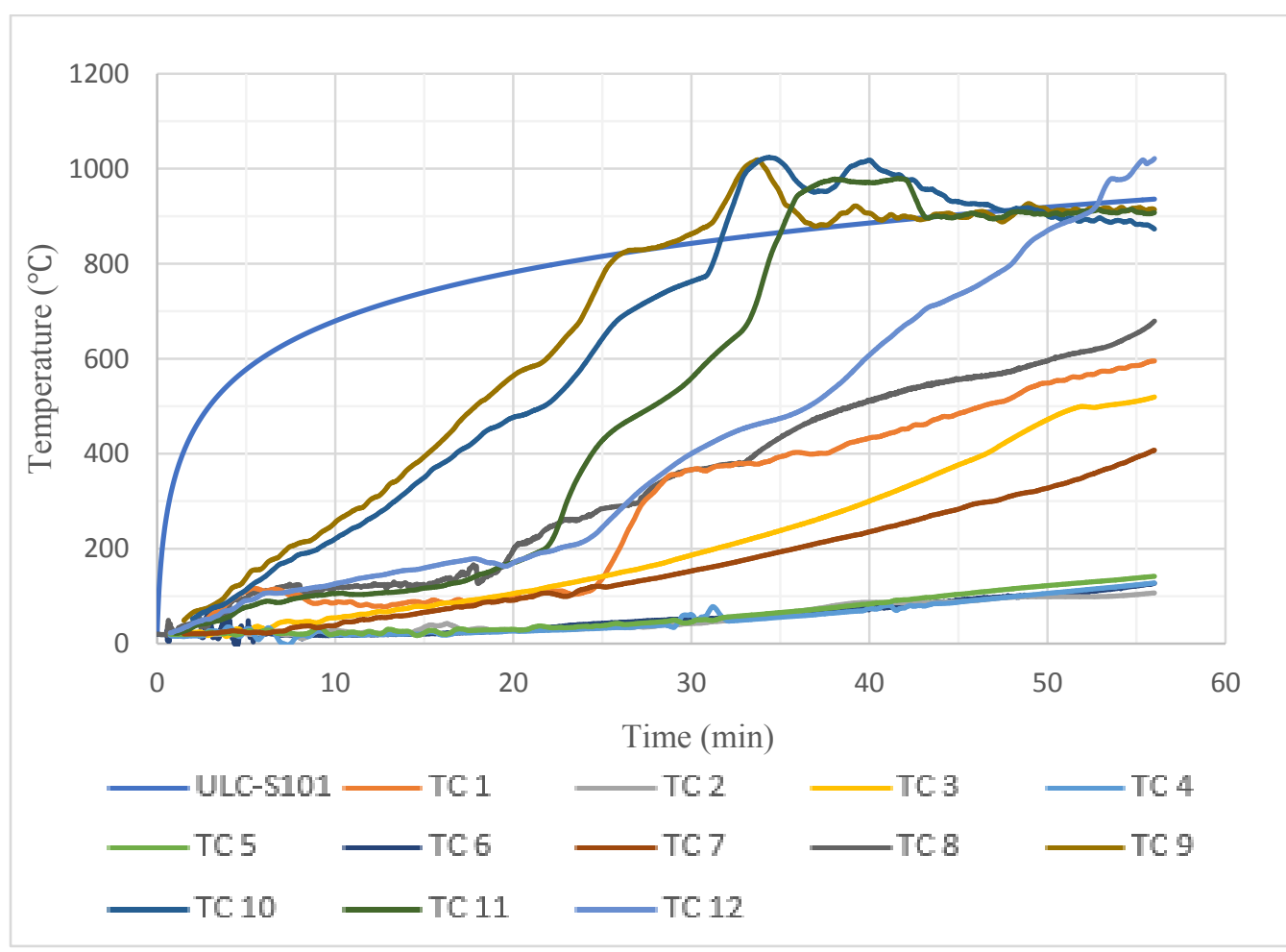

(g) Time-temperature curves for six-bolt pattern P1 connection subjected to $130 \%$ load ratio 


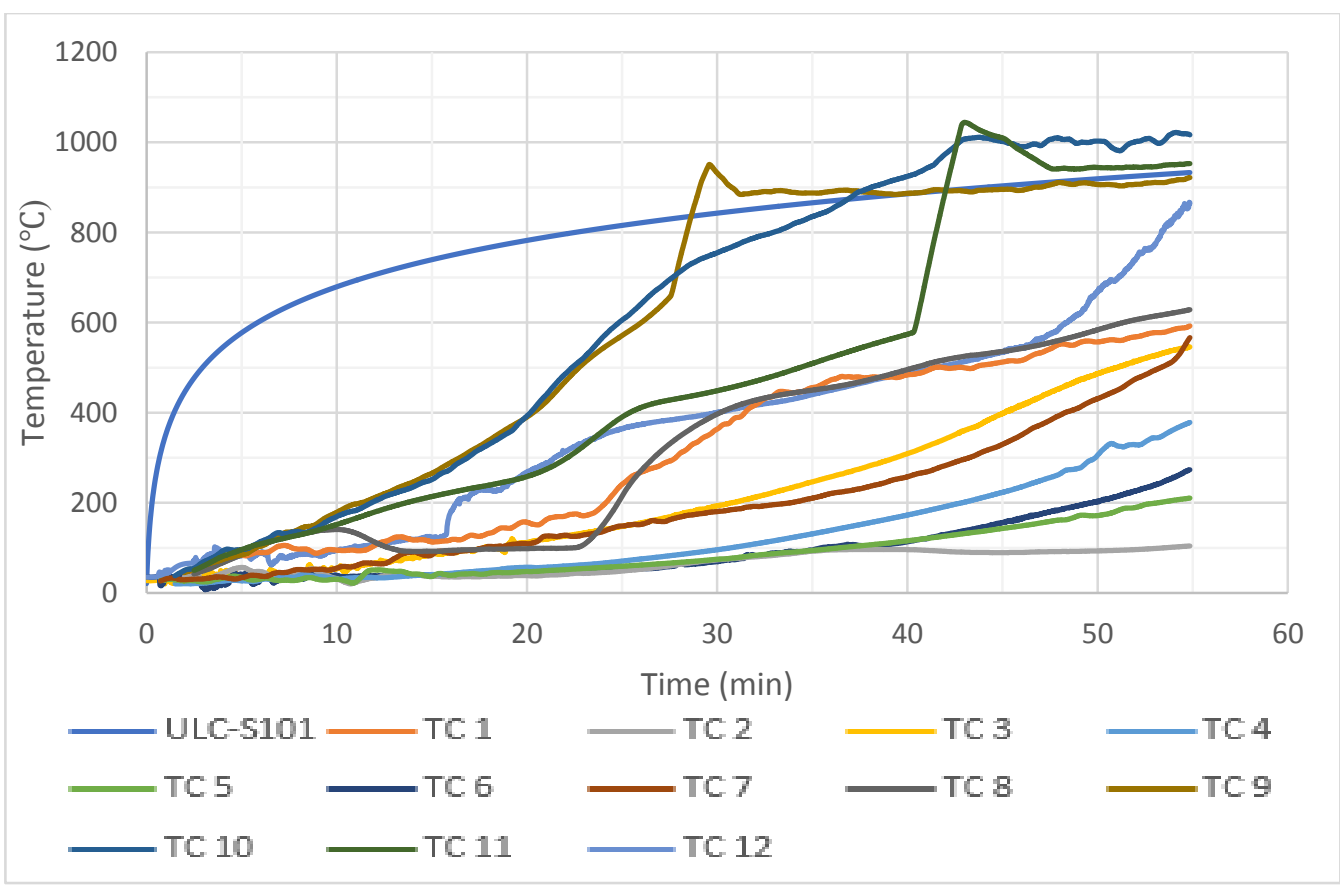

(h) Time-temperature curves for six-bolt pattern P2 connection subjected to $130 \%$ load ratio

Figure 4.2 Time-temperature curves for the eight (8) connections

\subsection{Charring Rates}

Charring rate is an important factor in the structural fire safety design for timber structures because the capacity and stability of the structure under fire condition depend largely on the uncharred residual section of the wood member. The charring rates for all the specimens were calculated from equation 4.1 using the thermal measurements recorded from the thermocouples during the tests. The char front for the specimens was defined by the $300^{\circ} \mathrm{C}$ isotherm, which implies that the charring rates of the connections were calculated from the times at which the temperatures of four thermocouples (TC 3, TC 7, TC 9 and TC 10) at different locations and depths reached $300^{\circ} \mathrm{C}$. The charring rates were calculated by dividing the depth of char by the time to reach $300^{\circ} \mathrm{C}$. This was the only method that could be used because the glulam beam sections were burnt out completely during the cooling phase of the furnace. The time- 
temperature curves and charring rate calculations are presented in Appendices B and C, respectively.

$$
\beta=C / t
$$

Where $\quad C$ is the depth of char front (mm)

$\beta$ is the rate of charring $(\mathrm{mm} / \mathrm{min})$

$t$ is the time difference for thermocouples at depths $20 \mathrm{~mm}$ and $40 \mathrm{~mm}$ to reach $300^{\circ} \mathrm{C}(\min )$.

The times to reach $300^{\circ} \mathrm{C}$ at the two fixed depths $(20 \mathrm{~mm}$, and $40 \mathrm{~mm})$ from the fire-exposed surface of the beam section were analysed to calculate the charring rate of the connections and the values are summarized in Table 4.2. It can be seen from Table 4.2 that the charring rate of the connections decreases with time. Also, the failure time of the connection decreases as the charring rate increases.

At the end of all tests, it was found that the protection of the metal components played an important role by delaying the wood inside from charring since thermocouples TC 2 and TC 6 at depth $85.7 \mathrm{~mm}$ recorded temperatures below the $300^{\circ} \mathrm{C}$ char front. At about a range of 2735 minutes into the tests, the wood around the bolts experienced slight charring due to heat transfer through the bolts, which led to the elongation of the bolt holes. The charring rates calculated in this research for the concealed wood-steel-wood connections are in good agreement with the charring rates reported by Peng et al. [11] and Ali [27].

Overall, it can be concluded that the behaviour of the connections in a fire depends largely on the charring rates, and as a result, there is a reduction of the failure time of the connections as the charring rate increases. 
Table 4.2 Charring rates ( $\mathrm{mm} / \mathrm{min}$ ) estimated for all eight connections tested in fire

\begin{tabular}{|c|c|c|c|c|c|c|}
\hline \multirow[t]{2}{*}{ Connection ID } & \multicolumn{2}{|c|}{$0-20 \mathrm{~mm}$} & \multicolumn{2}{|c|}{$20-40 \mathrm{~mm}$} & \multicolumn{2}{|c|}{$0-40 \mathrm{~mm}$} \\
\hline & TC 10 & TC 9 & TC $10 \&$ TC3 & TC 9 \& TC 7 & TC 3 & TC 7 \\
\hline 4BPILR60 & 1.54 & 1.55 & 0.76 & 0.77 & 1.02 & 1.03 \\
\hline Average & \multicolumn{2}{|c|}{1.55} & \multicolumn{2}{|c|}{0.77} & \multicolumn{2}{|c|}{1.03} \\
\hline 4BP2LR60 & 1.31 & 1.57 & 0.86 & 0.56 & 1.04 & 0.83 \\
\hline Average & \multicolumn{2}{|c|}{1.44} & \multicolumn{2}{|c|}{0.71} & \multicolumn{2}{|c|}{0.94} \\
\hline 4BPILR100 & - & 1.58 & - & 0.87 & 1.12 & 0.85 \\
\hline Average & \multicolumn{2}{|c|}{1.58} & \multicolumn{2}{|c|}{0.87} & \multicolumn{2}{|c|}{0.99} \\
\hline 4BP2LR100 & 1.21 & 1.32 & 0.80 & 0.72 & 0.97 & 0.93 \\
\hline Average & \multicolumn{2}{|c|}{1.27} & \multicolumn{2}{|c|}{0.76} & \multicolumn{2}{|c|}{0.95} \\
\hline 6BPILR100 & 1.62 & 0.96 & 0.62 & 0.79 & 0.9 & 0.87 \\
\hline Average & \multicolumn{2}{|c|}{1.29} & \multicolumn{2}{|c|}{0.71} & \multicolumn{2}{|c|}{0.89} \\
\hline 6BP2LR100 & 1.64 & 1.89 & 0.55 & 0.73 & 0.82 & 1.06 \\
\hline Average & \multicolumn{2}{|c|}{1.77} & \multicolumn{2}{|c|}{0.64} & \multicolumn{2}{|c|}{0.94} \\
\hline 6BPILR130 & 1.61 & 1.73 & 0.74 & 0.59 & 1.01 & 0.88 \\
\hline Average & \multicolumn{2}{|c|}{1.67} & \multicolumn{2}{|c|}{0.67} & \multicolumn{2}{|c|}{0.95} \\
\hline 6BP2LR130 & 1.23 & 1.30 & 0.85 & 0.73 & 1.01 & 0.93 \\
\hline Average & \multicolumn{2}{|c|}{1.28} & \multicolumn{2}{|c|}{0.79} & \multicolumn{2}{|c|}{0.97} \\
\hline
\end{tabular}

\subsection{Time to Failure in Fire}

The time to failure of the fire tests are summarized in Table 4.3. From the results, the failure time of all the connections tested exceeded 50 minutes, which is higher than the minimum fireresistance rating of 45 minutes specified in the current National Building code of Canada (NBCC) [9] for combustible construction. The connections were assumed to fail in deflection when the beam-end deflection corresponds to the connection rotational limit that was set to 0.1 radians. This failure occurred as a result of the charring of the beam section and around the bolt which caused an internal elongation in the bolt holes that further contribute to the rotation of 
the connections. It was observed that the connections reached the $0.1 \mathrm{rad}$ failure criterion 2 to 3 minutes before their loads drop dramatically without recovery.

It can be seen from Table 4.3 that loading the connections with a lower load ratio increased the failure time of the connections except for the four-bolt pattern $\mathrm{P} 2$ subjected to a $60 \%$ load ratio (4BP2LR60). This was due to an increase in the charring rate of the four-bolt pattern P2 connection loaded to a $60 \%$ load ratio. The disparity in the charring rates for connections 4BP2LR60 and 4BP2LR100 is as a result of many factors such as the difference in the wood's density, moisture content, harvest season and the severity of the fire during the tests.

At $60 \%$ load ratio, it was found that the connection with four-bolt pattern P1 had a failure time of 63 minutes which is 6 minutes (about 10.5\%) more than that of connection with four-bolt pattern P2. This implies that there is a considerable effect of the bolt pattern on the failure time of the connections. Furthermore, decreasing the load ratio from $100 \%$ to $60 \%$ in the four-bolt pattern P1 increased the failure time by 11 minutes (about $21.2 \%$ increase), while there was no effect of load ratio on the four-bolt pattern P2 due to the increased charring rate, Table 4.2.

When considering the effect of bolt pattern at $100 \%$ load ratio, it was noticed that in the fourbolt connections, bolt pattern P2 (4BP2LR100) showed a failure time of 57 minutes, which is slightly higher than the failure time of bolt pattern P1 (4BP1LR100) by 5 minutes (about 9.6\% increase). However, for the six-bolt connections, bolt pattern P1 with a failure time of 65 minutes performed better than bolt pattern P2 by 4 minutes (about $6.6 \%$ increase). The effect of increasing the number of bolts from four (4) to six (6) was seen to be significant in bolt pattern P1 than in bolt pattern P2. It can be seen from Table 4.1 that the six-bolt pattern P1 exhibited a failure time of 65 minutes which is significantly higher than the four-bolt pattern P1 by $25 \%$ (13 minutes), while in bolt pattern $\mathrm{P} 2$, the six-bolt pattern P2 with failure time of 61 minutes was slightly higher than the four-bolt pattern P2 by around 7\% (4 minutes). It is 
noteworthy to mention that the failure time of the six-bolt connections subjected to a $100 \%$ load ratio exceeded 60 minutes.

At a load ratio of $130 \%$, the effect of bolt pattern on the six-bolt connections was almost insignificant as the difference between the failure time of the bolt patterns is 2 minutes. When considering the effect of increasing the load ratio from $100 \%$ to $130 \%$ on the six-bolt connections, it was observed that the failure time of the six-bolt pattern P1 and P2 decreased by 11 minutes and 9 minutes, respectively. It can be concluded that increasing the load ratio on a connection reduces the failure time of the connection and this confirms the test results reported by Peng et al. [11], Ali [27] and Akotuah et al. [43]. Also, it should be noted that at all the load ratios, connections with bolt pattern P1 showed a higher failure time than bolt pattern P2 except at 100\% load ratio where four-bolt pattern P2 had a better failure time than four-bolt pattern P1 due to the high charring rate exhibited in four-bolt pattern P1.

The self-tapping screws were effective in significantly increasing the failure time of the fourbolt and six-bolt connections when compared with the failure time results reported by Owusu [22] on similar but unreinforced connections subjected to $100 \%$ load ratio. Owusu [22] reported a lesser failure time due to an earlier splitting failure that occurred at the glue-line of the wood members.

Table 4.3 Summary of test results

\begin{tabular}{|c|c|c|c|c|}
\hline $\begin{array}{c}\text { Connection } \\
\text { configuration }\end{array}$ & Load ratio (\%) & $\begin{array}{c}\text { Applied moment } \\
(\mathrm{kN.m})\end{array}$ & $\begin{array}{c}\text { Time to failure } \\
(\mathrm{min})\end{array}$ & Failure mode \\
\hline 4BP1LR60 & 60 & 8.9 & 63 & Deflection \\
\hline 4BP2LR60 & 60 & 8.9 & 57 & Deflection \\
\hline 4BP1LR100 & 100 & 14.8 & 52 & Deflection \\
\hline 4BP2LR100 & 100 & 14.8 & 57 & Deflection \\
\hline 6BP1LR100 & 100 & 14.8 & 65 & Deflection \\
\hline 6BP2LR100 & 100 & 14.8 & 61 & Deflection \\
\hline
\end{tabular}




\begin{tabular}{|l|l|l|l|l|}
\hline 6BP1LR130 & 130 & 19.3 & 54 & Deflection \\
\hline 6BP2LR130 & 130 & 19.3 & 52 & Deflection \\
\hline
\end{tabular}

\subsection{Connection Rotations}

The vertical displacements measured during the tests were used to calculate the rotation of the beam-to-column concealed connections and the time-rotation curves were plotted, as shown in Figures 4.3 through 4.16. The time-rotation curves show similar trends of increased rotation with time. At the early stage of the tests, all the connections' rotation curves remain constant at 0-rad for few minutes before exhibiting a linear increase in rotation values with time and thereafter, the curves rise significantly, then rapidly until structural failure occurred. At the early stages of the tests, the gradual decomposition of the wood material causes the glulam beam to lose material and strength to char and as a result, the rotation of the connection increases with time. As the test progresses, the wood material and its stiffness decrease due to temperature increase, causing a rapid increase in the rotation of the connections. During the tests, the applied load was kept constant until failure. At failure, the load dropped with no recovery, and this is reflected on the time-rotation curves by a plateau at the end of the tests. It is important to note that all the connections experienced a gradual failure.

\subsubsection{Effect of Bolt Pattern on the Connection Rotations with the Same Load Ratio.}

\subsubsection{Effect of Bolt Pattern on the Connection Rotations at 60\% Load Ratio}

Figure 4.3 shows the effect of bolt pattern on the connection's rotational behaviour of the fourbolt connection configuration types subjected to a $60 \%$ load ratio. Overall, the graphs show an upward trend in the rotational values of the connections with time, after which the rotation values remained linearly constant (or at a plateau) at the end of the tests. It is also noticed that both connections show a nearly similar time-rotation curve for the first 30 minutes of the tests. 
It was observed that the time-rotation curve for four-bolt pattern P1 (4BP1) remains constant at 0 -rad for about 8 minutes from the start of the fire test and subsequently, a slight linear increase is observed for about 33 minutes. At 44 minutes, the slope of the rotation curve increased due to the beam losing its section to char as thermocouples at $40 \mathrm{~mm}$ depths measured temperatures above $370^{\circ} \mathrm{C}$. The thermocouples TC1 and TC8 at the bolt heads had recorded temperatures above $430^{\circ} \mathrm{C}$, while thermocouples TC 11 and $\mathrm{TC} 12$ at the bolt nuts $(20 \mathrm{~mm}$ depths) had measured temperatures above $670^{\circ} \mathrm{C}$. The connection's rotation further increases significantly until the test assembly failed at $0.1 \mathrm{rad}$. Similar trends were noticed in the timerotation curve for the connection with the four-bolt pattern P2 (4BP2) except that the curve is constant for about 6 minutes and thereafter, the curve slightly increases in a linear trend for about 24 minutes. For the first 6 minutes of the test, thermocouples TC 1, TC 8, TC 9, TC 10 and TC 12 were observed to have recorded temperatures above $100^{\circ} \mathrm{C}$, while the remaining thermocouples measured temperatures below $100^{\circ} \mathrm{C}$. At 30 minutes into the test, the slope of the rotation curve increased and it was observed that thermocouples TC 3 and TC 7 at $40 \mathrm{~mm}$ depths measured temperatures below $200^{\circ} \mathrm{C}$, while thermocouples at the bolt heads and nuts had recorded temperatures above $300^{\circ} \mathrm{C}$. Thermocouple TC 3 measured a temperature of $306^{\circ} \mathrm{C}$ at 39 minutes, while thermocouple TC 7 recorded a temperature of $189^{\circ} \mathrm{C}$. At 49 minutes, thermocouples TC 7 measured a temperature of $324^{\circ} \mathrm{C}$, while other thermocouples at the bolt heads and nuts recorded temperatures above $500^{\circ} \mathrm{C}$. In summary, the rotational behaviour of the connection with the four-bolt pattern P1 (4BP1) is noticeably stiffer than that of the four-bolt pattern $\mathrm{P} 2$ (4BP2). As a result, the reduction in the rotation of the connection with four-bolt pattern P1 is significantly higher than the four-bolt pattern P2, thereby leading to an increase of 6 minutes in the time to failure of the connection with the four-bolt pattern P1. A plateau of the time-rotation curves is also observed after failure. 


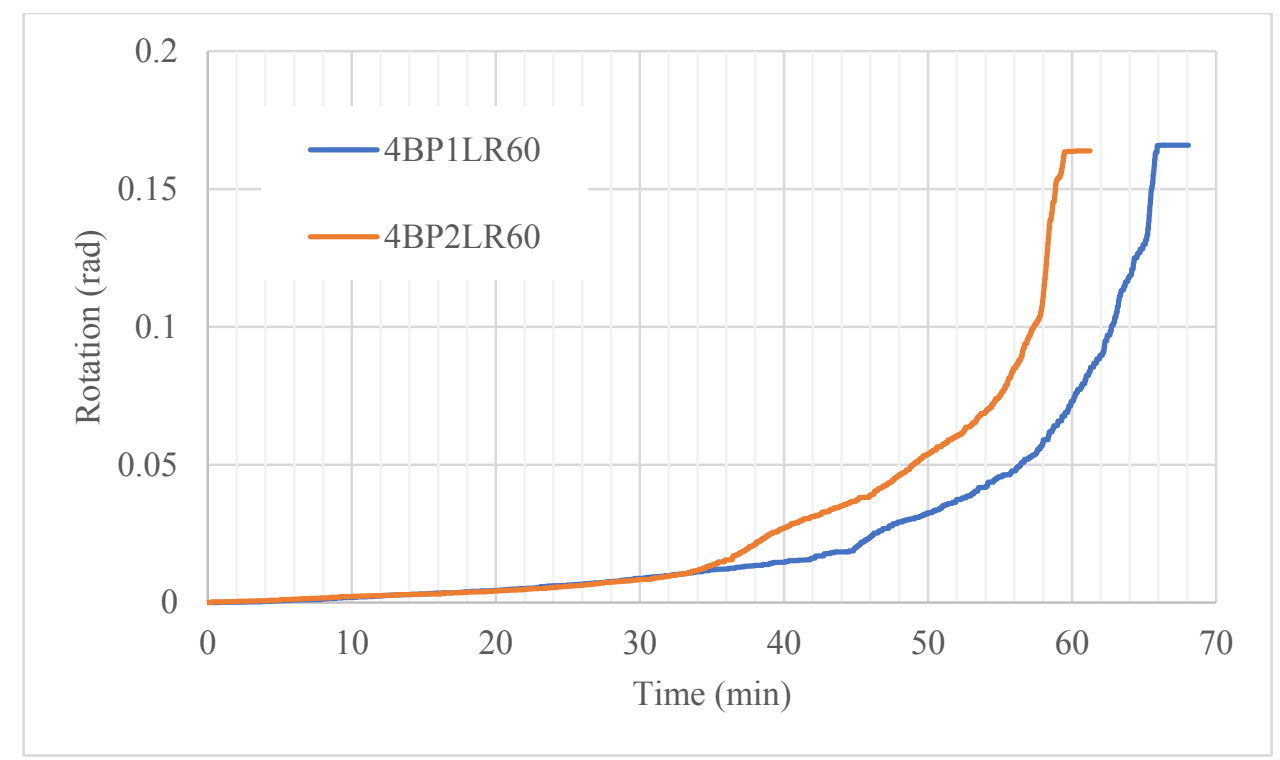

Figure 4.3 Time-rotation curves for four-bolt patterns P1 and P2 subjected to a $60 \%$ load ratio

\subsubsection{Effect of Bolt Pattern on the Connection Rotations at 100\% Load Ratio}

At a load ratio of $100 \%$, four connection configuration types were tested and examined. The connections were divided into two bolt patterns which consist of four bolts and six bolts. The effect of bolt pattern on the time-rotation curves of the four-bolt and six-bolt connection configuration types are shown in Figures 4.4 and 4.5, respectively. Generally, all four connection configuration types exhibited similar trend of increased rotations with time but at different time intervals. From the graphs, it is noticed that the bolt patterns for the four-bolt and six-bolt connections had almost the same difference of about 5 minutes in failure time.

For the four-bolt connections, a steady increase of the rotation is observed for both connections for about 30 minutes, however, the rotations of bolt pattern P1 increased significantly and exponentially than that of bolt pattern P2. As shown in Figure 4.4, the connection rotations for bolt pattern P1 increased faster than the rotations of bolt pattern P2. Therefore, the connection with bolt pattern P1 exhibited a time to failure of 5 minutes less than that of bolt pattern P2 connection. At about 32 minutes, the slope of the rotation curve of 4BP1LR100 connection 
increased and thermocouples TC 3 and TC 7 at $40 \mathrm{~mm}$ depths recorded $246^{\circ} \mathrm{C}$ and $143^{\circ} \mathrm{C}$, respectively. Thermocouples TC 1 and TC 8 measured temperatures of $363^{\circ} \mathrm{C}$ and $302^{\circ} \mathrm{C}$, respectively. At 44 minutes, thermocouple TC 7 had recorded a temperature of $271^{\circ} \mathrm{C}$ which causes a slight change in the slope of the rotation curve. For the four-bolt pattern P2 subjected to $100 \%$ load ratio, it was observed that at 30 minutes into the test thermocouples TC 1 , TC 3 , TC 7 and TC 12 recorded temperatures below $200^{\circ} \mathrm{C}$, while TC 8 measured temperature slightly above $250^{\circ} \mathrm{C}$. Thermocouples TC 1 and TC 8 at the bolt heads measured about $300^{\circ} \mathrm{C}$ at 34 minutes, while thermocouples at $40 \mathrm{~mm}$ depths measured temperature below $210^{\circ} \mathrm{C}$. At 46 minutes, all the thermocouples except the ones at $60 \mathrm{~mm}$ and $87.5 \mathrm{~mm}$ depths had measured temperatures above $300^{\circ} \mathrm{C}$.

Test results of similar tests conducted by Owusu [22] showed that the four-bolt pattern P1 of an unreinforced connection performed better than bolt pattern P2 due to the sudden splitting failure experienced in bolt pattern P2. Owusu [22] reported a gradual failure for the four-bolt pattern $\mathrm{P} 1$ connection which led to a failure time that was 8 minutes more than that of bolt pattern P2 connection.

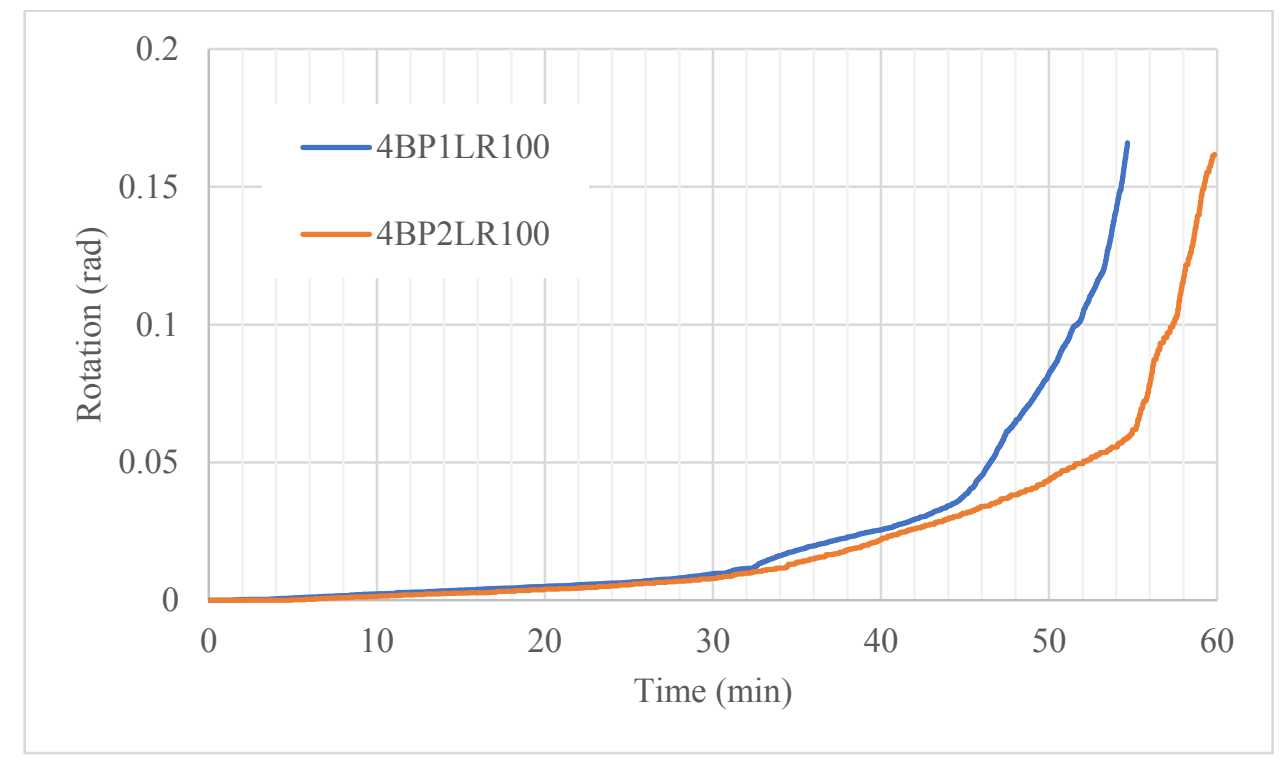

Figure 4.4 Time-rotation curves for four-bolt patterns P1 and P2 connections subjected to a $100 \%$ load ratio 
For the six-bolt connections, the effect of bolt pattern on the connection rotation is almost the same as the four-bolt connections having a difference of 4 minutes in the time to failure. The rotations of the connection configurations $6 \mathrm{BP} 1$ and $6 \mathrm{BP} 2$ are constant at 0 -rad for about 5 minutes before increasing linearly. The rotation of bolt pattern P1 connection increased linearly for about 27 minutes, and then significantly rose for about 23 minutes, while the rotations of bolt pattern P2 connection gradually increased for about 29 minutes and subsequently increased significantly for about 13 minutes. The rotations of bolt patterns P1 and P2 connections increased rapidly at 55 minutes and 50 minutes into the tests, respectively. Therefore, bolt pattern P1 connection performed better than bolt Pattern P2 connection (confirming the test results reported by Owusu [22]). At 44 minutes, a slope change was observed in the rotation curve of the 6BP1LR100 connection because the depth of the char layer is almost at the middistance of the wood-side member as thermocouples TC 3 and TC 7 at $40 \mathrm{~mm}$ depths recorded temperatures of $289^{\circ} \mathrm{C}$ and $277^{\circ} \mathrm{C}$, respectively, while other thermocouples measured temperatures above $300^{\circ} \mathrm{C}$ except for thermocouples at $60 \mathrm{~mm}$ depths and at $87.5 \mathrm{~mm}$ depths, which recorded temperatures below $300^{\circ} \mathrm{C}$. The time-rotation curve of the six-bolt pattern P2 experienced a change in slope at 32 minutes into the test, and it was observed that thermocouple TC 8 at the bolt head measured a temperature of $313^{\circ} \mathrm{C}$, while thermocouples TC 3 and TC 7 at $40 \mathrm{~mm}$ depths recorded temperatures below $250^{\circ} \mathrm{C}$. Thermocouples TC 1, TC 9, TC 10, TC 11 and TC 12 had measured temperatures above $300^{\circ} \mathrm{C}$. At 42 minutes, TC 7 and TC 3 recorded temperatures of $357^{\circ} \mathrm{C}$ and $231^{\circ} \mathrm{C}$, respectively. 


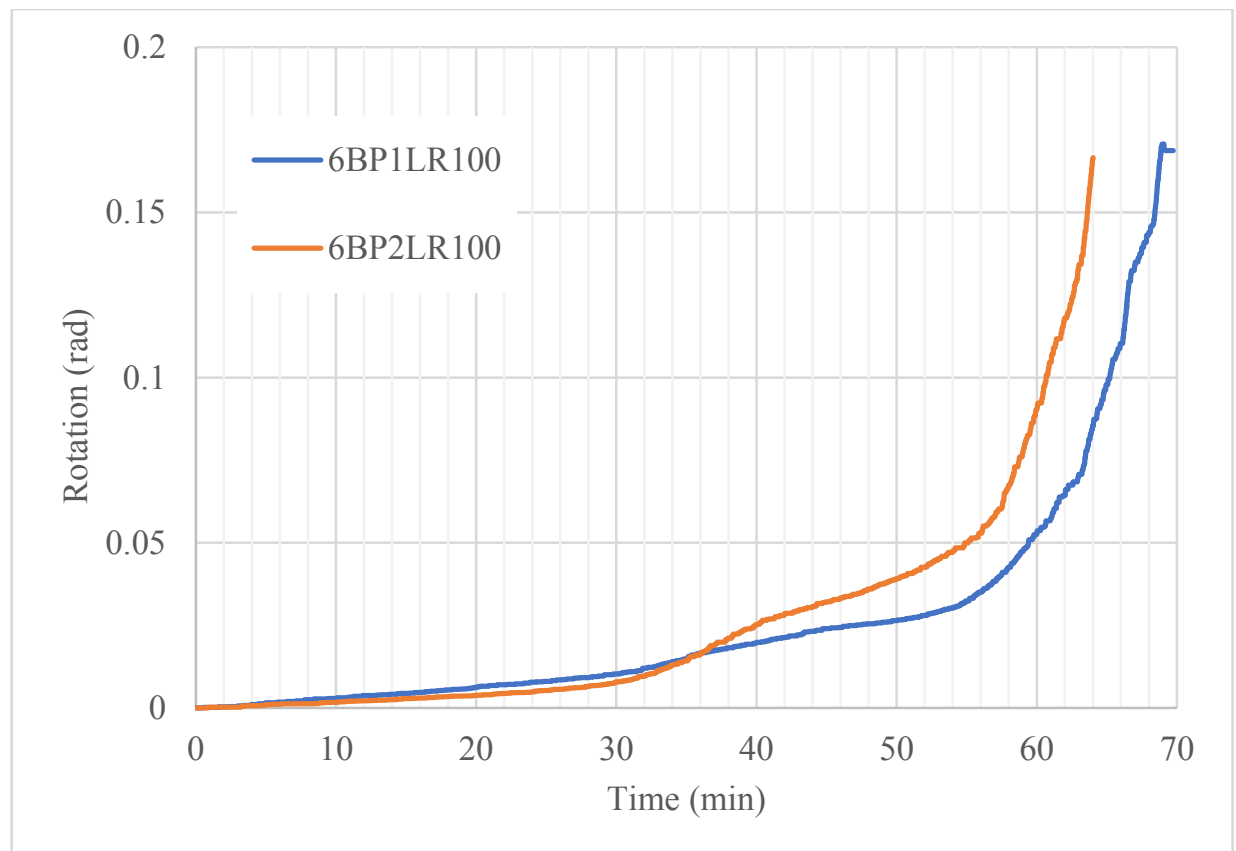

Figure 4.5 Time-rotation curves for six-bolt patterns P1 and P2 connections subjected to a $100 \%$ load ratio

As indicated in Figures 4.4 and 4.5, there is a significant effect of the bolt pattern on both connections with four bolts and six bolts. The effect is almost the same for both the four- and the six-bolt connections. However, the six-bolt connections appeared to be stiffer than the fourbolt connections leading to a reduction in the connections' rotation. This increased the failure time of the six-bolt connections in fire condition.

\subsubsection{Effect of Bolt Pattern on the Connection Rotations at $130 \%$ Load Ratio}

Figure 4.6 shows the effect of the bolt pattern for the six-bolt connection configuration types with a load ratio of $130 \%$ on the connection rotations. As shown in Figure 4.6, the time-rotation curve of bolt pattern $\mathrm{P} 2$ connection had a greater slope than that of bolt pattern P1 connection. The rotations of the two connections were constant for the first 5 minutes, after which the connection with pattern $\mathrm{P} 2$ rotated faster than pattern $\mathrm{P} 1$ connection. Thereafter, it is observed that the rotations of the connection with bolt pattern P1 gradually increased for about 33 
minutes, and after that significantly increased for about 7 minutes before it rapidly failed at 0.1 rad. While the six-bolt pattern P2 connection experienced a similar trend but with lesser time intervals. This leads to a reduction in time to failure for $6 \mathrm{BP} 2$ connection, which is 2 minutes lesser than that of 6BP1 connection. No significant difference in failure time was observed between the two connection configurations. For the six-bolt pattern P1 subjected to $130 \%$ load ratio, a change in the slope of the rotation curve was observed at 22 minutes and it was found that thermocouples TC 11 and TC 8 had measured temperatures close to $250^{\circ} \mathrm{C}$. Thermocouples TC 9 and TC 10 had measured temperatures above $500^{\circ} \mathrm{C}$, while the remaining thermocouples recorded temperatures below $200^{\circ} \mathrm{C}$. At 39 minutes, the char layer had proceeded to almost $40 \mathrm{~mm}$ depth from the fire exposed face as thermocouples TC 3 and TC 7 measured temperatures of $290^{\circ} \mathrm{C}$ and $233^{\circ} \mathrm{C}$, respectively. At 20 minutes into the test of sixbolt pattern P2 connection, it was found that thermocouples TC 11 and Tc 12 had measured temperatures close $300^{\circ} \mathrm{C}$, while TC 1 , TC 3, TC 7 and TC 8 recorded temperatures below $150^{\circ} \mathrm{C}$. A slope change was observed in the rotation curve at 29 minutes and it was observed that all the thermocouples at the bolt heads and nuts had measured temperatures above $300^{\circ} \mathrm{C}$, while thermocouples at $40 \mathrm{~mm}$ depths recorded temperatures below $200^{\circ} \mathrm{C}$. At 44 minutes, thermocouples TC 3 and TC 7 at $40 \mathrm{~mm}$ depths measured temperatures above $300^{\circ} \mathrm{C}$. 


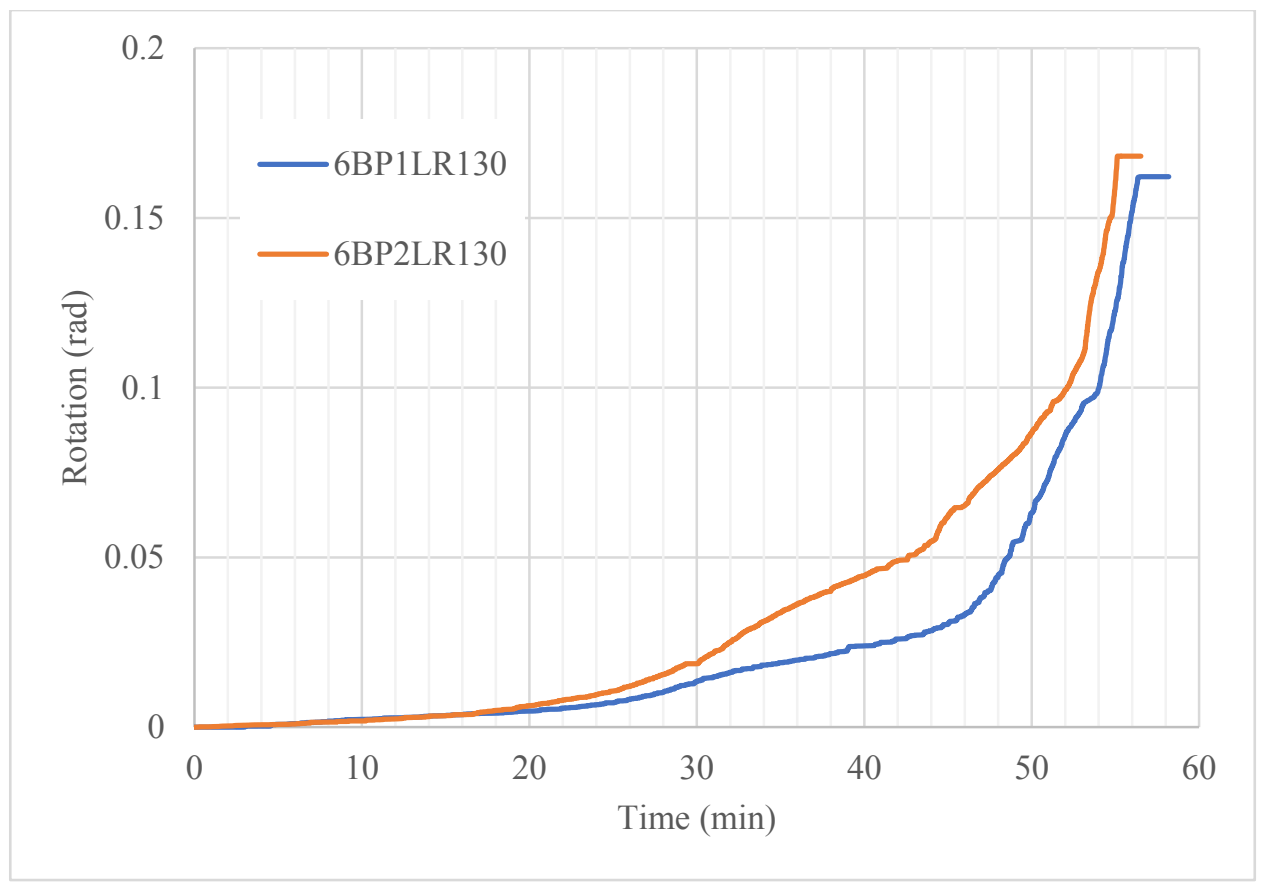

Figure 4.6 Time-rotation curves for six-bolt patterns P1 and P2 connections subjected to a $130 \%$ load ratio

Overall, for all the load ratios, it is observed that bolt pattern P1 connection exhibited lower rotations than that of bolt pattern P2 connections, except at a $100 \%$ load ratio in which fourbolt pattern P1 connection had a higher charring rate. This resulted in better performance in terms of failure time for bolt pattern P1 connection in fire condition.

\subsubsection{Effect of the Number of Bolts on the Connection Rotations}

The effect of increasing the number of bolts from four (4) to six (6) is considered for only the connections loaded at 100\% load ratio. As it can be seen in Figures 4.7 and 4.8, the six-bolt connections perform better in terms of rotations and failure time than that of the four-bolt connections.

For bolt pattern P1 connection, increasing the number of bolts from four (4) to six (6) increased the time to failure by $25 \%$. Figure 4.7 shows that both connection configurations exhibited 
similar trend of increased rotations for about 32 minutes, after which the four-bolt connection underwent a significant increase in rotations for about 12 minutes and then rapidly increased to failure at $0.1 \mathrm{rad}$. On the other hand, the six-bolt connection rotation gradually increased linearly for about 32 minutes and thereafter, gently increased for about 23 minutes before increasing rapidly at 55 minutes to failure. It can be concluded that the additional two bolts in the six-bolt connection contributed to the load distribution of the connection, thereby reducing the stresses (tensile and shear) on individual bolts. Therefore, the time to failure for the sixbolt connection was 13 minutes more than that of the four-bolt connection.

Conversely, in respective tests conducted on these connections but without self-tapping screws, Owusu [20] reported that the four-bolt pattern P1 connection had a failure time of 8 minutes more than the six-bolt pattern P2 connection. This was due to an earlier splitting failure (brittle) encountered along the bolt rows (placed at the glue line of the beam) of the six-bolt connection.

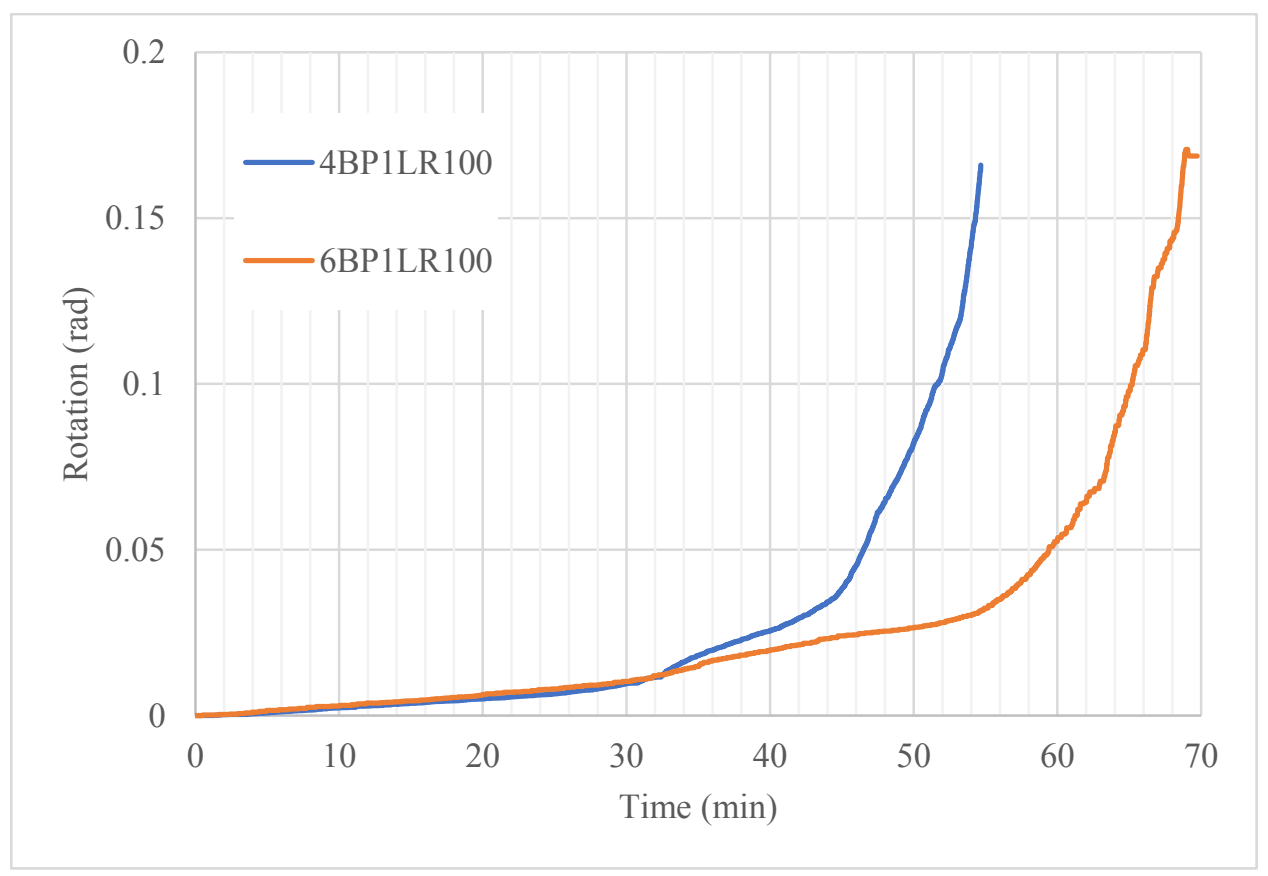

Figure 4.7 Time-rotation curves for four and six-bolt patterns P1 connection subjected to a $100 \%$ load ratio 
Figure 4.8 shows the effect of increasing the number of bolts from four (4) to six (6) in bolt pattern P2. As shown in the graph, the two connection configurations had a similar trend of increased rotations for about 33 minutes, after which the four-bolt connection increased gradually for about 19 minutes, and then rapidly to failure. The six-bolt pattern P2 connection exhibited a similar trend of linear increase of rotations, after which the rotations gradually increased for about 22 minutes before rapidly increasing to failure. This resulted in a failure time for $6 \mathrm{BP} 2$ connection, which is 4 minutes more than that of 4BP2 connection.

This result is contrary to the respective tests conducted by Owusu [22] on connections without self-tapping screws, where Owusu [22] reported a better fire performance for the four-bolt connection with a higher failure time of 7 minutes than the six-bolt connection 6BP2. This can be attributed to the complete splitting failure experienced along the second bolt row (located at the glue line plane) of the six-bolt connection (6BP2).

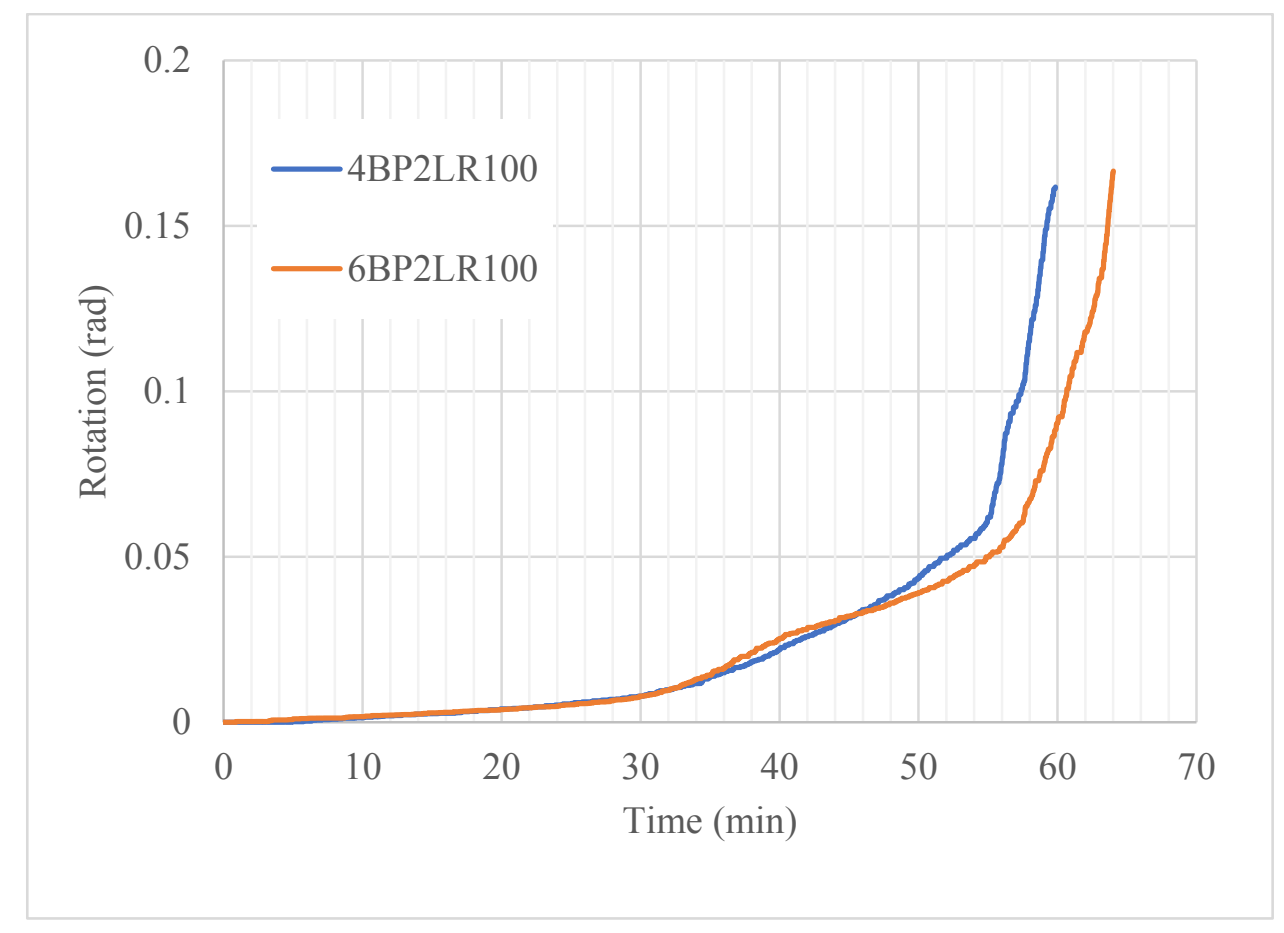

Figure 4.8 Time-rotation curves for four- and six-bolt patterns P2 connections subjected to a $100 \%$ load ratio 


\subsubsection{Effect of Load Ratio on the Connection Rotations}

\subsubsection{Effect of Load Ratio on the Four-Bolt Pattern P1 Connection Rotations}

The effect of increasing the load ratio from $60 \%$ to $100 \%$ on the four-bolt pattern P1 connection rotations is shown in Figure 4.9. As expected, there is a significant difference in the connection's rotational behaviour when the load ratio increased from $60 \%$ to $100 \%$, which led to a $21 \%$ increase in the increase rate of the rotation of the connection loaded to $100 \%$ load ratio. It is also noticed that at both load ratios $60 \%$ and $100 \%$, the connections exhibit the same trend of increased rotations for the first 30 minutes, after which the rotations of the connection loaded to $100 \%$ load ratio gradually increased for about 13 minutes, and thereafter underwent rapid rotations at 43 minutes to failure. While, at a $60 \%$ load ratio, the rotation increased linearly for 45 minutes before gradually increasing at 45 minutes to failure. As a result, the connection subjected to a load ratio of $60 \%$ has a failure time which is 11 minutes longer than the failure time of the connection loaded to a $100 \%$ load ratio.

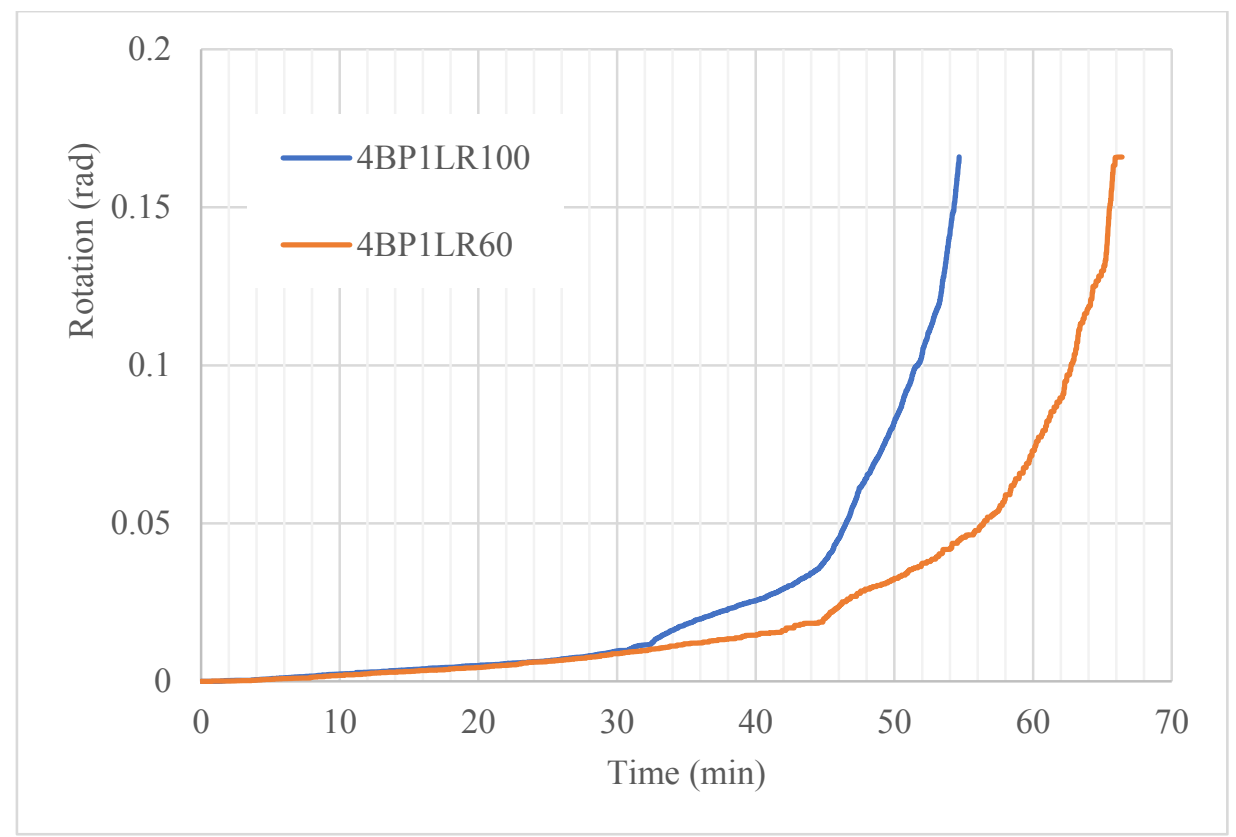

Figure 4.9 Time-rotation curves for four-bolt pattern P1 connection subjected to $60 \%$ and $100 \%$ load ratios 


\subsubsection{Effect of Load Ratio on the Four-Bolt Pattern P2 Connection Rotations}

Similar to the four-bolt pattern P1 connection, the connection of bolt pattern P2 was subjected to load ratios of $60 \%$ and $100 \%$. Figure 4.10 shows the time-rotation curves for the four-bolt pattern P2 connection subjected to $60 \%$ and $100 \%$ load ratios. Unlike the four-bolt pattern P1 connection, no difference in failure time was observed for the bolt pattern P2 connection as both tests failed at 57 minutes. It is observed that the time-rotation curves exhibit similar trends for about 37 minutes, after which bolt pattern P2 connection subjected to a $60 \%$ load ratio exhibited faster rotation until failure than the bolt pattern P2 connection subjected to $100 \%$ load ratio. This is due to the high charring rate observed in the connection subjected to a $60 \%$ load ratio, as presented in Table 4.2.

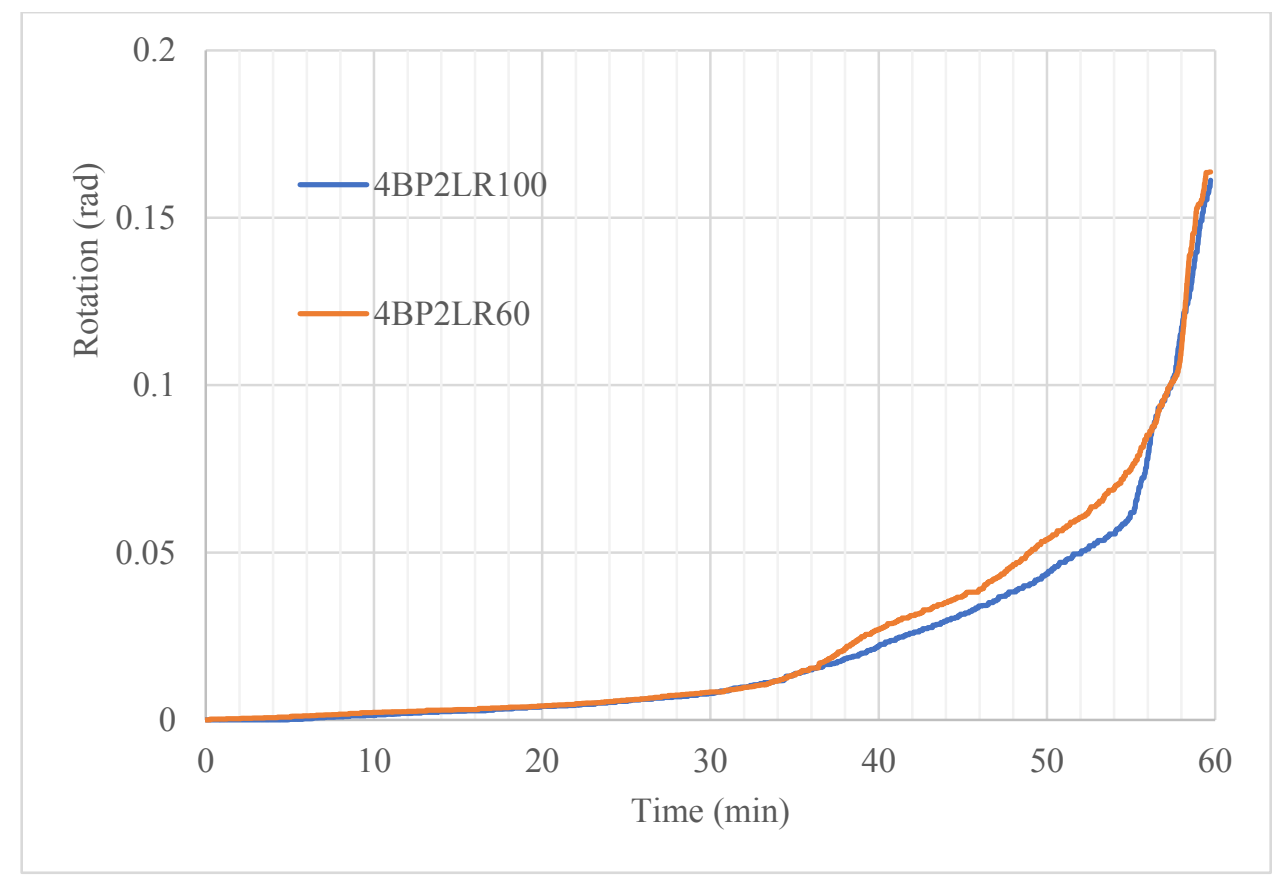

Figure 4.10 Time-rotation curves for the four-bolt patterns P2 connection subjected to $60 \%$ and $100 \%$ load ratios 


\subsubsection{Effect of Load Ratio on the Six-Bolt Pattern P1 Connection Rotations}

The effect of increasing the load ratio from $100 \%$ to $130 \%$ on the connections' rotation was more pronounced than the effect of increasing from $60 \%$ to $100 \%$ due to the higher applied load on the connection, which resulted in an increase in the increase rate of the connection rotations. Figure 4.11 depicts the time-rotation curves for the six-bolt pattern P1 connection subjected to $100 \%$ and $130 \%$ load ratios. At both load ratios, it can be seen that the connections exhibited a similar trend of increased rotations with time, whereas the connection subjected to a load ratio of $130 \%$ underwent a faster increased rotations than that of the connection loaded to $100 \%$ load ratio. For the connection loaded to $100 \%$ load ratio, it is observed that the connection's rotations linearly increased for about 32 minutes, after which the rotational values increased gradually for about 23 minutes before rapidly increasing at 55 minutes to failure. A similar increased rotation trend is observed for the connection loaded to $130 \%$, but with lesser time intervals. The connection exhibited a faster rate of rotation increase and rapidly increased at 45 minutes to failure. This resulted in a 11 minutes difference in the failure time of the connections with the connection subjected to a $100 \%$ load ratio performing better than the connection loaded to a $130 \%$ load ratio. 


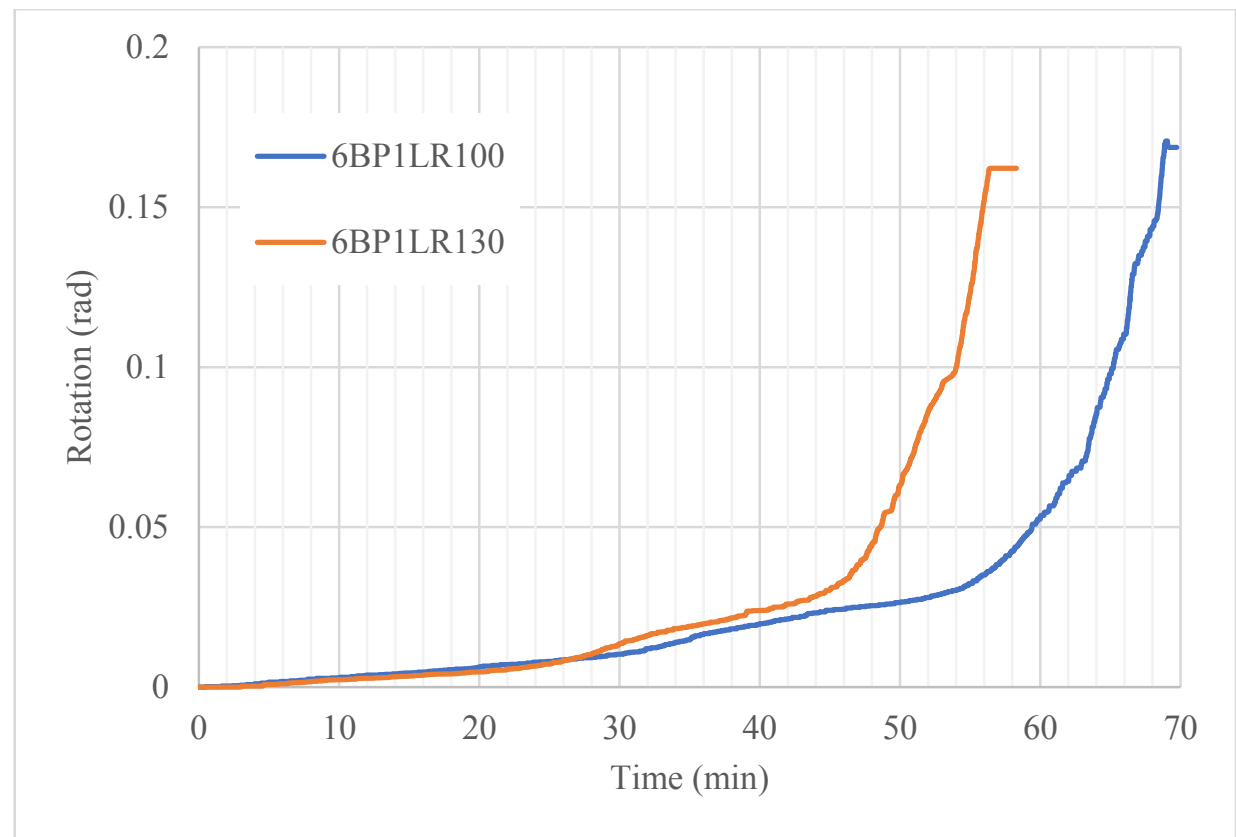

Figure 4.11 Time-rotation curves for the six-bolt patterns P1 connection subjected to $100 \%$ and $130 \%$ load ratios

\subsubsection{Effect of Load Ratio on the Six-Bolt Pattern P2 Connection Rotations}

Similar to the six-bolt pattern P1 connection, increasing the load ratio from $100 \%$ to $130 \%$ for the six-bolt pattern P2 connection has a considerable effect on the connection's rotational behaviour. Figure 4.12 shows the time-rotation curves for the six-bolt pattern $\mathrm{P} 2$ connection subjected to $100 \%$ and $130 \%$ load ratios. It can be seen that both connections experienced similar trend of increased rotations for about 17 minutes, after which the connection subjected to a load ratio of $130 \%$ exhibited a significant increase in its rotation values than those of the connection subjected to $100 \%$ load ratio. This results in a reduction in the time to failure by 9 minutes. 


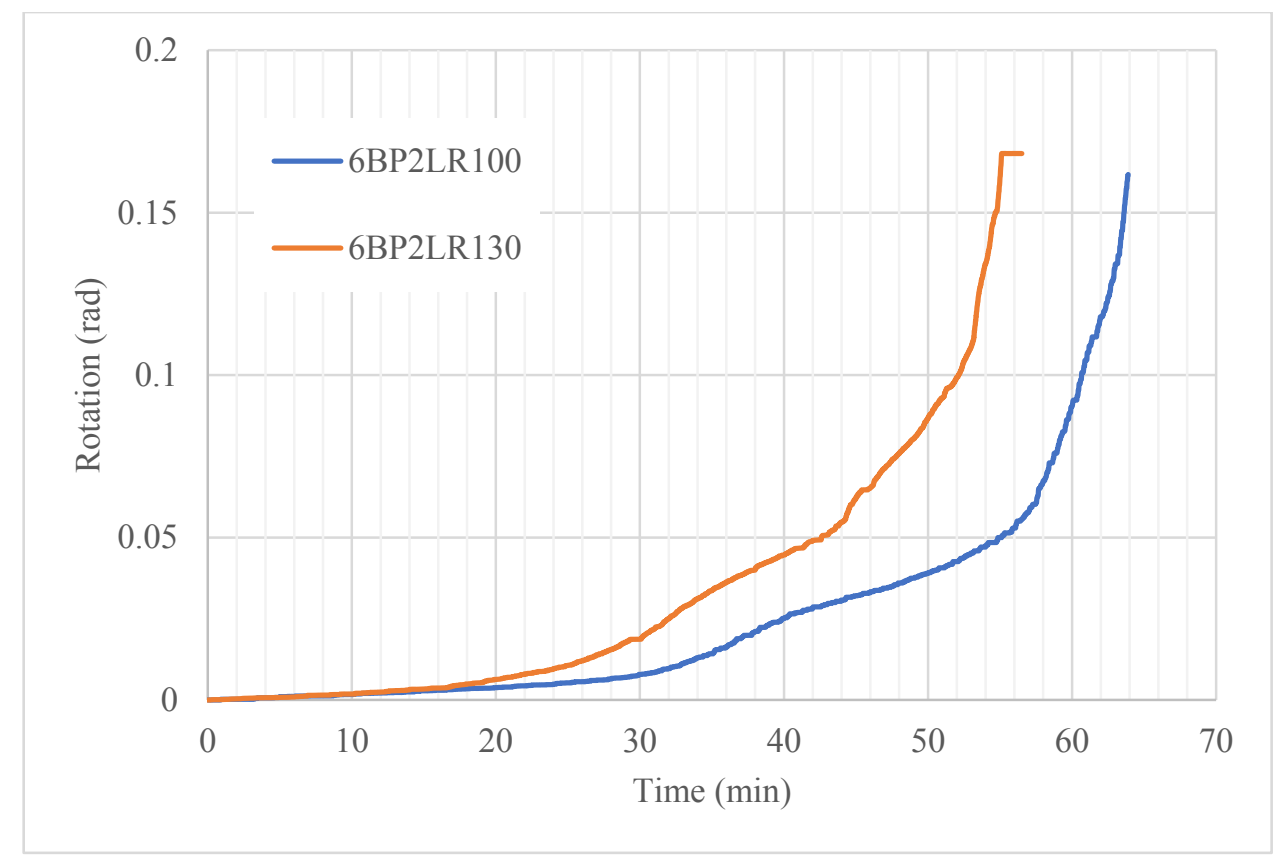

Figure 4.12 Time-rotation curves for the six-bolt patterns P2 connection subjected to 100\% and $130 \%$ load ratios

\subsubsection{Influence of Self-Tapping Screws on the Connection Rotations}

\subsubsection{Influence of Self-Tapping Screws on the Four-Bolt Connection Rotations}

In order to determine the influence of the self-tapping screws on the connections' rotational behaviour and failure time, the time-rotation curves of the connections with a $100 \%$ load ratio were compared with similar tests conducted by Owusu [22] on respective connections but without self-tapping screws. Figures 4.13 and 4.14 show the time-rotation curves for the fourbolt unreinforced connections and the four-bolt reinforced connections, respectively. Generally, it is observed that the reinforced connections perform better in rotation and failure time than the respective unreinforced connections except for the four-bolt pattern P1 connection. The unreinforced connections exhibited a faster rotation increase rate than that of the reinforced connections, and this implies that employing self-tapping screws increased the stiffness and moment-resisting capacity of the connections which as a result, reduced the 
rotation of the connections. Also, this led to an increase in the failure time of the reinforced connections.

For the four-bolt pattern P1 connection, it is observed that the reinforced connection had faster rate of rotation increase than that of the unreinforced connection which resulted in a failure time difference of 4 minutes. It was reported by Owusu [22] that the four-bolt pattern P1 connection failed in splitting during the fire test, and this is represented on the graph by a very rapid increase in the rotational values of the connection, whereas, there was no occurrence of splitting or row shear out in the reinforced connection.

In contrast, the reinforced connection performed better than the unreinforced connection when considering the four-bolt pattern P2 connections. It is observed that there is a considerable difference in the rotational behaviour of the connections with the unreinforced connection exhibiting a faster increase rate of the connection rotations than the reinforced connection which led to an increase in the rate of rotation of the unreinforced connection. As expected, the reinforced connection has a failure time which is 9 minutes longer than the unreinforced connection.

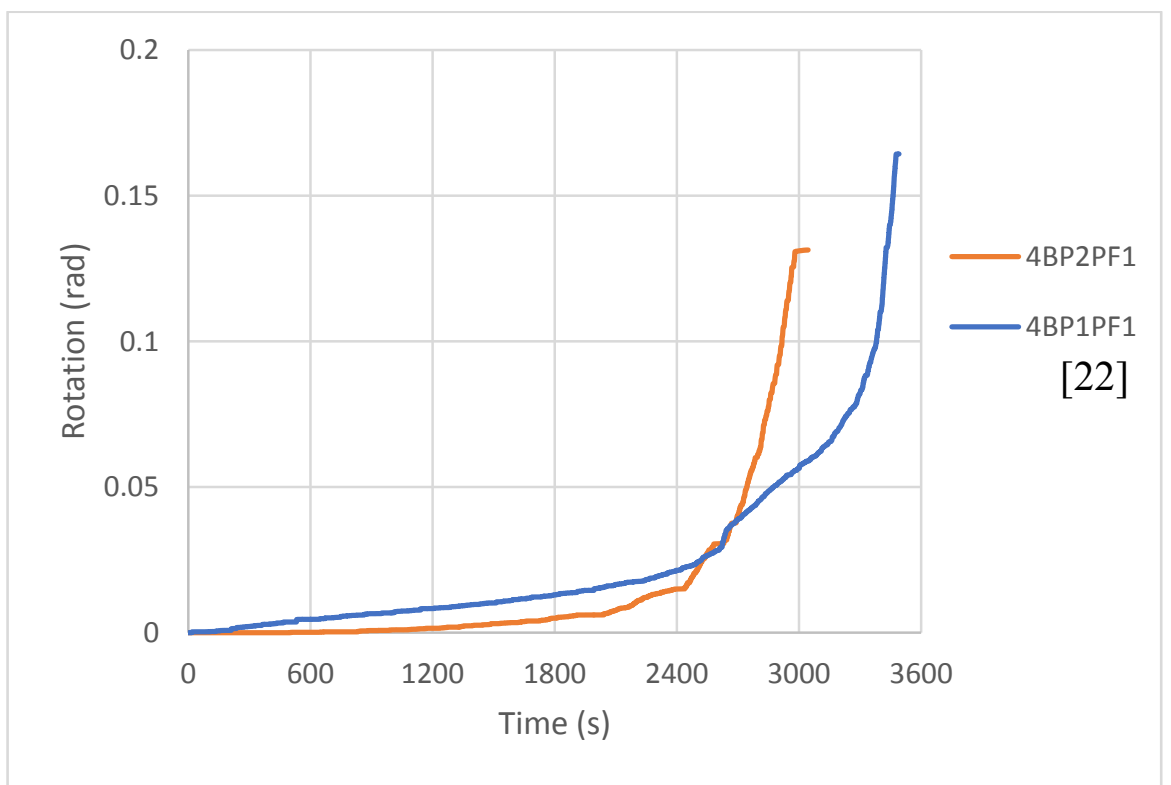

Figure 4.13 Time-rotation curves for the unreinforced four-bolt connections 4BP1 and 4BP2 


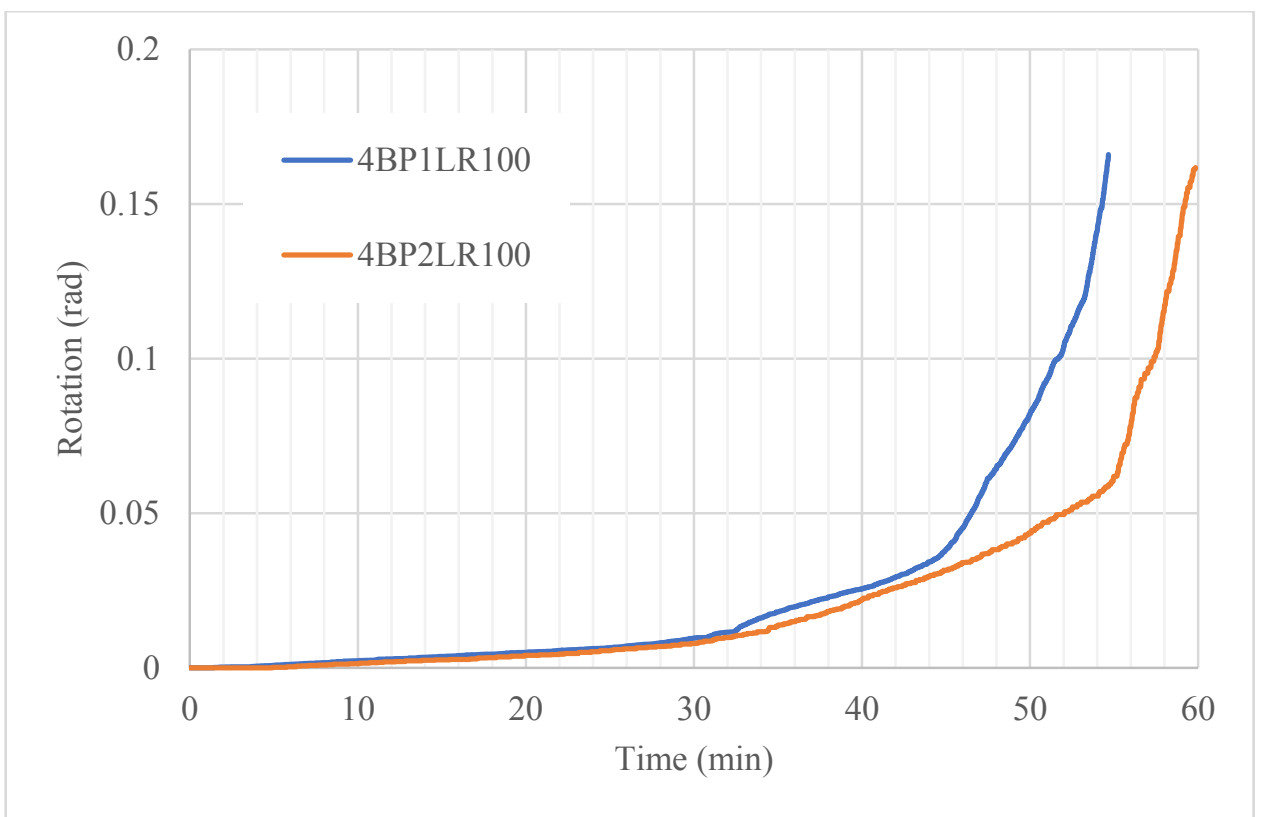

Figure 4.14 Time-rotation curves for the reinforced four-bolt connections 4BP1 and 4BP2

\subsubsection{Influence of Self-Tapping Screws on the Six-Bolt Connection Rotations}

When considering the influence of the self-tapping screws on the six-bolt connections, there is a significant difference between the rotations of the unreinforced connection and the reinforced connections. The time-rotation curves for the six-bolt unreinforced connections and the sixbolt reinforced connections are shown in Figures 4.15 and 4.16, respectively. The unreinforced connections experience an extremely rapid increase in rotation after 35 minutes into the tests, while the rotation of the reinforced connections increased gradually until failure. The rapid increase in rotations of the unreinforced connections was due to a sudden split that occurred at the second row of the bolts located in the glue-line plane of the beam, and this contributed to the propagation of the split along the whole length of the beam. For the reinforced connections, it is observed that neither splitting nor row shear out failure occurred in the connections. This resulted in a significant reduction in the rotation of the reinforced connections for $6 \mathrm{BP} 1$ and 6BP2. For this reason, the failure time of the reinforced connections of six-bolt pattern P1 
(6BP1) and $\mathrm{P} 2$ (6BP2) is longer by 17 minutes and 20 minutes, respectively than the unreinforced connections.

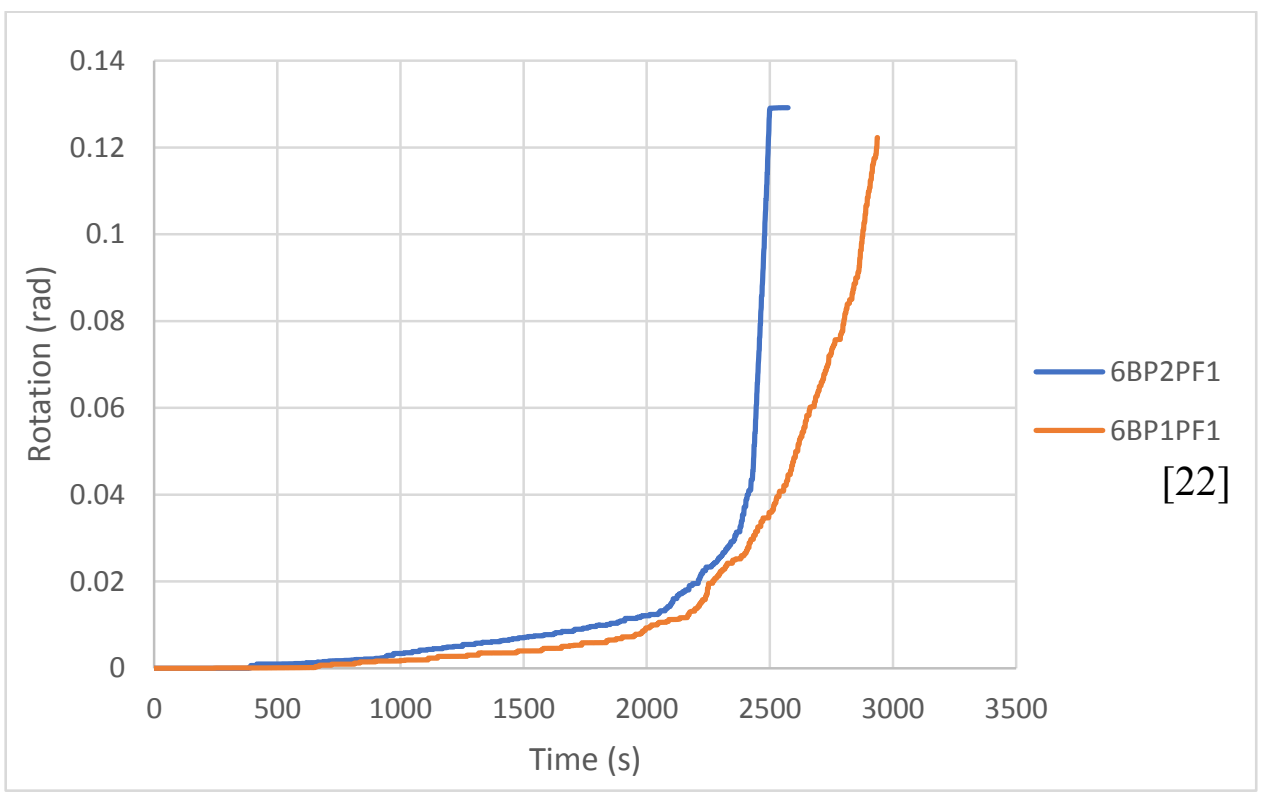

Figure 4.15 Time-rotation curves for the unreinforced six-bolt connections 6BP1 and 6BP2

[22]

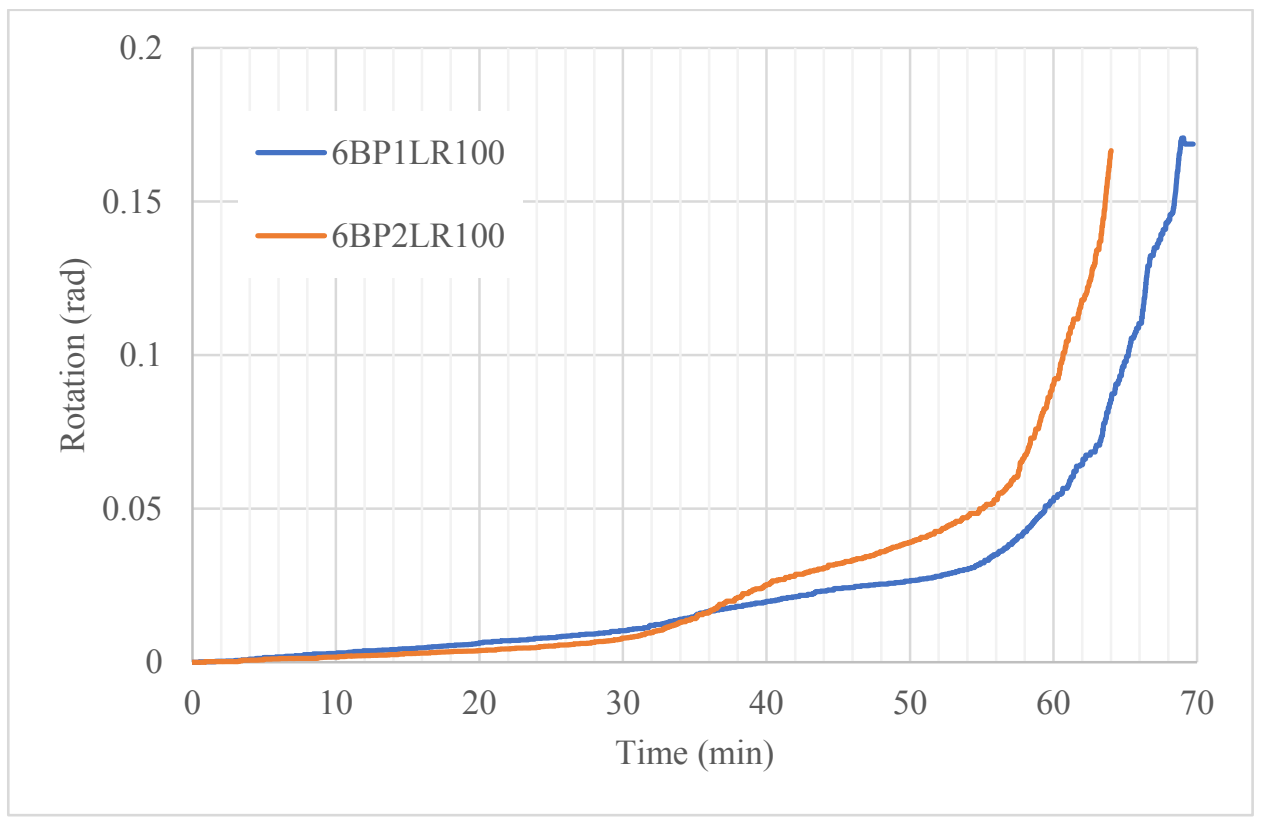

Figure 4.16 Time-rotation curves for the reinforced six-bolt connections 6BP1 and 6BP2 
Additionally, it was observed that the reinforced six-bolt connections loaded to a $130 \%$ load ratio performed better than the respective unreinforced connections subjected to a $100 \%$ load ratio. The unreinforced connections $6 \mathrm{BP} 1$ and $6 \mathrm{BP} 2$ (at 100\% load ratio) underwent a faster rate of rotation increase than that of the reinforced connections 6BP1 and 6BP2 (at 130\% load ratio). This led to an improvement in the failure time of the reinforced connections $6 \mathrm{BP} 1$ and 6BP2 by 8 minutes and 11 minutes, respectively. This implies that the improvement of the moment-resisting capacity of the reinforced connections reported by $[15,50,51,53,57]$ at ambient temperature, is to some degree retained (that is, not totally lost) at elevated temperatures. Furthermore, this result is in good agreement and confirms the results of Palma et al. [63], who reported that employing the self-tapping screws in the connections improved the load-carrying capacity, ductility and the failure time of the connections at elevated temperatures.

Based on the experimental observation and results of this study, it can be concluded that the application of the self-tapping screws reduces the rotation of the connections and as a result, improves their fire performance. Also, the tendency of brittle failure modes usually encountered in these types of connections was prevented and the reinforcements had a significant influence on improving the moment-resisting capacity as well as the failure time of the connections.

\subsection{Failure Modes}

It was observed that the wood member showed no visible failure because the brittle failure of wood splitting in the perpendicular-to-grain direction usually encountered in concealed connections was fully restrained with the application of self-tapping screws reinforcement. Also, the steel T-stub connector and steel bolts exhibit no deformation after the tests, but the 
self-tapping screws showed considerable bending based on their final location. After all tests, the two self-tapping screws located between the first bolt column and the beam end (labelled 1 in Figure 4.18) were observed to undergo considerable deformation, followed by the two sets of self-tapping screws positioned between bolt column one and bolt column two (labelled 1 and 2, respectively, in Figure 4.18). The least bent screws were the last two located 50-mm away from the second (labelled 3 in Figure 4.18) or third bolt column (labelled 4 in Figure 4.18). It is observed that the deformation of the reinforcements decreases with their location, thus, the farther the STS is placed away from the supported beam end, the lesser the bending. Figure 4.17 shows the charring of the wood member and rotation of the connections with time. While Figure 4.18 presents some of the bent screws after the tests.

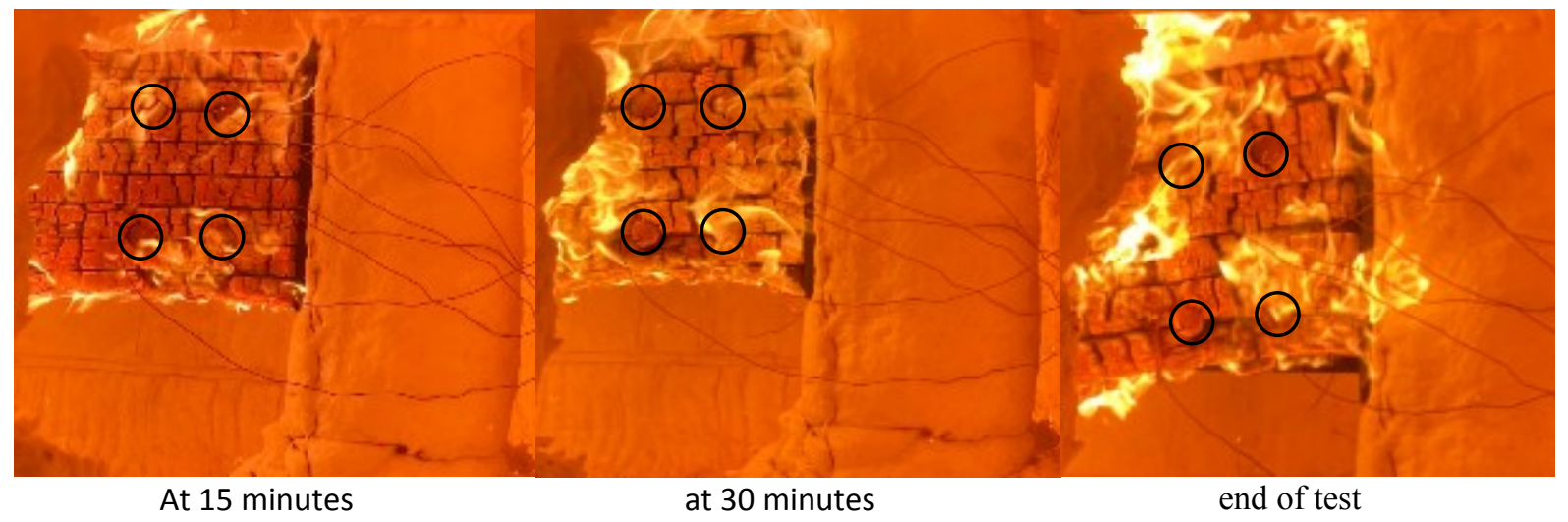

(a) Four-bolt pattern P1 connection undergoing rotation in fire at $60 \%$ load ratio

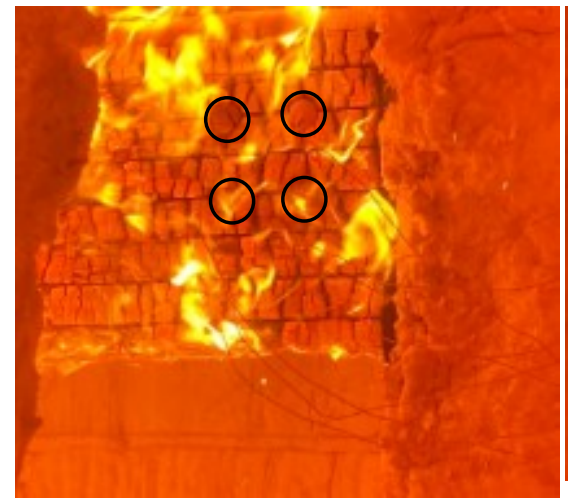

At 15 minutes

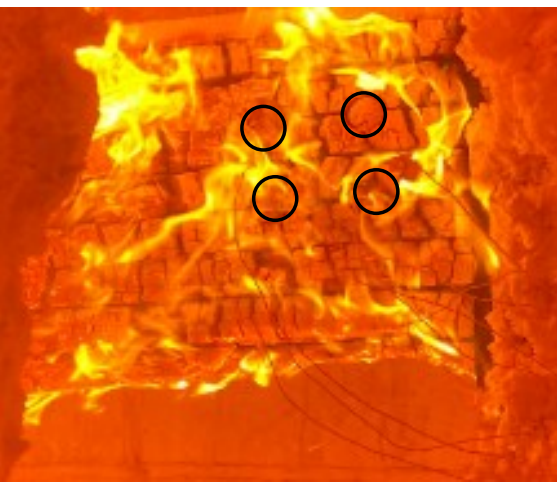

at 30 minutes

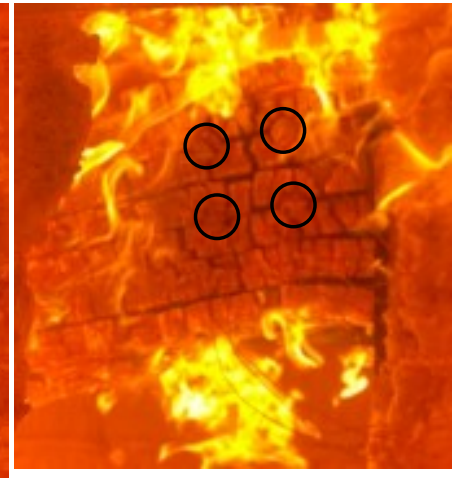

end of test

(b) Four-bolt pattern P2 connection undergoing rotation in fire at $60 \%$ load ratio 


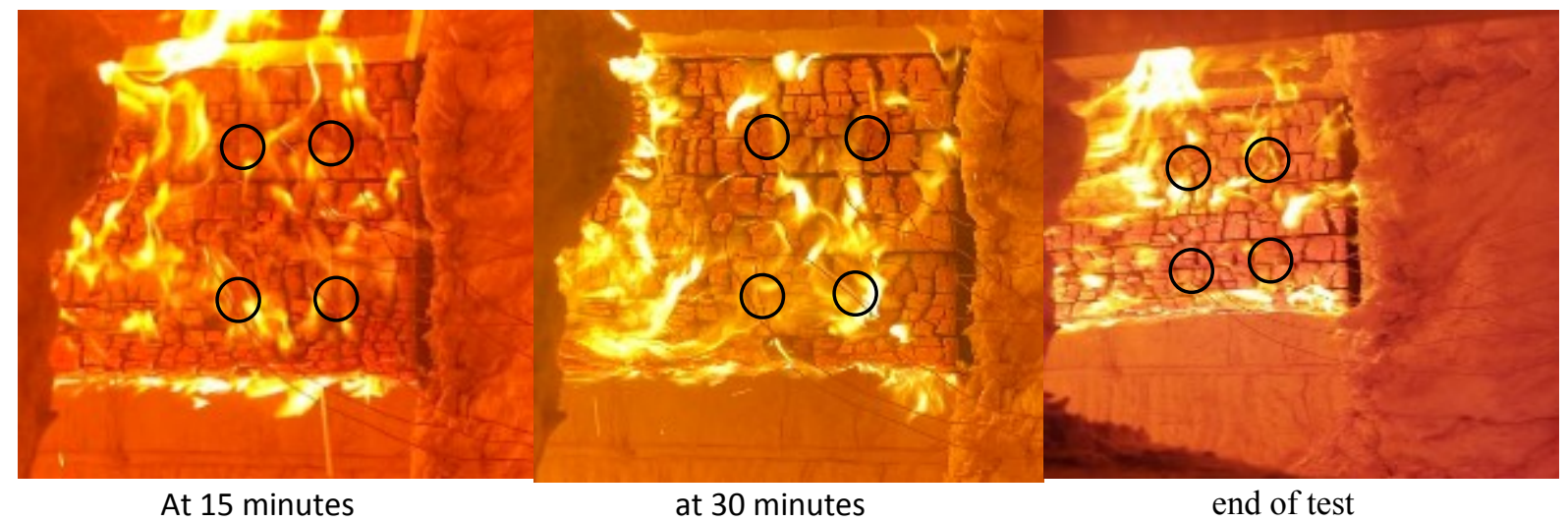

(c) Four-bolt pattern P1 connection undergoing rotation in fire at 100\% load ratio

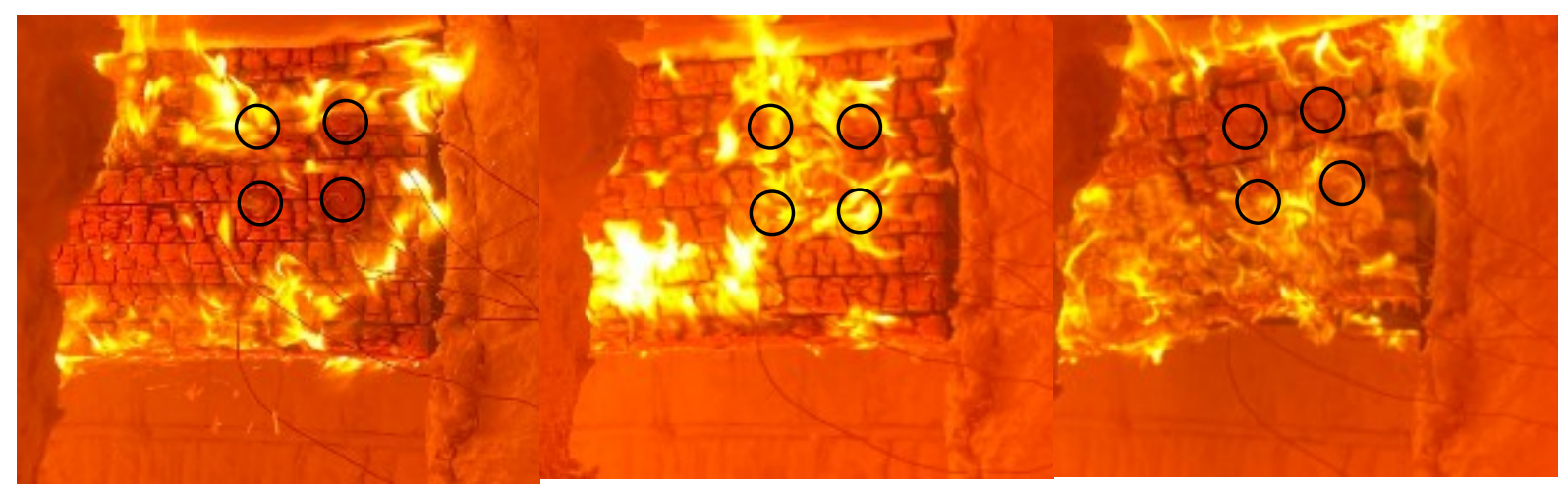

At 15 minutes

at 30 minutes

end of test

(d) Four-bolt pattern P2 connection undergoing rotation in fire at 100\% load ratio

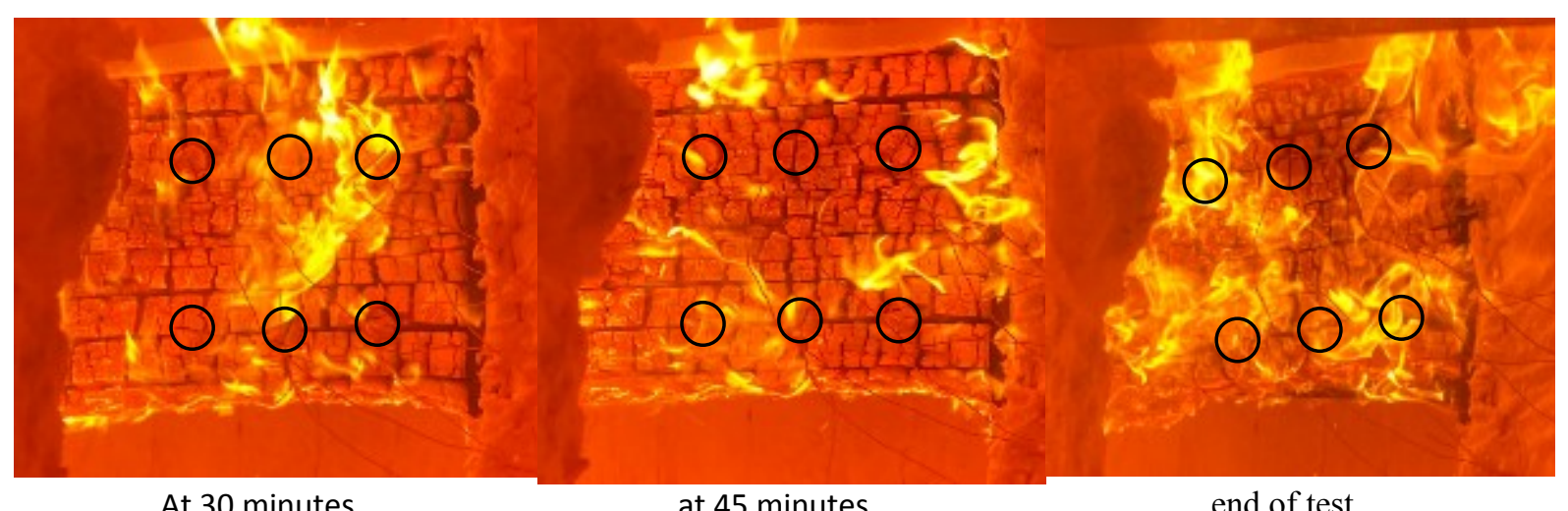

(e) Six-bolt pattern P1 connection undergoing rotation in fire at $100 \%$ load ratio 


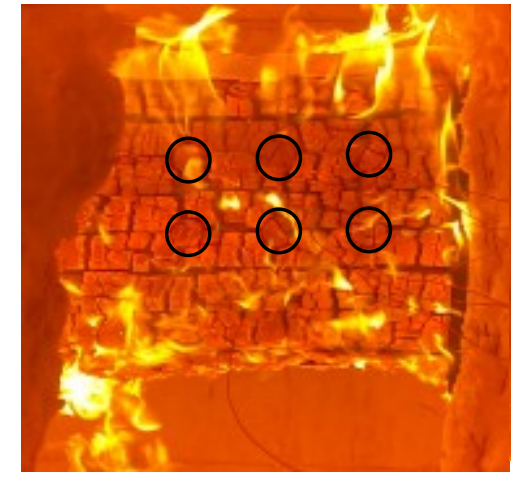

At 30 minutes

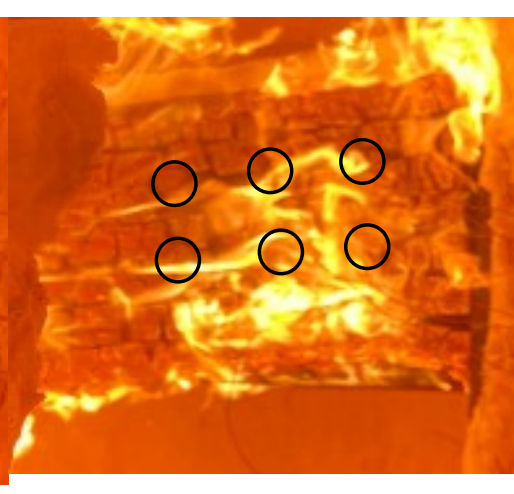

at 45 minutes

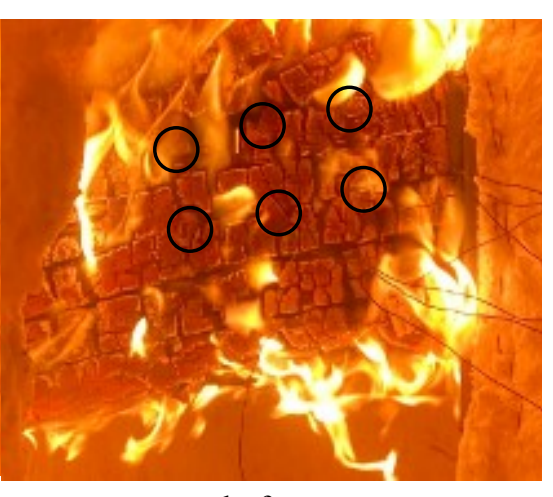

end of test

(f) Six-bolt pattern P2 connection undergoing rotation in fire at 100\% load ratio

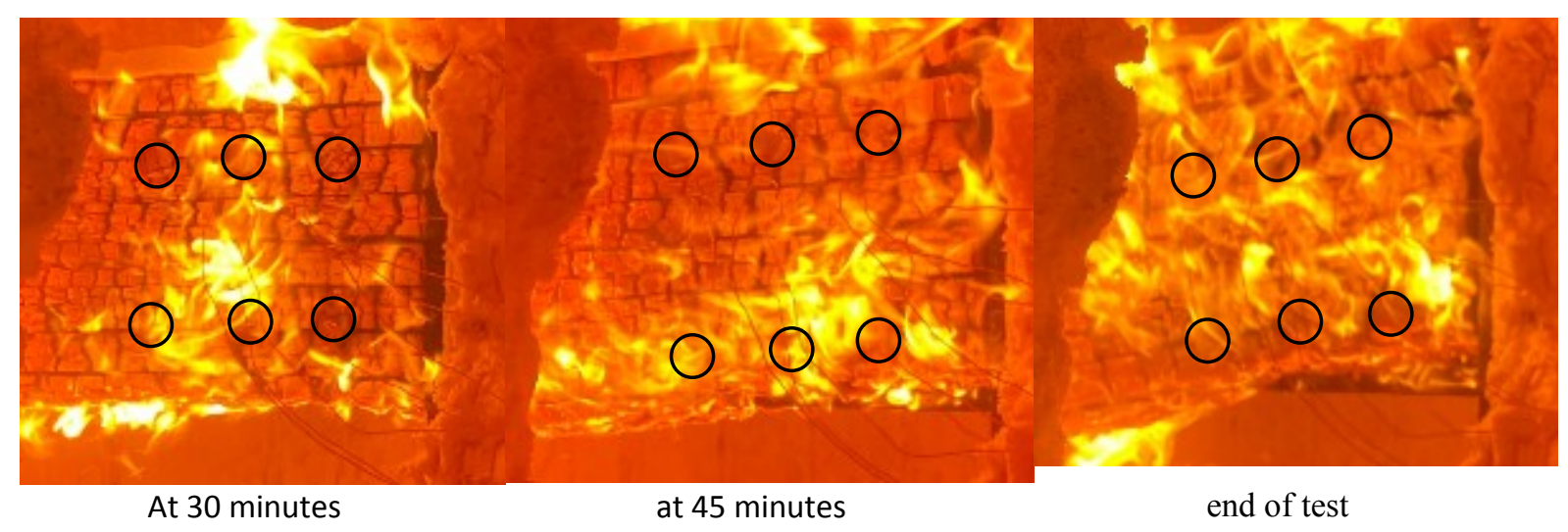

(g) Six-bolt pattern P1 connection undergoing rotation in fire at $130 \%$ load ratio

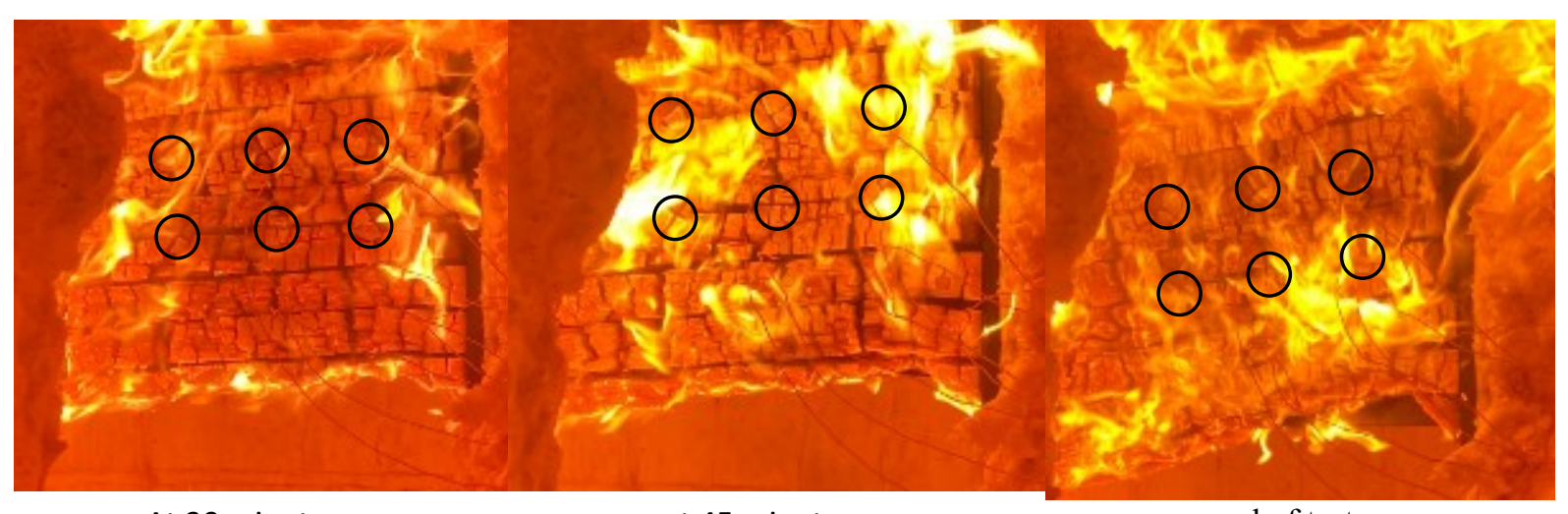

At 30 minutes

at 45 minutes

end of test

(h) Six-bolt pattern P2 connection undergoing rotation in fire at $130 \%$ load ratio

Figure 4.17 Rotation of the connections with time caused by the degradation of wood members 


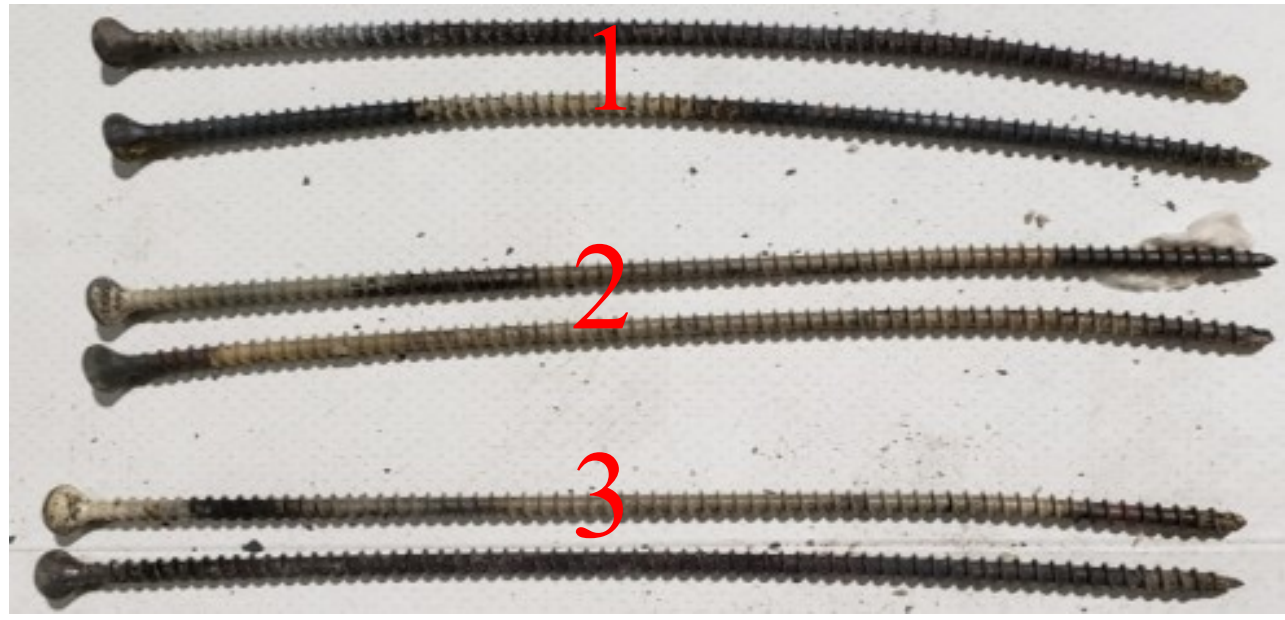

(a) Deformed self-tapping screws for 4BP1 connection

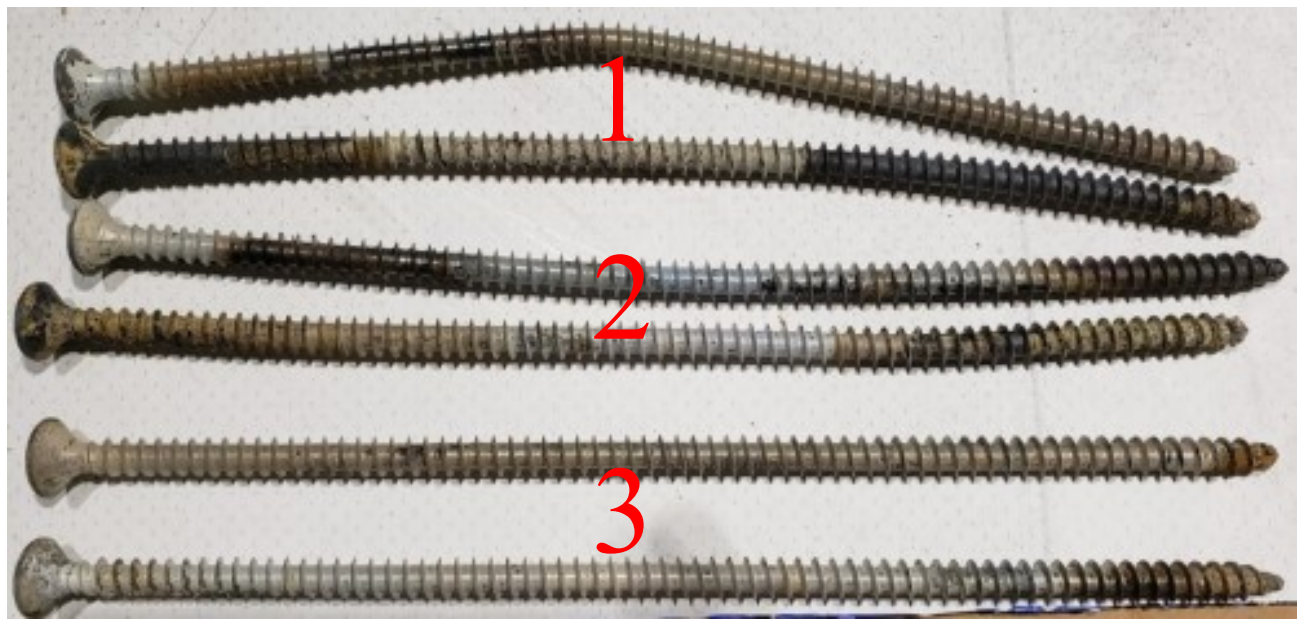

(b) Deformed self-tapping screws for 4BP2 connection

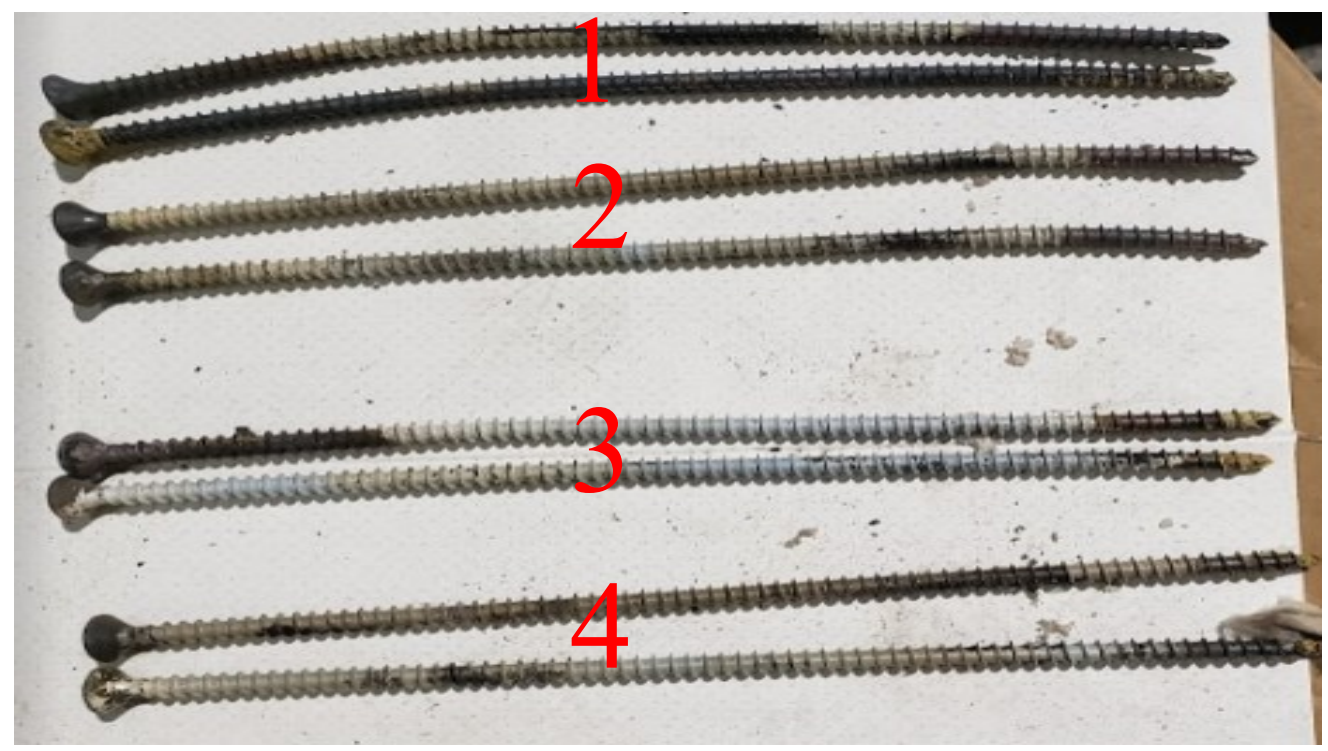

(c) Deformed self-tapping screws for 6BP1 connection 


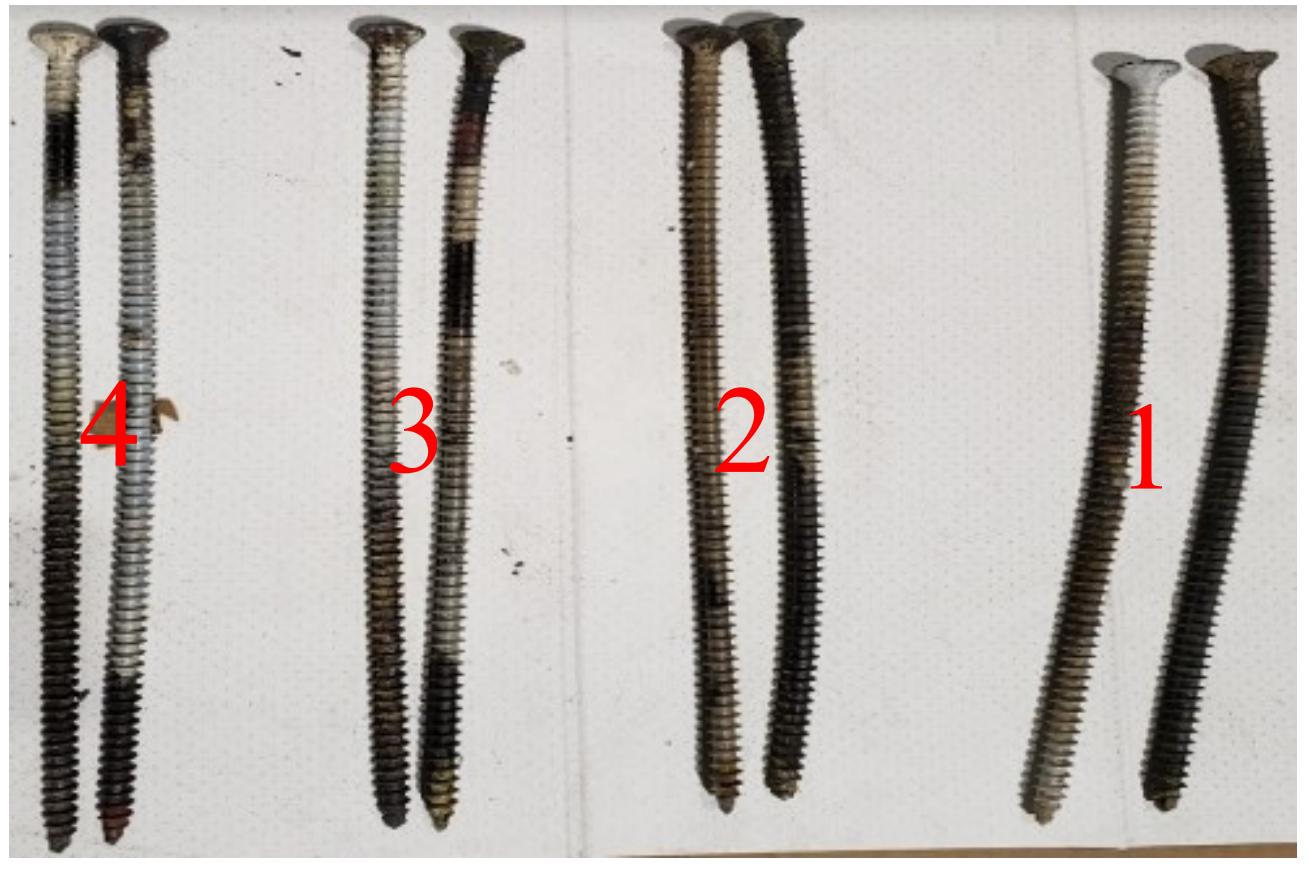

(d) Deformed self-tapping screws for 6BP2 connection

Figure 4.18 Typical failure mode for self-tapping screws

\subsection{Summary of Results}

The application of self-tapping screws in strengthening wood-steel-wood connections was effective in preventing the brittle failure modes frequently experienced in beam-to-column concealed connections. However, the probable failure mode experienced was the elongation of internal bolt holes due to slight charring that occurred around the bolt, which was caused by the heat transferred from the bolt to the wood since the temperatures of the bolts were observed to have risen above the char front temperature of wood. The stiffness and moment-resisting capacity of the connections were significantly improved, thereby resulting in more gradual failure of the connections. This allowed the beam section to be used to full capacity before complete combustion occurred. Overall, a significant increase in the failure time of the reinforced connections was observed as compared to the respective connections but without reinforcements. Also, it was observed that the six-bolt connections performed better than the four-bolt connections, while the bolt pattern P1 had improved failure time than bolt pattern P2 
except in four-bolt connections subjected to $100 \%$. Additionally, the effect of load ratio and influence of self-tapping screws were more pronounced than the effects of other variables considered in this study. Furthermore, it was observed that the fire performance of the connections significantly depends on the charring rate and hence, an increase in the charring rate caused a reduction in the failure time of the connections. This subsection discusses the summary of the effect of load ratio, bolt pattern, number of bolts, and the influence of selftapping screws on the failure time of the connections.

\subsubsection{Effect of Load Ratio}

The effect of load ratio on the connection configurations types is shown in Figure 4.19. It can be seen from the graph that the effect of load ratio is greatest in four-bolt pattern P1 (4BP1) and six-bolt pattern P1 (6BP1) connections. However, no effect is observed in four-bolt pattern P2 (4BP2) connection because of the charring rate for four-bolt pattern P2 connection with a load ratio of $60 \%$ (4BP2LR60) increases than that of four-bolt pattern P2 connection loaded to $100 \%$ load ratio (4BP2LR100). For each connection configuration type, the specimen subjected to lower load ratio has longer failure time than the specimen with a higher load ratio, except in four-bolt pattern P2 connection (4BP2). For four-bolt pattern P1 connection (4BP1), increasing the load ratio from $60 \%$ to $100 \%$ reduced the failure time by about $17.5 \%$ and $0 \%$ for $4 \mathrm{BP} 2$. While for six-bolt connections, increasing the load ratio from $100 \%$ to $130 \%$ reduces the failure time by about $16.9 \%$ for $6 \mathrm{BP} 1$ and $14.8 \%$ for $6 \mathrm{BP} 2$. Overall, increasing the load ratio decreases the failure time of the connections except in four-bolt pattern P2. 


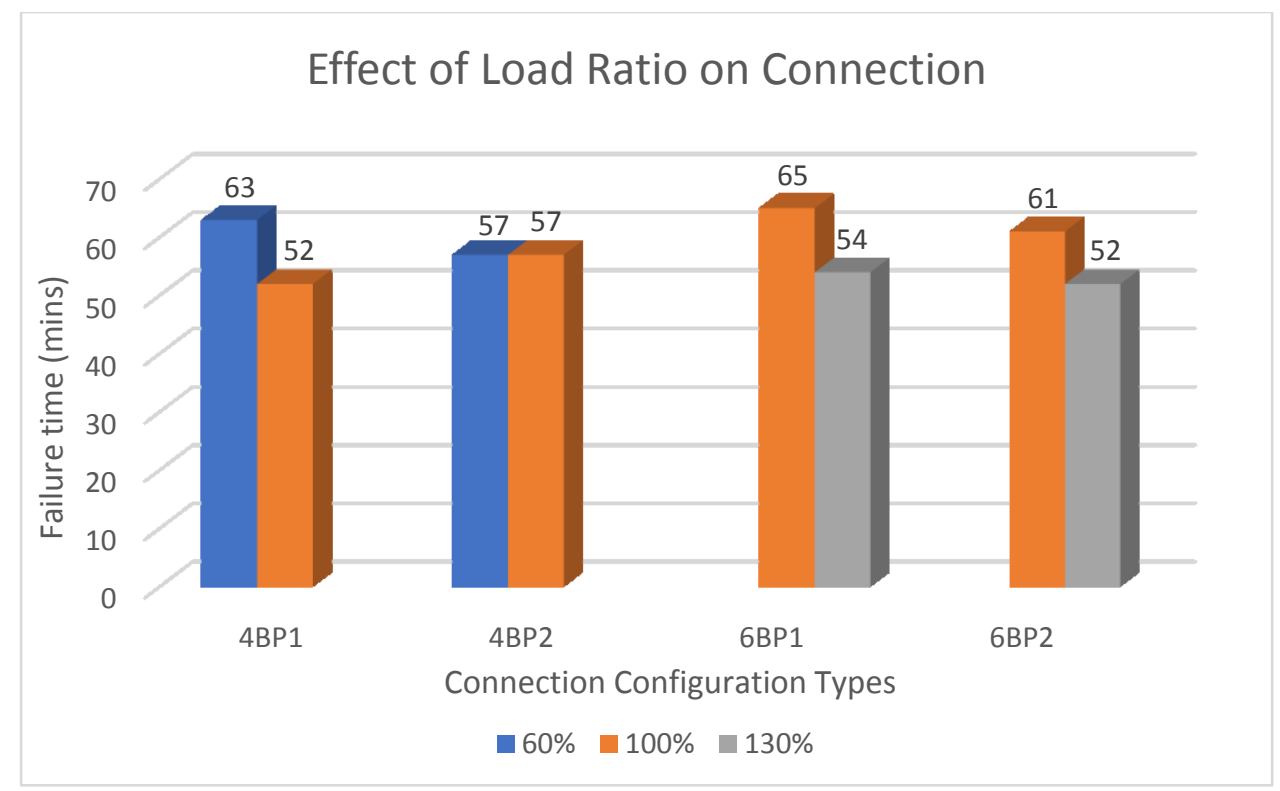

Figure 4.19 The effect of load ratio on the failure time for all connection configurations

\subsubsection{Effect of Bolt Pattern}

The effect of the bolt pattern is not as significant as that of the load ratio. Figure 4.20 shows the effect of bolt pattern at all load ratios. It can be seen that the difference in the failure time of the bolt patterns reduces as the load ratio increases. The difference in failure time is greatest in the connections with a $60 \%$ load ratio and least in the connections with a $130 \%$ load ratio. Bolt pattern P1 has a greater failure time than that of bolt pattern P2 at all load ratios except in four-bolt connections subjected to a 100\% load ratio. Four-bolt pattern P2 connection (4BP2) has a greater failure time than that of bolt pattern $\mathrm{P} 1$ connection because the 4BP1 connection exhibited a higher charring rate than the four-bolt pattern P2 connection (4BP2). At 100\% load ratio, the effect of bolt pattern is almost the same on the four- and six-bolt connections. 


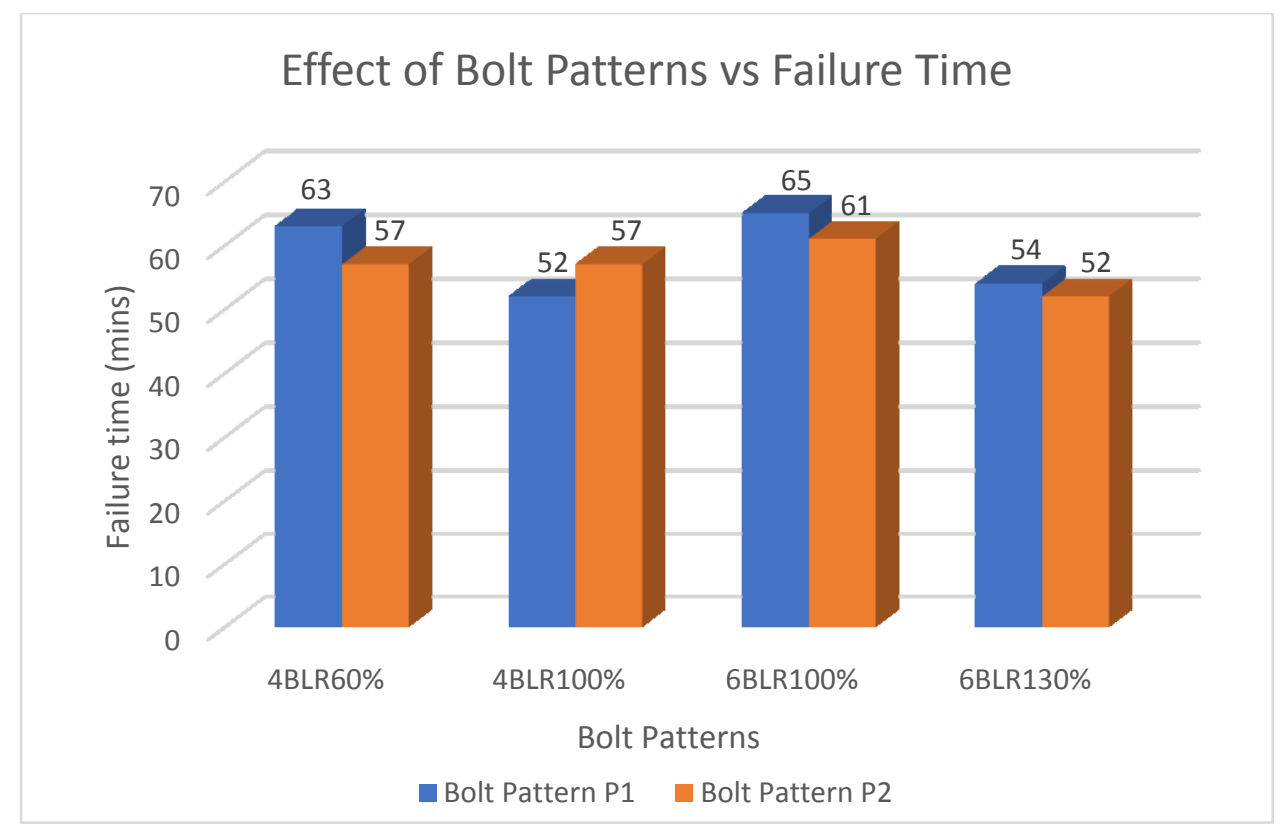

Figure 4.20 The effect of bolt patterns on the failure time for all connection configurations

\subsubsection{Effect of Number of Bolts}

Increasing the number of bolts from four (4) to six (6) improved the failure time of the connections. Figure 4.21 shows the effect of the number of bolts on each bolt pattern at $100 \%$ load ratio. It is observed that the effect of increasing the number of bolts is more pronounced in bolt pattern P1 than in bolt pattern P2. The six-bolt connections performed better in terms of the failure time than the four-bolt connections. It can be concluded that the additional two bolts in the six-bolt connections contributed to the load distribution within the connection, thereby reduced the stresses (tensile and shear) on individual bolt. 


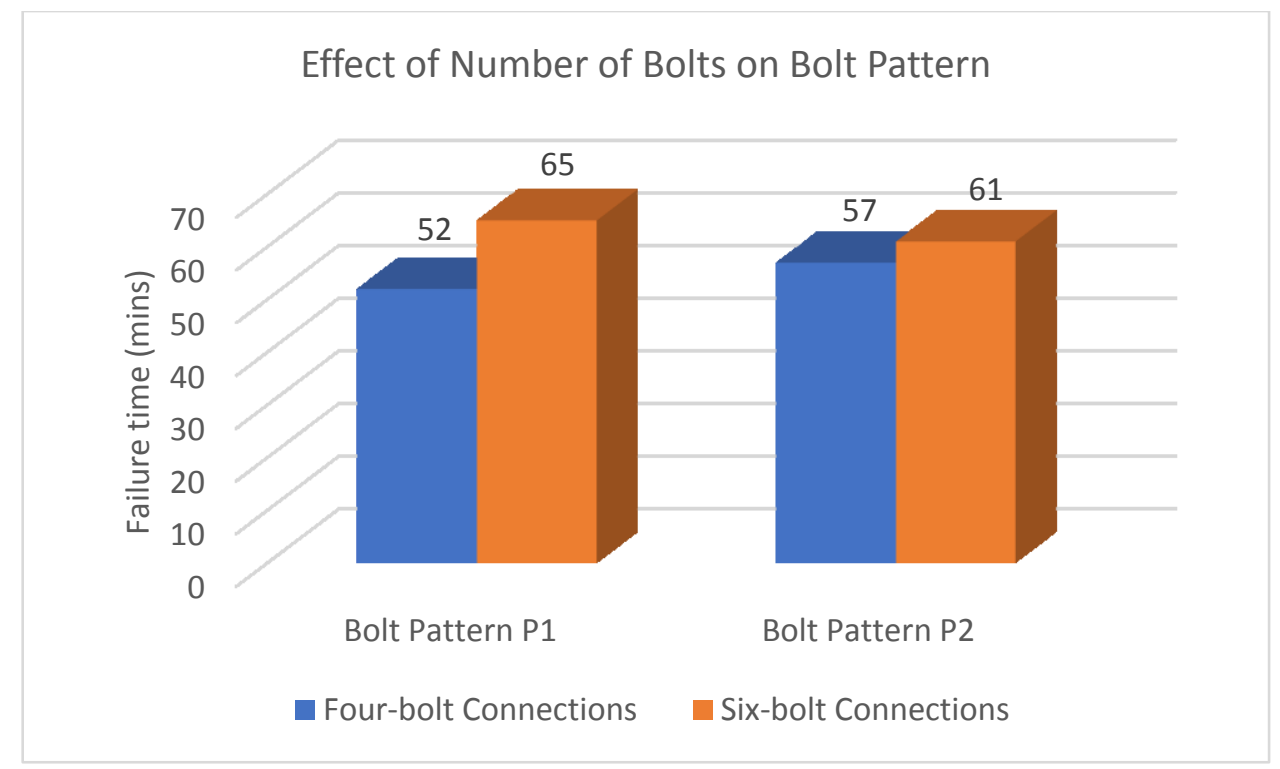

Figure 4.21 The effect of number of bolts on bolt pattern for connections subjected to $100 \%$ load ratio

\subsubsection{Influence of Self-Tapping Screws}

Figure 4.22 shows the comparison of reinforced and unreinforced connections for the four connection configuration types tested at $100 \%$ load ratio. The brittle failure mode reported by Owusu [22] in the unreinforced concealed connections were prevented by reinforcing the concealed connections with self-tapping screws, and this led to considerable increase in the failure time of the connections except in the four-bolt pattern P1, where the unreinforced connection is noticed to have a greater failure time than the reinforced connection. It is important to note that all the reinforced connections experienced gradual failure. The influence of the self-tapping screws was more significant in the six-bolt connections than in the four-bolt connections. Also, the reinforcements had a significant influence on improving the momentresisting capacity as well as the failure time of the connections. 


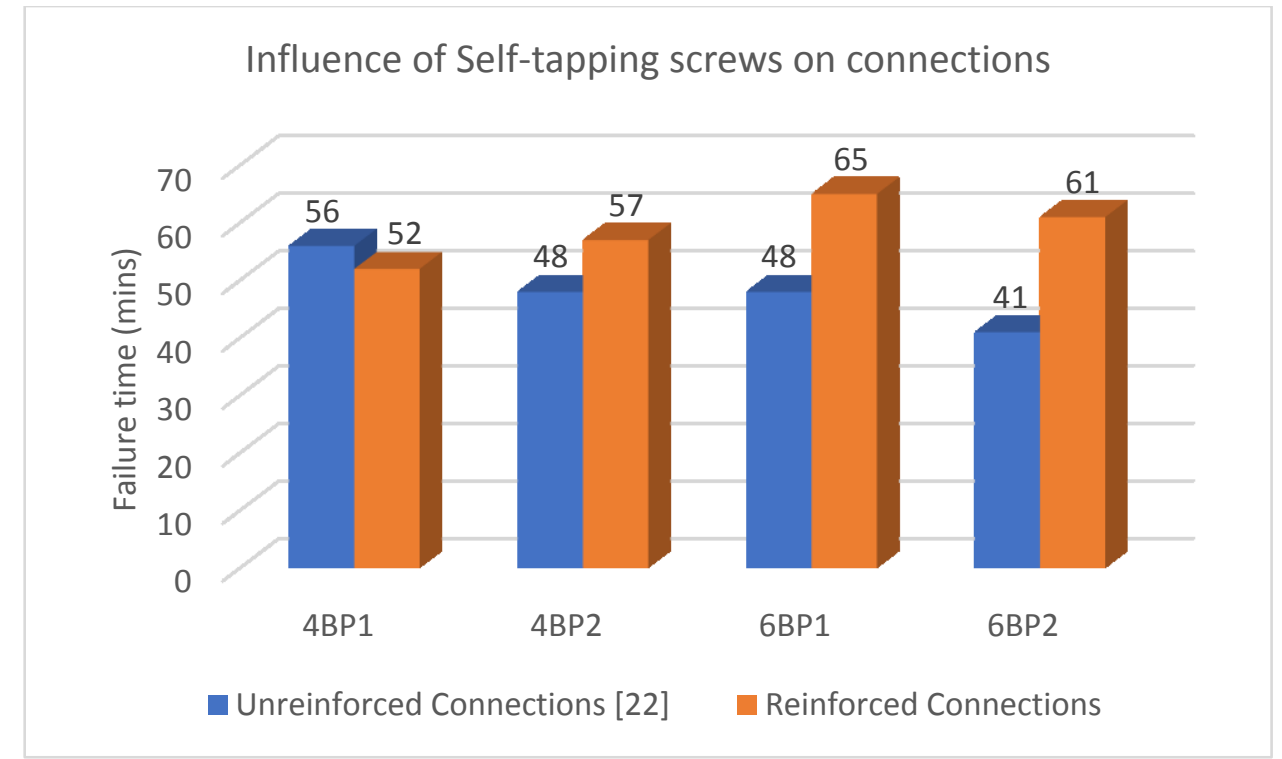

Figure 4.22 The influence of self-tapping screws on the connections' time to failure in fire condition 


\section{SUMMARY, CONCLUSIONS AND RECOMMENDATIONS}

\subsection{Summary}

The main objective of this research study was to investigate the effect of different variables on the fire performance of concealed glulam connections with self-tapping screws. To achieve this objective, eight (8) full-scale protected wood-steel-wood connections, involving four connection configurations, were reinforced perpendicular-to-wood grain with self-tapping screws, and tested in a large-scale furnace under exposure to the effects of elevated temperatures that followed the CAN/ULC S101-14 [26] standard time-temperature curve. All test specimens were exposed to the standard fire on three sides of the beams.

The $1600-\mathrm{mm}$ long glulam beams were subjected to load ratios of $60 \%, 100 \%$ and $130 \%$ of the ultimate design load (splitting failure load) of the weakest unreinforced connection, and a constant transverse load was applied on all specimens during fire tests. This chapter summarizes the most important findings and proposes a few recommendations for future work.

\subsection{Conclusions}

- Based on the research experimental study results and observations, the following conclusions have been drawn on the fire performance of concealed wood-steel-wood connections with STS reinforcement tested in this study. Due to the limited number of tests performed, general conclusions cannot be drawn. The results of the fire tests show that the failure time of the four-and six-bolt concealed connections loaded at $100 \%$ load ratio exceeded 50 and 60 minutes, respectively, which is more than the minimum fireresistance rating of 45 minutes recommended in the NBCC for combustible constructions. 
- Based on the experimental observations, the tendency of brittle failure modes frequently encountered in unreinforced concealed connections was prevented by the self-tapping screws, and thus all specimens experienced a gradual failure in deflection and longer failure times in standard fire exposure.

- The results show that increasing the number of bolts from four (4) to six (6), improved the failure time by factors of 1.25 and 1.07 in bolt patterns P1 and P2 connections, respectively.

- The test results show that bolt pattern P1 connection has improved failure time at all the applied load ratios except in four-bolt connections loaded to $100 \%$ load ratio. It can be concluded that the connections which had two rows of bolts symmetrically positioned near the top and bottom sides of the beam cross-section (bolt pattern P1) performed better than when the bottom row was raised to the mid-height of the beam section (bolt pattern P2) except in four-bolt connections subjected to $100 \%$ load ratio.

- The results show that the fire performance of the connections depends largely on its charring rate, hence, an increase in the charring rate of the connections resulted in a decrease in the failure time to the connections. The charring rates for the concealed connections are in a range of 0.73 to $0.87 \mathrm{~mm} / \mathrm{min}$.

- The results show that the behaviour of the connections in fire was largely influenced by the applied load ratio. It was observed that increasing the load ratio from $60 \%$ to $100 \%$ reduced the failure time of four-bolt pattern P1 connection (4BP1) by about $17.5 \%$ and six-bolt patterns $\mathrm{P} 1$ and $\mathrm{P} 2$ connections (6BP1 and 6BP2) by about $16.9 \%$ and $14.8 \%$, respectively, when the load ratio increased from $100 \%$ to $130 \%$. Hence, increasing the load ratio decreased the failure time in all bolt patterns except in four-bolt pattern P2. 
- The test results show that the wood near the T-stub flange did not experience charring because the thermocouples at the surface of the steel plate recorded temperatures below $300^{\circ} \mathrm{C}$. However, the wood around the bolt holes experienced slight charring.

\subsection{Recommendations for Future Work}

Based on the experimental results and observations in this study, the following recommendations for future studies on fire performance of concealed connections are suggested:

- In this research, the failure of some of the connections occurred when the char layer advanced beyond the location of the self-tapping screws by few millimetres. It is recommended that the self-tapping screws be installed at a location of two-third of the beam side member width from the fire exposed surface, which is one-third width from the T-stub connector flange. This will further contribute to the load-carrying capacity of the residual beam section beyond the failure time reported in this research since the beams did not char from the inner core.

- To reduce the slight charring and possible hole elongation around the bolts, it is recommended that further tests be conducted with a smaller bolt diameter of 12.7$\mathrm{mm}$. Reducing the bolt diameter will reduce the contact surface area of the bolt with the wood and this will result in less charring.

- To further increase the capacity of the concealed connections and also delay heat transfer to the bolt (protection time), it would be beneficial to protect the bolts' and nuts' heads with a single-layer of 15.9-mm Type X gypsum board in order to improve the fire resistance of the connections. 
- Numerical modelling should be conducted for future studies in order to further investigate the different parameters studied in this experimental research as well as broaden the spectrum of this study to investigate other parameters. 


\section{REFERENCES}

[1] Surprenant, D., The National Building Code of Canada, A Tool for Recovery in the forest Industry, Library of Parliament, Publication No. 2010-27E, Ottawa, Canada, 2010.

[2] Friquin, K.L., Charring rates of heavy timber structures for Fire Safety Design. n.d., 132.

[3] Tannert, T., Vallee, T., Muller, A., Critical Review on the Assessment of Glulam Structures using Shear Core Samples, Journal of Civil Structural Health Monitoring $2.6572,2012$.

[4] Buchanan, A.H., Abu, A.K., Structural design for fire safety, 2nd ed., John Wiley \& Sons, Ltd, University of Canterbury, New Zealand, 2017.

[5] König, J., Walleij, L., One-Dimensional Charring of Timber Exposed to Standard and Parametric Fires in Initially Unprotected and Post-protection Situations, Tarek (Swedish Institute for Wood Technology Research), Stockholm 1999.

[6] White, R.H., Analytical methods of determining fire resistance of timber members, 4th ed., Section 4/chapter 11, SFPE Handbook of Fire Protection Engineering, 2008.

[7] Buchanan, A.H., Abu, A.K., Structural design for fire safety, 2nd ed., John Wiley \& Sons, Ltd, University of Canterbury, New Zealand 2017.

[8] He, M., Li, Z., Evaluation of Lateral Performance of Timber-Steel Hybrid Lateral Resistant System Through Experimental Approach, Wood Conference on timber Engineering, Auckland 2012.

[9] NBCC, The National Building Code of Canada. Commission on Building and Fire Codes, National Research Council of Canada, Ottawa, Canada, 2015.

[10] NBCC, The National Building Code of Canada. Commission on Building and Fire Codes, National Research Council of Canada, Ottawa, Canada, 2020.

[11] Peng, L., Performance of heavy timber connections in fire, Doctor of Philosophy, Carleton University, Ottawa, Ontario, Canada, 2010. 
[12] Akotuah Ohene, A., Modelling the Fire Performance of Hybrid Steel-Timber Connections, Master of Applied Science, Carleton University, Ottawa, Ontario, Canada, 2014.

[13] Owusu, A., Salem, O., Hadjisophocleous, G., Fire performance of concealed timber connections with varying bolt patterns, in: Proceedings of the 6th International Conference on Applications of Structural Fire Engineering, Singapore, 2019.

[14] Zhang, C., Guo, H., Jung, K., Harris, R., et al., Using self-tapping screw to reinforce dowel-type connection in a timber portal frame. Engineering Structures 2019, 178, 656664.

[15] Gehloff, M., Closen, M., Lam, F., Reduced edge distances in bolted timber moment connections with perpendicular to grain reinforcements. Word Conference on Timber Engineering 2010, 1-8.

[16] Palma, P., Fire behaviour of timber connections, Doctor of Philosophy, ETH Zurich, 2016.

[17] Yurrita, M., Cabrero, J.M., Quenneville, P., Brittle failure in the parallel-to-grain direction of multiple shear softwood timber connections with slotted-in steel plates and dowel-type fasteners. Construction and Building Materials 2019, 216, 296-313.

[18] Shu, Z., Li, Z., Yu, X., Zhang, J., et al., Rotational performance of glulam bolted joints: Experimental investigation and analytical approach. Construction and Building Materials 2019, 213, 675-695.

[19] Yeh, M.-C., Lin, Y.-L., Huang, G.-P., Investigation of the structural performance of glulam beam connections using self-tapping screws. Journal of Wood Science 2014, 60, $39-48$.

[20] Lathuillière, D., Bléron, L., Descamps, T., Bocquet, J.-F., Reinforcement of dowel type connections. Construction and Building Materials 2015, 97, 48-54. 
[21] Petrycki, A., Structural Fire Performance of Bolted Glulam Beam-to-Column Concealed Connections, Master of Applied Science, Lakehead University, 2017.

[22] Owusu, A., Structural Performance of Hybrid Timber Connections with Varying Bolt Patterns at Ambient and Elevated Temperatures, Master of Applied Science, Carleton University, 2019.

[23] Benichou, N., Sultan, M.A., Fire resistance performance of lightweight wood-framed assemblies, Fire Technology, 36, 3, pp.184-219, 2000.

[24] ISO 834, Fire Resistance Tests-Elements of building Construction, Part 1: General Requirements, International Organization for Standardization, Switzerland, 1999.

[25] ASTM E119, Standard Test Methods for Fire Tests of Building Construction and Materials, American Society for Testing and Materials, 1988.

[26] CAN/ULC S101-14, Standard methods of fire endurance tests of building construction and materials. Underwriters Laboratories of Canada, Fifth edition, Ottawa, Canada, 2014.

[27] Ali, S.G., Hadjisophocleous, G., Fire Performance of Hybrid Timber Connections, Doctor of Philosophy, Carleton University, Ottawa, Ontario, Canada, 2016.

[28] American Wood Council, Today's Glulam: What Design and Building Professionals Need to Know for Code Conformance. 2015.

[29] Handbook, Timber Structures: Educational Material for Designing and Testing of Timber Strucvtures- TEMTIS, 1st ed., Leonardo da Vinci, 2008.

[30] Friquin, K.L., Material properties and external factors influencing the charring rate of solid wood and glue-laminated timber. Fire Mater. 2010, 35, 303-327.

[31] White, R.H., Nordheim, E. V, Charring Rate of Wood for ASTM E 119 Exposure. Fire Technology 1992, 28, 5-30.

[32] Mikkola, E., Charring of Wood Based Materials. Fire Saf. Sci. 1991, 3, 547-556. 
[33] Buchanan, A.H., Fire performance of timber construction. Progress in Structural Engineering and Materials 2000, 2, 278-289.

[34] White, R.H., Charring rate of different wood species, Doctor of Philosophy, University of wisconsin-Madison, 1988.

[35] Yang, T.-H., Wang, S.-Y., Tsai, M.-J., Lin, C.-Y., The charring depth and charring rate of glued laminated timber after a standard fire exposure test. Building and Environment $2009,44,231-236$.

[36] ASTME119, Standard Test Methods for Fire Tests of Building Construction and Materials. ASTM International: West Conshohocken, PA, U.S.A., American Society for Testing and Materials. 1983.

[37] Schaffer, E.L., Charring Rate of Selected Woods - Transverse to Grain. FPL Research Paper 691967.

[38] Hadvig, S., Charring of wood in building fires: Practice, theory, instrumentation measurements. Fire Safety Journal 1981, 5, 238.

[39] Yang, L., Zhou, Y., Wang, Y., Guo, Z., Predicting charring rate of woods exposed to time-increasing and constant heat fluxes. Journal of Analytical and Applied Pyrolysis $2008,81,1-6$.

[40] Eurocode 5, Design of timber structures - Part 1-1: General - common rules and rules for buildings, EN 1995-1-1, 2004. 2004.

[41] White, R.H., Charring Rate of Composite Timber Products. 2000, 12.

[42] Yang, T.-H., Wang, S.-Y., Tsai, M.-J., Lin, C.-Y., The charring depth and charring rate of glued laminated timber after a standard fire exposure test. Building and Environment n.d., 44, 231-236.

[43] Akotuah, A.O., Ali, S.G., Erochko, J., Zhang, X., et al., Study of the Fire Performance of Hybrid Steel-Timber Connections With Full-Scale Tests and Finite Element Modelling, 
in: Proceedings of the International Conference, Applications of Structural Fire Engineering, Dubrovnik, 2015.

[44] Peng, L., Hadjisophocleus, G., Mehaffey, J., Mohammad, M., Predicting the Fire Resistance of Wood-Steel-Wood Timber Connections. Fire Technology 2009, 47, 11011119.

[45] Peng, L., Hadjisophocleous, G., Mehaffey, J., Mohammad, M., Fire resistance performance of unprotected wood-wood-wood and wood-steel-wood connections: A literature review and new data correlations. Fire Safety Journal 2010, 45, 392-399.

[46] Ogrizovic, J., Wanninger, F., Frangi, A., Experimental and analytical analysis of momentresisting connections with glued-in rods. Engineering Structures 2017, 145, 322-332.

[47] Ling, Z., Yang, H., Liu, W., Zhu, S., et al., Local bond stress-slip relationships between glue laminated timber and epoxy bonded-in GFRP rod. Construction and Building Materials 2018, 170, 1-12.

[48] Blaß, H.J., Schädle, P., Ductility aspects of reinforced and non-reinforced timber joints. Engineering Structures 2011, 33, 3018-3026.

[49] Dietsch, P., Brandner, R., Self-tapping screws and threaded rods as reinforcement for structural timber elements - A state-of-the-art report. Construction and Building Materials 2015, 97, 78-89.

[50] Karagiannis, V., Málaga-Chuquitaype, C., Elghazouli, A.Y., Behaviour of hybrid timber beam-to-tubular steel column moment connections. Engineering Structures 2016, 131, $243-263$.

[51] Zhang, C., Guo, H., Jung, K., Harris, R., et al., Screw reinforcement on dowel-type moment-resisting connections with cracks. Construction and Building Materials 2019, $215,59-72$. 
[52] Blaß, H.J., Bejtka, I., Reinforcements perpendicular to the grain using self-tapping screws, in: Proceedings of the 8th World Conference on Timber Engineering, Lahti, Vol.1, 2004, pp. 1001-1006.

[53] Lam, F., Gehloff, M., Closen, M., Moment-resisting bolted timber connections. Proceedings of the Institution of Civil Engineers - Structures and Buildings 2010, 163, $267-274$.

[54] Bejtka, I., Blaß, H.J., Self-tapping screws as reinforcements in connections with doweltype fasteners, in: Proceedings of the CIB-W18 Meeting, Karlsruhe, Germany, Vol. 38, 2005.

[55] Bejtka, I., Blaß, H.J., Self-tapping screws as reinforcements in beam supports, in: Proceedings of the CIB-W18 Meeting, Florence, Italy, Vol. 39, 2006.

[56] Petrycki, A. and Salem, O. 2020. Structural integrity of bolted glulam frame connections reinforced with self-tapping screws in a column removal scenario. Journal of Structural Engineering, Vol. 146(10), ASCE, USA. https://doi.org/10.1061/(ASCE)ST.1943$541 X .0002792$.

[57] Lam, F., Schulte-WREDE, M., Yao, C.C., Moment resistance of bolted timber connections with perpendicular to grain reinforcements, in 10th World Conference of Timber Engineering, Miyazaki, Japan 2008, p. 8.

[58] Franke, S., Franke, B., Harte, A.M., Failure modes and reinforcement techniques for timber beams - State of the art. Construction and Building Materials 2015, 97, 2-13.

[59] Blaß, H.J., Schmid, M., Self-tapping screws as reinforcement perpendicular to the grain in timber connections, in: Proceedings of RILEM Symposium: Joints in Timber Structures, Stuttgart, Germany, 2001, pp. 163-172.

[60] CAN/CSA O86-14, Engineering design in wood, Canadian Standards Association, Rexdale, ON, Canada 2014. 
[61] Wang, M., Song, X., Gu, X., Tang, J., Bolted glulam beam-column connections under different combinations of shear and bending. Engineering Structures 2018, 181, 281-292.

[62] Peng, L., Hadjisophocleous, G., Mehaffey, J., Mohammad, M., Fire Performance of Timber Connections, Part 1: Fire Resistance Tests on Bolted Wood-Steel-Wood and Steel-Wood-Steel Connections. Journal of Structural Fire Engineering 2012, 3, 107-132.

[63] Palma, P., Frangi, A., Hugi, E., Cachim, P., et al., Fire resistance tests on steel-to-timber dowelled connections reinforced with self-drilling screws, in: 2nd CILASCI-Ibero-LatinAmerian Congresso in Fire Safety Engineering, ETH Library, Coimbra, Portugal 2013, p. 12.

[64] Palma, P., Frangi, A., Hugi, E., Cachim, P., et al., Fire resistance tests on timber beamto-column shear connections. Fire Engineering 2016, 7, 41-57.

[65] Petrycki, A.R., Salem, O. (Sam), Structural fire performance of wood-steel-wood bolted connections with and without perpendicular-to-wood grain reinforcement. Journal of Structural Fire Engineering 2019. https://doi.org/10.1108/JSFE-02-2019-0016

[66] Owusu, A., Salem, O., Hadjisophocleous, G., Fire performance of protected and unprotected concealed timber connections, in: Proceedings of the 3rd International Fire Safety Symposium (IFireSS), Ottawa, Ontario, Canada, 2019, pp. 370-378.

[67] CCMC (Canadian Construction Materials Centre). Evaluation report: Nordic Lam. Rep. No. CCMC 13216-R. Ottawa: CCMC, 2018

[68] CCMC (Canadian Construction Materials Centre). Evaluation report: SWG ASSY VG Plus and SWG ASSY 3.0 self-tapping wood screws. Rep. No. CCMC 13677-R. Ottawa: CCMC, 2014..

[69] Winandy, J.E., Wood poperties, USDA-Forest Service, Forest Products Laboratory, Encyclopedia of Agricultural Science, Volume 4, pp. 549-561, 1994. 
[70] Ross, R.J., Wood Handbook: Wood as an Engineering Material, USDA Forest Service, Forest Products Laboratory, General Technical Report FPL-GTR-190, 509p, 1 V. 190, 2010.

[71] Harper, C.A., Handbook of building materials for fire protection, McGraw-Hill, New York 2004.

[72] Knudson, R.M., Schniewind, A.P., Performance of Structural Wood Members Exposed to Fire. Forest Products Journal 1975, 25.

[73] Fredlund, B., Modelling of Heat and Mass Transfer in Wood Structures During Fire. Fire Safety Journal 1993, 20, 39-69.

[74] Mehaffey, J.R., Cuerrier, P., Carisse, G., A Model for Predicting Heat Transfer Through Gypsum-Board/Wood-Stud Walls Exposed to Fire. Fire Mater. 1994, 18, 297-305.

[75] Janssens, M.L., White, R.H., Temperature Profiles in Wood Members Exposed to Fire. Fire and Materials 1994, 263-265.

[76] Konig, J., Walleij, L., Timber Frame Assemblies Exposed to Standard and Parametric Fires, Part 2: A Design Model for Standard Fire Exposure, Tratek (Swedish Institute for Wood Technology Research), Rapport I 0001001, Stockholm 2000.

[77] Lie, T.T., American Society of Civil Engineers (Eds.), Structural Fire Protection, American Society of Civil Engineers, New York, N.Y, U.S.A 1992.

[78] Gammon, B.W., Reliability Analysis of Wood-Frame Wall Assemblies Exposed to Fire, Doctor of Philosophy, Thesis, University of California, 1987.

[79] Takeda, H., Mehaff ey, J.R., WALL2D: A Model for Predicting Heat Transfer Through Wood- Stud Walls Exposed to Fire. Fire and Materials 1998, 22, 133-140.

[80] Preusser, R., Plastic and Elastic Behaviour of Wood Affected by Heat in Open Systems. Holztechnologie 1968, 9, 229-231. 
[81] Schaffer, E.L., Elevated Temperature Effect on the Longitudinal Mechanical Properties of Wood, Doctor of Philosophy, Department of Mechanical Engineering, Univ. Wisconsin, Madison, 1970.

[82] Ostman, B.A., Wood Tensile Strength at Temperatures and Moisture Contents Simulating fire Conditions. Wood Science and Technology 1985, 19, 103-116.

[83] Janssens, M.L., A Method for Calculating the Fire Resistance of Exposed Timber Decks, in: The Fifth International Symposium, Australia 1997, pp. 1189-1200.

[84] Gerhards, C.C., Effect of the Moisture Content and temperature on the Mechanical Properties of Wood: An Analysis of Immediate Effects. Wood and Fibre 1982, 14, 4-36.

[85] Thomas, G.C., Fire Resistance of Light Timber Framed Walls and Floors, Doctor of Philosophy in Fire Engineering, University of Canterbury, 1997.

[86] Knudson, R.M., Performance of Structural Wood Members Exposed to Fire, Doctor of Philosophy, University of California, 1973.

[87] Code, P., Eurocode 3: Design of Steel Structures - Part 1-2: General Rules Structural Fire Design, London: European Committee for Standardisation, 2007. 


\section{APPENDIX A}

\section{A.1 Properties of Wood and Steel at Ambient and Elevated Temperatures}

\section{A.1.1 Wood and Steel}

Wood and steel react differently at elevated temperatures due to the various thermal and mechanical properties of the materials. This section discusses the behaviour of both materials at ambient and elevated temperatures.

\section{A.1.1.1 Wood at Ambient Temperature}

Wood is increasingly being used as a construction material because of its renewable and sustainability benefits. It is heterogeneous, hygroscopic, and anisotropic being an organic material composed of cellulose fibres. Wood exists naturally and abundantly; this is one feature that clearly distinguishes wood from all other construction materials. Therefore, it was the most widely used construction material in ancient times, and up till this age, it remains a common material for construction.

Wood, recognized as an orthotropic material has unique and independent properties in the directions of three mutually perpendicular axes of symmetry defined in the longitudinal, tangential, and radial directions as shown in Figure A.1. The longitudinal axis is parallel to the grain; the radial axis is normal to the growth rings (perpendicular to the grain in the radial direction), and the tangential axis is perpendicular to the grain but tangent to the annual growth rings. The major difference between the tangential axis and the radial axis is their orientation to the growth rings [69]. 


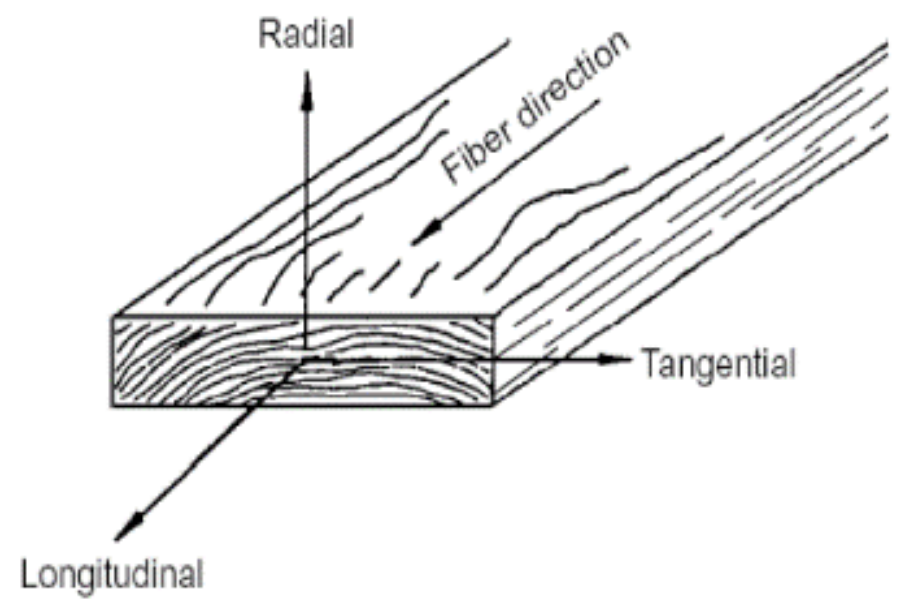

Figure A.1 The three principal axes in Wood [70]

The specific gravity of wood is an excellent indicator of wood strength because it indicates the amount of solid matter, the denser the wood, the stronger it is. Generally, wood is much stronger parallel to grain than perpendicular to grain; this is due to the vertical orientation of the wood cells and the microfibrils in the cell walls. Wood, when loaded parallel to the grain, exhibits great strength in both tension and compression. On the contrary, wood is very weak in tension when loaded perpendicular to grain due to the tearing apart of the fibres and this accounts for the brittle failure (splitting) experienced in wood. In the three principal axes, the tensile strength, as well as the compressive strength of wood, is greatest in the longitudinal direction.

Figure A.2 shows the stress-strain relationship for a small specimen of a wood void of any defects. In tension, a linear elastic behaviour is exhibited by wood when loaded parallel-tograin, however, at certain tensile stress $\mathrm{f}_{\mathrm{t}}$ wood experience a brittle failure by splitting of the wood fibres when the stress exceeds the wood tensile capacity. This is due to the inability of wood to share load within itself. While on the compression side, the relationship between stress and strain is linear in the elastic region and then begins to curve due to the crushing of the wood (yielding). 


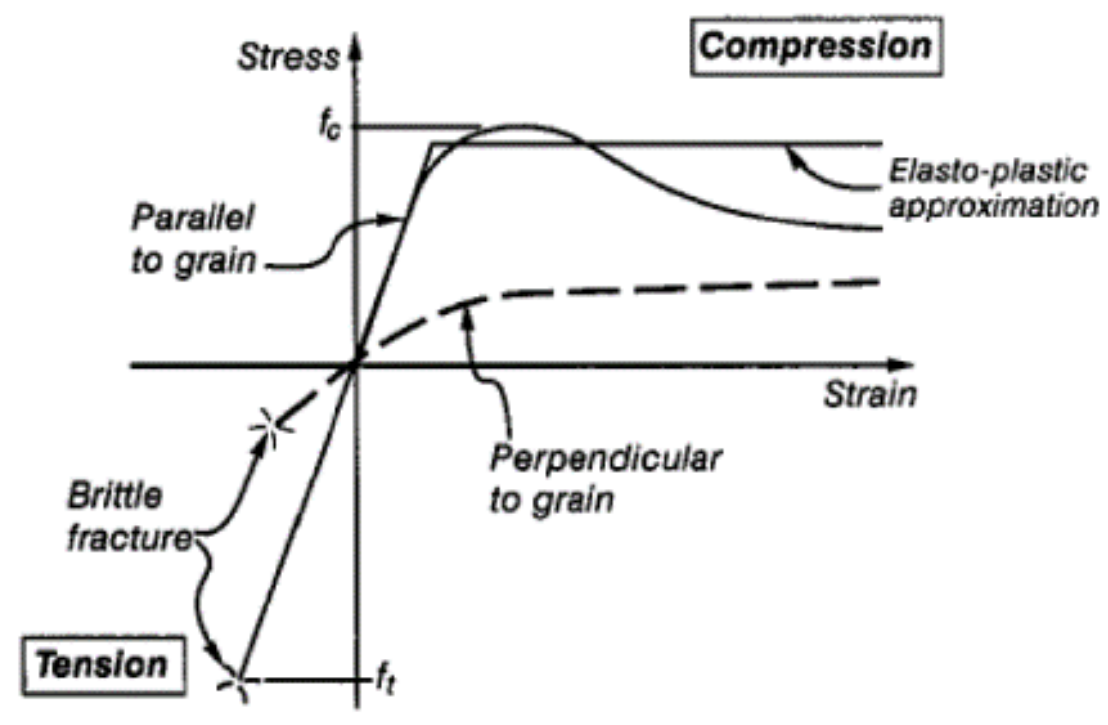

Figure A.2 Stress-Strain relationships for clear wood [7]

As wood is being crushed further, yielding continues and the stress-strain relationship for wood compressive strength reaches its peak and finally drops as shown in Figure A.2. An increase in strain causes the wood to deform in a ductile manner. In approximation, the behaviour of wood in compression is elasto-plastic in nature. The modulus of elasticity of wood loaded perpendicular to grain is lower than when loaded parallel to grain. The dotted line represents the stress-strain relationship when wood is loaded perpendicular to grain as shown in Figure A.2. In compression, wood shows a relatively ductile behaviour with gradually increasing load as the strains increase. When wood is loaded perpendicular to grain in tension, splitting of the wood fibres (brittle failure) occurs at a small load when the stress is equal to or greater than the tensile strength of the wood, Figure A.3. 

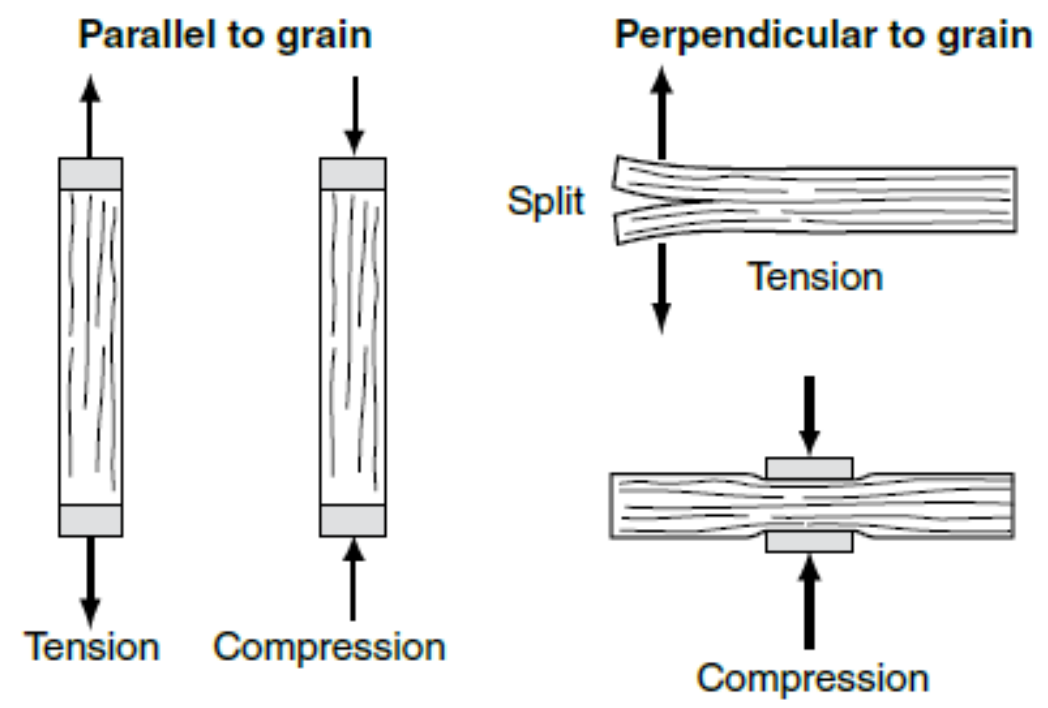

Figure A.3 Loading of wood members in parallel and perpendicular to grain directions [71]

\section{A.1.1.2 Steel at Ambient Temperature}

Unlike wood, structural steel is a man-prepared alloy that is made mainly from iron and carbon. Steel material is homogenous and isotropic, which means it has the same properties in all directions. Steel has the highest strength-to-weight ratio than any other building material and it has high tensile strength. Steel can experience large plastic deformation before failure due to its ductility. Owing to its unique strength characteristics, steel can resist more load and therefore, it is the most widely used material in the construction of structures with long spans and high load.

When a tensile force is applied to steel, the stress-strain relationship curve begins with a linear elastic curve which indicates that the ratio of stress to strain remains proportional as steel experiences an elastic deformation. This means, upon removal of the force or as the force is withdrawn steel returns to its original state without any permanent deformation. As stress increases, steel reaches an elastic limit, beyond which it experiences yielding and permanent deformation occurs. This is known as plastic deformation. 
In hybrid connections, steel is employed as fasteners and connectors. Deformation of steel components in hybrid connections is not as critical as that of wood members. Experimental tests have shown that the frequent steel failure experienced in timber connection is yielding of the fasteners, such as the steel bolts and dowels [16, 27].

\section{A.1.1.3 Wood at Elevated Temperatures}

Wood being a combustible material undergoes thermal decomposition when exposed to fire, resulting in a change of the physical and chemical properties of wood. When heavy timber is exposed to a heat source, the surface initially ignites, burns, and rapidly turns into a layer of char.

Generally, wood contains moisture in its natural state. Under fire exposure, the wood's temperature rises, and the water absorbed in the cell walls of the wood begins to evaporate at temperatures above $100^{\circ} \mathrm{C}$. Some portion of the moisture escapes away through the exposed burning wood surface as water vapour while the remaining portion migrates into the wood and re-condenses where the temperature is less than $100^{\circ} \mathrm{C}$ [71]. As the temperature of the wood continues to increase and reaches above $200^{\circ} \mathrm{C}$, the wood fibres undergo thermal degradation and combustible products are generated. This process is referred to as pyrolysis. A layer of heated wood of about $35 \mathrm{~mm}$ thick undergoing thermal decomposition is known as pyrolysis zone and this is characterized by discolouration and weight loss [7]. As the burning continues, wood finally turns to a layer of char at a temperature of about $300^{\circ} \mathrm{C}$. This char layer is like a spongy kind of material with much lower thermal conductivity than solid wood. The layer of char formed at the surface protects the unheated section of wood underneath from flame contact, exposure to heat and impedes oxygen penetration. Figure A.4 illustrates the char layer and pyrolysis zone in a timber beam. 


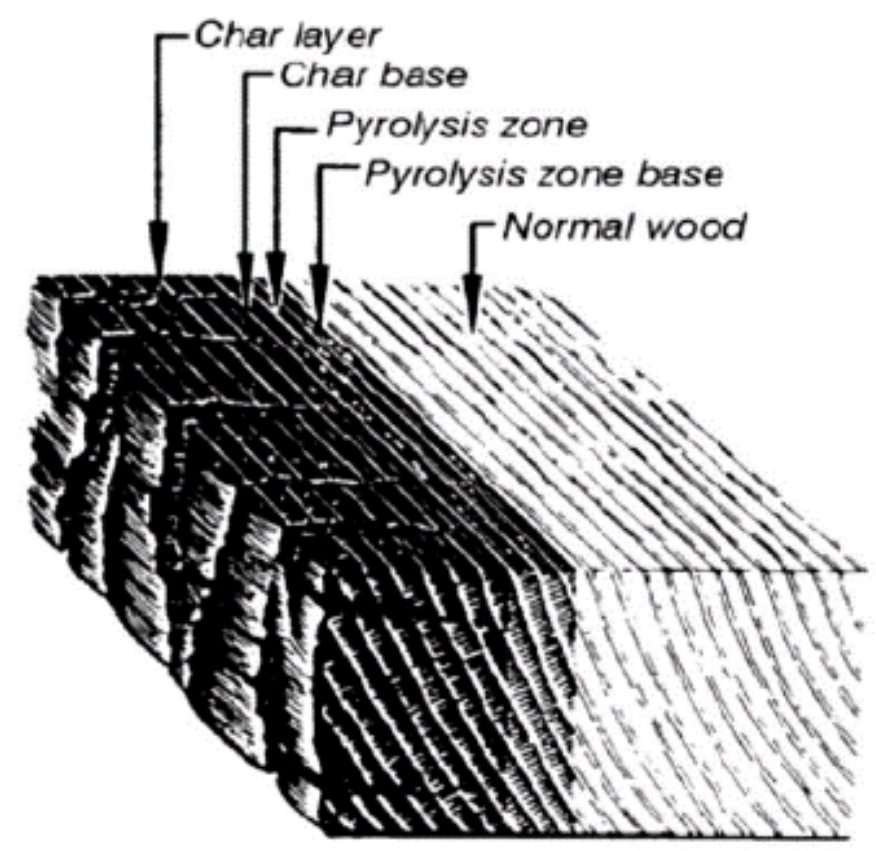

Figure A.4 Charring Distribution on a wooden beam [37]

\section{A.1.1.4 Thermal Properties of Wood}

\section{A.1.1.4.1 Thermal Conductivity}

Figure A.5 shows the variation of thermal conductivity of wood with temperatures as reported by five researchers; Knudson [72], Fredlund [73], Mehaffey et al. [74], Janssens [75] and Konig and Walleij [76]. Overall, the researchers reported a similar trend of linear increase in the thermal conductivity of wood up to a temperature of $200^{\circ} \mathrm{C}$, then a linear decline between $200^{\circ} \mathrm{C}$ and $350^{\circ} \mathrm{C}$, and a linear rise after $350^{\circ} \mathrm{C}$. As shown in the graph, the scattering in the data values is due to variation in wood species, wood density, moisture content and methods of testing.

Fredlund [73] published two set of values for wood charring, then assumed that wood turns to charcoal at $300^{\circ} \mathrm{C}$ Based on the work of Lie [77], Mehaffey et al. [74] derived values for thermal conductivity of wood. Janssens [75] used formulae to determine the thermal conductivity from the oven-dry density and moisture content. Janssens [75] noted that wood is 
made up of layers of solid wood fibres, void and moisture (at temperatures below $100^{\circ} \mathrm{C}$ ), and that the thermal conductivity of wood is at maximum if the layers are arranged in parallel and at minimum if the they are arranged in series. He used an interpolation factor to determine the conductivity from the maximum and minimum values. Knudson [72] reported sets of thermal conductivity values for wood and charcoal from temperatures up to $200^{\circ} \mathrm{C}$ and from $350^{\circ} \mathrm{C}$, respectively, and he used a linear relationship between temperatures of $20^{\circ} \mathrm{C}$ to $350^{\circ} \mathrm{C}$ and beyond, to describe the effect of the decomposition of wood. Konig and Walleij [76] increased the thermal conductivity values obtained from other researchers to temperatures over $500^{\circ} \mathrm{C}$ in order to consider the influence of cracks and shrinkage of the charred layer. The values of thermal conductivity of wood reported in Eurocode 5 are based on the work of Konig and Walleij [5].

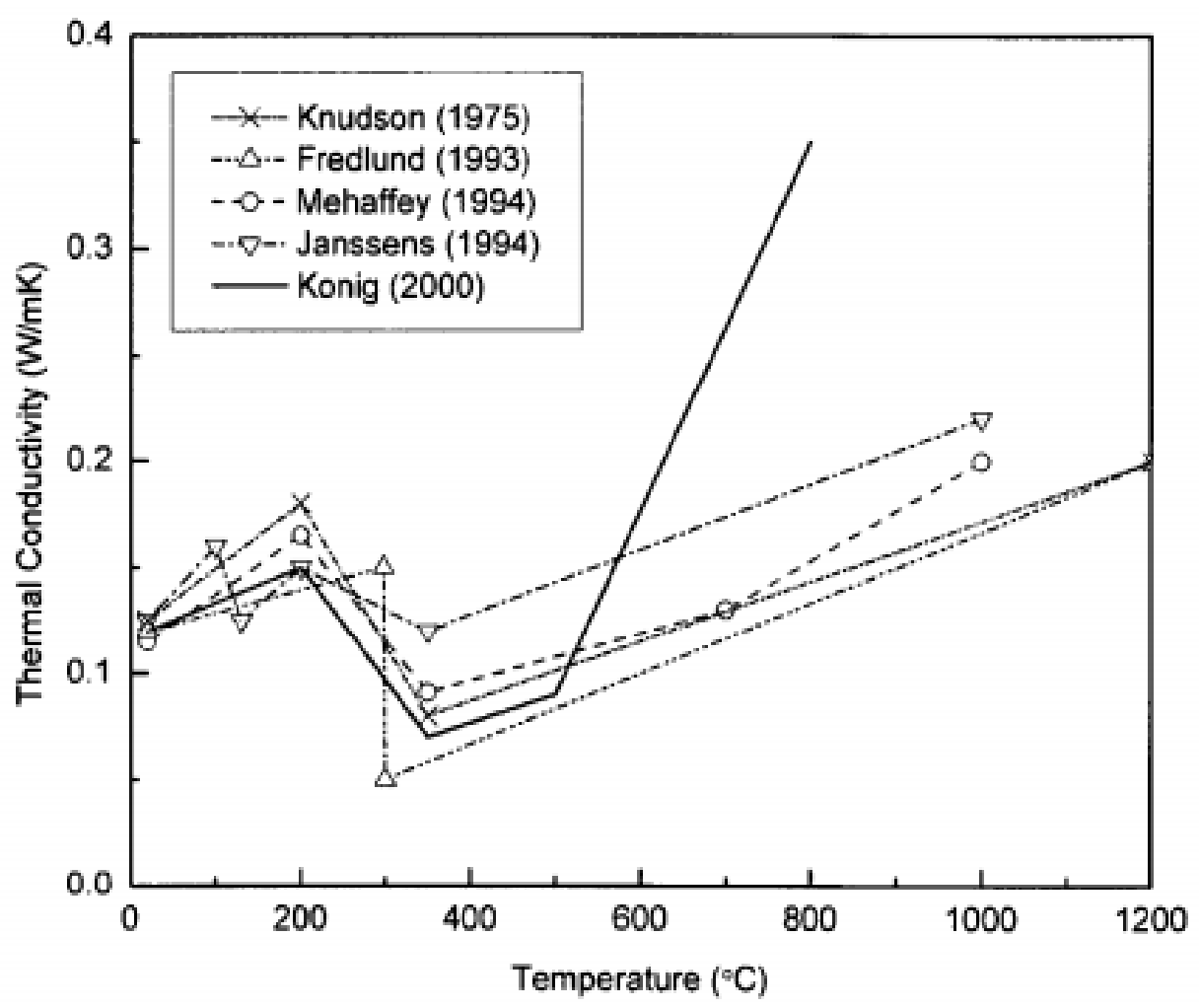

Figure A.5 Thermal conductivity of wood at elevated temperatures [Adopted from 11] 


\section{A.1.1.4.2 Specific Heat}

Figure A. 6 shows the relationships of specific heat of wood with temperature as reported by a number of researchers. The research work of Gammon [78], Janssens [75], Mehaffey et al. [74], and Konig and Walleij [76] on the specific heat of wood at elevated temperatures is shown in Figure 2.11. As it can be seen in the graph, the large spike observed in the specific heat values between $100^{\circ} \mathrm{C}$ and $120^{\circ} \mathrm{C}$ represents the extra energy needed to evaporate moisture in the wood as reported by Mehaffey et al. [74] and Konig [76]. It is observed that at temperatures below $100^{\circ} \mathrm{C}$, Janssens [50] curve exhibits higher specific heat values than that of Mehaffey et al. [74] and Gammon [78].

Mehaffey et al. [74] gives an equation to calculate the specific heat of wood for up to temperatures of $200^{\circ} \mathrm{C}$ and assumes a linear drop in its value at $200^{\circ} \mathrm{C}$ to $0.69 \mathrm{~kJ} / \mathrm{kg} . \mathrm{K}$ at $350^{\circ} \mathrm{C}$, after which the specific heat of char is assumed to remain at $0.69 \mathrm{~kJ} / \mathrm{kg} . \mathrm{K}$ for temperatures of char material over $350^{\circ} \mathrm{C}$ based on the work of Lie [77].

The specific heat of wood recommended in Eurocode 5 is based on the work of Konig and Walleij [76]. 


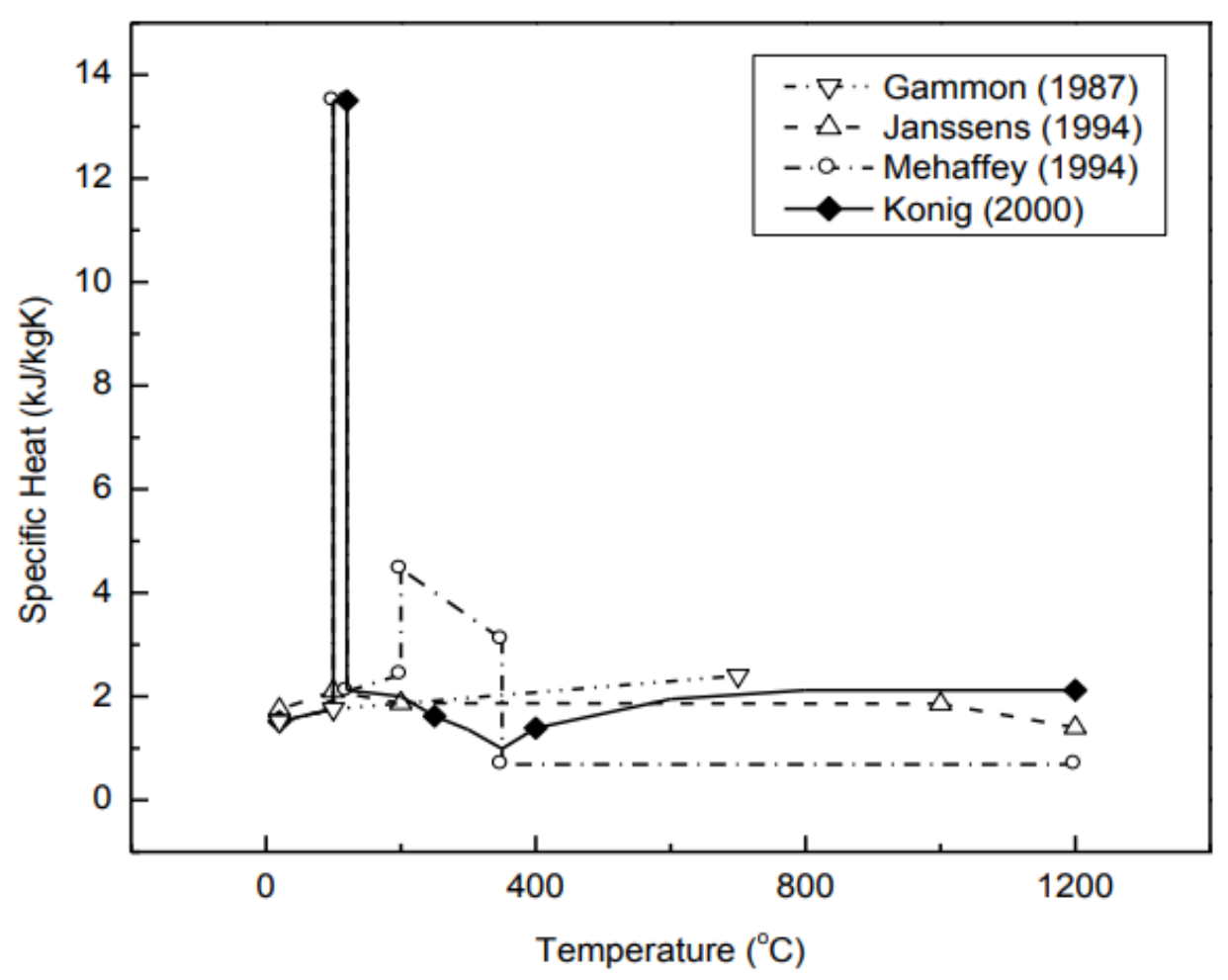

Figure A.6 Specific heat of wood at elevated temperatures [Adopted from 11]

Thomas reported the basic equation used by Gammon [78], Janssens [75] and Mehaffey et al. [74] in calculating the specific heat of wood as:

$$
C_{p}=\left(\frac{a+b T+4.187 u}{1+u}\right)+\Delta c
$$

Where $\quad C_{p}=$ specific heat $(\mathrm{kJ} / \mathrm{kg} . \mathrm{K})$

$a, b=$ coefficients which are given different values by the three researchers

$\mathrm{T}=$ Temperature $\left({ }^{\circ} \mathrm{C}\right)$

$\mathrm{u}=$ moisture content $(\mathrm{kg} / \mathrm{kg})$

$\Delta c=$ correction to allow for bound moisture:-

$$
\Delta c=(23.55 T-1326 u+2417) u
$$

This correction is used only by Janssens [75]. 


\section{A.1.1.4.3 Density}

Different studies have shown that the density of wood depends largely on temperature and varies between tree species. Figure A.7 shows the relation between density and temperature studied by different researchers. Generally, Lie [77], Takeda and Mehaffey [79] and Janssens [75] reported a similar decrease in density values as the temperature increases. As shown in the graph, the vaporization and migration of free water causes the density of wood to drop to a value between 0.9 and 0.95 at $200^{\circ} \mathrm{C}$, then decline rapidly to about 0.2 or 0.3 at approximately $350^{\circ} \mathrm{C}$ because wood undergoes pyrolysis in which it decomposes to char. After $350^{\circ} \mathrm{C}$, the density of wood decreases steadily.

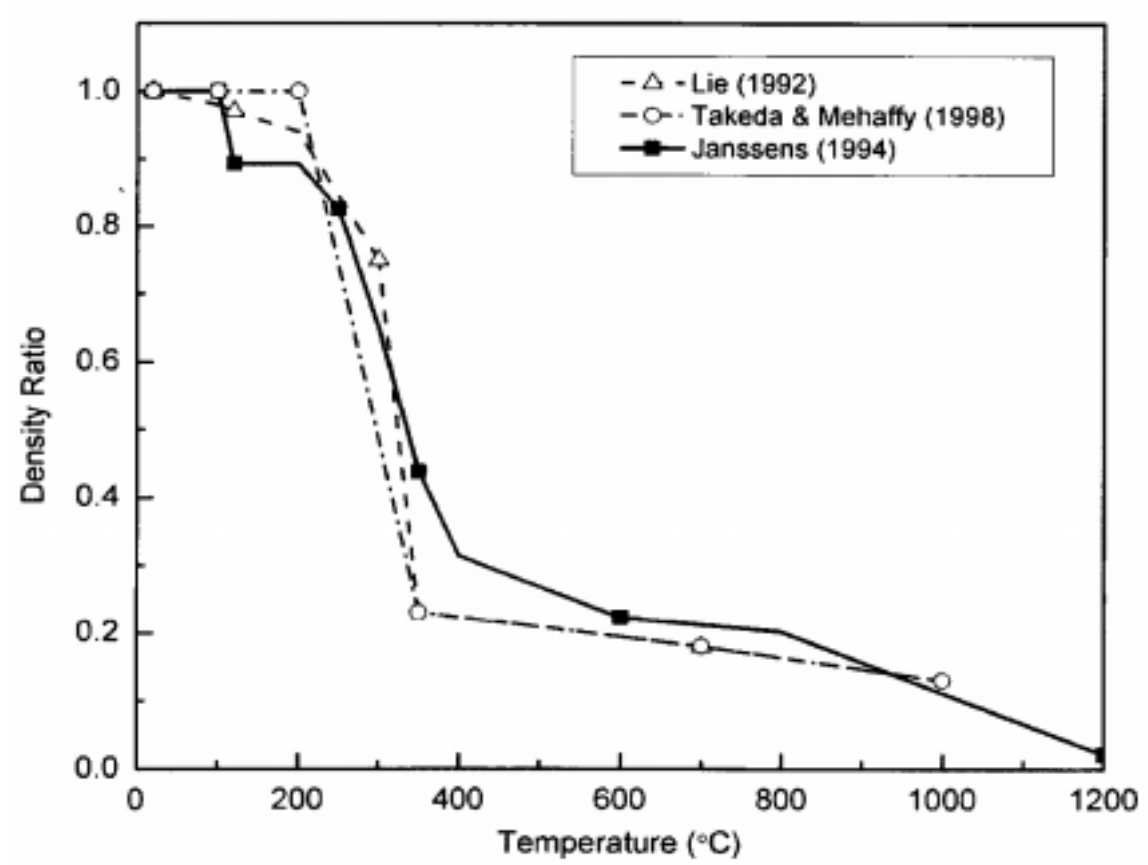

Figure A.7 Density of wood at elevated temperatures [Adopted from 11]

\section{A.1.1.4.4 Modulus of Elasticity}

Figure A.8 shows the effect of elevated temperatures on the modulus of elasticity of wood parallel-to-grain as reported by Preusser [80], Schaffer [81], Ostman [82], Lie [77] and 
Janssens [83]. In general, the values of the modulus of elasticity reported by the researchers show a decrease similar to that seen in density. For the modulus of elasticity of wood with a moisture content between 0-12\%, Preusser, Lie and Janssens reported an approximate linear relationship that gives a slow decrease in values up to a temperature of $180^{\circ} \mathrm{C}$ to $200^{\circ} \mathrm{C}$ Above $200^{\circ} \mathrm{C}$, the decrease is more rapid. According to Gerhards [84], the reduction in modulus of elasticity is about $20-30 \%$ at $180^{\circ} \mathrm{C}$. All researchers reported one set of values for tension and compression except for Thomas [85] and Konig [76] (see Figure A.9).

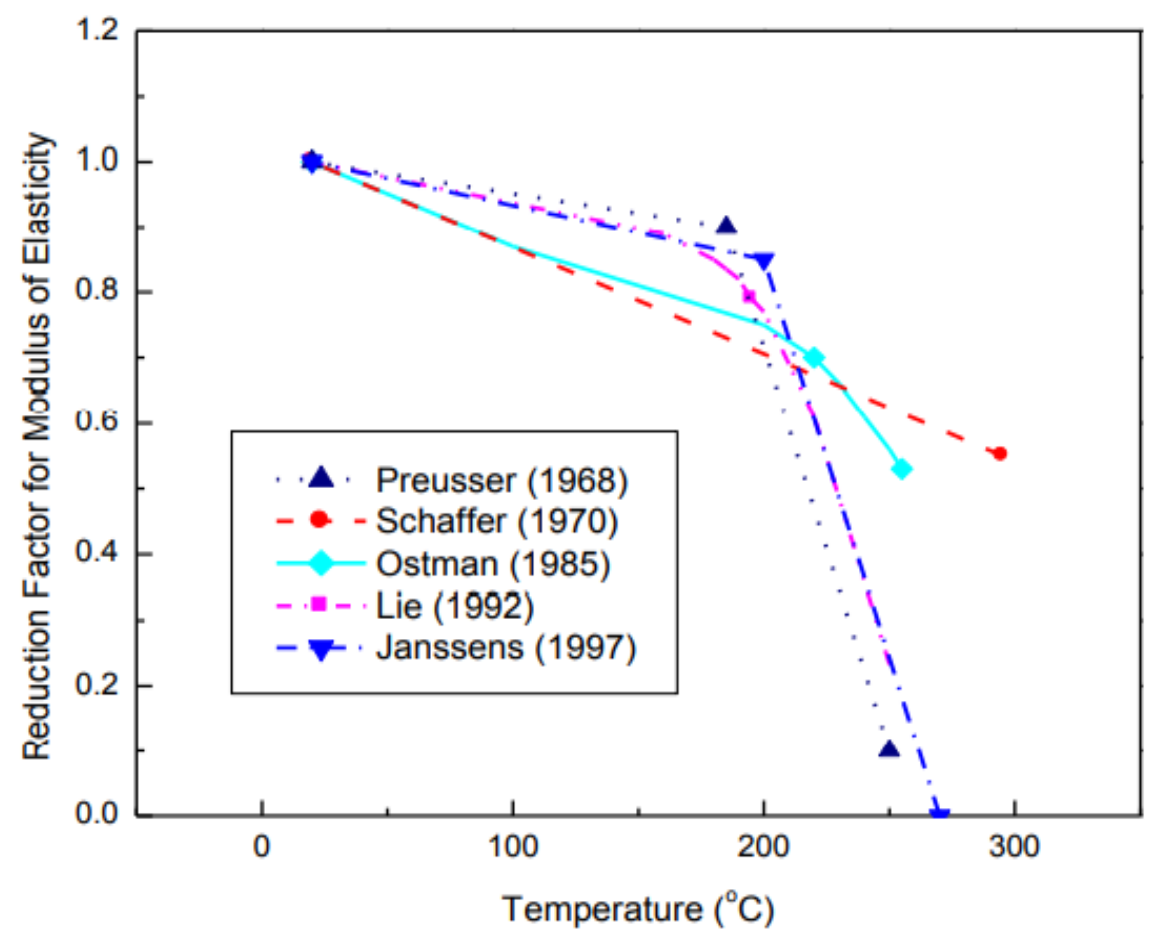

Figure A.8 Elastic modulus of wood at elevated temperatures [27]

Konig and Walleij [76] conducted tests on $145 \times 45 \mathrm{~mm}$ timber studs at elevated temperatures that followed the ISO 834 standard time-temperature curve in order to investigate the stiffness of wood at high temperatures. At $100^{\circ} \mathrm{C}$, the authors reported $50 \%$ and $65 \%$ reduction in the stiffness of wood in tension and compression, respectively. Then, the modulus of elasticity further decreased by about $100 \%$ as the temperature rose to $300^{\circ} \mathrm{C}$ 
At $100^{\circ} \mathrm{C}$, Thomas [85] reported that the modulus of elasticity in compression reduces by about $60 \%$ and further decreases by about $95 \%$ at $300^{\circ} \mathrm{C}$. The author reported that the modulus of elasticity in tension exhibited a linear decrease trend until charring and loses $40 \%$ of its strength in the first $300^{\circ} \mathrm{C}$. Thomas concluded that the effective stiffness of wood is the stiffness in the compression zone. Konig and Thomas are the only researchers that reported separate set of values for compression and tension as shown in Figure A.9.

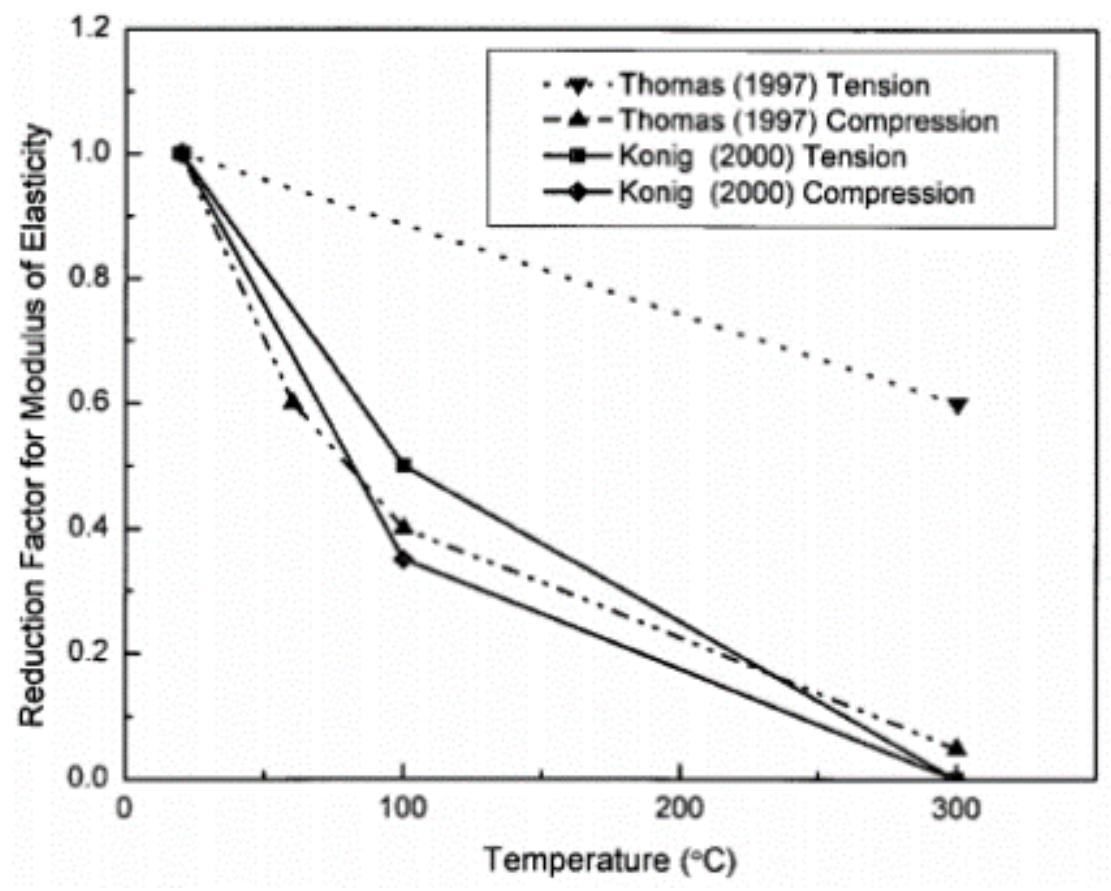

Figure A.9 Elastic modulus of wood at elevated temperatures [Adopted from 11]

\section{A.1.1.4.5 Tensile Strength}

Figure A.10 shows the effect of elevated temperature on the tensile strength of wood parallelto-grain as reported by Schaffer [81], Knudson [86], Thomas [85], Lie [77] and Konig [76]. The graph shows a roughly linear relationship that represents the reduction of tensile strength of wood with a moisture content between 0 to $12 \%$. Schaffer assumes that the tensile strength of wood exhibits a gradual linear decrease from its initial strength at room temperature to about $200^{\circ} \mathrm{C}$, and subsequently declined linearly at a more rapid rate at temperatures above $200^{\circ} \mathrm{C}$ 
Knudson [86] and Lie [77] reported a linear relationship from the initial room temperature to about the char temperature $\left(300^{\circ} \mathrm{C}\right)$. As it can be seen, Thomas reported that the tensile strength was steadily constant between $20^{\circ} \mathrm{C}$ and $80^{\circ} \mathrm{C}$, followed by a linear decrease to about $30 \%$ of its initial value at $295^{\circ} \mathrm{C}$ and wood finally loses its strength at $310^{\circ} \mathrm{C}$. Konig [76] used a bilinear relationship to represent the downward trend of tensile strength with temperature, and the values for the reduction factor of tensile strength falls more rapidly than other researchers. He reported that the tensile strength of wood decreases to about $60 \%$ of its original value at $100^{\circ} \mathrm{C}$, then reduces to about $0 \%$ at $300^{\circ} \mathrm{C}$. It is observed that the slope of the linear decrease varied among the researchers.

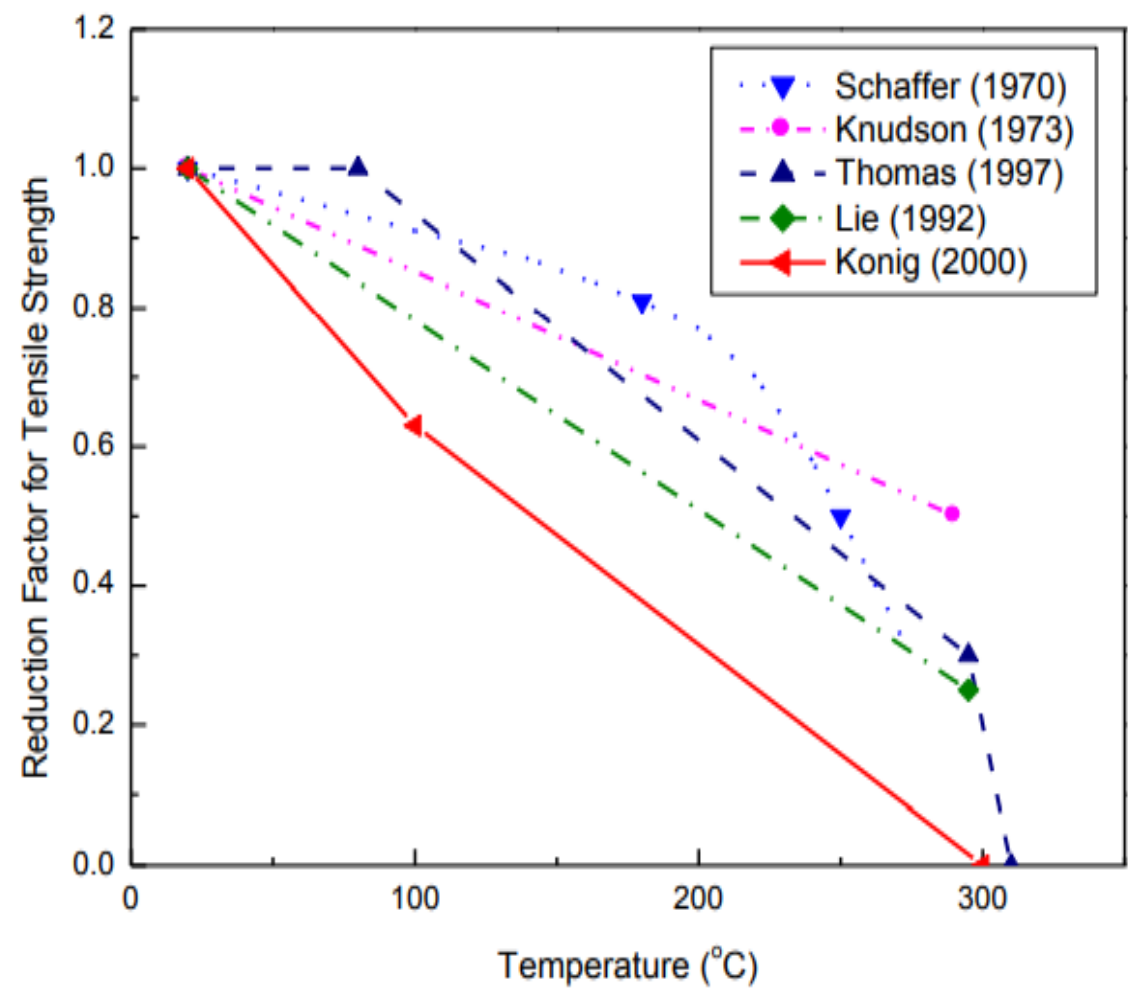

Figure A.10 Tensile strength of wood at elevated temperatures [27]

\section{A.1.1.4.6 Compressive Strength}

Figure A.11 shows the effect of elevated temperatures on the compressive strength of wood parallel-to-grain as reported by Schaffer [81], Lie [77], Thomas [85] and Konig [76]. The 
researchers reported that the compressive strength decreases with temperature at a faster rate than for tensile strength. Schaffer and Lie reported a linear relationship from the initial room temperature to about the char temperature $\left(300^{\circ} \mathrm{C}\right)$. The slopes of decline are very similar for Konig [76] and Thomas [85]. They both used a bilinear relationship with a breakpoint at $100^{\circ} \mathrm{C}$ to represent the decrease in compressive strength of wood.

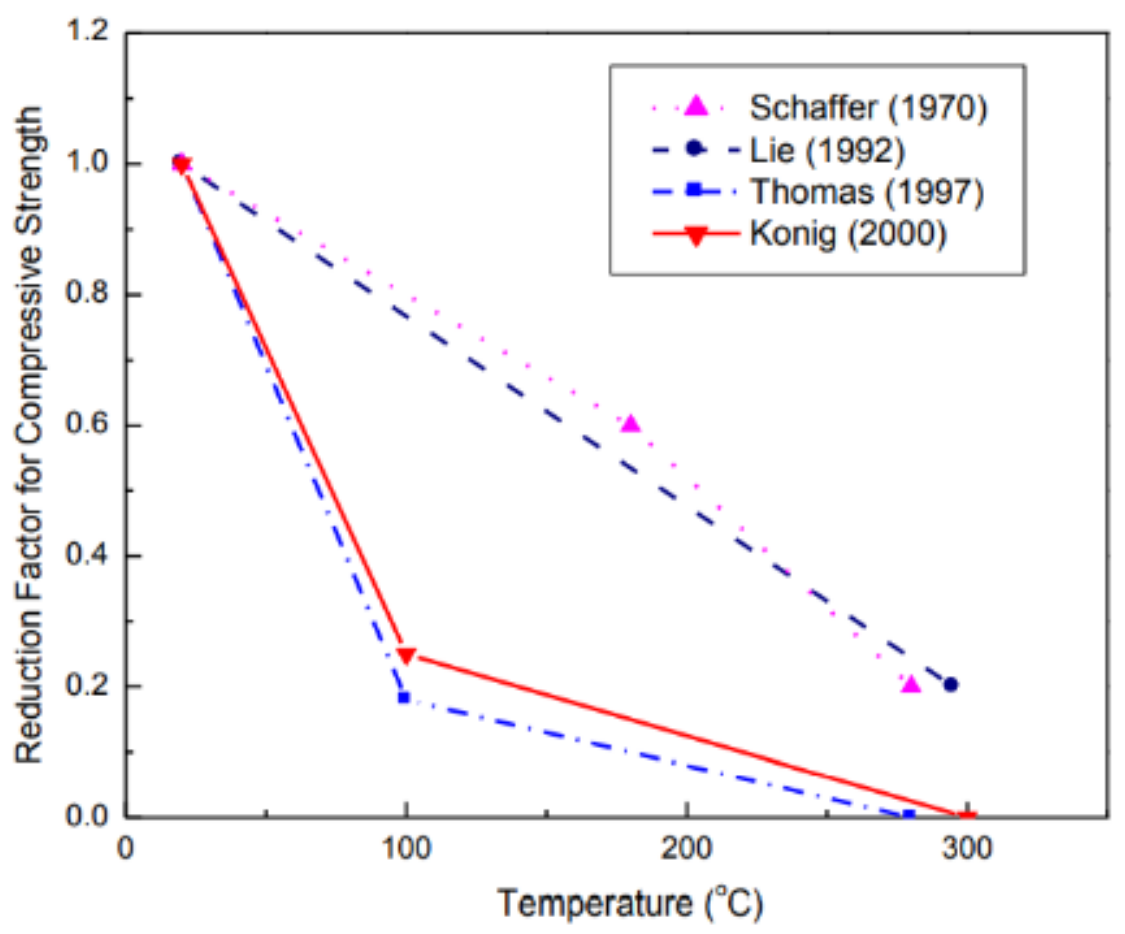

Figure A.11 Compressive strength of wood at elevated temperatures [27]

\section{A.1.1.5 Steel at Elevated Temperatures}

The behaviour of steel under fire exposure is largely dependent on its thermal conductivity, density, and specific heat. Unlike wood, steel has a high thermal conductivity and as a result, its temperature increases rapidly when exposed to fire. Owing to the increase in steel temperatures, the stiffness and strength of steel are significantly reduced at elevated 
temperatures thereby causing an increase in deformation which eventually leads to failure of the material [7]. This section describes the thermal properties of steel at high temperatures.

\section{A.1.1.5.1 Thermal Properties of Steel}

Under fire exposure, the knowledge of the thermal properties of steel is necessary for heat transfer calculations to determine the temperature profile within the steel. For structural fire engineering, the accurate estimation of steel temperature is important to effectively design steel structures to resist fire.

\section{A.1.1.5.2 Density}

The density of steel at elevated temperatures remains constant as its ambient value of 7850 $\mathrm{kg} / \mathrm{m}^{3}$. This is because steel does not decompose like wood.

\section{A.1.1.5.3 Thermal Conductivity}

Thermal conductivity is the rate of heat transferred through a unit thickness of the material per unit temperature difference, with units of $\mathrm{W} / \mathrm{mK}$. Figure A.12 illustrates the bilinear relationship between thermal conductivity and temperature [7]. The graph shows a linear reduction in the thermal conductivity of steel from $54 \mathrm{~W} / \mathrm{mK}$ at $0^{\circ} \mathrm{C}$ to $27.3 \mathrm{~W} / \mathrm{mK}$ at $800^{\circ} \mathrm{C}$. The thermal conductivity remains constant above $800^{\circ} \mathrm{C}$. As stated in Eurocode 3 [87], the equations for thermal conductivity of steel $\lambda$ are:

$$
\begin{array}{ll}
\lambda=54-0.0333 T \mathrm{~W} / \mathrm{mK} & 20{ }^{\circ} \mathrm{C} \leq T<800{ }^{\circ} \mathrm{C} \\
\lambda=27.3 \mathrm{~W} / \mathrm{mK} & 800{ }^{\circ} \mathrm{C} \leq T<1200{ }^{\circ} \mathrm{C}
\end{array}
$$

Where $T$ is the steel temperature $\left({ }^{\circ} \mathrm{C}\right)$. 
Thermal conductivity [ $\mathrm{W} / \mathrm{mK}$ ]

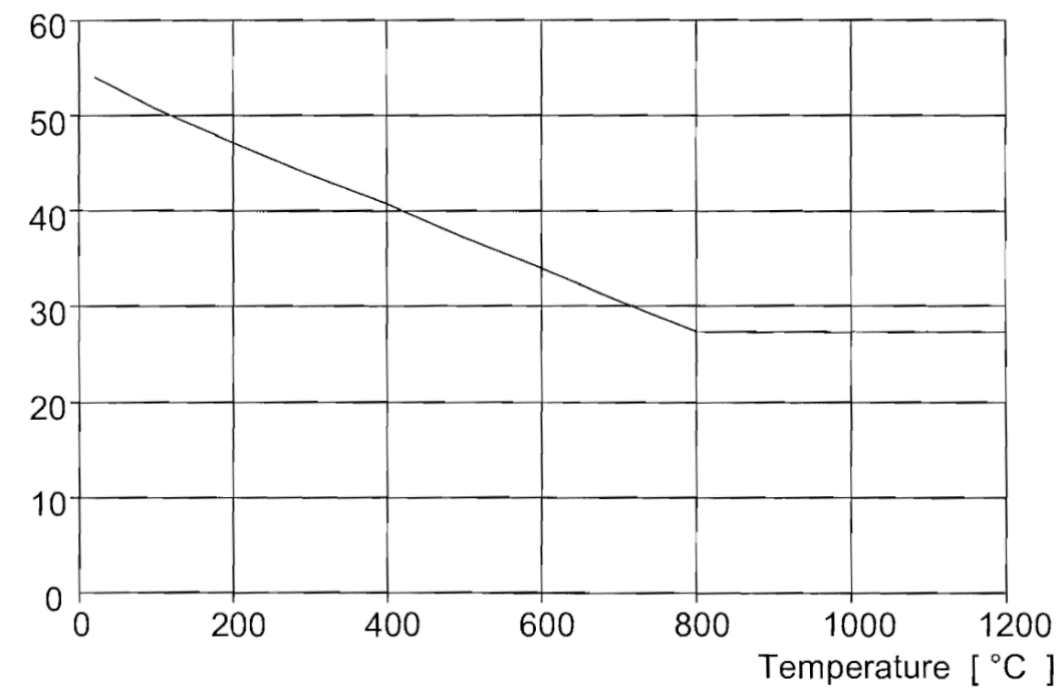

Figure A.12 Thermal conductivity of steel as a function of the temperature [87]

\section{A.1.1.5.4 Specific Heat}

The amount of heat needed to raise a unit mass of a material by one degree is referred to as specify heat $c_{p}$ with units of $\mathrm{J} / \mathrm{kgK}$. Figure A.13 illustrates the variation of specific heat with the temperature of steel as described in Eurocode 3 [87]. At around $730{ }^{\circ} \mathrm{C}$, the sudden rise in the specific heat of steel as shown in the figure is a result of a metallurgical change that occurs in steel. According to Eurocode 3, the equations for estimating specific conductivity of steel $\lambda$ are given as:

$$
\begin{array}{rlrl}
\mathrm{c}_{\mathrm{p}} & =425+0.773 T-1.69 \times 10^{-3} T^{2}+2.22 \times 10^{-6} T^{3} & 20{ }^{\circ} \mathrm{C} \leq T<600{ }^{\circ} \mathrm{C} \\
& =666+13002 /(738-T) & & 600{ }^{\circ} \mathrm{C} \leq T<735{ }^{\circ} \mathrm{C} \\
& =545+17820 /(T-731) & & 735{ }^{\circ} \mathrm{C} \leq T<900{ }^{\circ} \mathrm{C} \\
& =650 & & 900{ }^{\circ} \mathrm{C} \leq T<1200{ }^{\circ} \mathrm{C}
\end{array}
$$

Where $T$ is the steel temperature $\left({ }^{\circ} \mathrm{C}\right)$. 


\section{Specific heat $[\mathrm{J} / \mathrm{kg} \mathrm{K}$ ]}

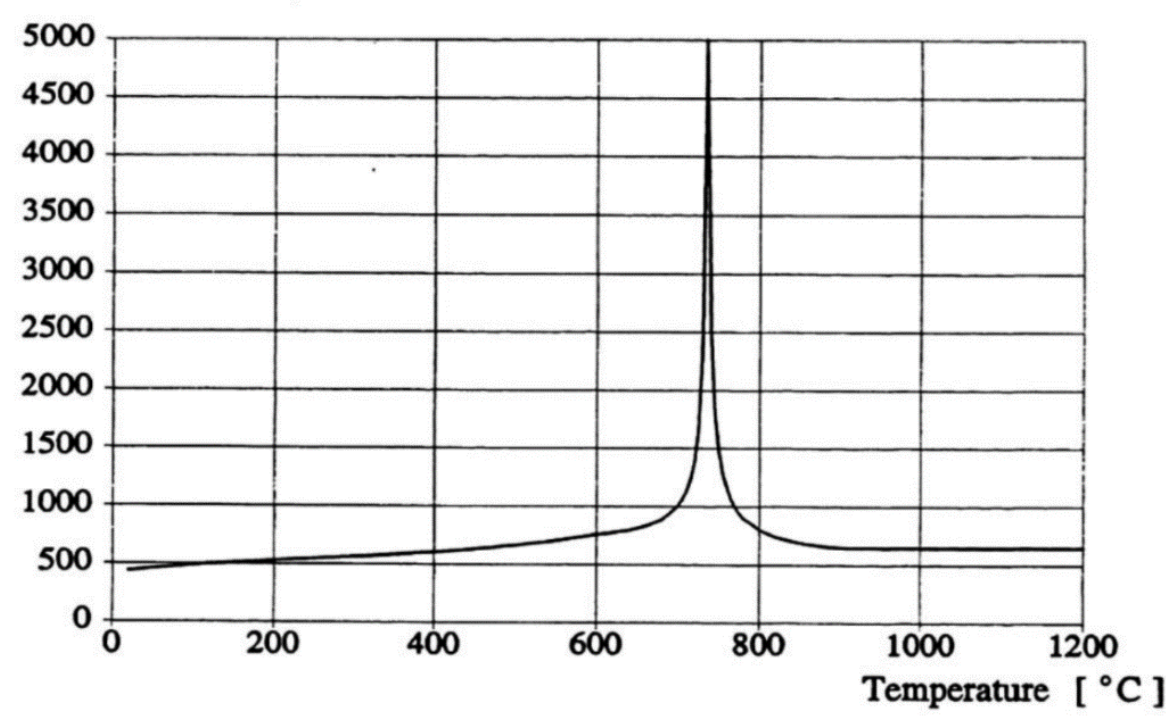

Figure A.13 Variation of specific heat of steel with temperature [87] 
APPENDIX B

\section{ESTIMATED LOAD RATIO CALCULATIONS}

Table B.1 Estimated load ratios

\begin{tabular}{|c|c|c|c|c|c|c|}
\hline $\begin{array}{c}\text { Connection } \\
\text { ID }\end{array}$ & $\begin{array}{c}\text { Max. failure } \\
\text { moment of } \\
\text { unreinforced } \\
\text { connections } \\
\text { (Exp. Test) [22] } \\
\text { (kN.m) }\end{array}$ & $\begin{array}{c}\text { Max. failure } \\
\text { moment of } \\
\text { reinforced } \\
\text { connections } \\
\text { (Estimated as } \\
\text { per [56]) } \\
\text { (kN.m) }\end{array}$ & $\begin{array}{l}\text { Max. moment } \\
\text { resistance of } \\
\text { reinforced } \\
\text { connections } \\
\text { (Estimated) } \\
\text { (kN.m) }\end{array}$ & $\begin{array}{l}\text { Applied } \\
\text { moment } \\
\text { (kN.m) }\end{array}$ & $\begin{array}{l}\text { Applied load ratio } \\
\text { with respect to the } \\
\text { max. moment } \\
\text { resistance of the } \\
\text { weakest unreinforced } \\
\text { connection }(\%)\end{array}$ & $\begin{array}{l}\text { Estimated load ratio } \\
\text { with respect to the } \\
\text { max. moment } \\
\text { resistance of each } \\
\text { reinforced } \\
\text { connection }(\%)\end{array}$ \\
\hline 4BP1LR60 & 26.5 & 53.8 & 30.1 & 8.9 & 60 & 30 \\
\hline 4BP2LR60 & 50.9 & 103.3 & 57.8 & 8.9 & 60 & 15 \\
\hline 4BP1LR100 & 26.5 & 53.8 & 30.1 & 14.8 & 100 & 50 \\
\hline 4BP2LR100 & 50.9 & 103.3 & 57.8 & 14.8 & 100 & 25 \\
\hline 6BP1LR100 & 44 & 66 & 36.9 & 14.8 & 100 & 40 \\
\hline 6BP2LR100 & 78 & 117 & 65.5 & 14.8 & 100 & 20 \\
\hline 6BP1LR130 & 44 & 66 & 36.9 & 19.3 & 130 & 50 \\
\hline 6BP2LR130 & 78 & 117 & 65.5 & 19.3 & 130 & 30 \\
\hline
\end{tabular}


Appendix B 
Petrycki and Salem [56] reported that the moment-resisting capacity of four- and six-bolt concealed connections increased by a factor of 2.03 and 1.5 , respectively, when reinforced with self-tapping screws. Based on these factors, the estimated load ratios with respect to the maximum moment resistance of each reinforced connection (\%) in this study were calculated as follows:

The estimated load ratio $=\frac{\text { Applied max.moment }}{\text { Max.moment resistance of reinforced }} \times 100$

For instance, estimated load ratio for: 4BP1LR60 $=\frac{8.9}{30.1} \times 100=30 \%$

$$
\begin{aligned}
& \text { 4BP2LR60 }=\frac{8.9}{57.8} \times 100=15 \% \\
& \text { 4BP2LR60 }=\frac{14.8}{30.1} \times 100=50 \% \\
& \text { 4BP2LR60 }=\frac{14.8}{57.8} \times 100=25 \% \\
& \text { 4BP2LR60 }=\frac{14.8}{36.9} \times 100=40 \% \\
& \text { 4BP2LR60 }=\frac{14.8}{65.5} \times 100=20 \% \\
& \text { 4BP2LR60 }=\frac{19.3}{36.9} \times 100=50 \% \\
& \text { 4BP2LR60 }=\frac{19.3}{65.5} \times 100=30 \%
\end{aligned}
$$

Therefore, the estimated load ratio is in respect to the actual maximum moment capacity of the reinforced connections. 
APPENDIX C

Time-Temperature Curves for Charring Rate Calculations

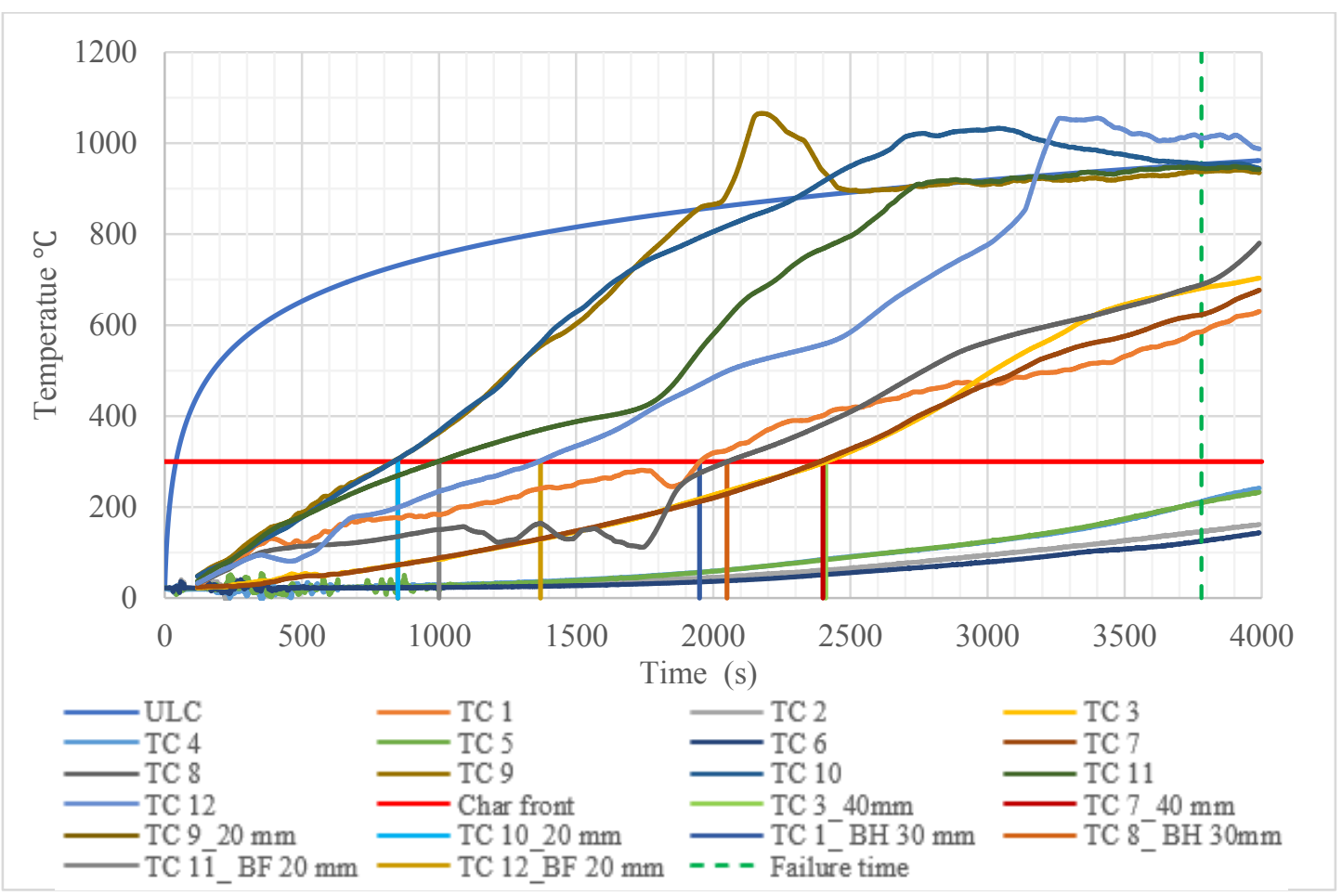

(a) Time-temperature curves for four-bolt pattern P1 at 60\% load ratio

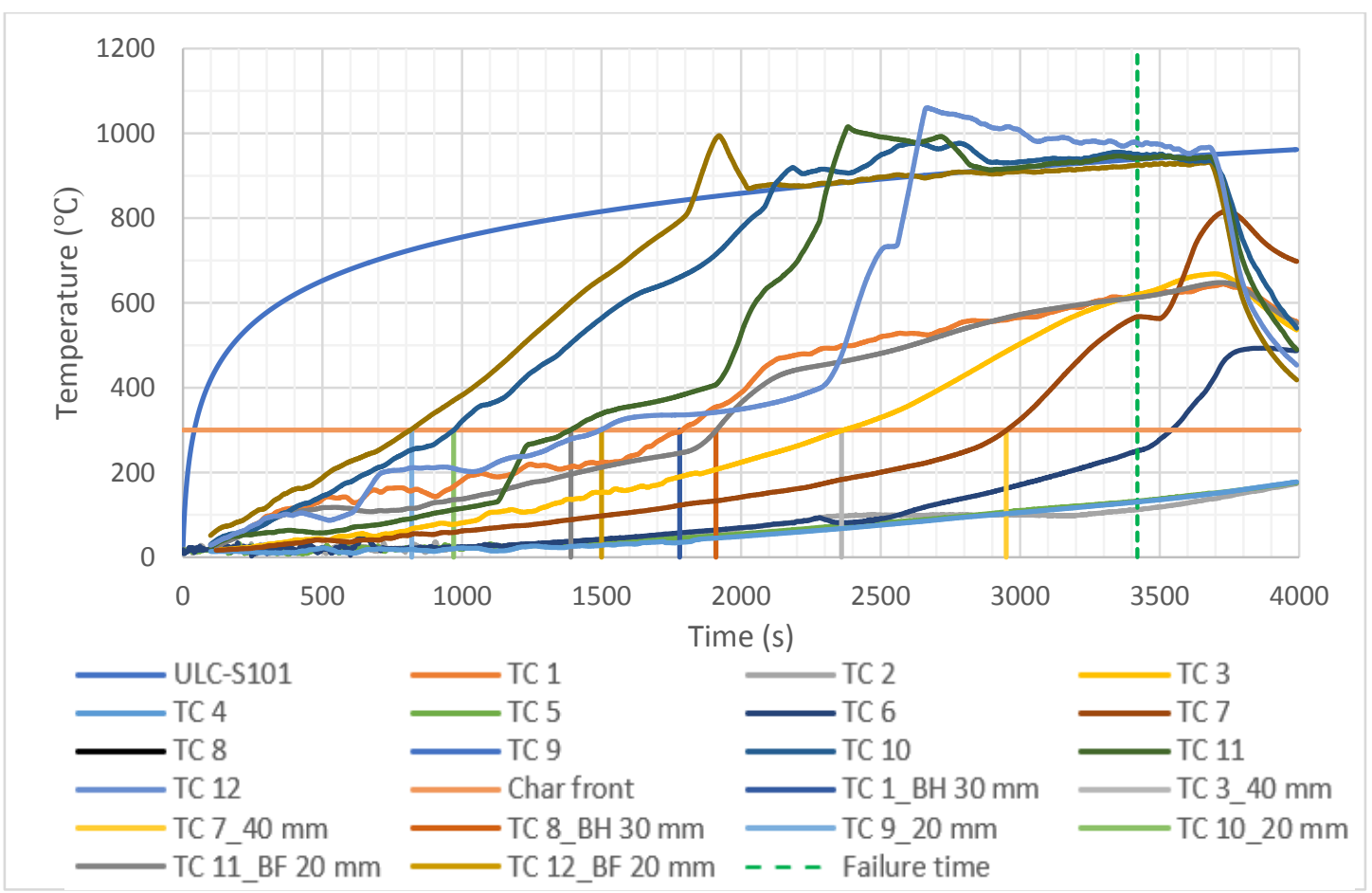

(b) Time-temperature curves for four-bolt pattern P2 at $60 \%$ load ratio 


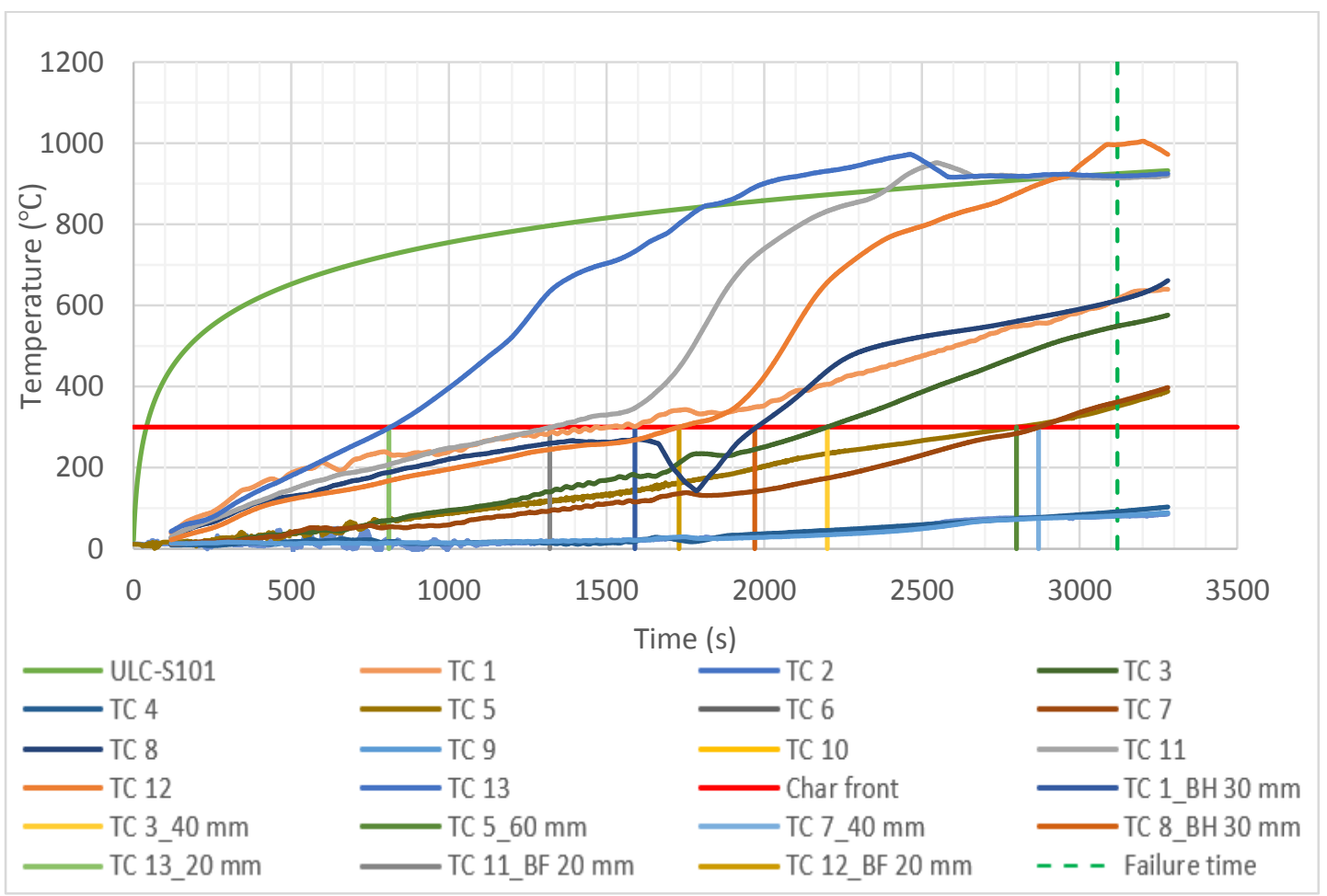

(c) Time-temperature curves for four-bolt pattern P1 at 100\% load ratio

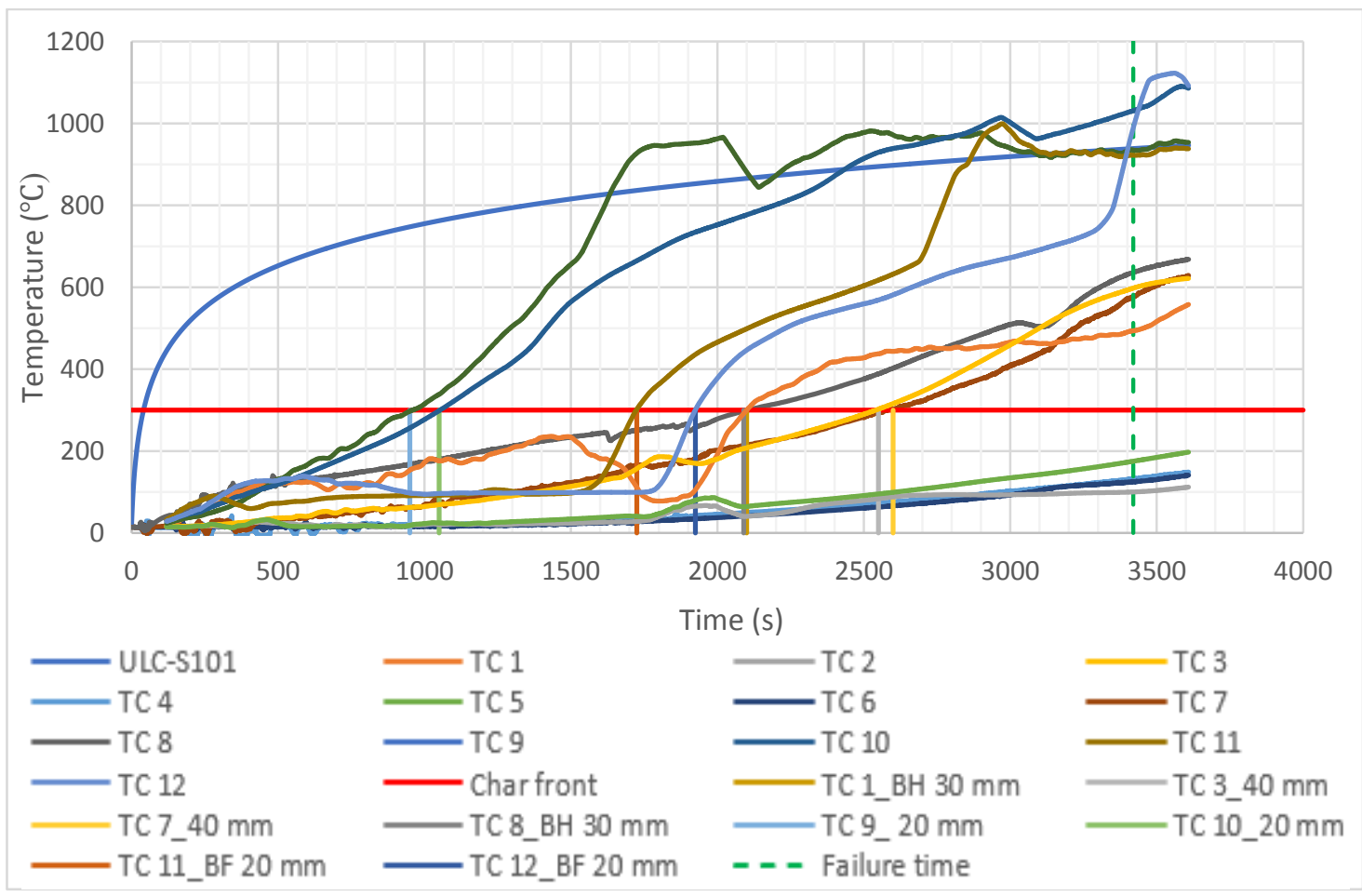

(d) Time-temperature curves for four-bolt pattern P2 at 100\% load ratio 


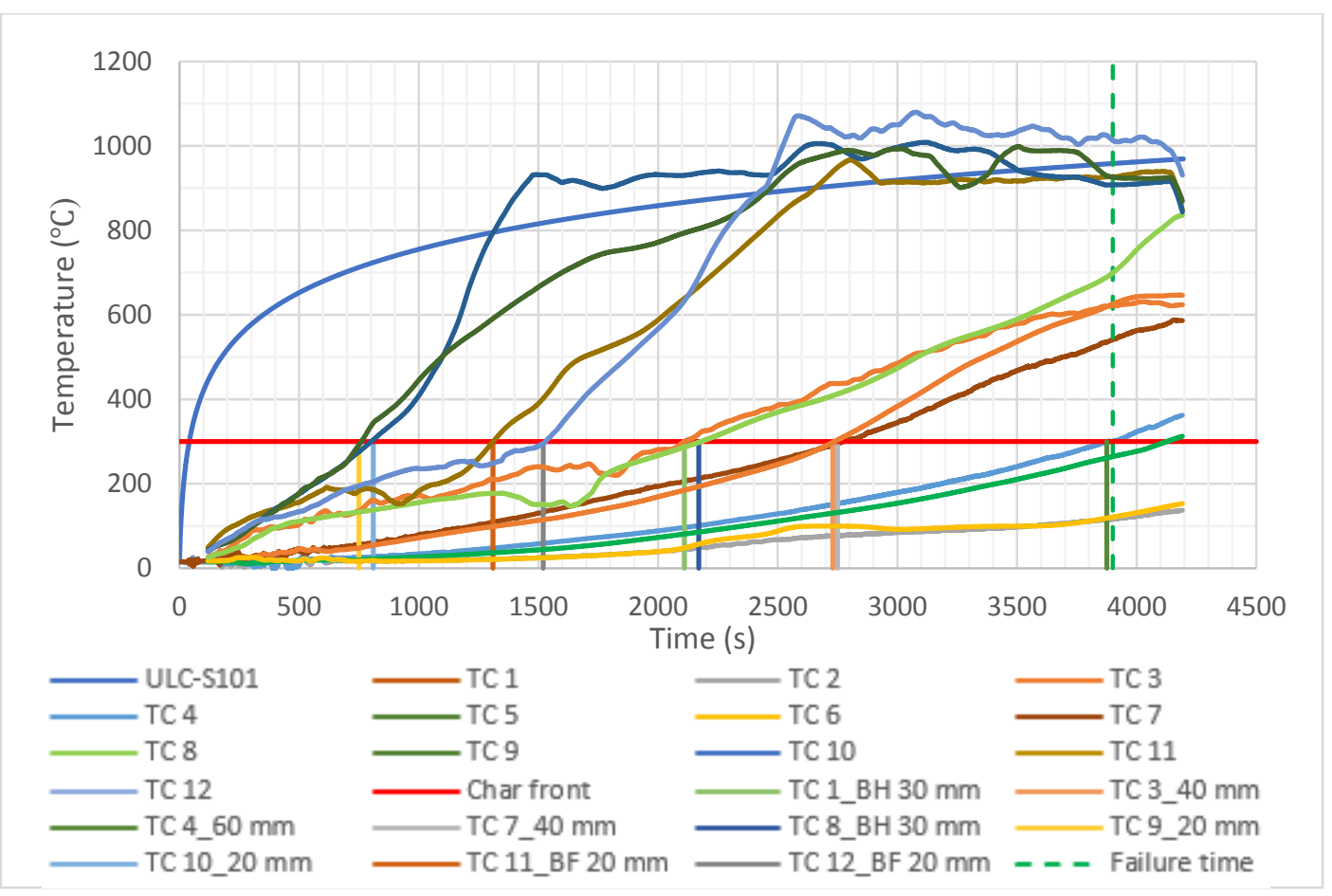

(e) Time-temperature curves for six-bolt pattern P1 at 100\% load ratio

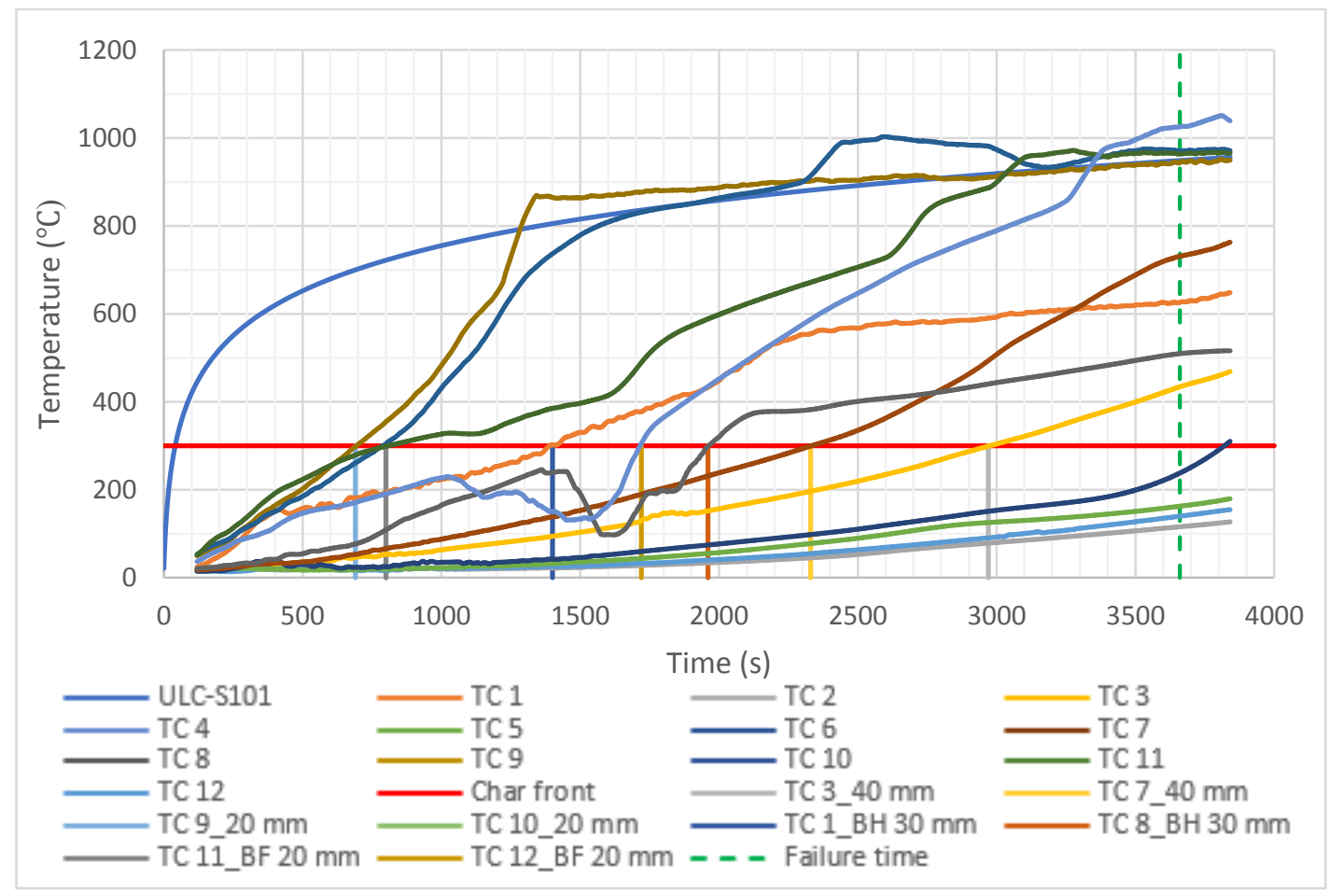

(f) Time-temperature curves for six-bolt pattern P2 at 100\% load ratio 


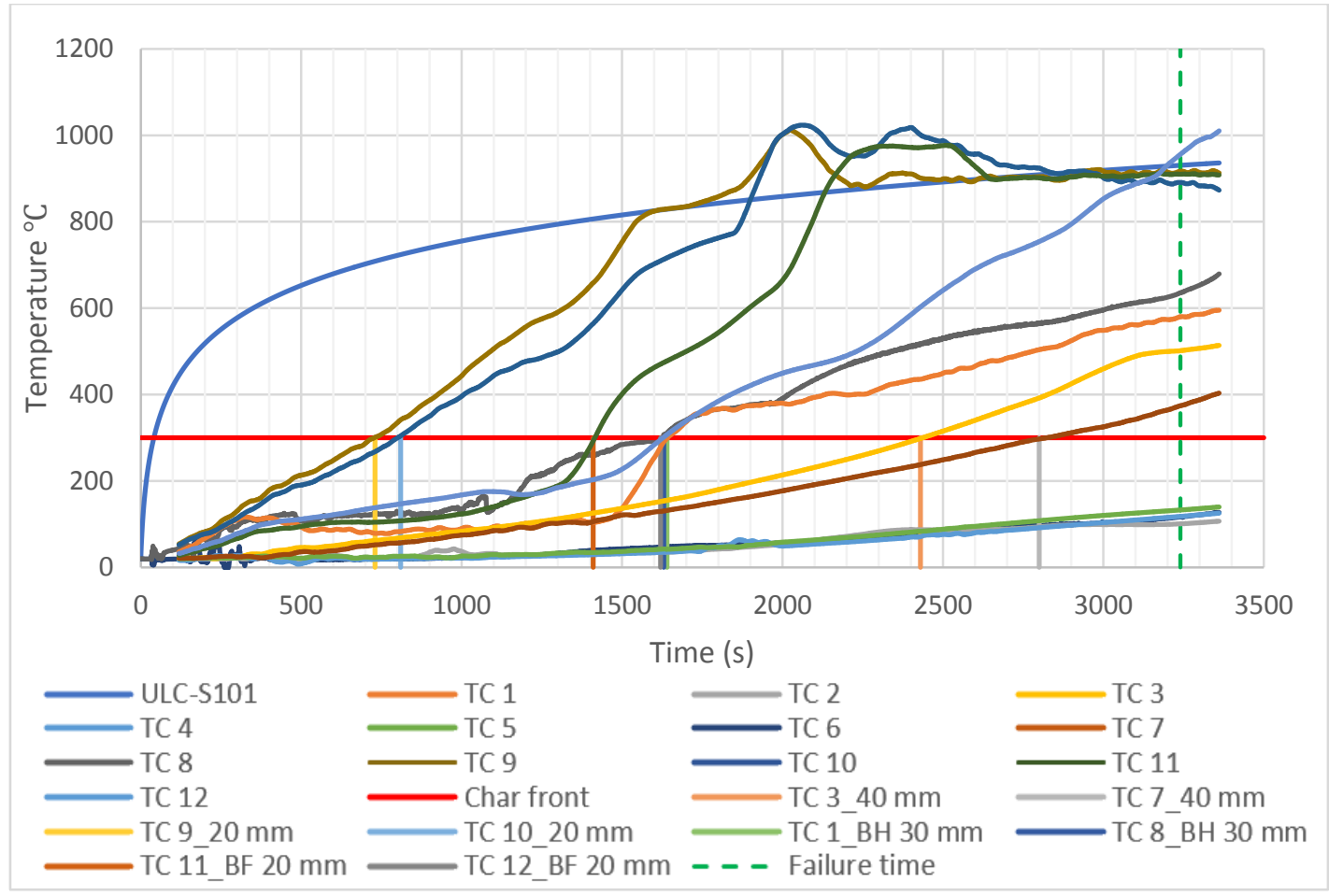

(g) Time-temperature curves for six-bolt pattern P1 at 130\% load ratio

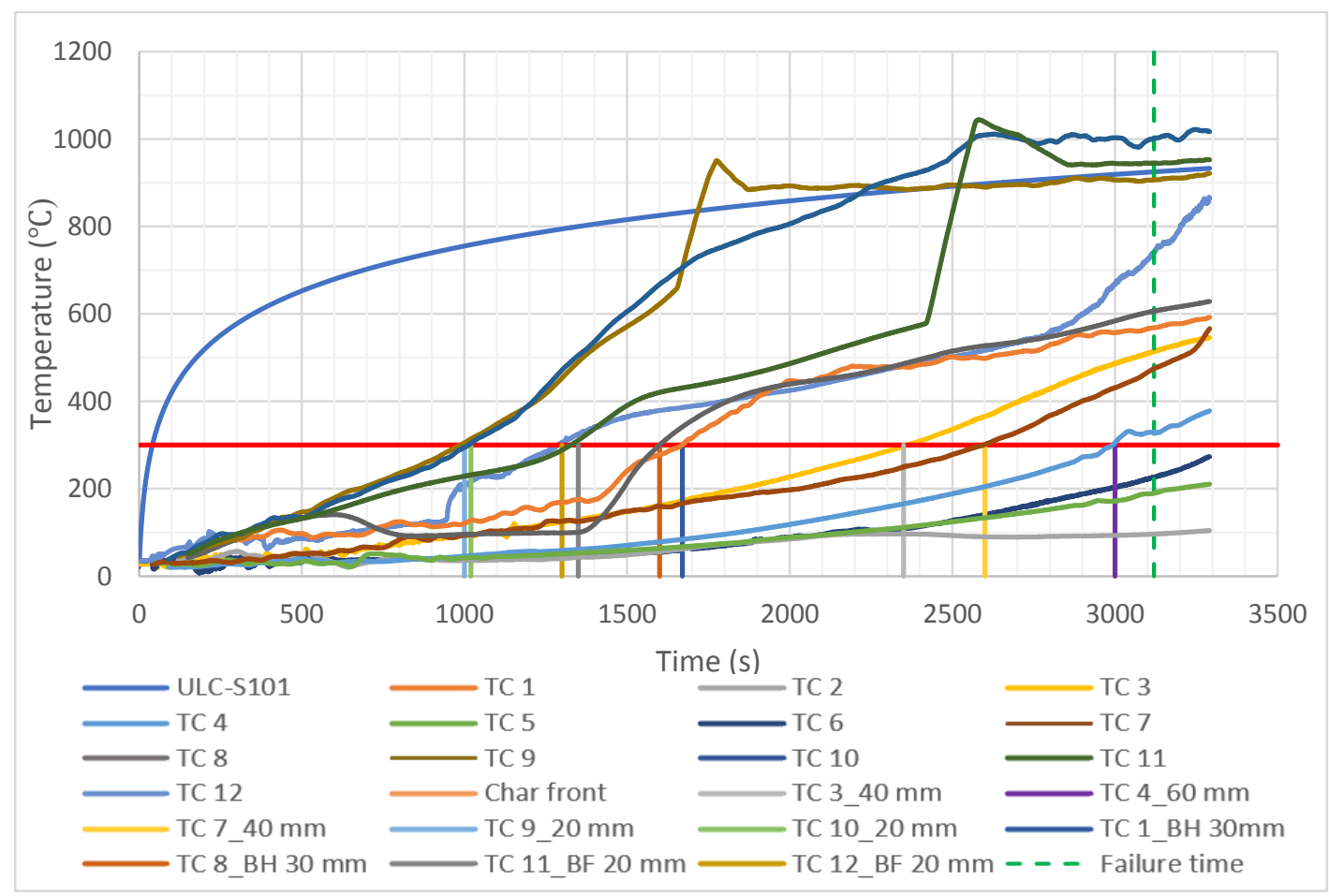

(h) Time-temperature curves for six-bolt pattern P2 at 130\% load ratio

Figure C.1 Time-temperature curves for the eight (8) connections. 
APPENDIX D

\section{Charring Rate Calculations}

Table D.1 Charring rate calculation ( $\mathrm{mm} / \mathrm{min})$

\begin{tabular}{|c|c|c|c|c|c|c|}
\hline Connection & \multicolumn{2}{|c|}{$0-20 \mathrm{~mm}$} & \multicolumn{2}{|c|}{$20-40 \mathrm{~mm}$} & \multicolumn{2}{|c|}{$0-40 \mathrm{~mm}$} \\
\hline ID & TC 10 & TC 9 & TC10 \& TC3 & TC9 \& TC7 & TC3 & TC7 \\
\hline 4BP1LR60 & $\frac{20-0}{\frac{777-0}{60}}=1.54$ & $\frac{20-0}{\frac{773-0}{60}}=1.55$ & $\frac{40-20}{\frac{2355-777}{60}}=0.76$ & $\frac{40-20}{\frac{2336-773}{60}}=0.77$ & $\frac{40-0}{\frac{2355-0}{60}}=1.02$ & $\frac{40-0}{\frac{2336-0}{60}}=1.03$ \\
\hline Average & \multicolumn{2}{|c|}{1.55} & \multicolumn{2}{|c|}{0.77} & \multicolumn{2}{|c|}{1.03} \\
\hline 4BP2LR60 & $\frac{20-0}{\frac{914-0}{60}}=1.31$ & $\frac{20-0}{\frac{765-0}{60}}=1.57$ & $\frac{40-20}{\frac{2307-914}{60}}=0.86$ & $\frac{40-20}{\frac{2898-765}{60}}=0.56$ & $\frac{\frac{40-0}{2307-0}}{60}=1.04$ & $\frac{40-0}{\frac{2898-0}{60}}=0.83$ \\
\hline Average & \multicolumn{2}{|c|}{1.44} & \multicolumn{2}{|c|}{0.71} & \multicolumn{2}{|c|}{0.94} \\
\hline 4BP1LR100 & & $\frac{20-0}{\frac{758-0}{60}}=1.58$ & \multicolumn{2}{|c|}{$\frac{40-20}{\frac{2141-758}{60}}=0.87$} & $\frac{40-0}{\frac{2141-0}{60}}=1.12$ & $\frac{40-0}{\frac{2810-0}{60}}=0.85$ \\
\hline Average & \multicolumn{2}{|c|}{1.58} & \multicolumn{2}{|c|}{0.87} & \multicolumn{2}{|c|}{0.99} \\
\hline
\end{tabular}




\begin{tabular}{|c|c|c|c|c|c|c|}
\hline 4BP2LR100 & $\frac{20-0}{\frac{991-0}{60}}=1.21$ & $\frac{20-0}{\frac{910-0}{60}}=1.32$ & $\frac{40-20}{\frac{2483-991}{60}}=0.80$ & $\frac{40-20}{\frac{2584-910}{60}}=0.72$ & $\frac{40-0}{\frac{2483-0}{60}}=0.97$ & $\frac{40-0}{\frac{2584-0}{60}}=0.93$ \\
\hline Average & \multicolumn{2}{|c|}{1.27} & \multicolumn{2}{|c|}{0.76} & \multicolumn{2}{|c|}{0.95} \\
\hline 6BP1LR100 & $\frac{20-0}{\frac{743-0}{60}}=1.62$ & $\frac{20-0}{\frac{1250-0}{60}}=0.96$ & $\frac{40-20}{\frac{2679-743}{60}}=0.62$ & $\frac{40-20}{\frac{2771-1250}{60}}=0.79$ & $\frac{40-0}{\frac{2679-0}{60}}=0.9$ & $\frac{40-0}{\frac{2771-0}{60}}=0.87$ \\
\hline Average & \multicolumn{2}{|c|}{1.29} & \multicolumn{2}{|c|}{0.71} & \multicolumn{2}{|c|}{0.89} \\
\hline 6BP2LR100 & $\frac{20-0}{\frac{730-0}{60}}=1.64$ & $\frac{20-0}{\frac{635-0}{60}}=1.89$ & $\frac{40-20}{\frac{2918-730}{60}}=0.55$ & $\frac{40-20}{\frac{2274-635}{60}}=0.73$ & $\frac{40-0}{\frac{2918-0}{60}}=0.82$ & $\frac{40-0}{\frac{2274-0}{60}}=1.06$ \\
\hline Average & \multicolumn{2}{|c|}{1.77} & \multicolumn{2}{|c|}{0.64} & \multicolumn{2}{|c|}{0.94} \\
\hline 6BP1LR130 & $\frac{20-0}{\frac{747-0}{60}}=1.61$ & $\frac{20-0}{\frac{692-0}{60}}=1.73$ & $\frac{40-20}{\frac{2378-747}{60}}=0.74$ & $\frac{40-20}{\frac{2730-692}{60}}=0.59$ & $\frac{40-0}{\frac{2378-0}{60}}=1.01$ & $\frac{40-0}{\frac{2730-0}{60}}=0.88$ \\
\hline Average & \multicolumn{2}{|c|}{1.67} & \multicolumn{2}{|c|}{0.67} & \multicolumn{2}{|c|}{0.95} \\
\hline 6BP2LR130 & $\frac{20-0}{\frac{960-0}{60}}=1.25$ & $\frac{20-0}{\frac{920-0}{60}}=1.30$ & $\frac{\frac{40-20}{2365-960}}{60}=0.85$ & $\frac{40-20}{\frac{2575-920}{60}}=0.73$ & $\frac{40-0}{\frac{2365-0}{60}}=1.01$ & $\frac{40-0}{\frac{2575-0}{60}}=0.93$ \\
\hline Average & \multicolumn{2}{|c|}{1.28} & \multicolumn{2}{|c|}{0.79} & \multicolumn{2}{|c|}{0.97} \\
\hline
\end{tabular}

